UNIVERSIDAD POLITÉCNICA DE VALENCIA

Instituto Universitario Mixto de Tecnología Química

(UPV-CSIC)

\title{
Rationalize the synthesis of zeolite catalysts by understanding reaction mechanism
}

TESIS DOCTORAL

Presentada por:

Chengeng Li

Dirigida por:

Prof. Avelino Corma Canós

Dr. Manuel Moliner Marín

Valencia, 2020 



\section{Acknowledgement}

I grew up in a science-centered family with everyone I had in contact had something related to science. For this reason, it has never been strange to me that people talk about science all the time - when my father picked up a phone, most probably I would hear words like ethene, propene, catalytic cracking, etc. and when I asked my mother what she was going to do after dinner, probably I would hear "kan wen xian", which is the chinese phrase for reading articles. Along my childhood I could not help wonder: Why should there be so many scientific things around us and why should those scientific stuffs be so important? The answer was revealed to me along all the time of my research career so far.

The year was 2015 when I set out my travel to Valencia to start my Ph.D study in ITQ, following professor Avelino Corma. These two names appear to every researcher in the field of zeolite catalysis when starting literature survey on the first day. People asked me, and I asked myself, what on earth has accomplished the achievements made by ITQ during the past three decades and what aspect of Avelino Corma has made him one of the leading scientists in the field? During my study time here, I realized it was not only the in-depth research into catalyst development, catalytic study, characterization techniques and theoretical calculation, but, more importantly, a systematical combination of them to push the frontier of heterogeneous catalysis. And above all these, an ambition to reveal the unknown and challenging the known. I am sincerely grateful to realize these beyond learning all the knowledge from professor Avelino Corma.

Dr. Manuel Moliner has provided guidance and support not only on zeolite synthesis researches, but also on fitting in the working system of ITQ where speciallists in different areas joint as a team. I am grateful to have the opportunity to work with Mercedes Boronat, Cristina Martínez, Joaquín Martínez, Cecilia Paris, who specialize ranging from organic synthesis, zeolite synthesis, catalytic reaction to theoretical calculations. Also, I had the privilege to work with Pablo Miguel and Francisco Llopis from University of Valencia, who taught me from scratch about reactor setup, performing reactions and reaction mechanism studies. 
Lab life made up most of my daily time. Luckily, I received support from different laboratories. All members from Síntesis (Tomás, Marta, Raquel, Vicent, Amparo, Miguel, Lichen, Ivan, Pilar, Fran...), from Combinatoria (Isabel, Elisa, Raquel, Núria, Eva, Aída, Adrían...) and from Reacción (Teresa, Pablo, Rocio...) are crucial for me to accomplish my Ph.D study, not only on the research but also in social life. Special thanks to Tomás who helped me with the tough negotiations in spanish with different companies.

My friends and family for the physically and mentally supports. My parents provided me with the scientific environment since I was a child. My wife Lisha has been supportive ever since I left home to pursuit my master and doctor studies. Wang and $\mathrm{Zi}$ for continuous accompanying in all the past years.

Now, the time is in April, 2020 when I myself am closing my Ph.D thesis and the world is experiencing a global pandemic named COVID-19 (Coronavirus disease 2019). One century ago, the virus from the same family caused the 1918 flu pandemic, which resulted in 500 million infections and millions of death. At the current time, these two numbers are 1 million and around 70 thousands, respectively, less than $1 \%$ of one century ago, and the plateau is on the horizon. The tremendous improves in healthcare science, technology and policies are results of countless efforts made by scientific workers over the century. The same has happened in chemistry, physics, biology, astronomy, geography, etc. in the history of man and are bring mankind into a more thriving and sustainable world. Now, it seems I could outline the answer to the question: Our lives are shaped by science and technologies, and it was not achieved by any single work by a single person, a group or a facility but the whole science community made up of individuals. So, my final thanks to every single one who is paving the road and shaping the future of human society. 


\section{Resumen}

La presente tesis se centra en la racionalización de la síntesis de zeolitas para su aplicación como catalizadores mediante la comprensión de la naturaleza de los sitios activos y sus microambientes, junto con su influencia en los mecanismos de las reacciones catalizadas.

En la primera parte de la tesis, se han realizado esfuerzos para intentar lograr la ubicación regioselectiva de los sitios activos en el catalizador zeolítico y, más específicamente, en la ubicación controlada de sitios ácidos en la red cristalina de la zeolita. El desarrollo de una estrategia de síntesis adecuada junto con un indicador que pueda describir la distribución de aluminio en la red de la zeolita es importante para evaluar si se ha logrado el objetivo final. En esta parte, para evaluar la distribución de aluminio en la red de la zeolita MFI, se ha propuesto un indicador basado en los mecanismos monomoleculares y bimoleculares asociados a la reacción de craqueo catalítico de n-hexeno. En primer lugar, se sintetizaron varias muestras de ZSM-5, que según la literatura tienen diferentes distribuciones de aluminio. Estas muestras se caracterizaron por ser análogas en propiedades fisicoquímicas y, posteriormente, se analizaron en la reacción de craqueo de n-hexeno para justificar la utilidad del indicador propuesto en este trabajo. A partir de RMN MAS de ${ }^{27} \mathrm{Al}$ se demostró que las ubicaciones de aluminio eran diferentes, lo que también se reflejó en el indicador propuesto en esta tesis, lo que justifica su aplicabilidad para evaluar distribuciones de aluminio. Posteriormente, este indicador se ha empleado para verificar la nueva metodología de síntesis de zeolitas que podría conducir a una distribución de aluminio diferente en sus estructuras cristalinas. En este sentido, se propone la síntesis de la zeolita ZSM-5 asistida por boro, considerando que el boro y el aluminio podrían tener un posicionamiento competitivo en la estructura MFI. Mediante cálculos de DFT, se ha estudiado si la celda unidad de MFI muestra diferente estabilidad cuando se introduce aluminio y/o boro en diferentes posiciones cristalográficas T. Se ha encontrado que la ubicación del boro está menos favorecida cuando se introduce en los canales de 10 miembros de la 
estructura MFI, mientras que el aluminio no muestra preferencia por el posicionamiento entre todos los sitios T. Se sintetizaron muestras de ZSM-5 con diferentes $\mathrm{Si} / \mathrm{Al}$ y $\mathrm{Si} / \mathrm{B}$ y se caracterizaron sus propiedades fisicoquímicas, así como la proporción relativa de estados emparejados y aislados de aluminio. La caracterización incluye el craqueo de n-hexeno, para el cual las muestras mostraron una preferencia diferente hacia las reacciones monomoleculares y bimoleculares. Finalmente, una vez demostrada la distinta distribución de aluminio en los materiales sintetizados, estos catalizadores se estudiaron en la reacció de metanol a propeno (MTP) para mostrar la influencia de la distribución de aluminio en una reacción relevante a nivel industrial, donde el confinamiento espacial tiene un impacto importante. De hecho, las muestras con aluminio posicionadas preferentemente en un canal de 10 miembros favorecen reacciones de craqueo monomolecular frente a reacciones secundarias bimoleculares, como por ejemplo reacciones de oligomerización y de transferencia de hidrógeno, dando un mayor rendimiento a propeno y una menor cantidad de alcanos y compuestos aromáticos.

La segunda parte de la tesis se centra en racionalizar la síntesis de zeolitas con cavidades para catalizar una reacción seleccionada "a priori". Más específicamente, la síntesis de zeolita se llevó a cabo utilizando agentes directores de estructura orgánicos (ADEO) que mimetizan el estado de transición (ET) o el intermedio relevante en la reacción objetivo. La producción de etilbenceno por transalquilación entre dietilbenceno y benceno se ha seleccionado como una reacción objetivo a catalizar. Se estableció el ET determinante de la reacción y se sintetizó un ADEO tipo diarildimetilfosfonio que mimetiza el estado de transición del mecanismo de la reacción de transalquilación entre benceno y dietilbenceno. Dicho ADEO permitió la cristalización de la zeolita de poro grande ITQ-27, cuyo comportamiento catalítico se estudió en la reacción de transalquilación entre benceno y dietilbenceno. La actividad catalítica de la zeolita ITQ-27 se mostró claramente superior al de otras zeolitas empleadas comercialmente, como USY, mordenita o Beta, todas ellas con propiedades fisicoquímicas similares a la ITQ-27. 
Finalmente, la reacción de metanol a olefinas (MTO) se eligió como otro sistema catalítico objetivo, donde los mecanismos de reacción son mucho más complicados que en el caso de la reacción de transalquilación entre benceno y dietilbenceno, pero, sin embargo, están bien establecidos en la literatura. Se sintetizaron varios ADEOs que mimetizan los intermedios y los estados de transición de la ruta "paring", que produce más propeno y butenos, y que son posiblemente los productos más demandados. Dichos ADEOs mímicos permitieron la formación de varias zeolitas de poro pequeño basadas en cavidades, como las zeolitas CHA, RTH y AEI. Todas las zeolitas obtenidas se probaron en la reacción MTO para evaluar su actividad catalítica, obteniéndose una alta selectividad hacia distintas olefinas ligeras, cuya selectividad depende de la forma y tamaño de la cavidad de cada zeolita. La tendencia de cada estructura hacia ciertas distribuciones de productos se ha relacionado con el mecanismo de reacción, pudiendo establecer una correlación estructura-reactividad al combinar los resultados experimentales con cálculos teóricos. 



\section{Abstract}

The present thesis focuses on the rationalization of the zeolite synthesis for catalysis by understanding the nature of active sites and their microenvironments, together with their influence on the mechanisms of catalyzed reactions.

In the first part of the thesis, efforts have been put on attempting to achieve the regioselective locating of active sites in zeolite catalyst and, more specifically, on tunning acid site locations in zeolite framework. The development of a zeolite synthesis strategy and an indicator that can describe the aluminum distribution in the zeolite framework is important to evaluate if the final objective has been achieved. In this part, in order to evaluate aluminum distribution in MFI framework, an indicator based on monomolecular and bimolecular mechanisms of n-hexene catalytic cracking was proposed. First, several ZSM-5 samples were synthesized, which have been reported in the literature to have different aluminum distributions. These samples were characterized to be analogous in physicochemical properties and, then, tested in the n-hexene cracking to justify the usefulness of the indicator proposed in this work. Using ${ }^{27} \mathrm{Al}$ MAS NMR, the aluminum locations were proved to be different, which was also reflected by the indicator in this thesis, justifying its applicability to evaluate aluminum locations. Afterward, this indicator has been employed to check the zeolite synthesis methodology that could potentially lead to different aluminum distribution in zeolite frameworks. Then, a boron-assisted synthesis is proposed considering that boron and aluminum may have competitive positioning in ZSM-5 framework. Then, and by means of DFT calculations, we have studied if the unit cell of MFI shows different stabilities when substituted by aluminum and/or boron in different $\mathrm{T}$ positions. It has been found that boron location is less favored when introduced in 10-ring channels of the MFI framework, while aluminum shows no preference for positioning among all the T-sites. ZSM-5 samples with different $\mathrm{Si} / \mathrm{Al}$ and $\mathrm{Si} / \mathrm{B}$ were synthesized and their physicochemical properties as well as the relative proportion of paired and isolated states of aluminum was characterized. Characterization includes n- 
hexene cracking, for which the samples showed different preference toward monomolecular and bimolecular reactions. Finally, once the materials were proved to have different aluminum distribution, they were employed in methanol-to-propene (MTP) reactions to show the influence of aluminum distribution on an industry-relevant reaction where the spatial confinement has an important impact. Indeed, the samples with aluminum preferentially positioned in 10-ring channel favored more monomolecular cracking and less bimolecular side reactions such as oligomerization and hydrogen transfer, giving higher propene yield and lower amount of alkanes and aromatics.

The second part of the thesis focuses on rationalizing the synthesis of zeolites with cavities for catalyzing "a priory" selected reaction. More specifically, zeolite synthesis was carried out using OSDAs that mimic the transition state (TS) or a relevant intermediate in the target reaction. Ethylbenzene production by transalkylation between diethylbenzene and benzene was selected as the reaction to be catalyzed. A potential reaction TS was established and a diaryldimethylphosphonium OSDA was synthesized that mimicks the transition state in the diaryl-mediated mechanism of transalkylation between benzene and diethylbenzene. Then, the OSDA successfully led to the formation of the largepore zeolite ITQ-27. This ITQ-27 was tested in the reaction of transalkylation between benzene and diethylbenzene. The catalytic performance of this material was benchmarked to be superior than other commercially employed zeolites, such as USY, mordenite or Beta with similar physicochemical properties.

Finally, Methanol to olefins (MTO) reaction was chosen as another target catalytic system, where the reaction pathways are more complicated than transalkylation between benzene and diethylbenzene but nevertheless they have been well established in the literature. Thus, several OSDAs were synthesized mimicking the intermediates and transition states of the paring pathway, which produces more propene and butenes, which are highly demanded among all products. The OSDAs led to formation of several cage-based small pore zeolites, such as CHA, RTH and AEI. All the zeolites obtained were tested in MTO reactions to evaluate their catalytic activity and gave high selectivity toward light olefins, which appeared to selectively depend on the zeolite tested. The tendency 
of each structure toward certain product distributions was related to the reaction mechanism by establishing a structure-reactivity correlation, when the experiment results were combined with theoretical calculations. It is proposed that different shape of the cavities stabilize different precursor intermediates present in the paring or side-chain pathways and this indicates the reaction preference between each pathway and therefore the product distributions. A linear correlation was obtained between the shape of cavities and the $\mathrm{C}_{3}{ }^{=} / \mathrm{C}_{2}{ }^{=}$ molar ratios being possible. In this way, ITQ-3 (ITE structure) was predicted that should also give higher selectivity toward paring pathway, which has been demonstrated experimentally. 



\section{Resum}

La present tesi es centra en la racionalització de la síntesi de zeolites per a la seva aplicació com a catalitzadors mitjançant la comprensió de la naturalesa dels centres actius i els seus microambientes, juntament amb la seva influència en els mecanismes de les reaccions catalitzades.

A la primera part de la tesi, s'han realitzat esforços per intentar aconseguir la ubicació regioselectiva dels centres actius en el catalitzador zeolític i, més específicament, en la ubicació controlada de centres àcids en la xarxa cristal·lina de la zeolita. El desenvolupament d'una estratègia de síntesi adequada juntament amb un indicador que descriga la distribució d'alumini a la xarxa de la zeolita és important per avaluar si s'ha aconseguit l'objectiu final. En aquesta part, per avaluar la distribució d'alumini a la xarxa de la zeolita MFI, s'ha proposat un indicador basat en els mecanismes monomoleculares i bimoleculars associats a la reacció de craqueig catalític de n-hexé. En primer lloc, es van sintetitzar diverses mostres de ZSM-5, que segons la literatura tenen diferents distribucions d'alumini. Aquestes mostres es van caracteritzar per ser anàlogues en propietats fisicoquímiques i, posteriorment, es van analitzar en la reacció de craqueig de nhexé per justificar la utilitat de l'indicador proposat en aquest treball. A partir dels espectres de RMN MAS de ${ }^{27} \mathrm{Al}$ es va demostrar que les ubicacions d'alumini eren diferents, el que també es va reflectir en l'indicador proposat en aquesta tesi, justificant la seva aplicabilitat per avaluar distintes distribucions d'alumini. Posteriorment, aquest indicador s'ha emprat per verificar la nova metodologia de síntesi de zeolites que podria conduir a una distribució d'alumini diferent al llarg de les seves estructures cristal·lines. En aquest sentit, s'ha proposat la síntesi de la zeolita ZSM-5 assistida per bor, considerant que el bor i l'alumini podrien tenir un posicionament competitiu en l'estructura MFI. Mitjançant càlculs de DFT, s'ha estudiat si la cel·la unitat de MFI mostra diferent estabilitat quan s'introdueix alumini i/o bor en diferents posicions cristal·logràfiques T. S'ha trobat que la ubicació dels àtoms de bor està menys afavorida als canals de 10 membres de la estructura MFI, mentre que l'alumini no mostra preferència pel posicionament entre tots els llocs T. Es van sintetitzar mostres de ZSM-5 amb 
diferents relacions de $\mathrm{Si} / \mathrm{Al}$ i $\mathrm{Si} / \mathrm{B}$ i es van caracteritzar les seves propietats fisicoquímiques, així com la proporció relativa d'estats aparellats i aillats d'alumini. La caracterització inclou la reacció de craqueig de n-hexé, on les mostres van mostrar una preferència diferent cap a les reaccions monomoleculares i bimoleculars. Finalment, un cop demostrada la diferent distribució d'alumini en els materials sintetitzats, aquests catalitzadors es van estudiar a la reacció de metanol a propè (MTP) per mostrar la influència de la distribució d'alumini en una reacció rellevant a nivell industrial, on el confinament espacial té un impacte important. De fet, les mostres amb alumini posicionades preferentment en un canal de 10 membres afavoreixen reaccions de craqueig monomolecular enfront de reaccions secundàries bimoleculars, com ara reaccions d'oligomerització i de transferència d'hidrogen, donant un major rendiment a propè i una menor quantitat d'alcans i compostos aromàtics.

La segona part de la tesi es centra en racionalitzar la síntesi de zeolites amb cavitats per catalitzar una reacció seleccionada "a priori". Més específicament, la síntesi de zeolita es va dur a terme utilitzant agents directors d'estructura orgànics (ADEO) que mimetitzen l'estat de transició (ET) o l'intermedi rellevant en la reacció objectiu. La producció de etilbenzè per transalquilació entre dietilbenzè i benzè s'ha seleccionat com una reacció objectiu a catalitzar. Es va establir l'ET determinant de la reacció i es va sintetitzar un ADEO tipus diarildimetilfosfoni que mimetitza eixe estat de transició. Eixe ADEO va permetre la cristal·lització de la zeolita de porus gran ITQ-27, i el seu comportament catalític es va estudiar en la reacció de transalquilación entre benzè i dietilbenzè. L'activitat catalítica de la zeolita ITQ-27 es va mostrar clarament superior a la d'altres zeolites emprades comercialment, com la USY, mordenita o Beta, totes elles amb propietats fisicoquímiques similars a la ITQ-27.

Finalment, la reacció de metanol a olefines (MTO) es va triar com un altre sistema catalític objectiu, on els mecanismes de reacció són molt més complicats que en el cas de la reacció de transalquilació entre benzè i dietilbenzè, però que, al mateix temps, estan ben establerts en la literatura. Es van sintetitzar diversos ADEOs que mimetitzen alguns dels intermedis i dels estats de transició de la ruta "paring", que produeix més propè i butens, i que són possiblement els 
productes més demandats. Aquests ADEOs mímics van permetre la formació de diverses zeolites de porus petit basades en cavitats, com les zeolites CHA, RTH i AEI. Totes les zeolites obtingudes es van provar en la reacció MTO per avaluar la seva activitat catalítica, obtenint una alta selectivitat cap a diferents olefines lleugeres, on la selectivitat cap a cada olefina lleugera depèn de la forma i mida de la cavitat de cada zeolita. La tendència de cada estructura cap a certes distribucions de productes s'ha relacionat amb el mecanisme de reacció, i s'ha pogut establir una correlació estructura-reactivitat al combinar els resultats experimentals amb càlculs teòrics. 



\section{Index}

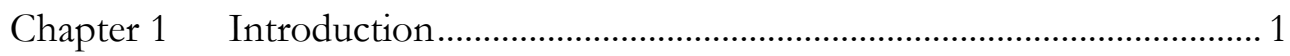

1.1. Historical development of solid acid catalysts .............................. 1

1.2. Development of zeolite as solid acid catalyst .................................. 3

1.3. Acidity studies of zeolite catalysts .................................................... 5

1.3.1. Aluminum zoning ............................................................................... 6

1.3.2. Paired/isolated aluminum species …………………………......... 9

1.3.3. Aluminum positioning at different $\mathrm{T}$-sites ....................................... 16

1.4. Design of pores/cavities in zeolites ..............................................29

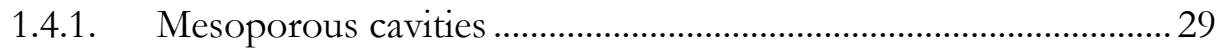

1.4.2. Molecular size cavities: OSDA-induced zeolite synthesis............. 33

1.4.3. Atomic-level cavity design : reaction-adapted synthesis ............... 40

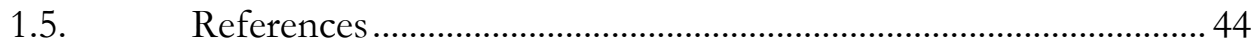

Chapter 2 Objectives ................................................................................. 58

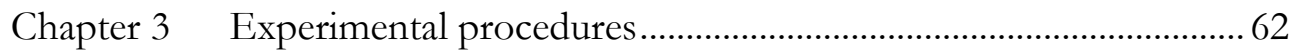

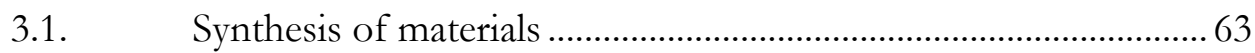

3.1.1. Conditions for synthesis of zeolitic materials .................................. 63

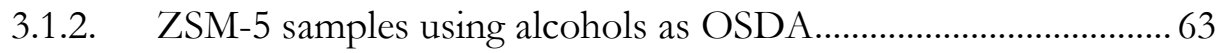

3.1.3. Boron-assisted synthesis of ZSM-5 samples.................................... 64

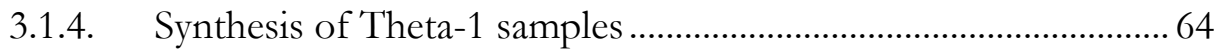

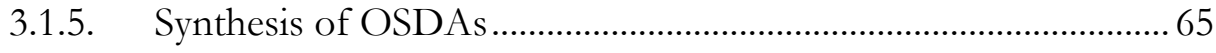

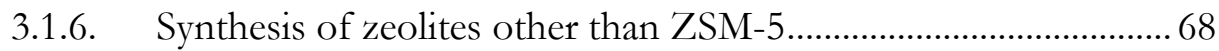

3.2. Characterization techniques ……………..................................... 72 
3.2.1. Powder X-Ray diffraction (PXRD) ................................................. 72

3.2.2. Inductively coupled plasma atomic emission spectroscopy (ICP-

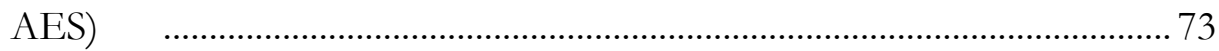

3.2.3. Elemental analysis (EA) ............................................................... 73

3.2.4. Thermogravimetric analysis (TGA)............................................. 73

3.2.5. $\mathrm{N}_{2}$ adsorption/desorption measurement ..................................... 74

3.2.6. Field emission scanning electron microscope (FE-SEM)............ 74

3.2.7. Nuclear magnetic resonance............................................................. 75

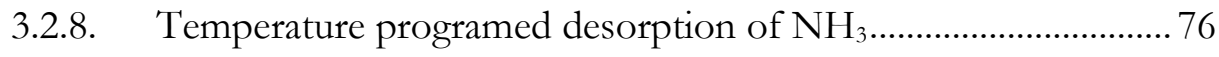

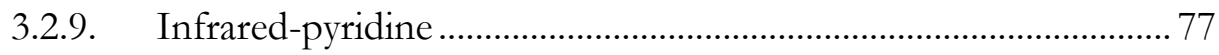

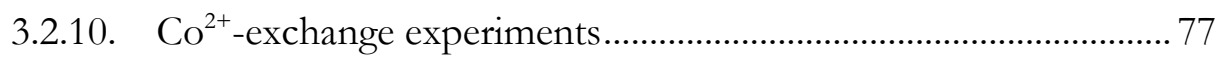

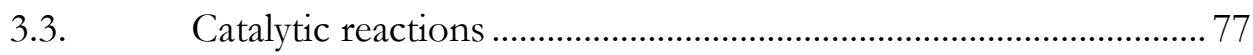

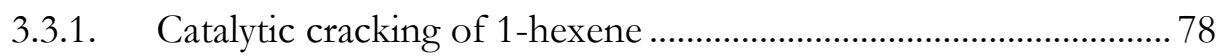

3.3.2. Methanol to olefins reaction using medium-pore zeolites............ 78

3.3.3. Liquid phase transalkylation of diethylbenzene with benzene.... 79

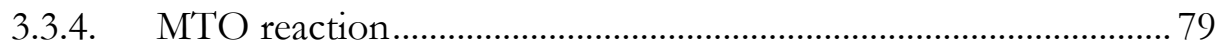

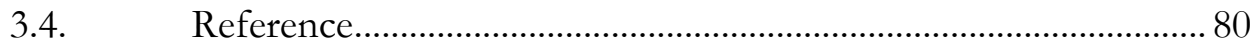

Chapter 4 Control of Aluminum distribution in zeolite.................................. 82

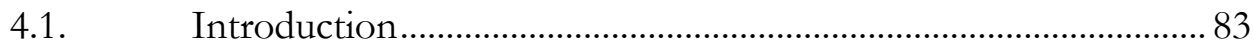

4.2. Establishment of an indicator for aluminum distributions........... 85

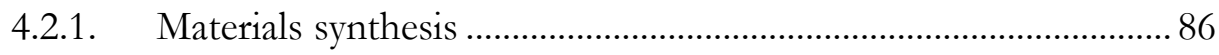

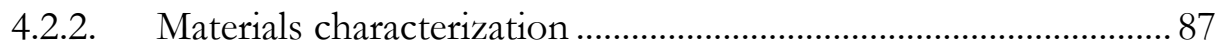

4.2.3. development of an indicator for $\mathrm{Al}$ location ................................... 90

4.3. Boron-assisted synthesis of ZSM-5 ............................................... 95

4.3.1. Competitive occupation of boron and aluminum in MFI unit-cell 
4.3.2. Materials synthesis ............................................................................ 103

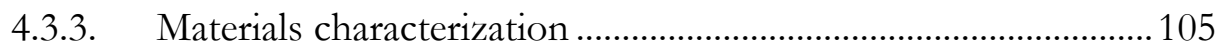

4.3.4. Study on aluminum distribution via catalytic tests........................ 115

4.3.5. Impact of aluminum distribution on Methanol to Hydrocarbons (MTH) reactions .......................................................................................... 124

4.4. Conclusion and perspectives ........................................................131

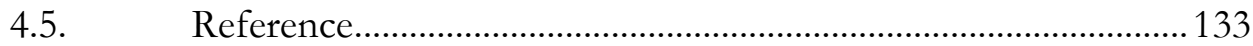

Chapter 5 "Ab-initio" synthesis of zeolites for catalytic reactions............... 137

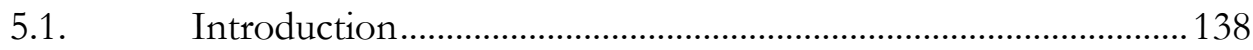

5.2. Ethylbenzene (EB) related chemical processes ............................ 140

5.2.1. Materials synthesis and characterization........................................ 143

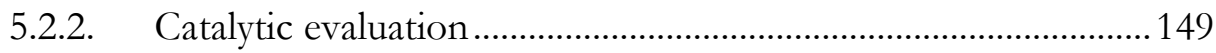

5.3. Methanol to Olefin reactions …………........................................157

5.3.1. Understanding of the reaction mechanism ....................................157

5.3.2. OSDA selection for zeolite synthesis .............................................. 160

5.3.3. Materials synthesis, characterizations and catalytic evaluations 165

5.3.4. Insights into reaction mechanisms ................................................ 190

5.3.5. Structure-performance relationship in MTO catalysts ................ 199

5.3.6. Directing selection of catalysts: ITQ-3 zeolite ............................. 210

5.4. Conclusions and perspective ........................................................216

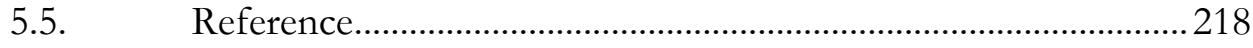

General conclusions and perspectives ..................................................................221 





\section{Chapter 1}

\section{Introduction}





\subsection{Historical development of solid acid catalysts}

The history of inorganic solid acids used as catalysts in industry could be traced back to more than half a century. The first example of a solid acid being industrially applied as catalyst was the use of an acid-leached natural aluminosilicates as cracking catalysts in the Houdry's process. ${ }^{1}$ At that time, the concept of solid acid was quite broad and included a large variety of solid acids, such as natural clays, cation exchanged resins, oxides and their mixtures (such as silica and alumina), inorganic salts and, as later became dominant, zeolites. ${ }^{2}$ The family of solid acids is very diverse, including materials with different acidic properties, ranging from solid with strong to weaker acid strengths.

Compared to liquid acid catalysts, solid acid catalysts provide important advantages, such as noncorrosive and environmentally benign syntheses, which are easier to separate and generate lower waste. ${ }^{3}$ Thus, it did not take long for solid acid catalysts to become the backbone of refinery and petrochemical processes, and by the studies on their structures and surface properties using modern instruments and highly sophisticated techniques were launched. ${ }^{4}$

By the end of the $20^{\text {th }}$ century, solid acid catalysis was already one of the most economically and ecologically important fields in catalysis, with more than 100 industrial processes using solid acids as catalyst. ${ }^{4}$ It is clear that through decades of technological development, the majority of solid acid catalysts focused on zeolites, oxides, ion-exchange resins and phosphates. In particular, zeolites had occupied $41 \%$ of all the solid acid-base catalysts and this number is still increasing with time. ${ }^{4}$

The reactions catalyzed by solid acids mainly occur at the accessible surface and the activity, stability and selectivity of the catalysts largely depend on their surface properties. The study on the nature of the acidity of these materials started not too long after their first industrial application. Tanabe et al. proposed the following postulates ${ }^{4}$ : 
"The coordination number of a positive element of metal oxide, C1, and that of a second metal oxide, C2, are maintained even when mixed."

and

"The coordination number of a negative element of a major component oxide is retained for all the oxygens in a binary oxide."

The description was general due to its need to cover most of solid acids. In the case of silicoaluminates as one particular family of solid acids, it could be interpreted as that when aluminum is incorporated in a silica framework, it should have tendency to form $\mathrm{AlO}_{4}^{-}$tetrahydron and the oxygen should tend to maintain "-O-" form. As a result, $\mathrm{AlO}_{4}^{-}$tetrahydron should have one oxygen unsatisfied by a whole valence, which could be compensated by a proton. ${ }^{5,6}$ Although this description is close to the understanding from modern times toward the origin of the acidity in zeolites, it was originally proposed to generally describe the acidity in all solid acids in form of silica-alumina. Theoretical calculations illustrated later that in silica-alumina cluster models, the origin of acidity was the proton that is compensating the negative charge on the hydroxyl oxygen bridging an aluminum and a silicon. ${ }^{7,8}$ Meanwhile, the strength of this kind of acid site is influenced by the strength of interaction between aluminum and bridging O. ${ }^{9}$

Following this understanding, it will be obvious that to maximize the acid amount in a silica-alumina based catalyst, it is necessary to form Al-O-Si while avoiding the formation of $\mathrm{Al}-\mathrm{O}-\mathrm{Al}$ bonding. In traditional alumina-based catalysts, it is inevitable to have Al-O-Al bond since it is the main composition of alumina. Beside maximizing the amount of acid sites, it is also important to optimize their accessibility. In the case of amorphous silica-alumina based solid acids, this was achieved by generating porosity and increase surface areas, which is realized by manipulating the hydrolysis of silicon and aluminum source materials via changing the nature of their sources, their concentrations, $\mathrm{pH}$ of the mixture, aging time as well as adding organic ammonium cations. ${ }^{10-14}$ Looking 
back as a zeolite scientist in $21^{\text {st }}$ century, one may find that these understandings and synthesis strategies were only a few steps away from the current view of zeolite design and synthesis except for the hydrothermal crystallization step.

\subsection{Development of zeolite as solid acid catalyst}

Despite the similarities between zeolites and other silica-alumina based catalysts, the discovery and development of zeolite science could trace back to a totally different origin and was following a different path. The term zeolite was first designated more than two centuries ago by Swedish mineralogist Axel Fredrik Cronstedt as a kind of natural mineral that could generate steam when heated after adsorbing water as a result of its porous structure. ${ }^{15}$ In the early era after its discovery, zeolite was mainly used as absorbent in water purification, cationexchange and molecule separation due to its porosity and capability to be exchanged with cations.

On the other hand, catalysis was practiced in human history long before people realized its real impact. Not inflating the influence of catalysis by tracing back thounsands of years of history in fermentation, the intended production of chemicals using "catalyst" was as early as 1746, when John Roebuck produced concentrated sulfuric acid in lead-lined chambers. ${ }^{16}$ In the following centuries the chemical production processes relied more and more on catalysis. ${ }^{16-19}$

Developing in parallel for more than two centuries, zeolites and catalysis finally meet in 1960s. Scientists from Union Carbide developed commercially viable routes to industrially produce zeolites in large scale, enabling widespread applications. At the end of the decade, Jules Rabo employed zeolites as catalyst for isomerization in petroleum refining and, later in 1962, Charles Plank and Ed Rosinski from Mobil Oil applied Y zeolite in catalytic cracking of heavy oil fractions, which opened a new era of zeolite catalysis. ${ }^{20}$ Only within two decades, the picture of modern zeolite-assisted chemical production was filled. A few representative milestones in this time are, while not limited to, replacing 3 
amorphous silica-alumina catalyst to Y zeolite in fluid catalytic cracking (FCC), ${ }^{20}$ metal-loaded zeolites as bifunctional catalysts for hydrocracking and alkane isomerization, ${ }^{21-27}$ the discovery of high-Si zeolite ZSM-5 in 1967 and later its successful application as cracking additive, ${ }^{28}$ the first titanosilicate TS-1 developed by ENI-SNAM and its use for epoxidation of olefins, ${ }^{29}$ and the discovery of SAPO-34 as a representative material of the silicoaluminophosphate family of zeotypes and its successful use in catalyzing methanol-to-olefins (MTO). ${ }^{30}$ In short, zeolites have soon covered a wide range of applications in energy-related and environmental related processes.

After a great expansion of application for zeolite catalysts, there is no doubt that this kind of porous solid acid materials is becoming one of the milestones and driving forces for modern catalysis. For this reason, scientists started to explore new possibilities to broaden the properties of zeolites and zeotype materials, and this exploration should always be revised together with the understanding toward structure and its related.

After decades of study, scientists have evolved the understanding of zeolite toward a higher level. Compared to former tentative descriptions where zeolites were considered as a family of mineral solid acids that possess porous structures, at the dawn of $21^{\text {st }}$ century zeolites were recognized as crystalline microporous materials that possess uniform channel system with sizes comparable to reactant molecules. Inside the channel or cavities, the acid sites are located in the form of bridging hydroxyl groups between framework aluminum and silicon and their strength, density and amount could be tuned by synthetic approaches. ${ }^{31}$

It was at this point that the understandings of zeolites and attempts to rationalize their synthesis and optimization were separated in two directions. One direction is the study of the acidic nature of aluminum and its adjacent bridging hydroxyl groups in terms of their microenvironments, such as the local enrichment of acid sites in certain parts of the crystal, the distance between two acid sites, the location of acid sites and their surrounding spatial confinements. The other direction focuses on the control of the crystalline framework of zeolites, particularly with adequate cavities and channels to facilitate the catalytic activity for target reactions. In this sense, efforts have been made to synthesize zeolites 
with new structures, as well as controlling the pore accessibility, such as reducing the particle size or generating internal mesoporosity.

\subsection{Acidity studies of zeolite catalysts}

Since zeolites possess large internal surface areas, which are the main place for catalyzing reactions and show spatial confinement, the acid sites can be distinguished between those placed on the internal surface and on the external surface. The latter should face less spatial confinement and behave more similar to amorphous silica-alumina catalysts. ${ }^{32-36}$ One particular example is the use of ZSM-5 zeolite in aromatic based reactions. ZSM-5 zeolite, with framework of MFI type, possesses 2-dimensionally interconnected 10-ring channels, whose sizes are similar to the alkyl-free aromatic ring. This unique size together with its high acidity rendered the material activity in catalyzing reactions, such as disproportionation of alkyl-benzene, isomerization of poly-alkylated benzene and alkylation of aromatics. ${ }^{37-44}$ When these aromatic-based reactions occur inside zeolite channels, the strict spatial confinement prohibits the formation of meta- and ortho- dialkylated, or even higher alkylated products. Thus, ZSM-5 showed significantly high selectivity to para- alkylated aromatics and this has been taken as one of the classical examples of zeolite showing shape-selectivity toward reaction products. The presence of acid sites on external surface, on the other hand, would decrease the shape-selectivity of ZSM-5. To prevent this undesired issue, scientists attempted to suppress the external acidity by means of passivating these external acid sites by chemical vapor deposition of silica or combination of silica and other oxides. ${ }^{33-35,45-47}$ Another proposed alternative was acid leaching using nitric acid to extract framework aluminum, resulting in ZSM5 with less amount of acid sites on both external and internal surfaces. ${ }^{32}$ The surface treatment could effectively block Si-OH-Al groups on the external surface and enhance para-selectivity in aromatic-based reactions. ${ }^{48}$ Despite their shortcomes in losing part of active sites and increasing diffusion limitation by pore-blocking, the attempts to manipulate acid sites distribution on ZSM-5 
zeolite was a successful example of how scientists started to go deeper into the nature of acidity in zeolites and tried to manipulated it.

The control between external and internal acid sites is an effective way to tune catalytic activity of zeolites, imposing substantial intrinsic differences between acid zeolites, even when they present the same crystalline structure. Along with development of this area, more topics on distributions of acid sites were proposed and systematically investigated.

\subsubsection{Aluminum zoning}

When scientists started to investigate into the catalytic activity normalized by the amount of acid sites, a linear function was observed between the aluminum content and catalytic activity. ${ }^{49}$ This was not surprising and was consistent with the understanding that zeolites possess relatively dispersed acid sites and, in principle, they should all be catalytically active. However, when investigating a ZSM-5 crystal larger than $50 \mu \mathrm{m}$ by X-Ray micrograph and electron probe analysis, von Ballmoos and Meier discovered and confirmed that the distribution of aluminum was not uniform in these crystals, being more concentrated in the rim portion of the crystals than in the center, where the amount of aluminum was barely above the detection limit. ${ }^{50}$ In fact, the aluminum distribution along zeolite crystals as well as the procedures to allow the different aluminum were important research topics. In the meantime that Ballmoos reported zoned aluminum distribution in ZSM-5, Suib et al. reported that the Si/Al on external surface and internal of various zeolites are not significantly different, as characterized by Auger electron spectroscopy. ${ }^{51}$ Not long after Suib's report, Derouane et al. reported that the homogeneity of the aluminum distribution was determined by synthetic factors, such as the source of silica or the duration of crystallization. In particular, larger crystals tend to have a silica-rich core surrounded by Al-rich shell and, these findings were testified by XPS measurements. ${ }^{52}$ Dessau et al. later provided proof from a post-synthesis treatment perspective. ${ }^{53}$ When they treated a calcined ZSM-5 sample with $1 \mathrm{M}$ $\mathrm{NaOH}$, the desilication occurs mainly on the internal part of the crystals, while 
the external shell remained barely changed. Since aluminum is inert to basic treatment and could protect adjacent silicon atom from desilication, this phenomenon could suggest higher aluminum concentration on the external shell of the crystals. Chao and Chern reported a similar description, suggesting also that this phenomenon could be critical to determine the crystal morphology of zeolites. $^{55}$

The heterogeneous distribution of aluminum is obviously important not only for studying the physicochemical properties, but, more importantly, also for their application in catalysis. During a catalytic reaction, the reactant should first interact with the external surface of the crystal and diffuse through the zeolite channels and react at the active sites. The aluminum distribution is directly related to the number and strength of the catalytically active acid sites and, their spatial distribution will directly influence the catalytic performance of the material.

In fact, after the observation of zoned aluminum distribution in zeolite, the acidcatalyzed reactions were also studied by spectroscopic techniques to evaluate if those reactions proceed differently in external or internal parts of zeolite crystals. ${ }^{56-63}$ Using in situ optical microspectroscopy, Weckhuysen et al. were able to map the catalytic activity of ZSM-5 crystals for styrene oligomerization along the crystals. ${ }^{58}$ The reaction products were more concentrated in the rim of crystal and the internal part remained clean. The researchers proposed that the zigzag channels would allow the diffuse of monomer styrene to inside of crystal and react with dimers to form higher oligomers, whereas the formation of carbocations in the straight pores near the surface readily blocked such accessibility to the interior of crystals. 


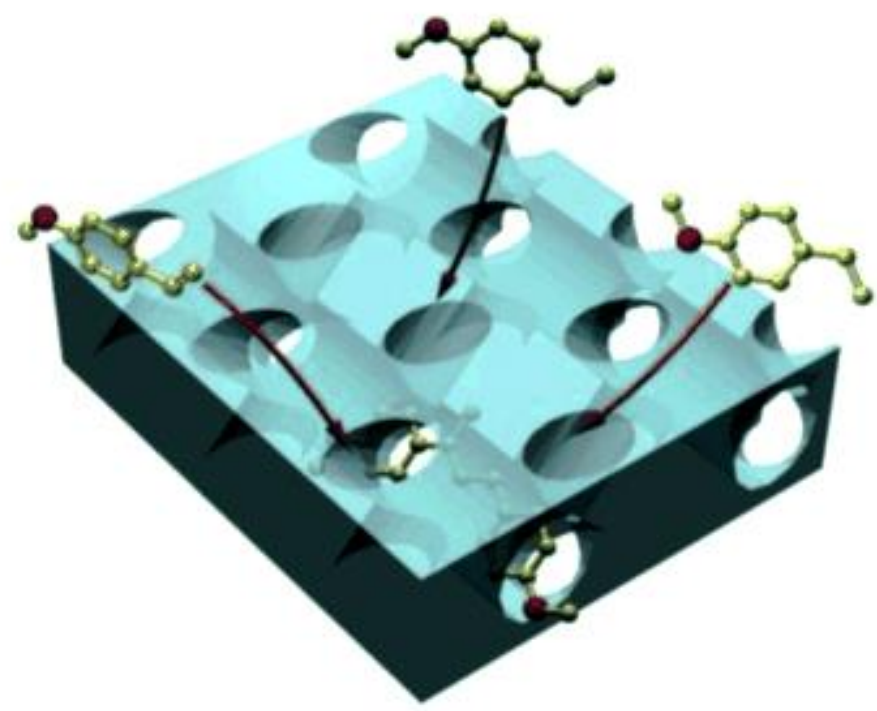

Figure 1.1 Illustration of different preference of pore-openings and zigzag channels toward styrene oligomerization. ${ }^{58}$

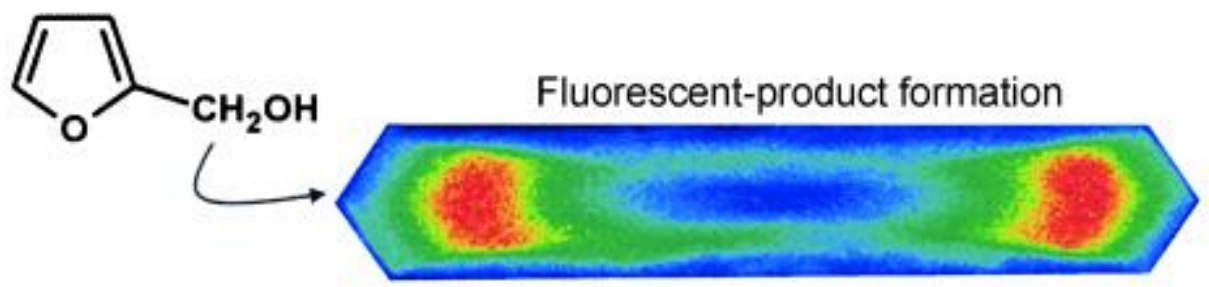

Figure 1.2 Acid-catalyzed condensation of furfuryl alcohol at certain part of ZSM-5 crystal, illustrated by fluorescence microscope. ${ }^{59}$

When studying acid-catalyzed condensation of furfuryl alcohol using fluorescence microscope, De Vos et al. observed that reaction mainly carried out in the internal part of the ZSM-5 crystals. ${ }^{59,61}$ These reports showed that the reactions catalyzed by zeolites are not homogeneously occurring in different 
parts of crystals. Thus, heterogeneity in the aluminum distribution within zeolite crystals should indeed have a clear influence on its intrinsic catalytic activity.

Due to abovementioned importance, scientists attempted to investigate the distribution of aluminum in the bulk and on the external surface of various zeolites, such as zeolite A, X, Y, mordenite and ZSM-5 using multiple surfacesensitive techniques. It was reported that the synthesis route, crystal sizes, bulk $\mathrm{Si} / \mathrm{Al}$ ratios and the use of counter cations, could influence the aluminum concentration in the internal or external parts of the zeolite crystals. ${ }^{64-69}$ Fast atom bombardment mass spectrometry (FABMS), ${ }^{6470}$ electron microprobe analysis (EPMA), X-ray fluorescence (XRF), ${ }^{66-70}$ and atomic absorption spectrometry (AAS), ${ }^{51}$ revealed homogeneous distribution of aluminum along ZSM-5 crystals, whereas a Si-rich surface of ZSM-5 was observed based on XPS. ${ }^{51}$ Sputter-depth profiling of about $1 \mu \mathrm{m}$ showed that the outer shell with thickness of $200 \mathrm{~nm}$ was low in aluminum or nearly Al-free. ${ }^{72}$ A summary of the observations indicated that the aluminum-rich rim is often observed in ZSM-5 synthesized using TPA as template, while other templates (i.e. 1,6-hexanediol) could lead to homogeneous aluminum distributions. ${ }^{66}$

\subsubsection{Paired/isolated aluminum species}

Different research groups convincingly reported that the siting and distribution of aluminum in zeolite frameworks is non-random and this issue is especially true for Si-rich zeolites. ${ }^{73-78}$ In fact, in cation-exchanged zeolites, the location of counter cations have shown non-random coordination toward particular rings, which could be a sign of preferential distribution of aluminum in certain local structures. Indeed, obtaining accurate information on siting and the aluminum distribution remains a challenging task due to the large amount of distinct framework T sites in Si-rich zeolites. Nevertheless, it is possible to simplify the problem of the aluminum distribution into the relative distance between acid sites. In another word, instead of considering the exact aluminum location in the whole crystal, it should be easier to consider only a fraction of the crystal composed of handful amount of acid sites, and investigate how they are distant 
from another acid site. This "fraction" should mostly influence chemical properties as well as catalytic activity of the overall material, since acid site is the place to perform catalytic reaction.

Thus, if one consider the distance between aluminum sites, the model can be simplified into a formula of Al-O- $(\mathrm{Si}-\mathrm{O})_{\mathrm{n}}-\mathrm{Al}$, where $\mathrm{n}$ represents the number of silicon tetrahydrons separating two acid sites. According to the Loewenstein law, the formation of $\mathrm{Al}-\mathrm{O}-\mathrm{Al}$ sequence is strictly prohibited in aluminosilicate zeolites, thus the case of $\mathrm{n}=0$ is in general not considered. In Si-rich zeolites $(\mathrm{Si} / \mathrm{Al}>8)$, the predominant sequences are closed-paired aluminum $(\mathrm{n}=2)$ and single aluminum atom ( $\mathrm{n}>2$ and in separated rings). These two cases are important since they can represent the ability of the zeolite to exchange divalent and monovalent cations as well as metal-oxo species, which directly influence the exchange capacity, stability and catalytic activity of metal-exchanged zeolites. Thus, in the discussion of the aluminum distribution in terms of aluminum distances, single aluminum sites and paired aluminum sites will be mostly considered. The possibility of siting Al-O-(Si-O) $)_{2}-\mathrm{Al}, \mathrm{Al}-\mathrm{O}-(\mathrm{Si}-\mathrm{O})_{>2}-\mathrm{Al}$ or Al-O$(\mathrm{Si}-\mathrm{O})_{>4-} \mathrm{Al}$ is summaried in Figure 1.3.

The sequence of $\mathrm{Al}-\mathrm{O}-(\mathrm{Si}-\mathrm{O})>4-\mathrm{Al}$ (see Figure 1.3, i) is simple since it represents two aluminum separated in such distance that they can barely balance any single divalent cation and could be considered as completely separated. Even when both aluminums are in one 12-ring, the distance between the two aluminum locations are too far away that cannot balance divalent cations. An example of that would be Cu-SSZ-13, where there is no record of $\mathrm{Cu}$ located in the middle of 12-ring cage and the most probable position is near the center of the double 6-ring (D6R) and 8-ring window. Thus, this sequence is designated as isolated aluminum. In most zeolite structures, isolated aluminum represents only one negative charge in a ring or even in one cavity and can only be balanced by monovalent cations such as $\mathrm{Li}^{+}, \mathrm{Na}^{+}$and $\mathrm{K}^{+}$. In general, it is still difficult for $\mathrm{Al}$ $\mathrm{O}-(\mathrm{Si}-\mathrm{O})_{4}-\mathrm{Al}$ (figure 1.3, g) sequence to balance divalent hexaquo complex since the distance is still not close enough, and, consequently, this sequence could also be considered as single aluminum. 
Al-O-Si-O-Al Al-O-(Si-O) $)_{2}-\mathrm{Al} \quad \mathrm{Al}-\mathrm{O}-(\mathrm{Si}-\mathrm{O})_{\mathrm{n}>2}-\mathrm{Al} \quad$ Single Al
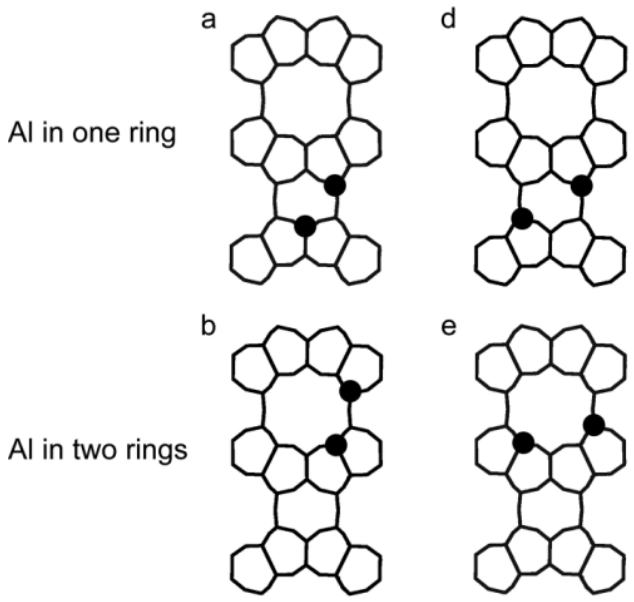

e

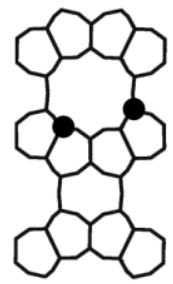

g

C

f
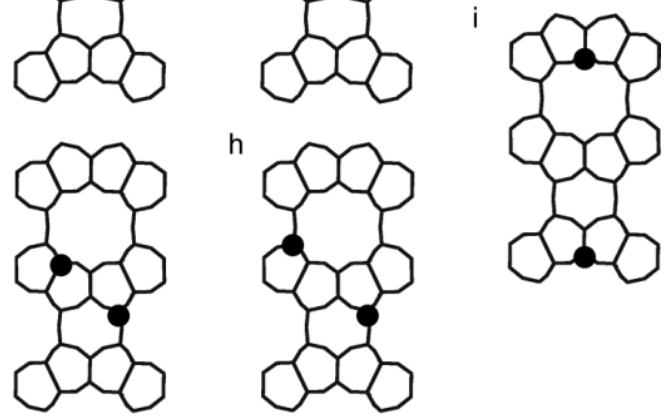

Al facing
channels

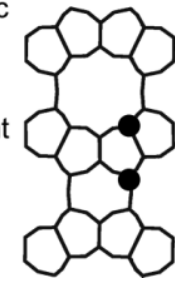

Figure 1.3 Illustration of different kinds of the aluminum distribution in a certain zeolite framework. ${ }^{79}$

In the case of $\mathrm{Al}-\mathrm{O}-(\mathrm{Si}-\mathrm{O})_{3}-\mathrm{Al}$, the two aluminum locations cannot be within one 5-ring since it will violate Loewenstein's law. The two aluminum can only be located in different 5-ring but they could be in the same 8- or 10-ring and their distance is close enough to balance hydrated divalent cations but not enough for bare divalent cations. When the two aluminum atoms of Al-O-(Si$\mathrm{O})_{3}-\mathrm{Al}$ are facing different 8 - or 10-ring (see Figure 1.3, h), although their distance is close, they can only balance one monovalent cation and should be considered as single aluminum.

The most complex case will be Al-O-(Si-O) ${ }_{2}-\mathrm{Al}$. The two aluminum atoms can be located either in one 5- or 6-ring (see Figure 1.3, d) or separated in two rings(see Figure 1.3, e, f). In both cases, they can either be located in the same 
(see Figure 1.3, e) or different larger ring (see Figure 1.3, f). When located in the same larger ring, the distance is close enough for both hydrated and bare divalent cations. When separated in two rings, they should also be considered as single aluminum.

Despite the complexity in classification of $\mathrm{Al}-\mathrm{O}-(\mathrm{Si}-\mathrm{O})_{\mathrm{n}}-\mathrm{Al}$ sequences and their location inside the framework models of zeolites, it is not complex from experimental point of view. Regardless of the exact distance between the aluminum, their capability of balancing cations could be classified according to three standards: the capability to balance monovalent cation, bare divalent cations and hydrated divalent cations. All aluminum sites should be able to balance monovalent cations as long as they are tetrahydrally coordinated in framework positions and provide Brønsted acidity. Two aluminum located inside the same 8- or 10-ring, while they were not separated by too many silicon, would be capable of balance hydrated divalent cations. Finally, only two aluminum sites located in one ring, and separated by less than two silicon, would be capable of balancing bare divalent cations.

According to this classification, it could be possible to develop a characterization method using cation exchange together with chemical analysis and UV-Vis spectra. By exchanging first monovalent cations like $\mathrm{Na}^{+}$, the total amount of aluminum sites in zeolites without EFAl should be consistent with total aluminum amount directly measured from ICP. By secondly exchanging the zeolite with divalent cations, such as $\mathrm{Co}^{2+}$, it should be able to reflect all aluminum pairs that are in one ring and close by less than 4 silicon. By further drying the zeolite and remove water from $\mathrm{Co}^{2+}$ cations, only closed aluminum sites are capable of balancing bare $\mathrm{Co}^{2+}$ and, those distant paired aluminum sites should release $\mathrm{Co}^{2+}$ and form either $\mathrm{Co}-\mathrm{OH}$ or Co-oxo species. The presence of $\mathrm{Co}-\mathrm{OH}$ is not probable at dehydrated conditions and will form Co-oxo species, which do not exhibit absorption in the visible region. ${ }^{80-82}$ To summarize, through a progressive cation exchange of $\mathrm{Na}^{+}$and $\mathrm{Co}^{2+}$ followed by dehydration, the amount of each kind of aluminum sequence could be quantified using the following relations: 


$$
\begin{gathered}
{[\mathrm{Al}]_{\text {single }}=\left[\mathrm{Na}^{+}\right]-\left[\mathrm{Co}^{2+}\right]_{\text {hydrated }}} \\
{[\mathrm{Al}]_{\text {close }}=2\left[\mathrm{Co}^{2+}\right]_{\text {hydrated }}} \\
{[\mathrm{Al}]_{\text {paired }}=2\left[\mathrm{Co}^{2+}\right]_{\text {bare }}}
\end{gathered}
$$

Based on UV-Vis spectra of Co-exchanged zeolites, the absorption peak can be devonvoluted into three peaks, each corresponding to a certain type of paired aluminum in particular framework positions, namely $\alpha$-, $\beta$ - and $\gamma$-type aluminum pairs. The corresponding center of absorption peak and their extinction coefficients were quantified by Dedecek et al..$^{80,83-85}$ Depending on the zeolite structure, the location of each type of aluminum pairs are different. For instance, their location in some common zeolites are showed in Figure 1.4.

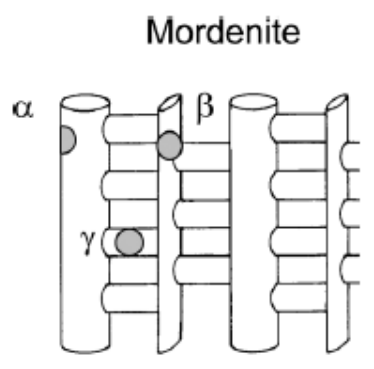

Ferrierite

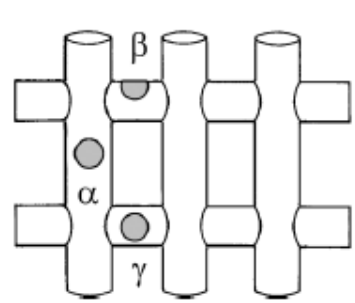

ZSM-5

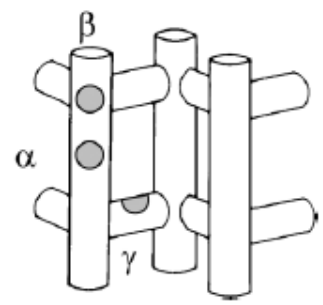

Figure 1.4 Illustration of positions of $\alpha$-, $\beta$ - and $\gamma$-type aluminum pairs in the channel system of mordenite, ferrierite and ZSM-5 zeolites.

Despite its low percentage in Si-rich zeolite, the presence of Al-O-(Si-O $)_{1}-\mathrm{Al}$ cannot be ignored since it provides closed acid sites which can provide concentrated proton distribution within a local environment. In this case, one silicon is connected to two $\mathrm{AlO}_{4}{ }^{-}$tetrahydrons, which forms $\mathrm{Q}^{4}(2)$ silicon species, and can be readily reflected by ${ }^{29} \mathrm{Si}-\mathrm{NMR}$ with signals between -92 to $-100 \mathrm{ppm}$ (see Figure 1.5). ${ }^{86-90}$ 

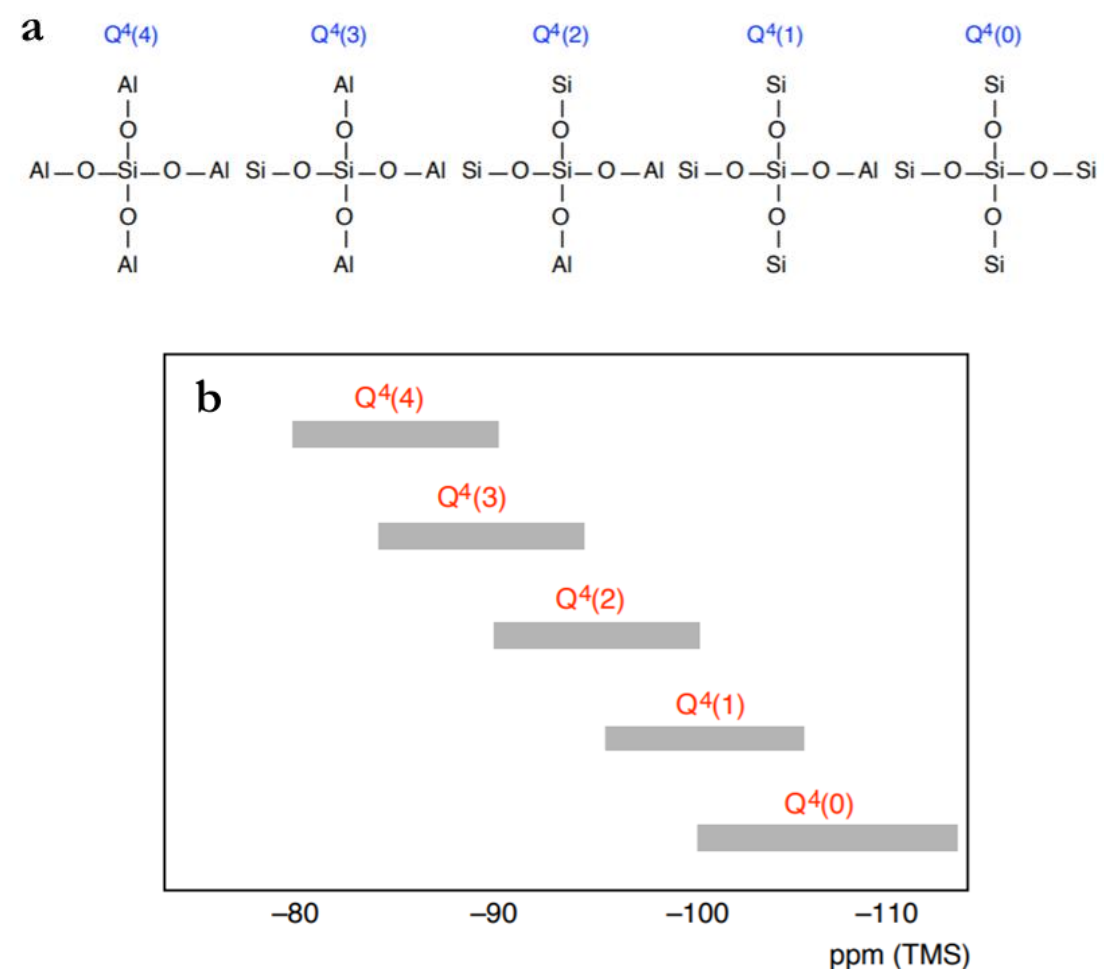

Figure 1.5 Illustration of silicon incorporated by different numbers of aluminum (a) and their corresponding assignment of Si-NMR signal (b). ${ }^{79}$

In fact, the above classification of the aluminum distribution in terms of capability of providing close or distant protons has high application value. Two close paired aluminum atoms can provide two protonic sites in one ring and can affect the transition state of the acid-catalyzed reactions. Sazama et al. tested ZSM-5 samples with different aluminum distributions and those samples with higher percentage of paired aluminum showed higher selectivity to paraffins and aromatics in 1-butene cracking. The reason is attributed to an enhancement of the bimolecular dimerization and hydrogen transfer. ${ }^{91}$ However, so far, there is no clear mechanistic explanation of such enhancement or the interaction between paired aluminum sites and reaction intermediates. 
Since the capability of balancing counter cations, especially divalent cations, are significantly different between each the aluminum distributions in zeolites, the metal-exchanged zeolites should behave differently when divalent metals are loaded on zeolites as active centers. In an pioneer study of NO decomposition, Iwamoto et al. ${ }^{92}$ indicated that the mechanism of $\mathrm{NO}$ decomposition requires adsorption of two NO molecules on adjacent cooperating $\mathrm{Cu}^{+}$ions. Although the concept of paired and isolated aluminum was not established at that time, this could give a hint that if one zeolite is capable of selectively stabilizing adjacent $\mathrm{Cu}^{+}$active sites, it should be a more active catalyst compared to its counterpart containing more isolated aluminum sites.

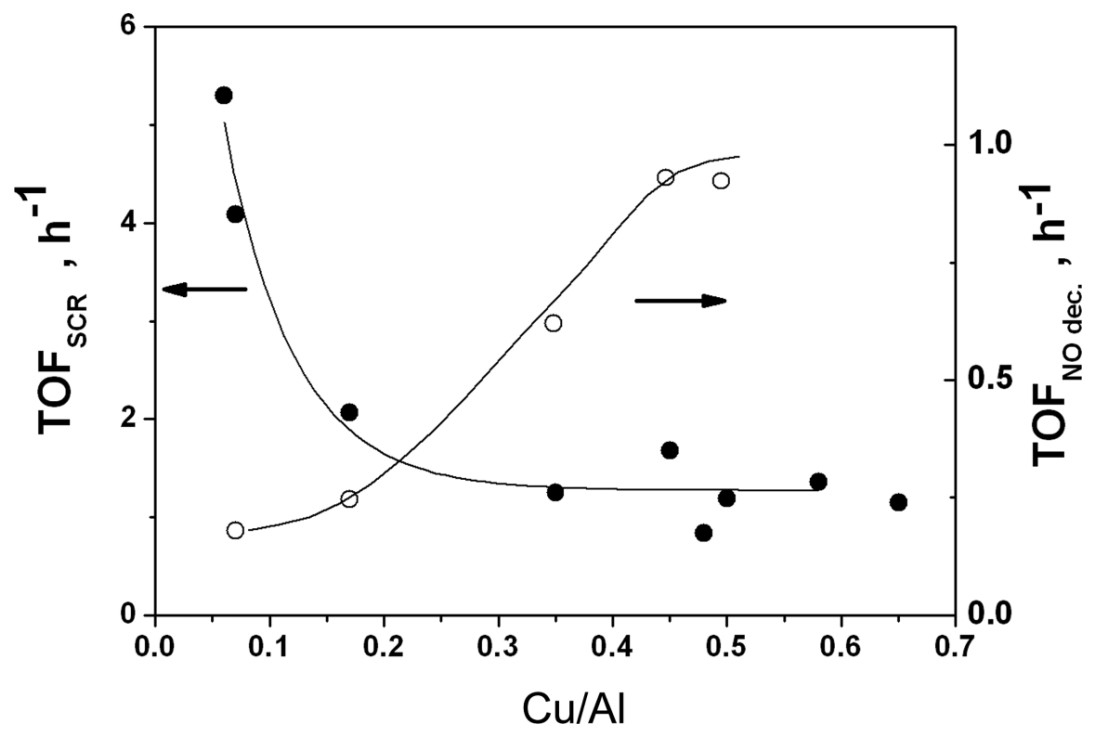

Figure 1.6 Dependence of NO conversion in $\mathrm{C}_{10} \mathrm{H}_{22}$-SCR-NO and NO decomposition on $\mathrm{Cu}$ loading in Cu-ZSM-5.93

When ZSM-5 was loaded with low Cu content, the paired aluminum is preferred for divalent $\mathrm{Cu}^{2+}$ cations. Sole $\mathrm{Cu}^{2+}$ cations are not active for $\mathrm{NO}$ decomposition and thus the low Cu-loading ZSM-5 showed low activity in NO decomposition (see Figure 1.6). Along with increasing of $\mathrm{Cu}$ content, the $\mathrm{Cu}$ ceased to be 15 
stabilized by two aluminum sites but to form $\mathrm{Cu}^{2+}-\mathrm{OH}$ at each adjacent aluminum sites. During the catalyst dehydration, such species will be reduced to $\mathrm{Cu}^{+}$and thus form adjacent $\mathrm{Cu}^{+}-\mathrm{Cu}^{+}$pairs. ${ }^{36,93,95}$ The latter is the active center for NO decomposition, justifying the higher activity observed for the Cu-ZSM5 catalyst with higher $\mathrm{Cu}$ loadig (see Figure 1.6).

The above introduction illustrated how the distance between aluminum sites could affect the catalytic activity of zeolites with similar composition, being therefore the aluminum distribution between isolated aluminum and paired aluminum a critical parameter to keep in mind when studying zeolite-based catalytic systems.

\subsubsection{Aluminum positioning at different $T$-sites}

Other than overall inhomogeneous distribution of aluminum between external and internal areas of zeolite crystals and aluminum sites separated by different distances, the distribution of aluminum at particular $\mathrm{T}$ sites as well as crystallographic positions facing certain spatial confinement would also have high impact on the chemical properties as well as catalytic activity of zeolites. Taking two zeolites ferrierite and mordenite as examples, whose structures and channels systems were well-studied. Both materials are composed of 2 dimensional intersected channels, being $10 \times 8$-ring pores in ferrierite and $12 \times 8$ ring pores in mordenite. In ferrierite, the aluminum located in T1, T2 and T4 positions could place protons in the 10-ring channel while that located in T3 sites would have proton facing 8-ring FER cage (see Figure 1.7, left). In the case of mordenite, aluminum in T1, T2 and T4 sites would provide protonic sites in 12-ring channel while aluminum in T3 position would be located in the 8-ring pockets (see Figure 1.7, right). aluminum sitings in channels with different pore openings could significantly influence the transition state of the acid-catalyzed reactions. ${ }^{96,97}$ 


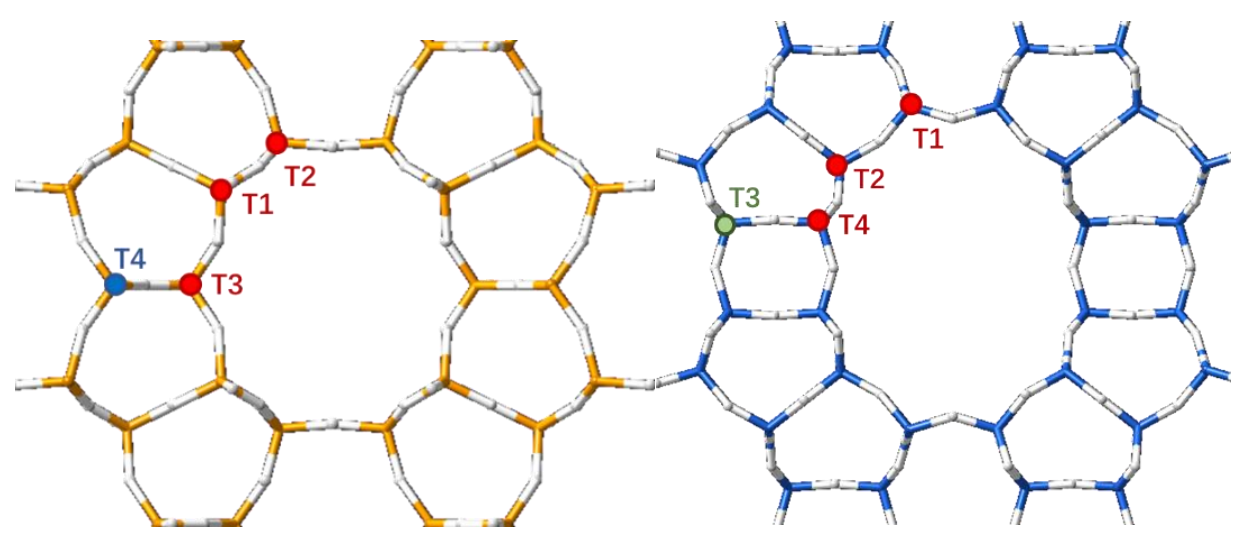

Figure 1.7 Illustration of the location of different T-sites in FER (left) and MOR (right).

One of the examples showing the importance of acid sites location in zeolites was reported for ferrierite, where Lercher et al. succeeded to distinguish different contribution of aluminum sites in 10-ring and 8-ring channels for the n-butene isomerization reaction. ${ }^{98}$

As stated above, FER structure possesses perpendicular intersected 10-ring and 8 -ring channels. Theoretical calculations combined with analysis using ${ }^{23} \mathrm{Na},{ }^{27} \mathrm{Al}$ and ${ }^{29} \mathrm{Si}$ solid NMR have proved that $\mathrm{Na}^{+}$has preference to be located in the 8ring channel. ${ }^{99-101}$ Taking advantage of this preferential $\mathrm{Na}^{+}$siting, Lercher et al. partially exchanged $\mathrm{Na}-\mathrm{FER}$ with proper amount of $\mathrm{NH}_{4}{ }^{+}$to selectively activate the proton sites in the 10-ring channels, leaving those in 8-ring pockets inactive for the catalytic reaction. The acid sites in 10-ring channel are the main active sites for skeletal isomerization of n-butene while those in 8-ring channel are in charge of side reactions to form propene and pentenes. As a result, FER with partially activated sites in 10-ring channels catalyzed preferentially skeletal isomerization of n-butene with low yield of byproducts. ${ }^{98}$

Few years later, the preferential aluminum siting in different $T$ sites in FER was realized by direct synthesis using combination of different organic ammonium cations as templates. ${ }^{102}$ As mentioned earlier, siting of aluminum is strongly 
determined by cations in the synthesis gel since it requires a charge balance between $\mathrm{AlO}_{4}^{-}$tetrahydrons and cations. Thus, using different combinations of pyrrolidine, tetramethylammonium (TMA) and 1-methylpyrrolidinium (bmp), all in absence of $\mathrm{Na}^{+}$, the location of aluminum should be determined by the position of the two templates in the final products (see Figure 1.7). The bmp molecule is too bulky to be contained in the 8-ring channel, while pyrrolidine has a proper size to fit in 8-ring channel.

\begin{tabular}{lll}
\hline Sample & \% of acid sites accessible to pyridine \\
FER-byrr-TMA & \\
FER-pyrr-OH & (Fluoride media) & \\
\hline
\end{tabular}

\begin{tabular}{|c|c|c|c|c|c|}
\hline \multirow[t]{2}{*}{ Sample } & \multicolumn{3}{|c|}{$\mathrm{m}$-Xylene isomerisation } & \multicolumn{2}{|c|}{ n-Butene isomerisation } \\
\hline & $\begin{array}{l}\text { Reaction rate } \\
\left(\mathrm{mol} / \mathrm{g}^{*} \mathrm{~h}\right)\end{array}$ & $\begin{array}{l}\mathrm{p} / \mathrm{o} \\
\text { ratio }\end{array}$ & $\begin{array}{l}\mathrm{I} / \mathrm{D} \\
\text { ratio }\end{array}$ & $\begin{array}{l}\text { Conversion } \\
(\%)\end{array}$ & $\begin{array}{l}\text { Select. }_{(\mathrm{i}-\mathrm{C} 4=)} \\
(\%)\end{array}$ \\
\hline FER-pyrr & $5.60 \mathrm{E}-04$ & n.d. & n.d. & 9.6 & 79.3 \\
\hline FER-pyrr-TMA & $6.40 \mathrm{E}-03$ & 1.4 & 4.3 & 14.8 & 79.1 \\
\hline FER-bmp-TMA & $2.20 \mathrm{E}-02$ & 1.4 & 10.9 & 24.0 & 69.2 \\
\hline FER-pyrr-OH & $3.90 \mathrm{E}-02$ & 4.6 & 46.2 & 40.2 & 24.6 \\
\hline
\end{tabular}

Figure 1.7 Synthesis of FER with preferential aluminum sitings using combination of different OSDAs and their catalytic performances. ${ }^{102}$ 
According to these results, using exclusively the small molecule pyrrolidine, acid sites are preferentially located within 8-ring channels, which are not accessible to pyridine. In contrast, when using the bulky template bmp, more acid sites were located in 10-ring channels, which are more accessible to pyridine. The activity of these ferrierites in n-butene isomerization is consistent with accessibility to pyridine (see Figure 1.7).

Another relevant example describing the catalytic influence of aluminum siting is the selective carbonylation of methanol with $\mathrm{CO}$ in mordenite. ${ }^{107}$ The reaction is controlled by the transition state and selectively occurs in the 8-ring channels. It has been reported that the reaction rate of carbonylation is proportionally related to the concentration of acid sites in the 8-ring channel of mordenite. ${ }^{103,106,107}$ Carbonylation of methanol and CO could be catalyzed by either ferrierite or mordenite, both of which possess 8-ring channels. The size of 8-ring channel of mordenite fits better the intermediate and favors the attack of a methoxy group by a CO molecule. More specifically, by analyzing methanol carbonylation at different $\mathrm{T}$ positions and proton sites at adjacent bridging hydroxyl group, Boronat et al. discovered that, specifically, T3-O33 proton is responsible of the outstanding carbonylation selectivity. ${ }^{104-106}$ The methoxy group at such position is aligned in the direction of 8 -ring pocket of mordenite and is favorable to be attacked by $\mathrm{CO}$ molecule. The selective catalysis of carbonylation reaction on $\mathrm{T} 3$ sites in 8-ring channel of mordenite was experimentally observed by Bhan et al. ${ }^{107}$ By poisoning selectively acid sites in 8ring channel by $\mathrm{Na}^{+}$exchange, the turnover rate of carbonylation disproportionally decreased with the decrease of total acid amount.

Ferrierite and mordenite zeolites are two of the commonly used and studied channel-based zeolites to evaluate the aluminum distribution. It is reasonable to think that aluminum siting at different $T$ sites should also applies, if not even more influential, to cage-based zeolites. Following a similar cooperative template concept as in the case of ferrierite, Yokoi et al. described the synthesis of RTH using 1,2,2,6,6-pentamethylpiperidine (PMP), N-methylpiperidine (MP) and pyridine as templates, or even without using of organic template, and claimed 
that the RTH zeolites obtained using PMP and MP as templates have aluminum more concentrated in $\mathrm{T} 4$ positions. ${ }^{108}$
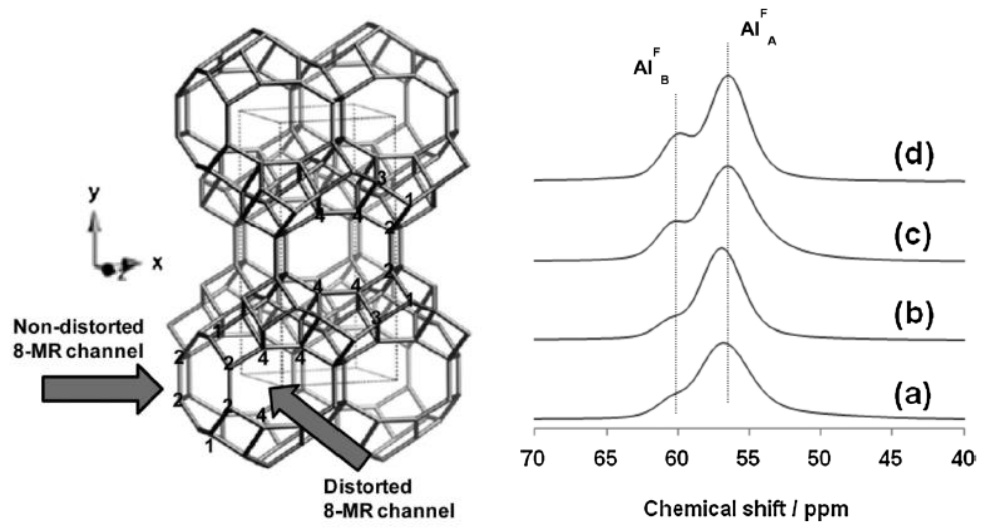

Figure 1.8 RTH structure and ${ }^{27} \mathrm{Al}$ MAS NMR spectra of RTH samples obtained with different templates

The researchers observed that the RTH zeolites prepared using different templates showed different signals in ${ }^{27} \mathrm{Al}$ MAS NMR spectra, observing a more intense shoulder peak centered at around $60 \mathrm{ppm}$ for samples synthesized with bulkier templates, such as PMP and MP (see Figure 1.8). The chemical shifts of each $\mathrm{T}$ site were referred based on the T-O-T angles calculated by Gies et al. in their original report on RTH material. ${ }^{109}$ Despite the fact the reason for thus preferential aluminum siting in RTH zeolite is mostly based on inferring, the significance of this report is that the aluminum siting could be distinguished using characterization. Different from previous examples of ferrierite and mordenite, in where different aluminum sites are facing channel with different sizes, in RTH cage T1, T2, T4 are accessible from inside the cage while T3 is not facing any cavity. Thus, activities of these sites will not be as distinguishable as in case of ferrierite and mordenite. The successful use of ${ }^{27} \mathrm{Al}$ MAS NMR technique has broadened potential available techniques to characterize aluminum siting in zeolite. 
The above examples showed different methods to characterize aluminum siting taking advantage of structural properties of the target zeolites. In channel-based ferrierite and mordenite zeolites, the differences in channel size and their activities toward certain reactions were the definitive explanation, whereas in case of RTH the difference in chemical shifts in NMR spectra was useful for aluminum siting identification. However, it became difficult when attempting to identify aluminum sitings in ZSM-5 with MFI structure.

MFI structure, as described previously, is composed of intersected 10-ring channels where both 10-rings are similar in diameter $(\sim 0.55 \mathrm{~nm})$. Thus, the aluminum sites in either channel should face similar spatial confinement. Moreover, this structure contains 12 crystallographic distinctive $\mathrm{T}$ sites in its orthorhombic crystal and 24 in monoclinic crystal. Such large amount of $T$ sites makes it very challenging the identification of the T sites using ${ }^{27} \mathrm{Al}$ MAS NMR since their chemical shifts are very similar, being only different within less than 1 ppm. Despite the structural complexity, researchers have been actively attempting the selective positioning of $\mathrm{T}$ sites within MFI structure since its potential impact on catalysis could be relevant. Compared to previous studies on ferrierite, mordenite and RTH, the studies on MFI usually combines multiple techniques.

Following a similar approach as in the case of RTH, Yokoi et al. attempted to synthesize ZSM-5 using a combination of TPA and $\mathrm{Na}^{+}$to achieve differentiated distributions of aluminum. ${ }^{110}$ It is commonly accepted that in as-synthesized ZSM-5, TPA molecule is located at the intersection of 10-ring channels of MFI structure, with ammonium cation in the center of the intersection and the linear propyl group stretch into the channel. When TPA is the only cation source, aluminum should be more located near ammonium cation at the intersection. In contrast, when $\mathrm{Na}^{+}$is employed in the synthesis, this inorganic cation is preferentially located in the middle of 10-ring channel, since all intersections are occupied by TPA molecules. As a result, aluminum should approach toward both TPA and $\mathrm{Na}^{+}$and should be located more homogeneously between intersection and channels (see Figure 1.9). Due to the abovementioned structural complexity, aluminum siting in MFI could not be identified directly using single 
characterization technique. Thus, the materials were analyzed using combination of ${ }^{27} \mathrm{Al}$ MAS NMR together with probe reactions. ${ }^{27} \mathrm{Al}$ MAS NMR spectra revealed that the aluminum distribution in both samples were indeed different, but the deconvolution was not clear due to the limit of resolution.
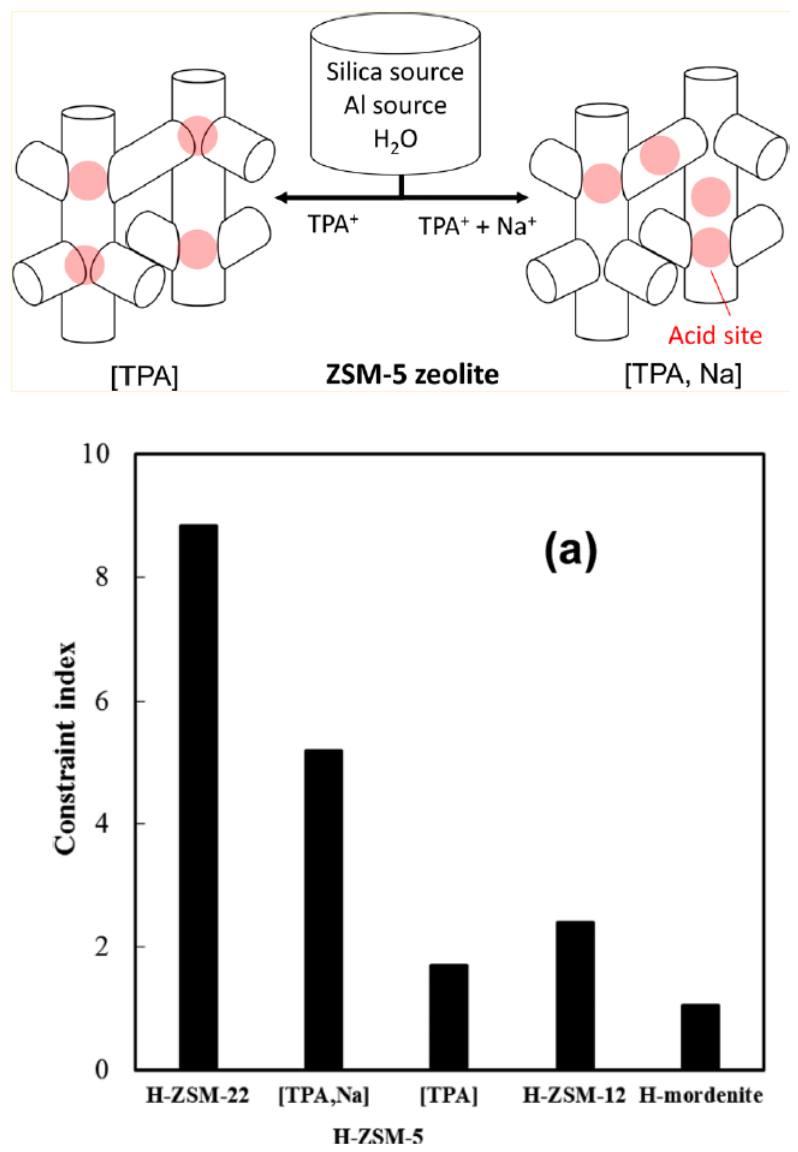

Figure 1.9 (Top) Illustration of the synthesis strategy of Yokoi et al. using combination of TPA and $\mathrm{Na}+$ to direct aluminum siting and difference in constraint index (Bottom). ${ }^{110}$

Additionally, Cracking of paraffins with different kinetic diameters was adopted as a probe reaction. Constraint index, as first proposed by Haag et al. in 1981, was defined as the ratio between cracking rate of 1-hexane and 3- 
methylpentane. ${ }^{111}$ It was adopted in this case to evaluate the spatial confinement faced by different aluminum siting. When aluminum is facing larger space, such as 10-ring intersection, the catalyst should enable higher cracking rate of branched 3-methylpentane compared to when aluminum sites are facing more toward 10-ring channels. Indeed, according to results by Yokoi et al., ZSM-5 synthesized with both TPA and $\mathrm{Na}^{+}$showed a three-fold increase of the constraint index compared to the ZSM-5 synthesized only with TPA (see Figure 1.9), similarly to the 10-ring channel ZSM-22 zeolite. The results were further supported by higher cracking rate of bulkier methylcyclohexane.

However, one should always keep in mind that the definition of constraint index is based on the overall reaction rate of paraffin cracking in where both the activation energy by diffusion and intrinsic catalytic activity are considered. In fact, by proposing the use of constraint index, Haag et al. originally intended to differentiate and quantify the transportation of reactant molecules in zeolites with different channel systems while the acid sites were considered homogeneously distributed in zeolite crystals. Thus, the difference caused by diffusion were considered together with kinetic distribution of aluminum siting. For this reason, the constraint index cannot fully reflect different aluminum distributions, but a probable difference and diffusion limitation should always be considered.

Compared with previous studies on ferrierite, mordenite and RTH zeolites, the study on ZSM-5 seemed uncertain and no decisive characterization could give solid results on how aluminum is distributed. However, these results from characterization and test reactions seem to be pointing to the same conclusion on aluminum locations. In fact, this is due to the lack of sufficient characterization technique and, at the moment, is the most feasible approach to understand the aluminum distribution in MFI structure.

Following the results obtained from ZSM-5 synthesized with TPA and $\mathrm{Na}^{+}$, Yokoi et al. extended the concept of using positive charges to locate aluminum in ZSM-5. ${ }^{112}$ Since aluminum can be directed to be located near both TPA and $\mathrm{Na}^{+}$during the zeolite synthesis when both are presented in the gel, it is reasonable to assume that if TPA is replaced by non-charged molecules with 23 
similar size and configuration to behave as pore-filling agent, aluminum should be more concentrated near $\mathrm{Na}^{+}$, which is in 10-ring channels. Using several alcohols together with seeding, ZSM-5 samples were obtained and showed even more different distribution according to ${ }^{27} \mathrm{Al}$ MAS NMR results and constraint index (see Figure 1.10).
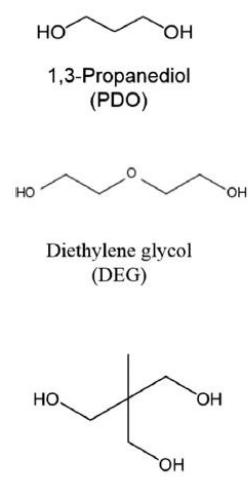

Trimethylolethane (TME)

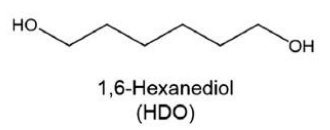

$\mathrm{HO} \mathrm{NO} \sim \mathrm{OH}$

Triethylene glycol

(TEG)

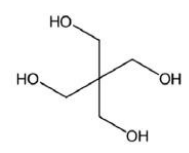

Pentaerythritol (PET)
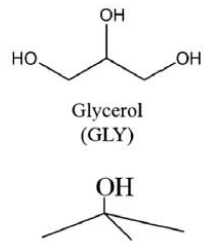

Tert-Butanol

(TBO)

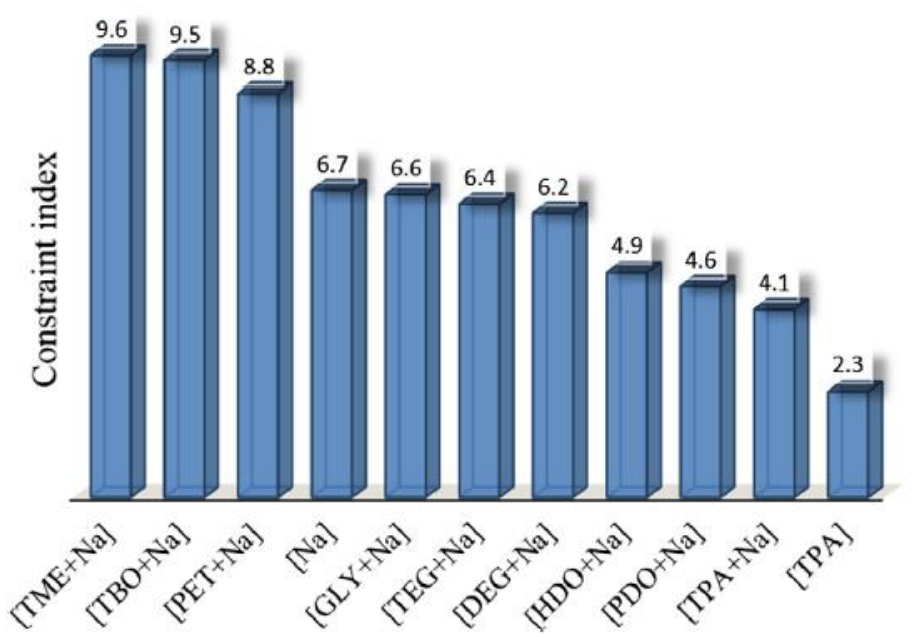

Figure 1.10 Different molecules employed as pore-filling agents and constraint index of each corresponding ZSM-5 samples. ${ }^{112}$ 
Due to the complexity of MFI structure and its ambiguous potential influences on catalyzed reactions with different aluminum siting, the use of one or two indicators derived from single characterization or probe reactions can only give approximating answers to how the aluminum is located. Thus, the research on aluminum siting in MFI requires systematic analysis on intrinsic activity of reactions on different active sites and must be accompanied by commensurable characterization and theoretical calculations. Bell et al. studied ZSM-5 samples with similar physicochemical and textural properties but different aluminum content, being $\mathrm{Si} / \mathrm{Al}$ ranged from $12-142 .{ }^{113}$ To investigate the aluminum siting, the samples were studied using cracking of n-butane as probe reaction. In particular, reaction rate of dehydrogenation, terminal cracking of paraffins and central cracking of paraffins were systematically investigated. Primarily comparing the reaction rates, it was observed that along with increasing aluminum content per unit cell, both the rate of dehydrogenation relative to cracking and the rate of terminal cracking relative to central cracking increased. Considering that the transition state of dehydrogenation has bulkier size and should fit better in larger voids, it was proposed that these changes could be a result of an enrichment of aluminum at the intersection, where there is less spatial confinement. To further prove this hypothesis, the researchers investigated the thermodynamic parameters of the reactions.

The researchers attributed the increase in reaction rates to a partial increase of the activation entropy, despite the fact that the activation energy was increasing alongside. Based on calculations of transition-state geometries and intrinsic activation energies, it was proposed that the three major reactions of n-butane favor less confined channel intersections in the following order: dehydrogenation $>$ terminal cracking $>$ central cracking. 


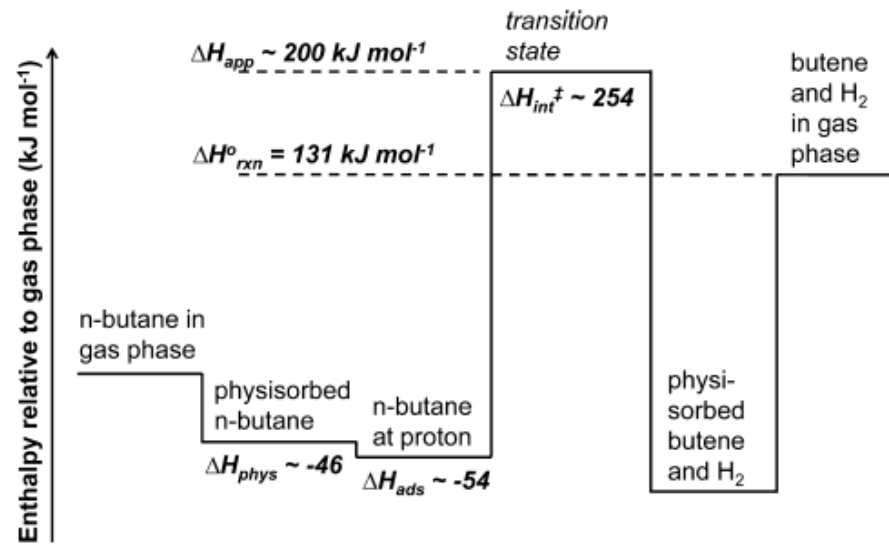

$$
\begin{aligned}
& \mathrm{A}(\mathrm{g}) \rightleftarrows \mathrm{A}(\mathrm{z}) \rightleftarrows \mathrm{A}(\mathrm{r}) \\
& \mathrm{A}(\mathrm{r})+\mathrm{Z}-\mathrm{OH} \rightleftarrows[\mathrm{TS}]^{\ddagger} \rightarrow \operatorname{products}(\mathrm{z})+\mathrm{Z}-\mathrm{OH}
\end{aligned}
$$

Figure 1.11 Illustration of the enthalpy changes involved in the elementary steps of monomolecular reactions of alkanes over acidic zeolites. Enthalpy values are indicated in the diagram for the dehydrogenation of n-butane. The standard enthalpy of reaction $\Delta \mathbf{H}^{\circ}{ }_{\mathrm{rxn}}$ has been extrapolated to $773 \mathrm{~K}$ from standard enthalpies of formation of $\mathrm{n}$-butane, hydrogen and 1butene at 1 bar and $298 \mathrm{~K} .114$

Based on these results, the researchers referred that when aluminum is more located in the channel intersection, dehydrogenation should be favored. Indeed, this hypothesis was testified by the highest rate of dehydrogenation among the three reactions when aluminum content was increased. (See Figure 1.12) 


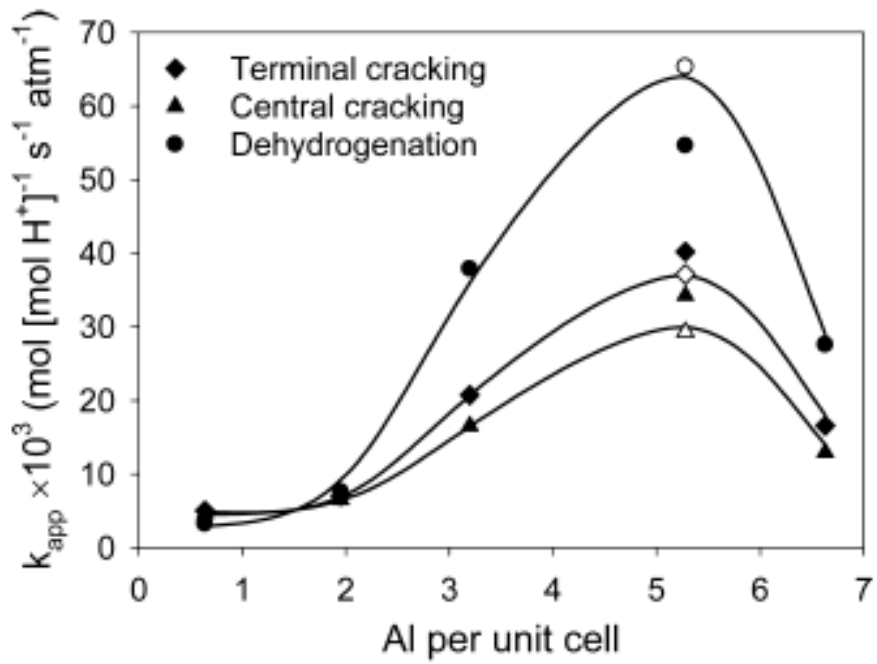

Figure 1.12 First-order rate coefficients of monomolecular cracking and dehydrogenation of nbutane versus aluminum atoms per unit cell in H-MFI. ${ }^{113}$

The systematic research of Bell et al. was significant not only because it provided commensurable results from independent studies of characterization, reaction and theoretical calculations, but also provided another approach to clarify the aluminum distribution in zeolites. That is the concept to employ theoretical calculations to have thermodynamic and kinetic data of side reactions with different preference toward confinements and, then, testify those calculated results with experimental data.

The microenvironment surrounding acid sites is a delicate issue and could be versatile denpending on factors such as temperature and presence of guest molecules. Leave along the massive amount of acid sites in a zeolite crystal. Thus, experimental data always give statistical average properties of all acid sites and could hardly provide accurate information on aluminum site at particular position. In this sense, theoretical calculations could be helpful to develop understanding of the property of individual acid sites. ${ }^{115}$ 
The hydrocarbon reactions on acid sites of zeolites proceed first through formation of carbocation intermediates by protonation of the hydrocarbon substrates. The stability of such carbocation intermediates is crucial for reaction since it determines the activation barriers. The information of stability of certain intermediates can be difficult to obtain through experimental method. According to the results from periodic DFT study, Rozanska et al. reported that the local geometry of the active sites could have important impact on the stability of tert-butoxide species, the intermediate of isobutene chemisorption on an acid site. When steric constraint is high, the bulkier intermediate i-butyl tertiary carbocation could be difficult to form, resulting in a less favored presence of ibutoxide.
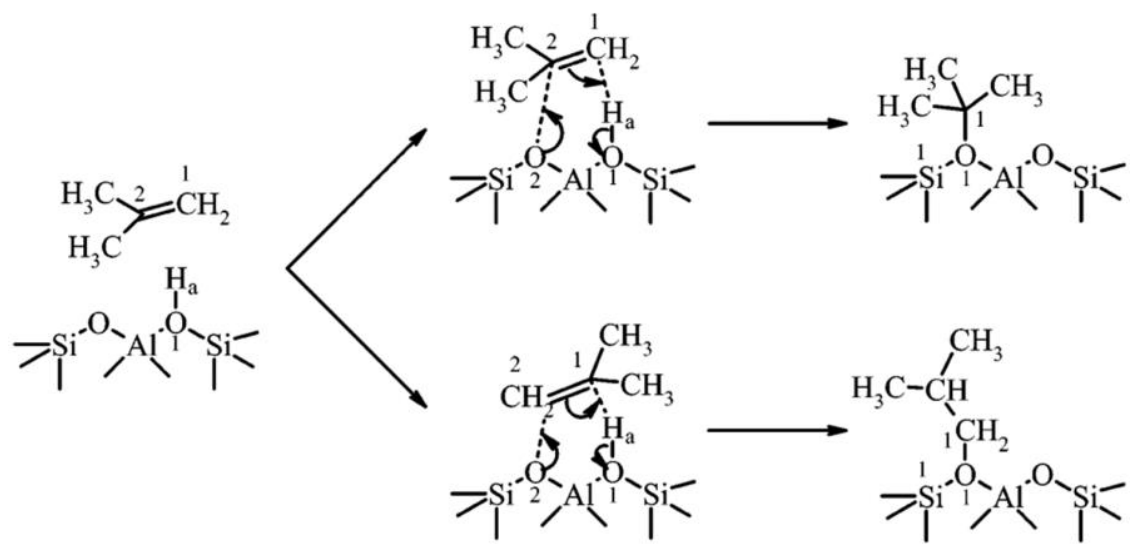

Scheme 1.1 mechanism of chemisorption of isobutene on acid sites in zeolites.

Corma et al. studied the protonation of olefins on different sites in mordenite through DFT calculations and predicted the formation of alkoxides or carbocations could be determined by the position of $\mathrm{T}$ sites. ${ }^{104,106,116}$ According to the study, the protonation of isobutene involves a tert-butyl carbenium intermediate. The tendency of this tert-butyl carbenium to convert to alkoxide is dependent on the location of $\mathrm{T}$ sites in the mordenite structure. ${ }^{104,106,116}$ 
From the above introduction of the progress on research of the aluminum distribution, it is clear that this topic has great impact on industrial applications as well as on the understanding of zeolite synthesis. However, the topic is complex since the aluminum distribution is not a single topic but rather a combination of at least three issues, as it has been stated in this introduction, the enrichment of aluminum at certain part of the zeolite crystal, the paired or isolated states of aluminum sites and the siting of aluminum among different $\mathrm{T}$ sites in the channel system. There is no guarantee that these three aspects would individually influence the overall properties of zeolites, neither to be determined by certain synthesis or post-synthesis preparation methods. Thus, when one is going to study the aluminum distribution in a certain zeolite, it is necessary to consider simultaneously influence of all these three aspects.

\subsection{Design of pores/cavities in zeolites}

The previous section introduced the progress in zeolite study focusing on acidic properties, a direction inherited from solid acid catalysts. Another direction, as mentioned earlier, is focusing on the porous nature and uniform channel/cage systems of zeolites and attempt to rationalize the porosity of zeolites by means of introducing mesopores and hierarchical porous systems as well as synthesizing zeolites with new structures containing particular channel/cage systems.

\subsubsection{Mesoporous cavities}

Due to previously mentioned scientific and technological contribution, zeolites experienced an expansion in the last thirty years. The uniform microporous channel system rendered this family of materials are sieve molecules, which makes them ideal materials for industrial uses as absorbents and/or catalysts. Not all kinds of porous solids can be classified as zeolites. In general, zeolites should be crystalline materials with uniform porous channel-based or cage-based open frameworks, whose pore size are within microporous region (usually $<1$ $\mathrm{nm})$. In contrast, for example, alumina, silica and activated carbons, which are materials widely used in a number of industrial related processes, are mostly 
disordered in the sense of having random distributions of pores, varying from microporous range $(<2 \mathrm{~nm})$ to macroporous range $(>50 \mathrm{~nm})$. Nevertheless, we have to say that using surfactant as sole template, silica can form porous solids containing uniform channels with sizes from $2 \mathrm{~nm}$ to $50 \mathrm{~nm}$ with amorphous silica channel walls. ${ }^{117,124}$ These materials are considered mesoporous silica and unlike zeolites, they do not present short range orders.

The uniform microporous channel systems of zeolites may impose severe masstransfer constraints when reactants or adsorbates present similar sizes compared to the pore openings. ${ }^{118-125}$ This is more problematic when the crystal size of zeolites is larger than several microns, where it has been described that even the diffusion of linear olefins could be limited to its outer shell. ${ }^{126}$ For this reason, there has always been a need to maximize catalytic performance while avoiding interference of diffusion.

It is well known that zeolites are prone to dissolution when treated with basic solutions, as a common nature for silicate salts. In 1992, Dessau et al. reported dissolution of ZSM- 5 crystals when treated with $\mathrm{Na}_{2} \mathrm{CO}_{3}$ solution..$^{53}$ Le Van Mao et al. reported also that the treatment of X, Y and ZSM-5 zeolites with $\mathrm{Na}_{2} \mathrm{CO}_{3}$ could effectively decrease their $\mathrm{Si} / \mathrm{Al}$ ratio while maintaining the crystal structures, microporous volumes and surface areas. ${ }^{54}$ In those years, the focus was on tuning the framework composition of the zeolites and little attention was paid to the generation of mesoporosity. Since, at that moment, the concept of mesoporous materials and mesoporosity was merely at the dawn, not much attention was paid to the nature and effect of such treatment on zeolites. One of the first papers reporting the generation of mesopores in ZSM- 5 by extraction of silicon by basic treatments was in $2000 .{ }^{128}$ In this work, Ogura et al treated ZSM-5 samples with $\mathrm{NaOH}$ aqueous solution at elevated temperature, generating uniform mesopores without significant sacrifice of micropore. Groen et al. confirmed that the mesopores generated by such treatment was intracrystal and the micropores from original ZSM-5 crystal was preserved. ${ }^{129,130}$ The researchers continued with this discovery and systematically investigated into the influence of different parameters, such as the framework $\mathrm{Si} / \mathrm{Al}$ ratio, crystal size and structure of parent zeolite. ${ }^{131,132}$ 
One of the important conclusions from these works was the protective role of aluminum against dissolution as it was previously reported by Dessau et al. When treating a zeolite with alkaline solution at elevated temperature, framework silica bond is subjected to dissolution, but the degree of such dissolution is not consistent under the same conditions and could be influenced by the Si/Al of the parent zeolite. In fact, the aluminum sites were well-preserved after the treatment, while dissolution occurred selectively on framework silica. As a result, a window of $\mathrm{Si} / \mathrm{Al}$ is proposed for proper desilication, roughly between 25 to 50 in ZSM-5 (see Figure 1.13). Due to this feature, the process of alkaline treatment was named desilication. As described in the previous section, the distribution of aluminum along the zeolite crystal is not always homogeneous and it could be enriched in certain parts of the crystal. When a ZSM-5 with aluminum zoned in shell is subjected to alkaline treatment, the desilication occurs mainly in the internal part of the crystal where aluminum is in lower content compared to the Al-rich shell. As a result, a core-shell structure ZSM-5 with hierarchical porous system could be obtained. ${ }^{132}$
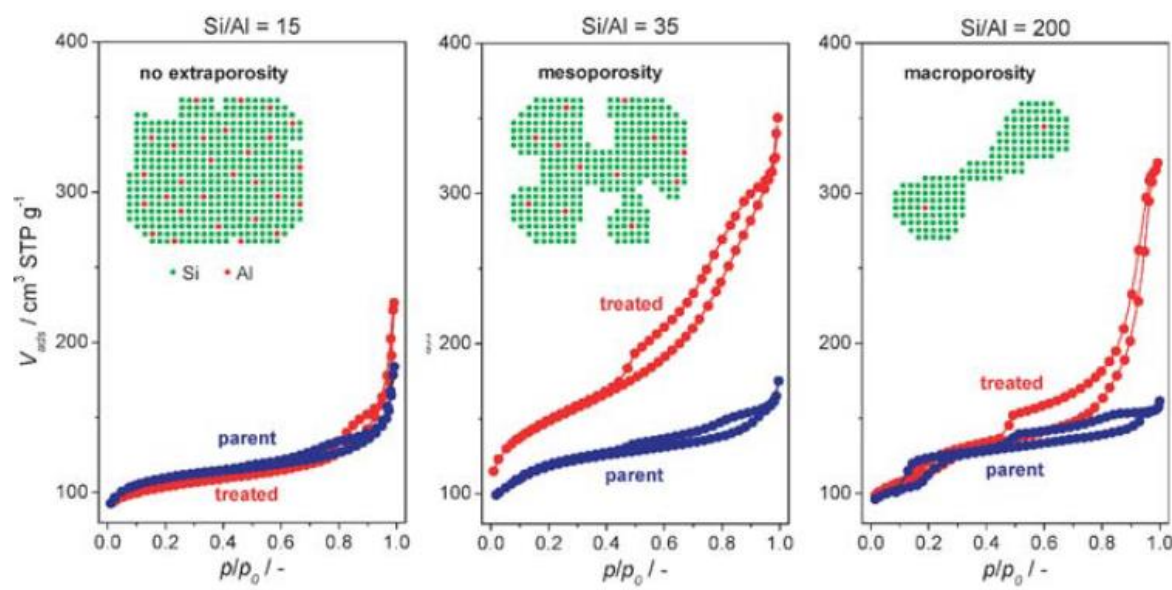

Figure 1.13 Illustration of protective role of framework aluminum on desilication of ZSM-5 zeolite. ${ }^{134}$ 
When mesopores are generated inside the crystals, the diffusional problem of microporous zeolites could not be well-addressed since the diffusion of guest molecules still requires penetrating the outer shell. The elimination of bulk silica from inside will diminish diffusion limitation inside of a crystal, whereas if one count the performance of single crystal there is not much improvement due to the limited presence of aluminum sites in the inner part. A more desirable generation of mesopores would be by desilication from the external part of zeolite crystal. Starting from a ZSM-5 with an homogeneous aluminum distribution, a ZSM-5 sample with hierarchical porosity was obtained, whose distribution is equally distributed along the internal and external parts of the crystal. $^{135}$

Dealumination by means of steaming or acid leaching is also reported to optimize diffusion in zeolite crystal through selective extraction of framework aluminum. In the case of dealumination, the extracted aluminum will leave a vacancy in its original site and either forms EFAl in zeolite channel or be washed by the solution. The mesoporosity generated in this way is not comparable to desilication, since aluminum only makes up minority of framework atoms. In the case of Si-rich zeolites, the importance of such treatment is to tune aluminum content in the crystal without significant sacrifice of crystallinity. ${ }^{136,137}$ Whereas in the case of zeolites with high content of $\mathrm{Al}$, such as $\mathrm{Y}$, dealumination could significantly increase mesoporosity in zeolite framework and hence improve the accessibility of acid sites, especially for bulky reactants. Starting from Y zeolite with $\mathrm{Si} / \mathrm{Al}$ of 2.4 , Corma performed dealumination with $\mathrm{SiCl}_{4}$ or steaming and studied the accessibility of acid sites within the treated samples. ${ }^{138}$ The former is milder and could generate small amount of mesopore while the latter could produce more mesopore in sacrifice of microporous volume. When cracking $n$ heptane, a molecule with smaller dynamic diameter and could penetrate through micropore, activity of $\mathrm{SiCl}_{4}$ dealuminated $\mathrm{Y}$ is higher than steam-dealuminated one. On the contrary, when cracking vacuum gas oil with larger size, the steamdealuminated $\mathrm{Y}$ zeolite was more active. This comparison indicated that in Alrich zeolites, dealimunation could effectively generate mesopore and optimize the substrate accessibility. Combining the advantages of both treatments, scientists could tailor the acidic properties as well as porosities on a zeolite 
through successive combination of desilication and dealumination. In fact, this has been adopted in preparation of high-silica or hierarchical analogous of zeolites, such as $\mathrm{Y}$, which can hardly be prepared through direct synthesis. ${ }^{139}$

The mesoporosity generated in zeolites could significantly alter physicochemical properties and catalytic activities of parent zeolites. Diffusion of bulkier molecules, such as 1,3-dimethylcyclohexane, in desilicated unidimensional 12ring zeolite ZSM-12 (structure code: MTW), ${ }^{140}$ and cumene in mesoporous ZSM-5, have been increased more than three-fold compared to parent materials. ${ }^{141}$ In liquid phase degradation of high-density polyethene (HDPE), desilicated ZSM-5 showed an activity 20-times higher than non-treated parent material. ${ }^{142}$ Liquid phase alkylation of benzene with ethene is a crucial industrial process in where ZSM-5 and mordenite showed outstanding selectivity toward ethylbenzene due to its proper micropore size and channel-based structure. The drawback of such material is the diffusion limitation to bulky reactant benzene and product ethylbenzene. When ZSM-5 and mordenite zeolites are treated by desilication, a clear improvement in conversion is observed, while high selectivity toward ethylbenzene is maintained. ${ }^{143,144}$ Nevertheless, the improvement by generating mesoporosity should go in the same line that decreasing zeolite crystal size, but with a better control of the material characteristics in the latter case.

\subsubsection{Molecular size cavities: OSDA-induced zeolite synthesis}

Represented by desilication and dealumination, the initial attempts to understand and optimize the transportation inside microporous zeolite mainly focused on post-synthetic strategies, applying changes to zeolites that already exist. Along with understanding the role of each component in the synthesis gel, researchers explored various strategies to rationalize zeolite synthesis to obtain new porous properties or new structures. ${ }^{145}$ In brief, the source material of silicon and aluminum, alkalinity, OSDAs, presence of fluoride anions and water, among others, could play crucial roles in determining the crystallized product phase. ${ }^{146-}$ ${ }^{153}$ However, sometimes, tuning such parameters can result in limited number of phases that could be obtained, since in such cases, the hydrothermal 
crystallization is controlled by colloidal chemical properties and the product phase would be the most stable phase even studying wide range of synthesis conditions.

Nevertheless, even those zeolites synthesized with the same structure could differ in physicochemical properties. One example is the synthesis of highly hydrophobic zeolites in presence of fluoride. $\mathrm{F}^{-}$can be incorporated in small cage units, such as double 3-member rings (D3R) or double 4-member rings (D4R), which are energetically unstable in its pure-silica form. Thus, such puresilica small ring structures suffer from either a difficulty to be formed or a tendency to exert silicon atom to relieve the tense Si-O-Si bond angle, decreasing crystallinity of zeolite. When $\mathrm{F}^{-}$is incorporated, it stabilizes such secondary building units thanks to the formation of pentacoordinated Si species with trapped $\mathrm{F}^{-}$. The introduction of $\mathrm{F}^{-}$within these small secondary building unites (SBUs) also allows compensating positive charges from inorganic and organic cations, substantially reducing the presence of structural defects in the crystallized zeolites. Moreover, in general, the presence of $\mathrm{F}^{-}$decreases the rate of nucleation, resulting in larger crystal sizes in the product zeolites. As a result, the zeolites synthesized in fluoride media usually possess large crystals and high hydrophobicity. The successful synthesis of high-silica Beta, ${ }^{154}$ ITQ-4, ${ }^{155}$ ITQ$7,{ }^{156}$ ITQ $-17^{157}$ and ITQ-24, ${ }^{158}$ proved the ability of fluoride in directing formation of high-silica hydrophobic zeolites.

Among all factors contributing to zeolite formation, the OSDA selected as template is crucial. The pioneer work of introducing OSDAs in zeolite synthesis was in 1960s by Barrer et al. ${ }^{161}$ and Kerr $^{162}$ and have first allowed the successful development of LTA zeolite for industrial applications in adsorption and separation. The invention of ZSM-5 and Beta by Mobil were the first examples of industrial zeolite catalysts synthesized using OSDAs. ${ }^{159,163}$ The larger sizes and bulkier structures of OSDA compared to inorganic cations could allow filling the cavities of zeolites with a limited amount of positive charges (usually one per molecule and two in the case of dicationic OSDAs), and, as a clear consequence, zeolites with lower aluminum contents can be achieved because the structure would require less aluminum species to balance the considerably lower positive 
charges compared to zeolite synthesized only with small inorganic cataions. The benefit of introducing OSDAs in zeolite synthesis was controlling the acidity of the achieved high-silica materials. In fact, it is well-studied that zeolites with low $\mathrm{Si} / \mathrm{Al}$ show high acid concentration but the acid strength is usually low due to the presence of Al-O-Si-O-Al sequences, which can also be understood by the concept of next nearest neighbor (NNN) aluminum. ${ }^{160}$ When the number of aluminum is increased in the NNN position of one aluminum site, the the acid strength of the aluminum site will be lower.

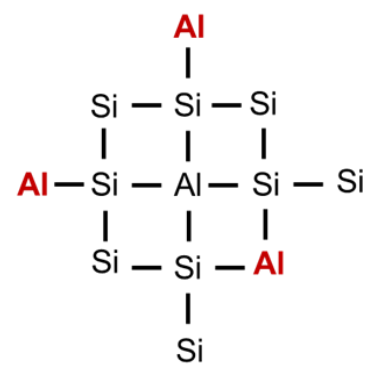

Scheme 1.2 illustration of NNN aluminum, oxygen atoms are emitted to simplify the scheme.

The aluminum sites in red represent the NNN position of the center aluminum atom.

By synthesizing high-Si zeolites, such as ZSM-5 and Beta using TPA and TEA as OSDAs, respectively, the resulting materials showed stronger Brønsted acidities. ${ }^{163,164}$ Moreover, framework aluminum is prone to dealumination during calcination and steam calcination treatments as a result of distorted Si-O-Al bonds compared to Si-O-Si. Thus, a decrease in aluminum by the postsynthesis dealumination of high $\mathrm{Al}$ content zeolites results in higher stability of the catalysts as well as resistance against deactivation by coke.

Starting from these discoveries, scientists attempted to broaden the application of OSDAs to obtain more zeolites with higher $\mathrm{Si} / \mathrm{Al}$ ratios, expecting to have isolated $\mathrm{Al}$ with stronger acidity. Gies and Marler started studies on the nature of OSDAs and synthesized a series of clathrasils using OSDAs with different sizes. ${ }^{165}$ Moreover, they succeeded in correlate cavity sizes in clathrasils and the size and shape of the OSDA molecules, proving the structure-directing role of 35 
OSDAs. ${ }^{165}$ In the meantime, Nakagawa and Zones showed that the synthesis of zeolites with more open structures can be achieve by increasing the size of the OSDA. ${ }^{166}$ One of the important discoveries was that when the OSDA becomes rigid and bulky, their specificity toward certain strctures increases. ${ }^{167}$ On the other hand, when an OSDA is flexible, it is possible to obtain different phases under different synthesis conditions using the same OSDA. For instance, using hexamethonium cation as OSDA, researchers from ITQ succeeded in the synthesis of ITQ-13, ITQ-22, ITQ-24 and ITQ-33, whose pore systems ranged from small to extra-large pores. ${ }^{157,169,169}$ Among these materials, ITQ-13 possesses unique $9 \times 10 \times 10$ channels and was proved to be an active catalyst for catalytic cracking, ${ }^{170}$ and ITQ-33 allows high yield of diesel and propene in cracking of vacuum gasoil at the same time as a result of its unique combination of 18- and 10-ring channels.

The successful attempts described above proved that OSDAs can play important role not only in defining aluminum content in the product, but also in determining the framework structure. Thus, the area of zeolite synthesis has stepped into a new era of OSDA-mediated material synthesis, and consequently, new synthesis strategies have been proposed.

The aim of this section was not to summarize all the published synthesis strategies but merely provided a few of them only to illustrate the accomplishments achieved by scientists in rationalizing zeolite synthesis for better acid catalysis applications, and from there to show our contribution to this subject. In the very beginning of this chapter, it was discussed that solid acids for catalysis require certain acidity together with proper accessibility. The attempts to rationalize zeolite synthesis mainly focus on these two subjects.

As described previously, the balance between positive and negative charges in the synthesis gel determines the amount of aluminum that can be introduced in the zeolite obtained. When an OSDA is employed in the synthesis and serves as one of the sources introducing positive charges, their size and charge will influence their capabilities to direct the formation of the proper zeolite phase for catalytic reactions. Thus, to obtain zeolites with the adequate cavity together with a proper amount of acid sites, the size to charge ratio of the OSDA molecule is 
crucial. One of the concepts for rationalizing zeolite synthesis that has achived this goal was the use of self-assembled OSDAs to form bulky organic species serving as structure-directing agents. Using two aromatic anilinium-derived molecules through $\pi-\pi$ stacking, high-Si and pure-Si analogous of LTA zeolites were obtained, materials that were named as ITQ-29 (see Figure 1.14). ${ }^{171}$ LTA zeolites were originally prepared through synthesis in absence of OSDAs, with a common product presenting $\mathrm{Si} / \mathrm{Al}$ molar ratios of around 1 . Such high content of aluminum makes the LTA material incapable of catalyzing reactions. Using small OSDAs, such as TEAOH, an LTA material with a Si/Al of 6 was obtained, and the key was to match the charge density of OSDA and framework of zeolite. ${ }^{172}$ In the case of ITQ-29, the self-assembly of two bulky anilinium OSDA molecules enabled maximizing the size to charge ratio, and, thus, the formation of the zeolite with very low aluminum content. Due to the low amount of aluminum, ITQ-29 has very high hydrothermal stability as well as acid strength to serve as acid catalyst.

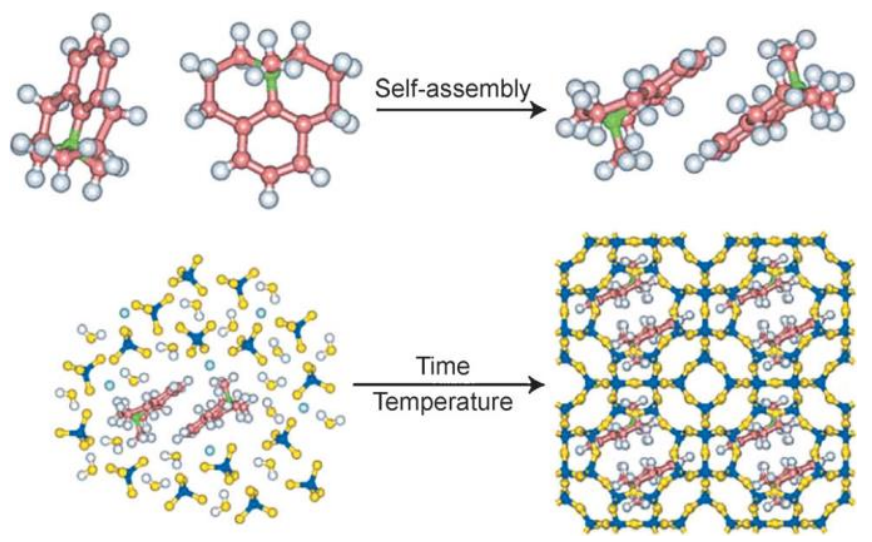

Figure 1.14 Illustration of self-assembly of anilinium-based template and its structure-directing role in ITQ-29 synthesis. ${ }^{171}$ 
As another important feature of solid acid catalysts, the transportation of guest molecules is decisive, and therefore, introducing mesopores in zeolite through direct synthesis or by post-synthesis desilication procedures were wellestablished methods, being the latter exclusively described in the previous section. Following thriving developments of OSDA-directed zeolite synthesis, the preparation of zeolites with controlled mesoporosity via direct synthesis became possible. Indeed, Ryoo et al. obtained a lamellar MFI zeolite nanosheet with thickness of the size of one unit-cell using a surfactant-type OSDA with two quaternary ammonium groups as hydrophilic head and a long alkyl group as hydrophobic tail. ${ }^{173}$ During the crystallization, the surfactant-type OSDA forms micelles in solution due to its amphiphilic nature (see Figure 1.15). The silica species interact with the dicationic heads and start nucleation, while the long alkyl group prevents the growth of crystals along b-axis (see Figure 1.15). As a result, the crystal grew only along a-c plane and maintained a unit-cell thick along b-axis. ${ }^{174}$
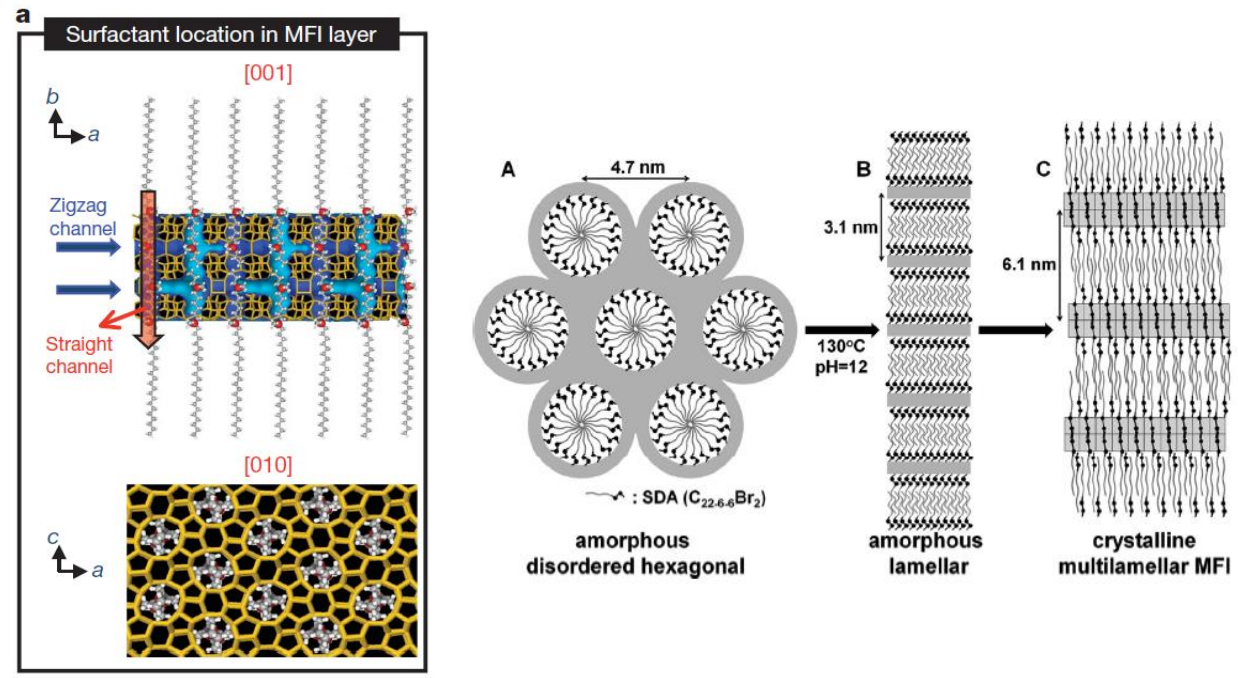

Figure 1.15 Formation of lamellar MFI zeolite nanosheet directed by surfactant like dicationic OSDA and proposed formation mechanism. ${ }^{173,174}$ 
The obtained lamellar MFI zeolite nanosheet possesses an extraordinarily large surface area of $700 \mathrm{~m}^{2} / \mathrm{g}$. Its aluminosilicate analogue was effective for the MTG process, and its lifetime is four times longer than conventional bulky ZSM-5 zeolite. $^{173}$

The above example illustrated that synthesizing zeolites containing mesoporous could effectively improve the intracrystal transportation. Nevertheless, the effective part of the crystals is still the microporous channels and cavities where the diffusion limitation remains unchanged. In order to optimize intrinsic intracrystal transportation of molecules, numerous attempts have been made by scientists to synthesize zeolites with large pores (12-ring channels) or extra-large pores (>12-ring channels) systems. ${ }^{175-177}$ In silica-based zeolites, the main part of the framework is composed of silica and alumina tetrahydrons and the optimized bond angle of T-O-T limits the channel sizes between 8-ring (for instance LTA) and 12-ring (for instance Beta). Larger pores require presence of small secondary building units (SBUs), such as D3R or D4R, to serve as linker to amplify the pores. ${ }^{178}$ The bond angle in such small SBUs is much lower than that requires for stable Si-O-Si bond, which renders such structure low stability, severely limiting the synthesis of extra-large pore zeolites in their high-silica form.

The breakthrough was when Ge was discovered to favor formation of D3R and D4R units. ${ }^{179,180}$ By employing Ge as heteroatom, a number of extra-large pore zeolites were successfully synthesized. ${ }^{181-183}$ In these Ge-containing zeolites, the location of germanium is not random and is preferentially in D4R or D3R units ${ }^{145,179,184}$ Ge incorporated in zeolite frameworks is prone to severe extraction when exposed to humid conditions. Recently, different authors have developed post-synthesis procedures to create high-silica extra-large pore zeolites, either by substitution of Ge with other heteroatoms or by transformation of the germanosilicate into another high-Si counterpart. ${ }^{185-187}$

The examples described above are merely a few illustrations out of countless discoveries to synthesize new zeolites and/or optimizing properties of zeolites via synthetic strategies. Most of the attempts were based on trial and error procedures, where the zeolite crystallization of zeolite is in general considered a 
black box, and the relationship between starting conditions and final products are basically empirical.

In fact, the attempt to initiatively predict zeolite synthesis has started in 1970s. In a pioneer work by Breck, a twinned polytype of the FAU framework, namely "Breck structure 6", was predicted and later synthesized (EMT structure). ${ }^{188}$ Other researchers have also proposed structures based on existing building blocks that do not violate crystal chemistry constraints. ${ }^{189,190}$

Thanks to the development of computer science, it is possible to predict new hypothetical zeolite frameworks using computational methods and artificial intelligence. ${ }^{191-205}$ Currently, there are two main databases of hypothetical zeolite structures available online. One is developed by Treacy et al., which gives over 5.4 million structures that theoretically could exist. ${ }^{208}$ This database has successfully predicted the existence of ITQ-33 and ITQ-51, both synthesized experimentally years later. ${ }^{169,} 209$ Another database was established by $\mathrm{Yu}$ et al., which aims to collect hypothetical zeolite frameworks with specified pores. ${ }^{211}$ This database provides pore information, such as accessible volume, cavity type and channel dimensionality. According to either database, there are millions of possible zeolite structures waiting to be synthesized. However, up to now, there are only 248 crystallographically distinct frameworks that have been accepted by the IZA, and their impact on industries has already reached a USD 3.6 billion market, being expected to reach USD 4.9 billion within the next 5 years. ${ }^{212}$ There is no doubt that some of the potential frameworks, if synthesized, could generate a tremendous impact. Then, predicting hypothetical zeolite frameworks could serve as guideline for zeolite synthesis.

\subsubsection{Atomic-level cavity design : reaction-adapted synthesis}

From experimental point of view, there is a need for development of synthetic strategies that could facilitate the preparation of zeolite materials with adapted structures for target reactions rather than following the traditional trial and error methodology, which is both time- and cost-consuming. In this sense, it has recently been proposed the "ab-initio" synthesis design of zeolites for certain catalytic processes based on pre-established knowledge on reaction mechanisms. 
It is accepted from transition-state theory that the reaction undergoes through the formation of transition states or intermediates, and this is particularly the case in acid-catalyzed reactions where carbenium or carbonium cations are usually involved as a result of protonation by acid sites. If the transition state of the reaction could be stabilized by a specific zeolite cavity, the activation energy of the reaction could be effectively reduced, favoring the catalysis of the target reaction. This idea was presented by Corma in 2004 and demonstrated as possible by working with a Diels-Alder reaction. ${ }^{213}$ Recently, Corma et al. developed a synthesis methodology that involves the use of OSDAs that mimic the transition state species of target reactions in terms of their structure, configuration, charge density and charge distribution. ${ }^{214}$ Toluene disproportionation, ethylbenzene isomerization and adamantane synthesis were adopted as the target reactions to illustrate this concept. The reactions were chosen due to their well-studied reaction mechanisms in where cationic species were established, and the synthesis of the corresponding ammonium or phosphonium OSDAs was available. It was expected that the materials obtained by using such OSDAs would facilitate their corresponding reactions.

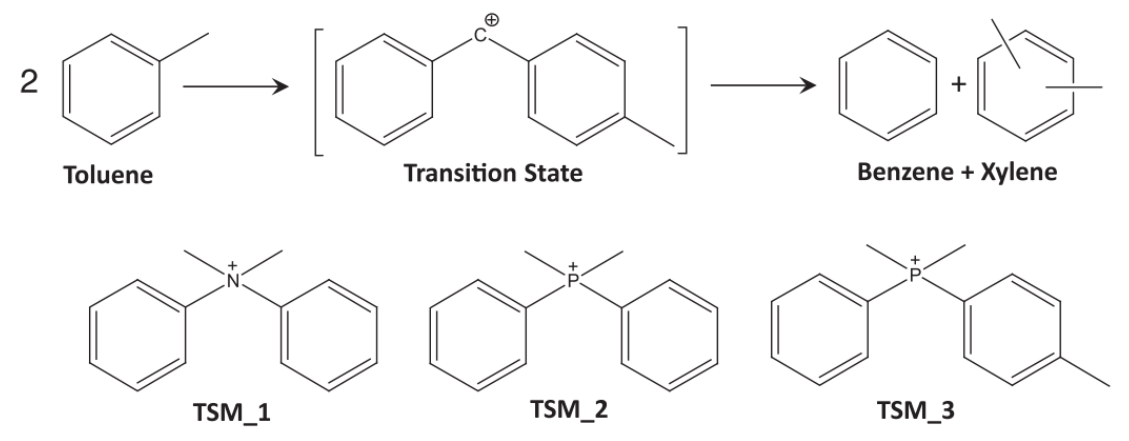

Figure 1.16 Mechanism of toluene disproportionation, structure of transition state and corresponding mimicking OSDA.214

In toluene disproportionation, the reaction undergoes either one-step transalkylation pathway, which involves formation of bulky diaryl transition state 41 
species, or a two-step dealkylation-alkylation pathway. The transalkylation intermediate is more selective to produce benzene and xylenes since it avoids over-alkylation to form polyalkylated products. Thus, by mimicking the transition state of the transalkylation mechanism, diaryl ammonium and diaryl phosphonium templates were synthesized and tested in zeolite synthesis (see Figure 1.16). The resultant zeolite was selectively ITQ-27, and it showed superior catalytic activity compared to other commercially-available zeolites, such as mordenite, ZSM-5 or Beta. ${ }^{214}$

A

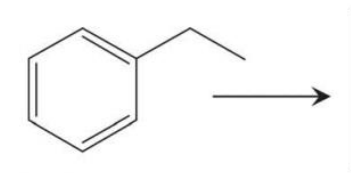

Ethylbenzene

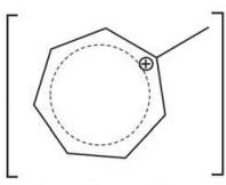

Transition State

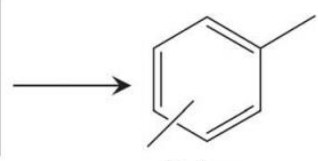

Xylenes

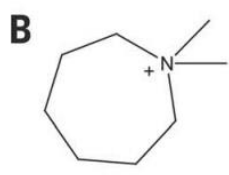

TSM_4

Figure 1.17 Mechanism of ethylbenzene isomerization, structure of transition state and corresponding mimicking OSDA.214

Mimicking the seven-member ring intermediate in ethylbenzene isomerization (see Figure 1.17), the researchers obtained ITQ-64, an analogous to the layered precursor of ferrierite PREFER. ${ }^{214}$ The overall yield of $(p+o)$-xylene selectivity using ITQ-64 for ethylbenzene isomerization was higher than other commercial zeolite catalysts for this process.Also, following this strategy, a mimic of the Diels-Alder intermediate formed when reacting.1,3-cyclohexadiene and $\mathrm{N}$ methylmaleimide, allowed the synthesis of BEC structure (see Figure 1.18). BEC is analogous to the pure polymorph $\mathrm{C}$ of Beta zeolite and it can be considered as a geometrical transformation of polymorph $\mathrm{A}$ and $\mathrm{B} .{ }^{215} \mathrm{Using}$ the pure silica polymorph BEC material obtained via this mimicking approach, the catalytic activity for the DA reaction between 1,3-cyclohexadiene and $\mathrm{N}$ methylmaleimide could be enhaced by 2-2.5 fold. The reason for such enhancement was attributed to a cavity-stabilization of the transition state with the corresponding decrease in the activation energy of the reaction. A lower 
enthalpy of activation and a larger decrease in entropy were calculated according to kinetic and thermodynamic data obtained experimentally. ${ }^{216}$

(A)<smiles>C1=CCCC=C1</smiles><smiles>CN1C(=O)[C+]=CC1=O</smiles>

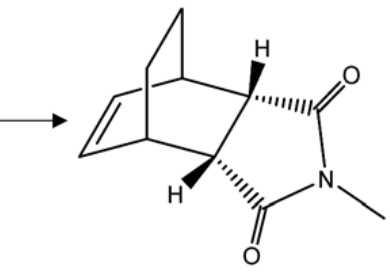

(B)

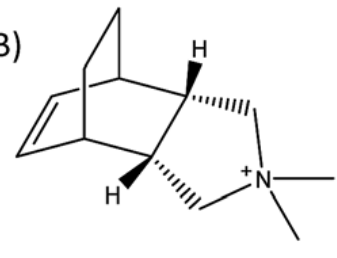

Figure 1.18 DA reaction between 1,3-cyclohexadiene and $\mathrm{N}$-methylmaleimide (A) and (3aR,4S,7R,7aS)-2,2-dimethyl-2,3,3a,4,7,7a-hexahydro-1H-4,7-ethanoisoindol-2-ium molecule as OSDA mimic of the DA adduct (B). 


\subsection{References}

1. E. Houdry, A. Joseph, Bull. Assoc. Fr. Tech. Pet., 1956, 117, 177.

2. K. Tanabe, Solid Acids and Bases; Academic Press: New York, 1970.

3. P. T. Anastas, M. M. Kirchhoff, T. C. Williamson, Appl. Catal. A, 2001, 221, 3.

4. K. Tanabe,T. Sumiyoshi, K. Shibata, T. Kiyoura, J. Kitagawa, Bull. Chem. Soc.Jpn., 1974, 47, 1064.

5. C. L. Thomas, Ind. Ens. Chem., 1949, 41, 2564.

6. K. Tamele, Disc. Faraday Soc., 1950, 8, 270.

7. W. Grabowslu, M. Misono, Y. Yoneda, J. Catal., 1980, 61, 103.

8. H. Hawakami, S. Yoshida, T. Yonezawa, J. Chem. Sac. Faraday Trans., 1984, 280, 205.

9. G. M. Zhidomirov, V. B. Kazansky, Adv. Catal., 1986,34, 131.

10. J. Friuiat, J. Natl. Conf. Clays Clay Minerals, 1963, 12, 327.

11. C. de Kimpl, M. C. Gastuche, G. W. Bhndley, Am. Mineral, 1961, 46, 1370.

12. C. J. Plank, L. C. Drake, J. Colloid Sci., 1947, 2, 399.

13. M. R. S. Manton, J. C. Davidtz, J. Catal., 1979, 60, 156.

14. A. Corma, V. Fornes, J. Perez-Pariente, F. Rey, D. Rawlence, Appl. Catal., 1990, 63, 145.

15. A. F. Cronstedt, Svenska Vetenskaps Akademiens Handlingar Stockholm., 1756, 17,120 .

16. E. Jones, Ind. Eng. Chem., 1950, 42, 2208.

17. R. Burwell, Heterogeneous Catalysis-selected American Histories, 1983, 222, 8.

18. J. Casci, C. Martin Lok, M. Shannon, Catal. Today, 2009, 145, 38.

19. J. N. Armor, Catal. Today, 2011, 163, 3. 
20. M. Guisnet, J.-P. Gilson (Eds.), Zeolites for Cleaner Technologies, World Scientific Publishing Company, 2002.

21. A. Delbianco, S. Meli, L. Tagliabue, N. Panariti, Proceedings of the World Petroleum Congress 19th, 2008, 1.

22. R. Montanari, S. Rosi, M. Marchionna, A. Delbianco, N. Panariti, Proceedings of the World Petroleum Congress 17th, 2002, 331.

23. N. Panariti, F. Bazzano, A. Delbianco, M. Marchionna, R. Montanari, S. Rosi, 221st ACS National Meeting, 2001, 6.

24. N. Panariti, A. Delbianco, M. Marchionna, R. Montanari, S. Rosi, American Institute of Chemical Engineers, Spring National Meeting, 2003.

25. N. Panariti, S. Rosi, Chim. Ind. (Milan, Italy), 2002, 84, 52.

26. A. Corma, A. Martínez, Stud. Surf. Sci. Catal., 2005, 157, 337.

27. M. Rigutto, Zeolites and Catalysis, Synthesis, Reactions and Applications, 2010, 2, 547.

28. E. Flanigen, Stud. Surf. Sci. Catal., 2001, 137, 11.

29. M. Taramasso, G. Perego, B. Notari, US 4410501A(1979).

30. P. T. Barger, US5095163A(1991).

31. A. Corma, Chem. Rev., 1997, 97, 2373.

32. U. Kurschner, H. G. Jerschkewitz, E. Schreier, J. Volter, Appl. Catal., 1990, $57,167$.

33. I. Wang, C. L. Ay, B. J. Lee, M. H. Chen, Appl. Catal., 1989, 54, 257.

34. Y. S. Bhat, J. Das, K. V. Rao, A. B. Halgeri, J. Catal., 1996, 159, 368.

35. D. Fraenkel, Ind. Eng. Chem. Res., 1990, 29, 1814.

36. S. M. Csicsery, Zeolites, 1984, 4, 202.

37. D. H. Olson, W. O. Haag, Catalytic Materials, ACS Symposium Series, 1984, 248. 
38. W. W. Kaeding, C. Chu, L. B. Young, B. Weinstein, S. A. Butter, J. Catal., 1981, 67, 159.

39. J. Das, Y. S. Bhat, A. B. Halgeri, Ind. Eng. Chem. Res., 1994, 33, 246.

40. H. P. Roger, M. Kramer, K. P. Moller, C. T. O’Connor, Micropor. Mesopor. Mater., 1998, 21, 607.

41. G. Mirth, J. A. Lercher, J. Catal., 1991, 95, 3736.

42. G. Mirth, J. Cejka, J. A. Lercher, J. Catal., 1993, 139, 24.

43. G. Mirth, J. A. Lercher, J. Catal., 1994, 147, 199.

44. T. Hibino, M. Niwa, Y. Murakami, J. Catal., 1991, 128, 551.

45. W. W. Kaeding, C. Chu, L. B. Young, S. A. Butter, J. Catal., 1981, 69, 392.

46. P. Tynjala, T. T. Pakkanen, J. Mol. Catal. A, 1997, 122, 159.

47. L. Y. Fang, S. B. Liu, I. Wang, J. Catal., 1999, 185, 33.

48. J. Cejka, N. Zilkova, B. Wichterlova., G. Eder-Mirth, J. Lercher, Zeolites, 1996, $17,265$.

49. D. H. Olson, W. O. Haag, R. M. Lago, J. Catal, 1980, 61, 390.

50. R. von Ballmoos, W. M. Meier, Nature, 1981, 289, 782.

51. S. L. Suib, G. D. Stucky, R. J. Blattner, J. Catal., 1980, 65, 174.

52. E. G. Derouane, J. P. Gilson, Z. Gabelica, C. Mousty-Despuquoit, J. Verbist., J. Catal., 1981, 71, 447.

53. R. M. Dessau, E. W. Valyocsik, N. H. Goeke, Zeolites, 1992, 12, 776.

54. R. Le Van Mao, S. Xiao, A. Ramsaran and J. Yao, J. Mater. Chem., 1994, 4.

55. K.-J. Chao, J.-Y. Chern, Zeolites, 1988, 8, 82.

56. C. Seebacher, J. Rau, F.-W. Deeg, C. Brauchle, S. Altmaier, R. Jager, P. Behrens, Adv. Mater., 2001, 13, 1374.

57. P. Kortunov, S. Vasenkov, C. Chmelik, J. Karger, D. M. Ruthven, J. Wloch, Chem. Mater., 2004, 16, 3552. 
58. M. H. F. Kox, E. Stavitski, B. M. Weckhuysen, Angew. Chem. Int. Ed., 2007, 46,3652 .

59. M. B. J. Roeffaers, B. F. Sels, H. Uji-i, B. Blanpain, P. L'Hoest, P. A. Jacobs, F. C. de Schryver, J. Hofkens, D. E. de Vos, Angew. Chem., Int. Ed., 2007, 46, 1706.

60. D. Tzoulaki, L. Heinke, W. Schmidt, U. Wilzcok, J. Karger, Angew. Chem., Int. Ed., 2007, 47, 3954.

61. M. B. J. Roeffaers, R. Ameloot, A.-J. Bons, W. Mortier, G. de Cremer, R. de Kloe, J. Hofkens, D. E. De Vos, B. F. Sels, J. Am. Chem. Soc., 2008, 130, 13516.

62. B. M. Weckhuysen, Angew. Chem. Int. Ed., 2009, 48, 4910.

63. M. H. F. Kox, K. F. Domke, J. P. R. Day, G. Rago, E. Stavitski, M. Bonn, B. M. Weckhuysen, Angew. Chem. Int. Ed., 2009, 48, 8990.

64. G. Debras, A. Gourgue, J. B. Nagy, Zeolites, 1985, 5, 369.

65. J.-C. Lin, K.-J. Chao, J. Chem. Soc., Faraday Trans., 1986, 82, 2645.

66. R. Althoff, B. Schulz-Dobrick, F. Schuth, K. Unger, Micropor Mater., 1993, 1, 207.

67. V. Gabova, J. Dedecek, J. Cejka, Chem. Commun., 2003, 1196.

68. S. Sklenak, J. Dedecek, C. Lo, B. Wichterlova, V. Gabova, M. Sierka, J. Sauer, Phys. Chem. Chem. Phys., 2009, 11, 1237.

69. J. B. Nagy, P. Bodart, H. Collette, J. El Hage-Al Asswad, Z. Gabelica, Zeolites, 1988, 8, 209.

70. J. Dwyer, F. R. Fitch, G. Qin, J. C. Vickerman, J. Phys. Chem.,1982, 86, 4574.

71. A. E. Hughes, K. G. Wilshier, B. A. Sexton, P. Smart, J. Catal., 1983, 80, 221.

72. L. Karwacki, M. H. F. Kox, D. A. M. de Winter, M. R. Drury, J. D. Meeldijk, E. Stavitski, W. Schmidt, M. Mertens, P. Cubillas, N. John, A. Chan, S. R. 
Bare, M. Anderson, J. Kornatowski, B. M. Weckhuysen, Nat. Mater., 2009, 8, 959.

73. J. A. van Bokhoven, D. C. Koningsberger, P. Kunkeler, H. van Bekkum, A. P. M. Kentgens, J. Am. Chem. Soc., 2000, 122, 12842.

74. J. Dedecek, D. Kaucky, B. Wichterlova, Chem. Commun., 2001, 11, 970.

75. J. A. van Bokhoven, T. L. Lee, M. Drakopoulos, C. Lamberti, S. Thiess, J. Zegenhagen, Nat. Mater., 2008, 7, 551.

76. J. Dedecek, D. Kaucky, B. Wichterlova, O. Gonsiorova, Phys. Chem. Chem. Phys. 2002, 4, 5406.

77. O. H. Han, C. S. Kim, S. B. Hong, Angew. Chem. Int. Ed., 2002, 41, 469.

78. P. Magusin, V. E. Zorin, A. Aerts, C. J. Y. Houssin, A. L. Yakovlev, C. E. A. Kirschhock, J. A. Martens, R. A. van Santen, J. Phys. Chem. B, 2005, 109, 22767.

79. J. Dedecek, Z. Sobalik, B. Wichterlova, Catal. Rev., 2012, 54, 135.

80. J. Dedecek, B. Wichterlova, J. Phys. Chem. B, 1999, 103, 1462.

81. L. Benco, T. Bucko, J. Hafner, H. Toulhoat, J. Phys. Chem. B, 2005, 109, 20361.

82. A. B. P. Lever, Inorganic Electronic Spectroscopy, 2nd ed., 1984, 864.

83. J. Dedecek, D. Kaucky, B. Wichterlova, Micropor. Mesopor. Mater., 2000, 356, 483.

84. D. Kaucky, J. Dedecek, B. Wichterlova, Micropor. Mesopor. Mater., 1999, 31, 75.

85. J. Dedecek, L. Capek, D. Kaucky, Z. Sobalik, B. Wichterlova, J. Catal., 2002, 211, 198.

86. K. J. D. Mackenzie, M. E. Smith, Multinuclear Solid State NMR of Inorganic Materials, 2002. 
87. G. Engelhardt, A. D. Michel, High-Resolusion Solid State NMR of Siilicates and Zeolites, 1987.

88. J. M. Thomas, J. Klinowski, Adv. Catal., 1985, 33, 199.

89. C. A. Fyfe, G. C. Gobbi, G. J. Kennedy, J. Phys. Chem., 1984, 88, 3248.

90. M. J. Duer, Solid-State NMR Spectroscopy: Principles and Applications, 2002.

91. P. Sazama, J. Dedecek, V. Gabova, B. Wichterlova, G. Spoto, S. Bordiga, J. Catal., 2008, 254, 180.

92. M. Iwamoto, H. Furukawa, Y. Mine, F. Uemura, S. I. Mikuriya, S. Kagawa, J. Chem. Soc. Chem. Commun., 1986, 16, 1272.

93. J. Dedecek, L. Capek, B. Wichterlova, Appl. Catal. A, 2006, 307, 156.

94. B. Wichterlova, J. Dedecek, Z. Sobalik, A. Vondrova, K. Klier, J. Catal., 1997, 169, 194.

95. L. Capek, J. Dedecek, B. Wichterlova, L. Cider, E. Jobson, V. Tokarova, Appl. Catal. B, 2005, 60, 147.

96. S. M. Csicsery, Zeolites, 1984, 4, 202.

97. C. D. Chang, Methanol-to-Gasoline Process - Reaction-Mechanism. ACS Symposium Series, 1988, 368, 596.

98. L. Domokos, L. Lefferts, K. Seshan, J. Lercher, J. Mol. Catal. A: Chemical, 2000, 162, 147.

99. F. Blanco, G. Urbina-Villalba, M.M.R. de Agudelo, Mol. Simul., 1994, 14, 165.

100.J. Jousse, L. Leherte, D.P. Vercauteren, Mol. Simul., 1996, 17, 175

101. P. Sarv, B. Wichterlova, J. Cejka, J. Phys. Chem. B, 1998, 102, 1372.

102. A. B. Pinar, C. Marquez-Alvarez, M. Grande-Casas, J. Perez-Pariente, J. Catal., 2009, 263, 258.

103. Y. Roman-Leshkov, M. Moliner, M. E. Davis, J. Phys. Chem. C, 2011, 115, 1096. 
104. M. Boronat, C. Martinez-Sanchez, D. Law, A. Corma, J. Am. Chem. Soc., 2008, 130, 16316.

105. M. Boronat, P. M. Viruela, A. Corma, J. Am. Chem. Soc., 2004, 126, 3300.

106. M. Boronat, C. Martinez, A. Corma, Phys. Chem. Chem. Phys., 2011, 13, 2603.

107. A. Bhan, A. D. Allian, G. J. Sunley, D. J. Law, E. Iglesia, J. Am. Chem. Soc., 2007, 129, 4919.

108. M. Liu, T. Yokoi, M. Yoshioka, H. Imai, J. N. Kondo, T. Tatsumi, Phys. Chem. Chem. Phys., 2014, 16, 4155.

109. S. Vortmann, B. Marler, H. Gies, P. Daniels, Micropor. Mater., 1995, 4, 111.

110. T. Yokoi, H. Mochizuki, S. Namba, J. N. Kondo, T. Tatsumi, J. Phys. Chem. C, 2015, 119, 15303.

111. V. J. Frillette, W. O. Haag, R. M. Lago, J. Catal., 1981, 67, 218.

112. T. Biligetu, Y. Wang, T. Nishitoba, R. Otomo, S. Park, H. Mochizuki, J. N. Kondo, T. Tasumi, T. Yokoi, J. Catal., 2017, 353, 1.

113. A. Janda, A. T. Bell, J. Am. Chem. Soc., 2013, 135, 19193.

114. D. R. Stull, E. F. Westrum, G. C. Sinke, The Chemical Thermodynamics of Organic Compounds, 1987.

115. M. Boronat, A. Corma, Catalysis Letters, 2014, 145, 162.

116. M. Boronat, P. Concepcion, A. Corma, M. T. Navarro, M. Renz, S. Valencia, Phys. Chem. Chem. Phys., 2009, 11, 2876.

117. C. T. Kresge, M. E. Leonowicz, W. J. Roth, J. C. Bartuli, J. S. Beck, Nature, 1992, 359, 710 .

118.J. Karger, D. Freude, Chem. Eng. Technol., 2002, 25, 769.

119. K. Beschmann, L. Riekert, U. Muller, J. Catal., 1994, 145, 243.

120.J.-H. Kim, T. Kunieda, M. Niwa, J. Catal., 1998, 173, 433.

121. A. Taguchi, F. Schuth, Micropor. Mesopor. Mater., 2005, 77, 1. 
122. C. T. Kresge, M. E. Leonowicz, W. J. Roth, J. C. Vartuli, J. S. Beck, Nature, 1992, 359, 710.

123. D. Zhao, J. Feng, Q. Huo, N. Melosh, G. H. Fredrickson, B. F. Chmelka, G. D. Stucky, Science, 1998, 23, 548.

124.Z. Zhang, Y. Han, L. Zhu, R. Wang, Y. Yu, S. Qiu, D. Zhao, F.-S. Xiao, Angew. Chem., Int. Ed., 2001, 40, 1258.

125. R. Mokaya, Chem. Phys. Chem., 2002, 3, 360.

126. W. O. Haag, R. M. Lago, P. B. Weisz, Faraday Discuss. Chem. Soc., 1981, 72, 317.

127. R. M. Dessau, E. W. Valyocsik, N. H. Goeke, Zeolites, 1992, 12, 776.

128. M. Ogura, S. Y. Shinomiya, J. Tateno, Y. Nara, E. Kikuchi, H. Matsukata, Chem. Lett., 2000, 29, 882.

129. J. C. Groen, J. C. Jansen, J. A. Moulijn and J. Perez-Ramirez, J. Phys. Chem. $B, 2004,108,13062$.

130.J. C. Groen, L. A. A. Peffer, J. A. Moulijn and J. Perez-Ramirez, Chem.-Eur. J., 2005, 11, 4983.

131.J. C. Groen, L. A. A. Peffer, J. A. Moulijin, J. Perez-Ramírez, Colloids. Surf. $A$, 2004, 241, 53.

132. J. C. Groen, J. A. Moulijin, J. Perez-Ramírez, Ind. Eng. Chem. Res., 2007, 14, 4193.

133.J. C. Groen, T. Bach, U. Ziese, A. M. Paulaime-van Donk, K. P. de Jong, J. A. Moulijn, J. Perez-Ramirez, J. Am. Chem. Soc., 2005, 127, 10792.

134.J. Perez-Ramirez, C. H. Christensen, K. Egeblad, C. H. Christensen, J. C. Groen, Chem. Soc. Rev., 2008, 37, 2530.

135.J. C. Groen, W. Zhu, S. Brouwer, S. J. Huynink, F. Kapteijn, J. A. Moulijn, J. Perez-Ramirez, J. Am. Chem. Soc., 2007, 129, 355. 
136. P. Kortunov, S. Vasenkov, J. Karger, R. Valiullin, P. Gottschalk, M. F. Elia, M. Perez, M. Stocker, B. Drescher, G. McElhiney, C. Berger, R. Glaser, J. Weitkamp, J. Am. Chem. Soc., 2005, 127, 13055.

137. A. H. Janssen, A. J. Koster, K. P. de Jong, Angew. Chem. Int. Ed., 2001, 40, 1102.

138. A. Corma, Stud. Surf. Sci. Catal., 1989, 49, 49.

139.Z. Qin, B. Shen, X. Gao, F. Lin, B. Wang, C. Xu, J. Catal., 2011, 278, 266.

140.X. Wei, P. G. Smirniotis, Micropor. Mesopor. Mater., 2006, 97, 97.

141. L. Zhao, B. Shen, J. Gao, C. Xu, J. Catal., 2008, 258, 228.

142.D. H. Choi, J. W. Park, J.-H. Kim, Y. Sugi, Polym. Degrad. Stab., 2006, 91, 2860.

143.J. C. Groen, T. Sano, J. A. Moulijn, J. Perez-Ramirez, J. Catal., 2007, 251, 21.

144.J. C. Groen, S. Abello, L. Villaescusa, J. Perez-Ramirez, Micropor. Mesopor. Mater., 2008, 114, 93.

145. M. Moliner, F. Rey, A. Corma, Angew. Chem. Int. Ed., 2013, 52, 13880.

146. A. Corma, M. E. Davis, Chem. Phys. Chem., 2004, 5, 304.

147. C. S. Cundy, P. A. Cox, Micropor. Mesopor. Mater., 2005, 82, 1.

148. G. T. Kerr, J. Phys. Chem., 1966, 70, 1047.

149. E. G. Derouane, S. Detremmerie, Z. Gabelica, N. Blom, Appl. Catal., 1981, $1,201$.

150. C. D. Chang, A. T. Bell, Catal. Lett., 1991, 8, 305.

151.S. L. Burkett, M. E. Davis, J. Phys. Chem., 1994, 98, 4647.

152. R. M. Barrer, D. A. Ibbitson, Trans. Faraday Soc., 1944, 40, 195.

153.D. W. Breck, J. Chem. Educ., 1964, 41, 678.

154.M. A. Camblor, A. Corma, S. Valencia, Chem. Commun., 1996, 2365. 
155. P. A. Barrett, M. A. Camblor, A. Corma, R. H. Jones, L. A. Villaescusa, Chem. Mater., 1997, 9, 1713.

156. L. A. Villaescusa, P. A. Barrett, M. A. Camblor, Angew. Chem. Int. Ed., 1999, 38, 1997.

157. A. Cantin, A. Corma, M. J. Diaz-Cabanas, J. L. Jorda, M. Moliner, F. Rey, Angew. Chem. Int. Ed., 2001, 40, 2277.

158. A. Cantin, A. Corma, M. J. Diaz-Cabanas, J. L. Jorda, M. Moliner, J. Am. Chem. Soc., 2006, 128, 4216.

159. R. J. Argauer, G. R. Landolt, US3702886 (1969).

160. L. Pine, J. Catal., 1984, 85, 466.

161. R. M. Barrer, P. J. Denny, J. Chem. Soc., 1961, 971.

162. R. M. Barrer, P. J. Denny, E. M. Flanigen, US Patent 3,306,922, 1967.

163. R. L. Wadlinger, G. T. Kerr, E. J. Rosinski, US Patent 3,308,069, 1967.

164. R. J. Argauer, G. R. Landolt, US Patent 3,702,886, 1972.

165. H. Gies, B. Marler, Zeolites, 1992, 12, 42.

166. Y. Nakagawa, S. I. Zones, Molecular Sieves, Synthesis of Microporous Materials, 1992, 1, 222.

167. R. F. Lobo, S. I. Zones, M. E. Davis, J. Inclusion Phenom. Mol. Recognit. Chem., 1995, 21, 47.

168. A. Cantin, A. Corma, M. J. Diaz-Cabanas, J. L. Jorda, M. Moliner, J. Am. Chem. Soc., 2006, 128, 4216.

169. M. Moliner, M. J. Diaz-Cabanas, V. Fornes, C. Martinez, A. Corma, J. Catal., 2008, 254, 101.

170. R. Castañeda, A. Corma, V. Fornés, J. Martínez-Triguero, S. Valencia, J. Catal., 2006, 238, 79.

171. A. Corma, F. Rey, J. Rius, M. J. Sabater, S. Valencia, Nature, 2004, 431, 287. 
172. G. J. Lewis, M. A. Miller, J. G. Moscoso, B. A. Wilson, L. M. Knight, S. T. Wilson, Stud. Surf. Sci. Catal., 2004, 154, 364.

173. M. Choi, K. Na, J. Kim, Y. Sakamoto, O. Terasaki, R. Ryoo, Nature, 2009, $461,246$.

174. K. Na, W. Park, Y. Seo, R. Ryoo, Chem. Mater., 2011, 23, 1273.

175. C. C. Freyhardt, M. Tsapatsis, R. F. Lobo, K. J. Balkus, M. E. Davis, Nature, 1996, 381, 295.

176. P. Wagner, M. Yoshikawa, K. Tsuji, M. E. Davis, M. Lovallo, M. Tsapatsis, Chem. Commun., 1997, 2179.

177. A. W. Burton, S. A. Elomari, C. Y. Chen, R. C. Medrud, I. Y. Chan, L. M. Bull, C. Kibby, T. V. Harris, S. I. Zones, E. S. Vittoratos, Chem. Eur. J., 2003, 9, 5737.

178. M. O’keeffe, O. Yaghi, Chem. Eur. J., 1999, 5, 2796.

179. T. Blasco, A. Corma, M. J. Diaz-Cabañas, F. Rey, J. A. Vidal-Moya, C. M. Zicovich-Wilson, J. Phys. Chem. B, 2002, 106, 2634.

180. A. Corma, M. J. Diaz-Cabanas, J. Jiang, M. Afeworki, D. L. Dorset, S. L. Soled, K. G. Strohmaier, Proc. Natl. Acad. Sci., 2010, 107, 11935.

181. A. Corma, M. J. Díaz-Cabañas, F. Rey, S. Nicolopoulus, K. Boulahya, Chem. Commun., 2004, 1356.

182.J. Jiang, Y. J., A. Corma, Angew. Chem., Int. Ed., 2010, 49, 3120.

183. J. Sun, C. Bonneau, A. Cantín, A. Corma, M. J. Díaz-Cabañas, M. Moliner, D. Zhang, M. Li, X. Zou, Nature, 2009, 458, 1154.

184. C. Li, M. Moliner, A. Corma, Angew. Chem. Int. Ed., 2018, 57,15330.

185. F. Gao, M. Jaber, K. Bozhilov, A. Vicente, C. Fernandez, V. Valtchev, J. Am. Chem. Soc., 2009, 131, 16580.

186. W. J. Roth, O. V. Shvets, M. Shamzhy, P. Chlubn, M. Kubu, P. Nachtigall, J. Cejka, J. Am. Chem. Soc., 2011, 133, 6130. 
187.E. Verheyen, L. Joos, K. Van Havenbergh, E. Breynaert, N. Kasian, E. Gobechiya, K. Houthoofd, C. Martineau, M. Hinterstein, F. Taulelle, V. Van Speybroeck, M. Waroquier, S. Bals, G. Van Tendeloo, C. E. A. Kirschhock, J. A. Martens, Nat. Mater., 2012, 11, 1059.

188. D. W. Breck, Zeolite Molecular Sieves: Structure, Chemistry, and Use, 1974. 189.J. V. Smith, W. J. Dytrych, Nature, 1984, 309, 607.

190.J. V. Smith, Chem. Rev., 1988, 88, 149.

191. M. W. Deem, J. M. Newsam, Nature, 1989, 342, 260

192. M. W. Deem, J. M. Newsam, J. Am. Chem. Soc., 1992, 114, 7189.

193. M. Falcioni, M. W. Deem, J. Chem. Phys., 1999, 110, 1754

194. D. J. Earl, M. W. Deem, Ind. Eng. Chem. Res., 2006, 45, 5449.

195. M. M. J. Treacy, K. H. Randall, S. Rao, J. A. Perry, D. J. Chadi, Z. Kristallogr., Cryst. Mater., 1997, 212, 768.

196. M. M. J. Treacy, I. Rivin, E. Balkovsky, K. H. Randall, M. D. Foster, Micropor. Mesopor. Mater., 2004, 74, 121.

197. O. D. Friedrichs, A.W. M. Dress, D. H. Huson, J. Klinowski, A. L. Mackay, Nature, 1999, 400, 644.

198. M. D. Foster, A.Simperler, R. G. Bell, O. D. Friedrichs, F. A. A. Paz, J. Klinowski, Nat. Mater., 2004, 3, 234.

199. M. D. Foster, O. D. Friedrichs, R. G. Bell, F. A. A. Paz, J. Klinowski, J. Am. Chem. Soc., 2004, 126, 9769.

200. A. Simperler, M. D. Foster, O. D. Friedrichs, R. G. Bell, F. A. A. Paz, J. Klinowski, Acta Crystallogr. Sect. B, 2005, 61, 263.

201. C. Mellot-Draznieks, J. M. Newsam, A. M. Gorman, C. M. Freeman, G. Ferey, Angew. Chem. Int. Ed., 2000, 39, 2270.

202. C. Mellot-Draznieks, S. Girard, G. Ferey, J. C. Schon, Z. Cancarevic, M. Jansen, Chem. Eur. J., 2002, 8, 4102. 
203. C. Mellot-Draznieks, S. Girard, G. Ferey, J. Am. Chem. Soc., 2002, 124, 15326. 204. Y. Li, J. H. Yu, D. H. Liu, W. F. Yan, R. R. Xu, Y. Xu, Chem. Mater., 2003, $15,2780$.

205. Y. Li, J. H. Yu, Z. P. Wang, J. N. Zhang, M. Guo, R. R. Xu, Chem. Mater, 2005, 17, 4399.

206. Y. Li, J. H. Yu, J. X. Jiang, Z. P.Wang, J. N. Zhang, R. R. Xu, Chem. Mater., 2005, 17, 6086.

207.S. M. Woodley, C. R. A. Catlow, P. D. Battle, J. D. Gale, Chem. Commun., 2004, 22.

208. M. D. Foster, M. M. J. Treacy, http://www.hypotheticalZeolitesnet/.

209. R. Martinez-Franco, M. Moliner, Y. Yun, J. Sun, W. Wan, X. Zou, A. Corma, Proc. Natl. Acad. Sci., 2013, 110, 3749.

210. M. Moliner, M. J. Diaz-Cabanas, V. Fornes, C. Martinez, A. Corma, J. Catal., 2008, 254, 101.

211. Y. Li, J. H. Yu, R. R. Xu, http://mezeopor.jlu.edu.cn/.

212. Worldwide Zeolite Market Analysis (2019-2024) by Type, Application and Region

213. A. Corma, Catal. Rev., 2004, 46, 369.

214.E. M. Gallego, M. T. Portilla, C. Paris, A. Leon-Escamilla, M. Boronat, M. Moliner, A. Corma, Science, 2017, 355, 1051.

215.J. M. Newsam, M. M. J. Treacy, W. T. Koetsier, C. B. de Gruyter, Proc. R. Soc. London A, 1988, 420, 375.

216. E. M. Gallego, C. Paris, A. Cantin, M. Moliner, A. Corma, Chem. Sci., 2019, 10,8009 . 

Chapter 2

\section{Objectives}


The present thesis attempts to go into a rational zeolite catalyst preparation by controlling the location of active sites, pore or cavity and their microenvironments required to maximize reaction rate and selectivity. and their microenvironments, accompanied by understanding of their influence on the mechanism of catalyzed reactions.

The first part of the thesis will focus on tuning the acid sites in different locations of zeolites. As described in the introduction, the concept of aluminum distribution includes three parts, being the aluminum zoning, aluminum states in paired or isolated form and different aluminum locations. In order to distinguish only the location of aluminum sites, an indicator based on the selectivity to monomolecular and bimolecular reactions in n-hexene cracking is proposed. The applicability of this indicator will be justified using ZSM-5 samples that, according to the literature, have different aluminum locations. Once this indicator is justified, it will be employed in directing synthesis of new ZSM-5 samples that could potentially have different aluminum distribution. A boron-assisted synthesis is proposed here since boron and aluminum should be prone to a competitive positioning when incorporated in zeolite framework. DFT calculations will be employed to investigate, from a thermodynamic point of view, if boron and aluminum will have different preference to be placed in different crystallographic positions in the MFI unit cell. Experimentally, ZSM-5 samples with different $\mathrm{Si} / \mathrm{Al}$ and $\mathrm{Si} / \mathrm{B}$ molar ratios will be synthesized and characterized to have analogous physicochemical properties as well as paired and isolated aluminum species. Then, the samples will be tested in $n$-hexene cracking to be evaluated by the abovementioned indicator. Once the materials are characterized to have different aluminum positions, they will be tested in MTP reactions, where the spatial confinement could influence the reaction mechanism and, therefore, the product distributions as well as catalytic lifetime.

The second part of the thesis focuses on directing the synthesis towards zeolite structure with adequate pores and cavities for the reaction to be catalyzed. To begin, a mimic synthesis approach will be employed where zeolites will be synthesized using OSDAs mimicking the configuration of important intermediates and transition states of the target reactions. Transalkylation 59 
between diethylbenzene and benzene will be selected as the first example since this reaction has well-established mechanisms as well as bulky intermediates. The OSDAs mimicking the intermediates in diaryl-mediated pathway will be put into synthesis using "high-throughput" synthesis technique. The obtained zeolites will be tested in transalkylation between diethylbenzene and benzene. To benchmark their catalytic performance, industrial used zeolite catalysts will be taken as reference.

Finally, MTO reactions will be employed as another target system and representative of complex reaction networks. Specifically, among all reaction pathways, paring pathway is selected since it produces higher value-added products propene and butenes. Several OSDAs will be synthesized mimicking the intermediates and transition states in paring mechanism. The obtained zeolites will be tested in MTO reactions to evaluate their catalytic performance. The potential relationship between the cavity structure, reaction mechanism and product distributions is presented that establishes the structure-reactivity coordination 


\section{Chapter 3}

\section{Experimental procedures}




\subsection{Synthesis of materials}

\subsubsection{Conditions for synthesis of zeolitic materials}

As a general procedure the different zeolites prepared by mixing the corresponding reagents in different ratios, resulting in the formation of homogeneous gels. These gels are prepared in Teflon-lined autoclaves, which are heated at temperatures between 100 and $200^{\circ} \mathrm{C}$, at the autogenous system pressure. After the necessary hydrothermal treatment time, the autoclaves are cooled to room temperature, and the contents are washed with deionized water. The final solids are dried at $100^{\circ} \mathrm{C}$ overnight. Finally, solids are characterized by powder X-ray diffraction. If a more thorough characterization of the synthesized materials or their catalytic evaluation is desired, they are calcined at $550^{\circ} \mathrm{C}$ for 6 hours in air.

\subsubsection{ZSM-5 samples using alcohols as OSDA}

In a typical synthesis of ZSM-5 using 1,3-propanediol (PDO), 1,6-hexanediol (HDO), trimethyloethane (TME) or pentaerythritol (PET) as OSDAs, one of the said alcohols was dissolved into $\mathrm{NaOH}$ aqueous solution under stirring at ambien temperature for 4h. Colloidal silica (Ludox, HS-40, Sigma-Aldrich) as silica source was added into the solution under stirringat $353 \mathrm{~K}$ for $24 \mathrm{~h}$. Then $\mathrm{Al}\left(\mathrm{NO}_{3}\right)_{3} \cdot 9 \mathrm{H}_{2} \mathrm{O}$ was added to the solution as $\mathrm{Al}$ source. Finally, $5 \mathrm{wt} \%$ seeds based on silica were added to the mixture. The final gel has the molar composition:

$$
1.0 \mathrm{SiO}_{2}: 0.02 \mathrm{Al}_{2} \mathrm{O}_{3}: 0.5 \text { alcohols : } 0.125 \mathrm{Na}_{2} \mathrm{O}: 27 \mathrm{H}_{2} \mathrm{O}
$$

The mixture was transferred into Teflon-lined autoclave and heated at $175^{\circ} \mathrm{C}$ for $72 \mathrm{~h}$.

To eliminate organic molecules trapped inside zeolites, the samples were calcined at $560^{\circ} \mathrm{C}$ in air for 8 hours. After cooling to room temperature, the solid was mixed with $1 \mathrm{~mol} / \mathrm{L} \mathrm{NH}_{4} \mathrm{NO}_{3}$ solution with a liquid/solid mass ratio of 50 and stirred at room temperature for 16 hours to in order to obtain the ammonium form of the zeolites. Finally, the zeolites were further calcined at $550^{\circ} \mathrm{C}$ for 3 hours to retain its proton form.

63 


\subsubsection{Boron-assisted synthesis of ZSM-5 samples}

ZSM-5 samples were synthesized using tetraethoxysilane (TEOS) as silica source, $\mathrm{Al}(\mathrm{NO})_{3} \cdot 9 \mathrm{H}_{2} \mathrm{O}$ as aluminum source, $\mathrm{H}_{3} \mathrm{BO}_{3}$ as boron source, and tetrapropylammonium hydroxide (TPAOH) as organic template. The general composition of the synthesis gels is

$$
1.0 \mathrm{SiO}_{2}: x \mathrm{Al}_{2} \mathrm{O}_{3}: y \mathrm{H}_{3} \mathrm{BO}_{3}: 0.125 \text { TPAOH }: 8 \mathrm{H}_{2} \mathrm{O}
$$

$\mathrm{x}(0,1 / 200,1 / 150,1 / 100)$ and $\mathrm{y}(0,1 / 15,1 / 50)$ were determined according to desired composition of resultant solid. After all chemicals were mixed and form a clear solution separated into two layers, the mixture was kept under mechanic stirring for 24 hours at room temperature. The mixture turned into a homogeneous clear solution and was aged at $100^{\circ} \mathrm{C}$ for another 24 hours. Once the aging finished, the solution was transferred to a stainless-steel autoclave with a Teflon liner and kept static at $175^{\circ} \mathrm{C}$ for 7 days. The solid product was recovered by filtration and washed with abundant distilled water and dried in air at $60^{\circ} \mathrm{C}$ overnight.

To eliminate the organic molecules trapped inside zeolites, the samples were calcined at $550^{\circ} \mathrm{C}$ in air for 8 hours. After cooling to room temperature, the solid was mixed with $1 \mathrm{~mol} / \mathrm{L} \mathrm{NH}_{4} \mathrm{NO}_{3}$ solution with a liquid/solid mass ratio of 50 and stirred at room temperature for 16 hours to wash boron species extracted from framework during calcination. The zeolites were further calcined at $550^{\circ} \mathrm{C}$ for 3 hours to retain its proton form. The process has been repeated for at least two times to obtain a good level of deboronation.

\subsubsection{Synthesis of Theta-1 samples}

Theta-1 samples were synthesized using diethanolamine as OSDA. In a typical synthesis, $10.3 \mathrm{~g}$ sodium aluminate and $6.65 \mathrm{~g}$ sodium hydroxide were added in $140 \mathrm{~g}$ water and form a clear solution. Then, $180 \mathrm{~g}$ diethanolamine was melted and added to the solution and the mixture was kept stir at $30^{\circ} \mathrm{C}$ for 5 minutes.

Another solution was prepared mixing $500 \mathrm{~g}$ Ludox AS-40 and $355 \mathrm{~g}$ water added dropwise maintaining the temperature at $30^{\circ} \mathrm{C}$. When adding was finished, 
the mixture was kept under stirring for additional 30 minutes. The synthesis gel has a final composition of:

$1.0 \mathrm{SiO}_{2}: 0.038 \mathrm{NaAlO}_{2}: 0.05 \mathrm{NaOH}: 0.12$ diethylamine $: 8.3 \mathrm{H}_{2} \mathrm{O}$

Then, the synthesis gel was transferred to a Teflon-lined autoclave and heated at $175^{\circ} \mathrm{C}$ for $24 \mathrm{~h}$. The solid product was recovered by filtration and washed with abundant distilled water and dried in air at $60^{\circ} \mathrm{C}$ overnight.

To eliminate organic molecules trapped inside zeolites, the samples were calcined at $560{ }^{\circ} \mathrm{C}$ in air for 8 hours. After cooling to room temperature, the solid was mixed with $1 \mathrm{~mol} / \mathrm{L} \mathrm{NH}_{4} \mathrm{NO}_{3}$ solution and stirred at room temperature for 16 hours to obtain its proton form. The zeolites were further calcined at $550{ }^{\circ} \mathrm{C}$ for 3 hours to retain its proton form.

A post-synthesis desilication was employed to prepare a mesopore-containing Theta-1 sample. Theta-1 sample prepared here was subjected to a treatment of $0.5 \mathrm{M} \mathrm{NaOH}$ solution with a solution/solid mass ratio of 33 . The mixture was heated to $85^{\circ} \mathrm{C}$ and kept under vigorous stir for 30 minutes. Then the treatment was quenched in an ice bath and the sold was collected by filtration, washed and dried overnight at $100^{\circ} \mathrm{C}$. Finally, the sample was ion-exchanged in a $2.0 \mathrm{M}$ oxalic acid solution with a solution/solid mass ratio of 10 at $70^{\circ} \mathrm{C}$ for $2 \mathrm{~h}$. The sample is designated as Theta-1-treated.

\subsubsection{Synthesis of OSDAs}

\subsubsection{Synthesis of diphenyldimethylphosphonium OSDA (DPDMP)}

The diphenyldimethylphosphonium iodide was obtained by contacting diphenylphosphine with methyl iodide in chloroform in the presence of $\mathrm{K}_{2} \mathrm{CO}_{3}$ at room temperature for $72 \mathrm{~h}$. The hydroxide form of the OSDA was prepared from ion exchange using Amberlite IRN-78 resin (Supelco).

\subsubsection{Synthesis imidazolium-based dicationic OSD A for ITQ-27}

$18.3 \mathrm{~g}$ of tetramethylimidazole (TCI) was mixed with $10.64 \mathrm{~g}$ 1,4-dibromobutane (Sigma-Aldrich) and $50 \mathrm{~mL}$ of dry methanol. Then, the mixture was heated 
under reflux for 72 hours. When the reaction has finished, the mixture was cooled down and the solvent was separated by rotary evaporator under vacuum. The solid product was then redispersed in a few drops of methanol and recrystallized with ethylacetate. Then the solid was collected by filtration and dried at room temperature under vacuum. The collected product was the bromide form of the template, and the solid yield was 50-60\%.

In order to prepare hydroxide form of the same template, $25.1 \mathrm{mmol}$ of the bromide form of template was dissolved in water. Then, $51 \mathrm{~g}$ of anion-exchange resin (Amberlite IRN-78) was added to the solution and kept under stirring for 24 hours. Finally, the solution was collected by filtration and the obtained hydroxide form of template had an exchange efficiency of at least $95 \%$.

\subsubsection{Synthesis of N,N,N-trimethyladamantamonium (TMAda)}

To synthesize the TMAda cation, a solution of $25.2 \mathrm{~g}$ of 1-adamantamine hydrochloride (99\%, Alfa Aesar) in $250 \mathrm{~mL}$ of chloroform (99\%, JT Baker) was mixed with $250 \mathrm{ml}$ of another aqueous solution of potassium hydroxide $(99 \%$, Sigma Aldrich) at $10 \%$ by weight. The mixture was stirred for two hours and finally extracted three times with chloroform. Subsequently, the organic phase was dried with anhydrous magnesium sulfate (pure, Scharlau). The magnesium sulfate was filtered, and the solvent evaporated to obtain the corresponding 1 adamantamine.

To quaternize the primary amine, $18.2 \mathrm{~g}$ of 1 -adamantamine was dissolved in $320 \mathrm{~g}$ of chloroform, to which $64 \mathrm{~g}$ of anhydrous potassium carbonate $(99.9 \%$, Sigma Aldrich) was added. Then, the reaction mixture was kept under stirring in an ice bath, and 10 equivalents of methyl iodide (99.95\%, Sigma Aldrich) were added dropwise. The resulting mixture was kept under stirring at room temperature for 3 days and, finally, the liquid was separated from the potassium carbonate by filtration. The solution was concentrated and diethyl ether $(\geq 99 \%$, Sigma Aldrich) was added, obtaining a white precipitate corresponding to the N, $\mathrm{N}, \mathrm{N}$-trimethyl-1-adamantamonium iodide, which was separated from the rest of the solution by filtration (superior yield to $90 \%$. 
The hydroxide form of the OSDA was prepared from ion exchange using Amberlite IRN-78 resin (Supelco).

\subsubsection{Synthesis of 3-Hydroxy-1-isopropyl-1-methylpyrrolidin-1-ium (OSDA1a)}

The reaction was performed under argon atmosphere. 1-methyl-3-pyrrolidinol (13.82 $\mathrm{g}, 0.137$ moles) was poured into a two-neck round flask (previously dried at $110{ }^{\circ} \mathrm{C}$ ) equipped with a glass condenser and stirring; and dissolved with 200 $\mathrm{ml}$ of anhydrous methanol. Then, four equivalents of 2-bromopropane (67.40 g, 0.548 moles) were added and the solution was heated over $72 \mathrm{~h}$ at methanol reflux temperature. Once the reaction was finished, the solvent was removed under reduced pressure and the product crystallized by the addition of acetone. The product was highly hygroscopic, so immediately after precipitation, was filtered under reduced pressure and dried under vacuum and heating. The resultant bromide salt was exchanged to the hydroxide form using a commercially available hydroxide ion exchange resin (Dowex SBR).

\subsubsection{Synthesis of 3,3,6,6-Tetramethyl-3-azabicyclo[3.1.0] hexan-3-ium (OSDA1b).}

Synthesis of the OSDA1b was performed under nitrogen atmosphere. $6.30 \mathrm{~g}$ (0.057 moles) of 6,6-dimethyl-3-azabicyclo-[3.1.0] hexane was dissolved in $60 \mathrm{ml}$ of cooled anhydrous methanol and poured into a two-neck round flask equipped with a glass condenser. Then, $3.95 \mathrm{~g}$ of $\mathrm{K}_{2} \mathrm{CO}_{3}$ (0.029 moles) was added and the solution was stirred over one hour at $0^{\circ} \mathrm{C}$. The addition of iodomethane (48.67 g, 0.343 moles) was performed dropwise, maintaining the solution at low temperature. Once the crude was stabilized, the solution was left to react for 72 $\mathrm{h}$ at room temperature. Then, the solvent was completely removed under reduced pressure and the residue obtained was dissolved with chloroform. The inorganic salts were separated by filtration, and the organic phase was reserved. Finally, the solution was concentrated and the product was precipitated by addition of diethyl ether. The OSDA1b was filtered and dried under reduced pressure and heating. The resultant iodide salt was exchanged to the hydroxide form using a commercially available hydroxide ion exchange resin (Dowex SBR).

\subsubsection{Synthesis of 1,2,3,4,5-pentamethyl-1H-imidazol-3-ium (OSDA2).}


The OSDA2 was synthetized under nitrogen atmosphere. 1,2,4,5tetramethylimidazole (10.99 g, 0.089 moles) was dissolved in $120 \mathrm{ml}$ of anhydrous 2-propanol and then the solution was cooled in a dry ice bath. An excess of iodomethane $(37.7 \mathrm{~g}, 0.266$ moles) was added dropwise and the mixture was then slowly warmed to room temperature and stirred for $48 \mathrm{~h}$. The solvent was removed under reduced pressure and the product was recrystallized from an acetone-diethyl ether solution. Finally, the product was separated by filtration and dried by vacuum. The resultant iodide salt was exchanged to the hydroxide form using a commercially available hydroxide ion exchange resin (Dowex SBR).

\subsubsection{Synthesis of 1,2,4,6-Tetramethylpyridin-1-ium (OSDA3)}

In a two-neck round flask previously equipped with a glass condenser, 2,4,6trimethylpiridine (19.80 g, 0.163 moles) was dissolved with $300 \mathrm{ml}$ of ethanol. The solution was cooled in an ice-bath and, then, iodomethane $(69.6 \mathrm{~g}, 0.490$ moles) was gradually added under vigorous stirring. The crude was stabilized at room-temperature and then the mixture was allowed to react for $48 \mathrm{~h}$ at $40^{\circ} \mathrm{C}$. Fine crystals were formed at the bottom of the flask. The solution was concentrated and left at $4^{\circ} \mathrm{C}$ for product crystallization. Finally, the OSDA3 was separated by filtration and dried under reduced pressure. The resultant iodide salt was exchanged to the hydroxide form using a commercially available hydroxide ion exchange resin (Dowex SBR).

\subsubsection{Synthesis of zeolites other than ZSM-5}

\subsubsection{Synthesis of ITQ-27 materials}

\section{-Using diphenyldimethylphosphonium as OSDA(DPDMP)}

$30.01 \mathrm{~g}$ of diphenyldimethylphosphonium hydroxide was mixed with $4.37 \mathrm{~g}$ of tetraethylorthosilicate (TEOS, Sigma-Aldrich, 98wt\%) and $0.12 \mathrm{~g}$ aluminum isopropoxide. Then, the mixture was kept under stirring at room temperature in a sealed bottle for two hours to enable a fully hydrolysis of $\mathrm{Si}$ and $\mathrm{Al}$ source. The ethanol and isopropanol generated during this process were evaporated at room temperature. When the alcohols were fully evaporated, $0.44 \mathrm{~g} \mathrm{HF}$ solution (48\%) 
was added with mechanical stirring. The water content of the mixture was adjusted by heating to obtain a mixture with the following composition $\mathrm{SiO}_{2} /$ $0.028 \mathrm{Al} / 0.5 \mathrm{OSDAOH} / 0.5 \mathrm{HF} / 4 \mathrm{H}_{2} \mathrm{O}$. The mixture was then transferred into a Teflon-lined stainless autoclave and heated under rotation at $150^{\circ} \mathrm{C}$ for 14 days. The solid product was collected by filtration and washed with abundant distilled water. The solid yield was $90 \%$.

The solid was calcined in air at $580^{\circ} \mathrm{C}$ for 6 hours in order to eliminate the organic molecules trapped in the framework. The obtained material is named IWV-M

\section{-Using imidazolium-based dicationic OSDA}

$1 \mathrm{~g}$ of $1 \mathrm{~mol} / \mathrm{L}$ sodium hydroxide was mixed with $1.77 \mathrm{~g}$ deionized water and $3.47 \mathrm{~g}$ solution containing $29.3 \%$ hydroxide form of template from section 3.1.4.1. Then, $0.9 \mathrm{~g}$ faujasite zeolite (CBV760) was added together with $0.1 \mathrm{~g}$ of calcined ITQ-27 zeolite seeds into the solution. The mixture was transferred into a Teflon-lined autoclave and heated at $175^{\circ} \mathrm{C}$ under rotation for 7 days. The product was collected by filtration and washed with abundant water and the solid product was dried in air overnight at $60^{\circ} \mathrm{C}$.

In order to eliminate the organic molecules trapped inside the framework, the zeolite was calcined in air at $550^{\circ} \mathrm{C}$ for 6 hours. After cooled to room temperature, the solid was mixed with $1 \mathrm{~mol} / \mathrm{L}$ ammonium nitrate solution at a liquid/solid mass ratio of 50 without heating for 16 hours. Finally, the solid was separated by filtration and dried in air at $60^{\circ} \mathrm{C}$ and then calcined again in air at $500^{\circ} \mathrm{C}$ for 3 hours. The obtained material is named IWV-D

\subsubsection{Synthesis of MCM-22(MWW) zeolite}

$0.94 \mathrm{~g}$ sodium aluminate was added to $86 \mathrm{~g}$ of deionized water followed by the addition of $5 \mathrm{~g}$ of a $20 \%$ sodium hydroxide aqueous solution. The mixture was kept stirred until a transparent solution was obtained. Then, $19.83 \mathrm{~g}$ hexamethyleneimine (HMI) was added to the solution and kept under stir until homogenization. Finally, $15 \mathrm{~g}$ of fumed silica was added to the mixture forming a gel. After mechanically stirred till homogenous, the gel was transferred to a 
Teflon-lined autoclave and heated under rotation at $150^{\circ} \mathrm{C}$ for 7 days. The solid product was then separated by filtration, washed with abundant water and dried in air at $60^{\circ} \mathrm{C}$. The obtained as-synthesized MCM-22 zeolite has a solid yield over $95 \%$.

In order to prepare the proton form of this zeolite for catalysis, the zeolite was first calcined in air in a muffle at $550^{\circ} \mathrm{C}$ for 6 hours. Afterwards, the solid was mixed with $1 \mathrm{~mol} / \mathrm{L}$ ammonium nitrate solution at a liquid/solid mass ratio of 50 and maintained at room temperature for 16 hours. Finally, the solid was separated by filtration, dried in air at $60^{\circ} \mathrm{C}$, and calcined again in air at $500^{\circ} \mathrm{C}$ for 3 hours. The obtained material is named MWW.

\subsubsection{General synthesis procedure for silicoaluminate materials for MTO mimics}

Using the above described OSDA molecules described in sections from 3.1.4.4 to 3.1.4.7, the general synthesis procedure for the zeolites is described. In a typical synthesis procedure for silicoaluminates, an aqueous solution of the organic template (OSDA) in its hydroxide form was firstly mixed with the proper amount of water and, when required, an aqueous solution of sodium hydroxide $(20 \%)$. Secondly, the required amount of aluminum hydroxide (Sigma-Aldrich) and the required amount of Ludox HS-40 were added to the above mixture. The gel was kept stirring to reach homogeneity and, then, water was evaporated by heating to reach the required concentration. The final gel compositions were $\mathrm{SiO}_{2} / 0.016-0.066 \mathrm{Al}_{2} \mathrm{O}_{3} / 0.2-0.4$ OSDA / 0-0.1 Na $\mathrm{Na}_{2} \mathrm{O}$ 3-15 $\mathrm{H}_{2} \mathrm{O}$. The gels were introduced into a Teflon-lined stainless autoclave and heated at $175^{\circ} \mathrm{C}$ in static conditions for 14 days. The synthesis conditions of different aluminosilicate zeolites are summarized in Chapter 5. After the crystallization procedure, the products were filtered and washed with abundant distilled water and dried at $100^{\circ} \mathrm{C}$ overnight. The samples were calcined at $550^{\circ} \mathrm{C}$ in air for $6 \mathrm{~h}$ to properly remove the occluded organic molecules.

\subsubsection{Standard SSZ-13 (SSZ-13_std) and nanosized SSZ-13 (SSZ-13_nano)}

In order to compare with the silicoaluminate zeolites obtained in this study, conventional SSZ-13 and nanosized SSZ-13 zeolite were obtained and employed as reference catalysts. Conventional SSZ-13 zeolite was synthesized with the 
following gel composition: $0.1 \mathrm{Na}_{2} \mathrm{O}: 1 \mathrm{SiO}_{2}: 0.025 \mathrm{Al}_{2} \mathrm{O}_{3}: 0.2 \mathrm{~N}, \mathrm{~N}, \mathrm{~N}-$ trimethyl-1-adamantanammonium hydroxide (TMAdOH) : $44 \mathrm{H}_{2} \mathrm{O}$. TMAdOH was firstly mixed with $\mathrm{NaOH}$ and deionized water at room temperature until it was dissolved completely. Then, $\mathrm{SiO}_{2}$ (Aerosil) was added to the TMAdOH solution. Finally, $\mathrm{Al}_{2} \mathrm{O}_{3}$ was dissolved into the solution mentioned above. The resulting gel was stirred at room temperature for 1 hour to obtain a homogeneous gel, which was then transferred into a Teflonlined steel autoclave and kept statically in an oven at $160^{\circ} \mathrm{C}$ for 6 days. The product was separated by filtration, washed with deionized water and dried at $100^{\circ} \mathrm{C}$. The catalyst was calcined in air at $580^{\circ} \mathrm{C}$ to remove the template. H-SSZ-13 was obtained by ion exchange of calcined sample with $2.5 \mathrm{M} \mathrm{NH} \mathrm{NH}_{4} \mathrm{Cl}$ solution $\left(80^{\circ} \mathrm{C}\right.$ and liquid to solid ratio of 10) for 2 hours and then calcined at $500{ }^{\circ} \mathrm{C}$ for three hours in air.

Nano-SSZ-13 was synthesized following the same procedure and gel composition as for SSZ-13. Then, the initial gel was heated in the autoclave at $160^{\circ}$ for 1 day and after that time, CTAB was added to the aged gel with the molar ratio of $\mathrm{CTAB} / \mathrm{SiO}_{2}=0.12$. The resultant gel, now containing CTAB, was transferred into the Teflon-lined autoclave again and heated at $160^{\circ} \mathrm{C}$ for 9 days. The product was recovered by filtration, washed with deionized water, dried, calcined at $580^{\circ} \mathrm{C}$, ion exchanged with $\mathrm{NH}_{4} \mathrm{Cl}$ solution and calcined at $500^{\circ} \mathrm{C}$.

\subsubsection{General synthesis procedure for silicoaluminophosphate (SAPO) materials}

In a typical synthesis procedure for the silicoaluminophosphate (SAPO) materials, an aqueous solution of the organic template (OSDA) in its hydroxide form was firstly mixed with the required amount of alumina (Condea Pural SB), and the mixture was kept under stirring until homogeneity was reached. Secondly, orthophosphoric acid (85\%, Sigma-Aldrich) and fumed silica (Cab-OSil) were added to the gel. The gel was kept under stirring to reach homogeneity and, then, water was evaporated by heating to reach the required concentration. The final gel compositions were $0.1-0.2 \mathrm{SiO}_{2} / 0.25 \mathrm{Al}_{2} \mathrm{O}_{3} / 0.2-0.225 \mathrm{P}_{2} \mathrm{O}_{5} /$ 0.2-0.4 OSDA / 3-40 $\mathrm{H}_{2} \mathrm{O}$. The gels were introduced into a Teflon-lined autoclave and heated at $175^{\circ} \mathrm{C}$ in static conditions for 7 days. The synthesis conditions of the different SAPO materials are summarized in Chapter 5. After 
the crystallization procedure, the products were filtered and washed with abundant distilled water and dried at $100^{\circ} \mathrm{C}$ overnight. The samples were calcined at $550^{\circ} \mathrm{C}$ in air for $6 \mathrm{~h}$ to properly remove the occluded organic molecules.

\subsubsection{Standard SAPO-34 (SAPO-34_std)}

In order to compare with the silicoaluminate zeolites obtained in this study, conventional SAPO-34 was obtained and employed as reference catalysts. In a typical synthesis of SAPO-34, $16.4 \mathrm{~g}$ of an aqueous solution of tetraethylammonium (TEAOH, 35\%wt Sigma-Aldrich) hydroxide was mixed with $1.5 \mathrm{~g}$ of distilled water and $4.0 \mathrm{~g}$ of phosphoric acid ( $85 \% \mathrm{wt}$, Aldrich). This mixture was stirred for $30 \mathrm{~min}$. Secondly, $2.94 \mathrm{~g}$ of alumina (75\%wt, Condea) and $0.88 \mathrm{~g}$ of a colloidal suspension of silica (Ludox AS40 40\%wt, Aldrich) were introduced in the above mixture, and the resultant gel was stirred until complete homogenization. The chemical composition of the synthesis gel was $0.09 \mathrm{SiO}_{2}$ : $0.25 \mathrm{Al}_{2} \mathrm{O}_{3}: 0.2 \mathrm{P}_{2} \mathrm{O}_{5}: 0.5 \mathrm{TEAOH}: 10 \mathrm{H}_{2} \mathrm{O}$. The crystallization was conducted at $200^{\circ} \mathrm{C}$ for $1 \mathrm{~d}$ under dynamic conditions. The solid product was filtered and washed with abundant water and dried at $100{ }^{\circ} \mathrm{C}$. The crystalline sample was calcined at $550^{\circ} \mathrm{C}$ in air to remove the occluded organic species.

\subsection{Characterization techniques}

\subsubsection{Powder $X$-Ray diffraction (PXRD)}

Since the materials used in this work have a characteristic X-ray powder diffraction pattern, this technique is essential for the identification of synthesized crystalline structures.

X-ray powder diffraction of the samples is performed using a Philips X'Pert model of Bragg-Brentano geometry diffractometer, equipped with a graphite monochromator and an automatic divergence slit, using $\mathrm{Cu} \mathrm{K} \alpha$ radiation. The diffraction equipment has a platform with movement in the X-Y-Z axes, so that multiple samples can be prepared in parallel. In this equipment, X-ray diffraction patterns are measured with a Bragg-Brentano geometry using a fixed divergence 
slit $\left(1 / 16^{\circ}\right)$, a goniometer with an arm length of $240 \mathrm{~mm}, \mathrm{CuK}_{\alpha} 1.2$ radiation $(\lambda$ $=1.5406,1.5441 \AA$ ) and an X'Celerator detector. The tube voltage and current were $45 \mathrm{kV}$ and $40 \mathrm{~mA}$, respectively, while the measuring range (20) was from $4.0^{\circ}$ to $35.0^{\circ}$, with a spacing of $0.017^{\circ}(2 \theta)$ and a time of $1200 \mathrm{~s}$ per step.

\subsubsection{Inductively coupled plasma atomic emission spectroscopy (ICP-AES)}

Atomic emission spectroscopy is a method that allows several chemical elements to be analyzed simultaneously with excellent detection limits (ppb). This methodology uses an inductive coupling plasma, in which the sample is injected for ionization. The generated ions emit radiation at different wavelengths characteristic of each element and with an intensity directly proportional to the concentration of said element.

The materials used in this thesis have been analyzed using a Varian 715-ES equipment, in order to determine the content of $\mathrm{Si}, \mathrm{Al}, \mathrm{P}, \mathrm{B}, \mathrm{Na}, \mathrm{K}$ or $\mathrm{Co}$ depending on the sample. Prior to the measurement process, a small portion of the sample $(30-40 \mathrm{mg})$ is disintegrated using an acid mixture $\left(\mathrm{HNO}_{3}: \mathrm{HF}: \mathrm{HCl}\right.$, in volumetric ratio 1: 1: 3). In all cases, by means of commercial standards, a calibration curve is determined that matches the expected analyte concentration.

\subsubsection{Elemental analysis (EA)}

The content of organic matter $(\mathrm{C}, \mathrm{N}, \mathrm{O}, \mathrm{H})$ in the different samples is determined by elementary analysis using a Fisons EA1108 and sulfanilamide equipment as a reference.

\subsubsection{Thermogravimetric analysis (TGA)}

Thermogravimetric analysis allows to determine the loss or gain of mass of a material as a function of temperature in a controlled atmosphere. Through this technique, the organic content of the material, as well as the amount of adsorbed water, can also be known more closely. 
The analysis of the samples is carried out in an air atmosphere, and a temperature range between $20-800^{\circ} \mathrm{C}$, a temperature at which all the organic matter occluded inside the cavities of the zeolites has generally been removed. The measurements are carried out by using a Mettler Toledo TGA / SDTA851e device, using between 5 and $10 \mathrm{mg}$ of sample, and a heating rate of $10^{\circ} \mathrm{C} / \mathrm{min}$.

\subsection{5. $\mathrm{N}_{2}$ adsorption/desorption measurement}

Physical adsorption or physisorption of gases in solids is the most used techniques for the study of the porous texture of solids. This technique allows the determination of the specific surface, and the volume and distribution of pore size.

In the present thesis, for the determination of surface area and pore volume of the materials, quantitative adsorption of $\mathrm{N}_{2}$ to $77 \mathrm{~K}$ is used (temperature of liquid $\mathrm{N}_{2}$ ), thus obtaining the adsorption isotherm. This isotherm is determined with a Micromeritics ASAP-2000 device. Prior to the adsorption measurements, the samples are calcined and pelletized to obtain a particle size between 0.6-0.8 mm, and treated under vacuum for 24 hours at a temperature of $400^{\circ} \mathrm{C}$.

The determination of the specific surface is carried out using the BrunauerEmmet-Teller (BET) model. While the micropore area and volume are obtained using the t-plot method.

\subsubsection{Field emission scanning electron microscope (FE-SEM)}

This technique allows to obtain information about the shape and size of the crystals. It is also useful for determining the presence of small impurities from other phases. The difference with respect to conventional scanning electron microscopy is that through FE-SEM a higher resolution can be obtained and therefore crystal sizes on the nanometric scale can be distingushed. In addition, this technique allows working at low potentials $(0.02-5 \mathrm{KV})$, thus avoiding problems associated with loading and damage to sensitive samples. 
The electron microscopy images of the samples obtained in this thesis have been collected using an Ultra 55 (Zeiss) microscope, operating at a voltage of $2.0 \mathrm{KV}$, and using dispersed powder samples without any type of coating on an adhesive tape of double face attached to the sample holder. The same equipment also allows analyzing the composition of the samples using an X-ray detector (EDX). Since the energy of X-ray is characteristic for each element, it is possible to obtain analytical, qualitative and quantitative information of the desired areas. This technique is known as EDX microanalysis.

\subsubsection{Nuclear magnetic resonance}

Nuclear magnetic resonance (NMR) spectroscopy is a technique of great importance for the analysis of molecular structures, since it studies the behavior of magnetically active nuclei under an external magnetic field. The foundation of this technique is based on the interaction of the nuclear magnetic moments of certain atoms, with an external magnetic field. These nuclear magnetic moments have different orientations within a magnetic field, which produces a split between the energy states of a non-zero spin core. The transition between these consecutive energy states, and the modification of the orientation of the magnetic moments of the core with respect to the magnetic field, occur when a radiofrequency current passes through the sample.

The interaction of nearby nuclear magnetic moments produces changes in energy levels, causing variations in the position and shape of the signals that make up the NMR spectrum. This allows the identification of the chemical environment of the atomic nucleus of interest. In the case of liquids, nuclear interactions are averaged due to the rapid movement of molecules, which gives rise to narrow line spectra. However, in solids the spectral signals are broader, and resolution is lost. The interactions responsible for the widening of these signals are the anisotropy of the chemical shift, the dipole couplings (homo and heteronuclear) and the quadrupole coupling. However, different techniques have been developed that allow obtaining high resolution spectra while preserving the information provided by these interactions. An example is the method of turning with a magic angle (MAS), which allows eliminating dipole 
interactions between different nuclei and first-order quadrupole interactions, as well as reducing the anisotropy of chemical displacement. This method is based on rotating the sample at an angle of $54^{\circ} 44^{\prime}$ 'with respect to the axis of the external magnetic field. In addition, to improve the signal-to-noise ratio in those spectra of poorly abundant nuclei and long relaxation times, the transfer of polarization of abundant nuclei, usually $1 \mathrm{H}$, to other less abundant ones is used by using the cross-polarization technique.

The nuclei studied in this doctoral thesis are: ${ }^{1} \mathrm{H},{ }^{13} \mathrm{C},{ }^{29} \mathrm{Si}$ and ${ }^{27} \mathrm{Al}$.

${ }^{13} \mathrm{C}$ spectroscopy is used to characterize the OSDAs and also to check if their structures remain intact within the materials synthesized after the crystallization process.

${ }^{29} \mathrm{Si}$ spectroscopy provides information about the coordination of silicon in zeolitic materials. This technique allows to distinguish species $\mathrm{Si}-(\mathrm{nAl})$, where $\mathrm{n}$, represents the number of atoms of aluminum in the second coordination sphere of the silicon atom considered, and it can vary from 0 [Si- $(0 \mathrm{Al})$, characteristic of silicon-rich domains] to 4 [Si-(4Al), characteristic of isolated network silicons].

${ }^{27} \mathrm{Al}$ spectroscopy allows identifying the presence of aluminum in different coordination states. The chemical shifts of aluminum, depending on whether it is tetracoordinated, pentacoordinated, or hexacoordinated, are very different. In our case, NMR spectra of solids were performed with a Bruker AVANCE III HD 400 WB.

\subsubsection{Temperature programed desorption of $\mathrm{NH}_{3}$}

This technique is based on chemisorption of $\mathrm{NH}_{3}$ as a probe molecule and is used to quantitatively evaluate the number of active sites. Specifically, it allows the evaluation of the surface acidity of the samples and the heat of adsorption of $\mathrm{NH}_{3}$ on different acid sites.

To carry out the measurements, $\mathrm{NH}_{3}$ is first adsorbed on the catalyst and then the desorption of $\mathrm{NH}_{3}$ is studied by a progressive increase in temperature. The measurements are made using an Autochem II (Micromeritics) device with 
thermal conductivity detector (TCD) and a GC-MS (OmniStar Bazers Instruments) mass spectrometer.

\subsubsection{Infrared-pyridine}

The acidity of the zeolites was determined by infrared spectroscopy combined with adsorption-desorption of pyridine at different temperatures. Infrared spectra were measured with a Nicolet 710 FT-IR spectrometer. Pyridine adsorption-desorption experiments were carried out on self-supported wafers $\left(10 \mathrm{mg} / \mathrm{cm}^{2}\right)$ of original samples previously activated at $400{ }^{\circ} \mathrm{C}$ and $10^{-2} \mathrm{~Pa}$ for 2 h. After wafer activation, the base spectrum was recorded and pyridine vapor $\left(6.5 \times 10^{2} \mathrm{~Pa}\right)$ was admitted into the vacuum IR cell and adsorbed onto the zeolite. Desorption of pyridine was performed under vacuum over $1 \mathrm{~h}$ periods of heating at $350{ }^{\circ} \mathrm{C}$, followed by IR measurement at room temperature. All the spectra were scaled according to the sample weight. The numbers of Brønsted and Lewis acid sites were determined from the intensities of the bands at ca. 1545 and $1450 \mathrm{~cm}^{-1}$, respectively.

\subsubsection{0. $\mathrm{Co}^{2+}$-exchange experiments}

In order to investigate the distribution of isolated and paired $\mathrm{Al}$ sites, samples were exchanged stepwise with $\mathrm{Na}^{+}$and $\mathrm{Co}^{2+}$. For a single experiment the detailed procedures were as follows: $1 \mathrm{~g}$ zeolite in the proton form was mixed with $50 \mathrm{~mL}$ of $0.5 \mathrm{~mol} / \mathrm{L} \mathrm{NaNO}_{3}$ solution and kept under stirring at room temperature for 3 hours and retrieved by filtration and dried at $60^{\circ} \mathrm{C}$ in air. The exchange with $\mathrm{Na}^{+}$was repeated three times. To exchange the $\mathrm{Na}^{+}$-form samples with $\mathrm{Co}^{2+}, 1 \mathrm{~g}$ of the Na-exchanged solid was mixed with $150 \mathrm{~mL}$ of $0.05 \mathrm{~mol} / \mathrm{L} \mathrm{Co}\left(\mathrm{NO}_{3}\right)_{2}$ solution and kept under stirring at room temperature for 8 hours. After the exchange process, the solid was retrieved by filtration and dried at room temperature. The exchange of $\mathrm{Co}^{2+}$ was repeated three times. Finally, the solid was dried in vacuum at room temperature overnight to exclude physically adsorbed water. Then, the samples were tested by ICP and UV-Vis spectroscopy following the procedure described in the literature. ${ }^{3}$

\subsection{Catalytic reactions




\subsubsection{Catalytic cracking of 1-hexene}

The catalytic cracking of 1 -hexene was carried out at $500^{\circ} \mathrm{C}$, atmospheric pressure, and a hydrocarbon partial pressure of 0.251 , in a continuous fixed-bed, quartz reactor of $11 \mathrm{~mm}$ internal diameter and $300 \mathrm{~mm}$ length. The reactor was heated in an electric furnace. The catalyst was first pelletized, crushed and sieved into $0.2-0.4 \mathrm{~mm}$ particle sizes and diluted with silicon carbide with particle size $0.6-0.8 \mathrm{~mm}$ in order to keep constant the length of the catalytic bed. 1-hexene was injected with syringe pumps and $\mathrm{He}$ was used as carrier gas. The flow of $\mathrm{He}$ was measured and controlled with a mass flow controller. Experiments were conducted at different contact times by varying catalyst amount and fixing the hydrocarbon flow. The catalyst was first activated in $\mathrm{He}$ flow at $540^{\circ} \mathrm{C}$ for 1 hour and then cooled to the desired reaction temperature. 1-hexene feeding started once the temperature reached stable. Sample were taken at the outlet of the reactor at a programmed time following the procedure described before. ${ }^{4}$ The components were separated in a $100 \mathrm{~m}$ capillary column (Petrocol DH-Supelco) for the first multisampling and in a $2 \mathrm{~m} \times 1 / 8$ inch packed column (HayeSep D 80/100) for the second multisampling, and then analyzed using FID and TCD detectors, respectively.

The catalytic cracking of 1-hexene in the presence of 2,4-dimethylquinoline (2,4DMQ) was performed using the same procedure as described above. Only the feeding of pure 1-hexene was replaced with a solution of 2,4-DMQ in 1-hexene. The concentration of 2,4-DMQ in 1-hexene was controlled to have a feeding rate of 2,4-DMQ of $0.9 \mathrm{mmol} \cdot \mathrm{g}^{-1} \cdot \mathrm{h}^{-1}$.

\subsubsection{Methanol to olefins reaction using medium-pore zeolites}

The zeolite samples in their protonic form were pelletized, crushed and sieved into $0.2-0.4 \mathrm{~mm}$ particle sizes. $50 \mathrm{mg}$ of the sample was mixed with $2.0 \mathrm{~g}$ of quartz $(0.2-0.4 \mathrm{~mm})$ and loaded into a fix-bed reactor of $7 \mathrm{~mm}$ diameter. The catalyst was first activated at $540^{\circ} \mathrm{C}$ for 1 hour in nitrogen flow of $90 \mathrm{~mL} / \mathrm{min}$. Then the temperature was decreased to $450^{\circ} \mathrm{C}$. After the temperature was stable, $\mathrm{N}_{2}(20 \mathrm{ml} / \mathrm{min})$ was bubbled in methanol held at room temperature, giving WHSV of $10 \mathrm{~h}^{-1}$, and fed into reactor. Products were analyzed every 35 minutes 
with two online gas chromatographs (BRUKER 450GC, with PONA and $\mathrm{Al}_{2} \mathrm{O}_{3}$-Plot Capillary columns equipped with FID detectors). Conversion and selectivity were considered on the carbon basis and methanol and dimethyl ether were lumped together for calculation of conversion.

\subsubsection{Liquid phase transalkylation of diethylbenzene with benzene}

The liquid phase transalkylation of diethylbenzene with benzene was carried out in a fixed bed continuous reactor. The feedstock is a liquid mixture of benzene and diethylbenzene (Bz:DEB weight ratio 3:1, molar ratio 5.16) containing $n-$ octane as internal standard. $400 \mathrm{mg}$ of pelletized catalyst was properly mixed with silicon carbide to reach a total volume of $12.6 \mathrm{ml}$. The catalyst was activated in dry $\mathrm{N}_{2}$ flow at $360^{\circ} \mathrm{C}$ for 3 hours. Then, the temperature of reactor was cooled down to the reaction temperature. When the temperature was stable, the system was pressurized to $3.5 \mathrm{MPa}$ with dry $\mathrm{N}_{2}$ and maintained stable. Then, the abovementioned liquid mixture was fed into the reactor in liquid phase and the pressure was controlled at $3.5 \mathrm{MPa}$ by a back-pressure regulator. The product was analyzed on-line with a Varian-450 gas chromatograph equipped with a 30 m 5\% phenyl / 95\% dimethyl polysiloxane capillary column connected to a flame ionization detector.

\subsubsection{MTO reaction}

The zeolite catalysts were pelletized, crushed and sieved into $0.2-0.4 \mathrm{~mm}$ particle size. $50 \mathrm{mg}$ of sample was mixed with $2.0 \mathrm{~g}$ quartz (Fluka) before being introduced into the fixed-bed reactor $\left(7 \mathrm{~mm}\right.$ diameter). $\mathrm{N}_{2}(30 \mathrm{ml}$ min-1) was bubbled in methanol held at $-17^{\circ} \mathrm{C}$, giving a WHSV $=0.8 \mathrm{~h}^{-1}$. The catalyst was first activated with a nitrogen flow of $80 \mathrm{ml}$ min for $1 \mathrm{~h}$ at $540^{\circ} \mathrm{C}$, and, then, the temperature was decreased to reaction conditions $\left(350^{\circ} \mathrm{C}\right)$. In each experiment samples were analyzed every $5 \mathrm{~min}$ with an online gas chromatograph (Bruker 450GC, with PONA and $\mathrm{Al}_{2} \mathrm{O}_{3}$-Plot capillary columns, and two FID detectors). Conversion and selectivities were considered on carbon basis. 


\subsection{Reference}

1. V. Blay, P. J. Miguel, A. Corma, Catal. Sci. Technol., 2017, 7, 5847.

2. D. Massiot, F. Fayon, M. Capron, I. King, S. Le Calvé, B. Alonso, J-O. Durand, B. Bujoli, Z. Gan, G. Hoatson, G., Magn. Reason. Chem., 2002, 40, 70.

3. J. Dedecek, V. Balgová, V. Pashkova, P. Klein, B. Wichterlová, Chem. Mater., 2012, 24, 3231.

4. A. Corma, P. J. Miguel, A. V. Orchillés, J. Catal., 1997, 172, 355. 



\section{Chapter 4}

\section{Control of Aluminum}

distribution in zeolite 


\subsection{Introduction}

Zeolite acidity is generated by isomorphous substitution of framework $\mathrm{T}^{\mathrm{IV}}$ atom by $\mathrm{T}^{\mathrm{III}}$ tetrahedrally coordinated atoms. By doing so one negative charge is generated on the bridging $\mathrm{O}$ atoms connecting the $\mathrm{T}^{\mathrm{III}}$ atom, which can be compensated by a cation. When said cation is a proton, the zeolite framework can behave as solid Brønsted acid. To describe the acid properties of one particular zeolite material, there are several aspects that need to be clarified, such as the acid strength, acid amount, acid density and the accessibility of each acid sites.

The acid strength is rigorously described by the energy required for deprotonation, that is, to enable the balancing proton to be separated from the zeolite framework to a non-interacting distance. Such energy is named deprotonation energy (DPE) and enumerately defined as:

$$
\mathrm{DPE}=\mathrm{E}_{\mathrm{Z}-}-\mathrm{E}_{\mathrm{H}+}+\mathrm{E}_{\mathrm{ZH}}
$$

Where $\mathrm{E}_{\mathrm{Z}}, \mathrm{E}_{\mathrm{H}+}$ and $\mathrm{E}_{\mathrm{ZH}}$ are the respective energies of anionic zeolite framework, gaseous proton and the corresponding $\mathrm{H}$-form of zeolite. The deprotonation energies among different $\mathrm{T}$ sites and also among different high $\mathrm{Si} / \mathrm{Al}$ zeolite framework structures vary negligible, being in the range of $1201 \pm 11 \mathrm{~kJ} \mathrm{~mol}^{-1}$. Despite similar acid strengths, the catalytic activity of acid sites in different zeolites as well as different $T$ sites in one zeolite framework can differ due to the influence of confinement effects on intermediates and transition states. ${ }^{2-6}$

Since proton is the actual center of acidity and is placed adjacent to aluminum by local charge balancing, the location of the acid sites is controlled by siting and distribution of aluminum within the zeolite framework. Thus, the distribution of acid sites could be similarly considered as distribution of aluminum sites. In fact, there are in general two types of aluminum distributions: one distribution mainly describes the distance between two aluminum atoms, and the other distribution considers the exact position where the aluminum is located. Therefore, it is important to specify which kind of distribution is going to be discussed when considering the aluminum distribution in aluminosilicate zeolites. 
As it was said in the introduction chapter, when aluminum atoms are separated by more than one silica tetrahydron, there are in general two possible distribution of aluminum sites depending on if they are facing the same ring, namely paired and unpaired aluminum (see Figure 1.3). The paired aluminum facing the same ring can effectively generate two neighboring negative charges, which can be balanced by dicationic species. On the contrary, the unpaired aluminum atoms can only provide one negative charge in one ring, acting as single aluminum despite their close distance. The only example reported of Al-O-(Si-O) ${ }_{3}-\mathrm{Al}$ balancing dicationic species is when the two aluminum are in the 8-ring of mordenite. Taking advantage of their ability of balancing dicationic species, paired aluminum can be identified by cation exchange of divalent cations and, afterwards analyzed by chemical analysis. Dedecek et al. reported that the hexaquo complex of cobalt $\mathrm{Co}\left(\mathrm{H}_{2} \mathrm{O}\right)_{6}{ }^{2+}$ has a proper size to balance paired $\mathrm{Al}^{7}$

Aside from distance between two aluminum atoms, another concept of tunning distribution of aluminum is the $\mathrm{T}$ positioning within the zeolite framework. Controlling the location of acid sites in zeolites can have a great impact on their catalytic behavior. One of the paradigmatic cases in where the control of the acid site distribution could have important practical impact is the MFI framework, whose aluminosilicate form is the medium-pore ZSM-5 zeolite, one of the most used catalyst in petrochemical processes. The channel system of MFI is composed of intersected 10-ring channels with similar sizes of $5.6 \AA$ and the intersection of channel is larger, with size of approximately $9 \AA$. Depending on the location of Al, the acid sites in ZSM-5 can either point the confined 10-ring channels or the open intersection. During reaction, a given reactant molecule could interact with either kind of acid site yet the molecular confinement and the enthalpic and entropic effects on the adsorbed reactant and on the transition state will not be necessarily the same. ${ }^{3-6,13-15}$ Thus, if it is possible to control aluminum distribution in ZSM-5, it should have high impact on its catalytic activity. Deconvolution of the ${ }^{27} \mathrm{Al}$ MAS NMR spectra of ZSM- 5 into different peaks has allowed the demonstration of aluminum siting. ${ }^{16}$ However, the complexity in different kinds of $\mathrm{T}$ sites make it difficult to assign peaks to particular positions, limiting the applicability of such characterization. 
In this chapter, the target will be first to establish an indicator to effectively evaluate the location of acid sites in ZSM- 5 zeolite and then use this indicator to develop a synthesis strategy to prepare ZSM-5 materials with controlled aluminum distributions.

It is not difficult to see that the distribution of aluminum in single/paired form or at certain locations in framework are not independent issues. They can all be influenced by changing synthesis conditions, such as starting $\mathrm{Si}$ and aluminum sources, adding alkaline cations combined with OSDAs as well as synthesis temperature. Thus, when evaluating the results from characterization and catalytic reactions, influence of both types of aluminum distributions should be considered.

Then, there are two main tasks when studying the aluminum distribution in zeolite. One is to find a proper method to characterize the location of $\mathrm{Al}$, especially in the case of MFI structure with a large number of topological distinctive $\mathrm{T}$ sites. It should be mentioned that this characterization does not have to be able to distinguish all $\mathrm{T}$ sites but should be distinguishable among $\mathrm{T}$ sites with different catalytic activities when substituted with Al. Another task is to establish novel strategies, either direct synthesis methods or post-synthesis treatments, to obtain zeolites with different aluminum distributions. In fact, these two tasks are in most cases combined since without a proper characterization, there is no reliable approach to testify if the strategies have succeeded in tuning aluminum distribution.

\subsection{Establishment of an indicator for aluminum distributions}

According to Yokoi et al., the location of aluminum in ZSM-5 can be tuned by using combination of templates and alkaline cations. ${ }^{16}$ The reason lies in the fact that during zeolite crystallization, the negative charge of the $\mathrm{AlO}_{4}^{-}$tetrahydron tends to interact with cations in synthesis gel. When TPAOH is the only source of cation, the $\mathrm{AlO}_{4}^{-}$tend to approach TPA. As a result, in the final product, aluminum should be located close to where TPA molecules. It is commonly accepted, and it will be proved once again later in this thesis, that TPA molecules are strictly located at channel intersection of MFI structure. Consequently, when 85 
ZSM-5 samples are synthesized using only TPAOH, the aluminum in final product should be concentrated near the channel intersection. In the same gel, when adding $\mathrm{Na}^{+}$, the extra positive charge should share negatively charged $\mathrm{AlO}_{4}^{-}$tetrahydron species, resulting in more equally aluminum distribution between intersection and inside channels. Furthermore, in the same synthesis gel, when TPA is replaced by molecules with similar structure and configuration but without positive charges such as alcohols, the $\mathrm{AlO}_{4}^{-}$tetrahydron should approach to $\mathrm{Na}^{+}$exclusively. Meanwhile, when the shape and configuration of the alchols are similar with TPA molecule, it should guarantee the location of alcohols to be at intersection and leave $\mathrm{Na}^{+}$in the channel, which finally lead to aluminum located more in channel than intersections.

\subsubsection{Materials synthesis}

Following the results reported by Yokoi et al., the first step of this study was to synthesize zeolites according to the procedures with different combinations of OSDAs and alkaline cations (see experimental section, Chapter 4 for details). ZSM-5 samples with high crystallinity were obtained using TEOS as silica source, aluminum nitrate as aluminum source, sodium chloride as sodium source and a OSDA, selected from TPAOH, 1,3-propanediol (PDO), 1,6-hexanediol (HDO), trimethylolethane (TME) and pentaerythritol (PET) (see Scheme 4.3). The zeolite obtained were named here as Z5-TPA, Z5-PDO, Z5-HDO, Z5-TME and Z5-PET, correspondingly.

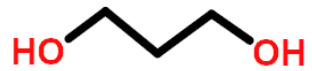

1,3-propanediol (PDO)

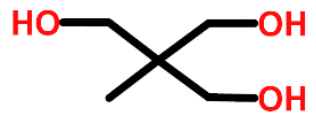

trimethyloethane (TME)

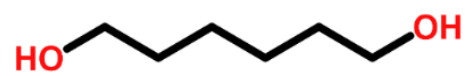

1,6-hexanediol (HDO)

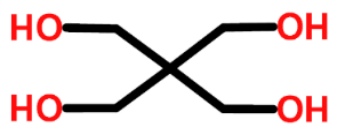

pentaerythritol (PET) 
Scheme 4.3 Illustration of the different alcohol molecules employed as OSDAs for the ZSM-5 synthesis

\subsubsection{Materials characterization}

These samples have been first characterized by various techniques to see their physiochemical properties. The PXRD patterns of all samples reveal pure phase of MFI without the presence of amorphous phases or impurity, indicating a high crystallinity for all of them (see Figure 4.1). All samples contain similar microporous volume as well as external surface area (see Table 4.1).

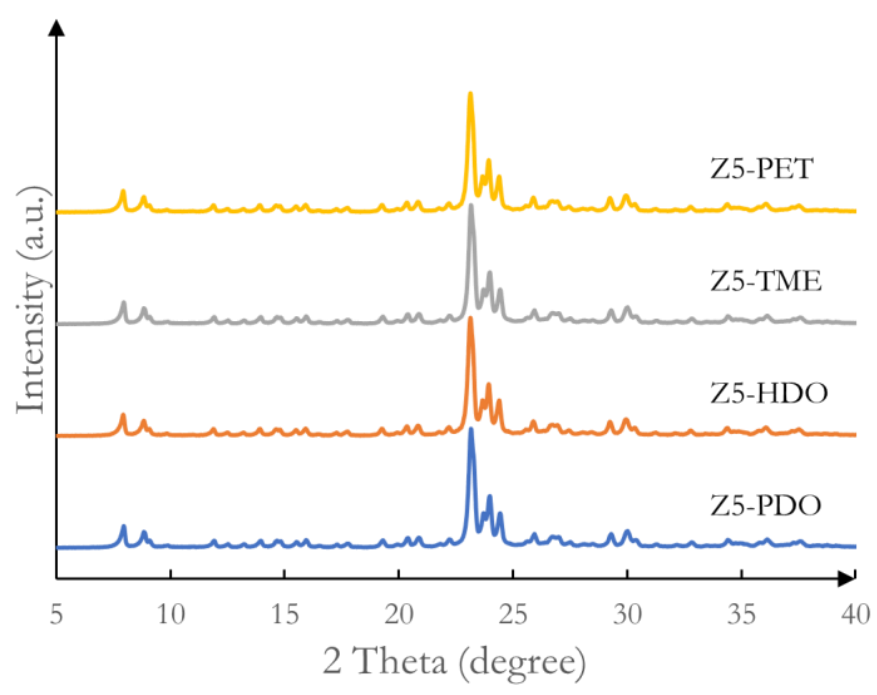

Figure 4.1 XRD patterns of ZSM-5 samples synthesized with different alcohols as OSDAs.

FESEM images show that all the samples have typical hexagonal prism morphology, with particle sizes between $2-3 \mu \mathrm{m}$ (see Figure 4.2). Usually, large particle sizes could generate hinderance for internal diffusion of reactants and/or products in catalytic reactions, and this hinderance could significantly increase when particle size is larger than several microns. However, it has been systematically studied by Haag et al. that in the case of MFI structure framework, the diffusion of $n$-hexene could be considered similar in crystals with sizes 
ranging between $0.025 \mu \mathrm{m}$ and $1.35 \mu \mathrm{m} .{ }^{17}$ At this point, it is possible to conclude that the samples are comparable from a crystallographic point of view. Then, it is possible to proceed to study the acidic properties.
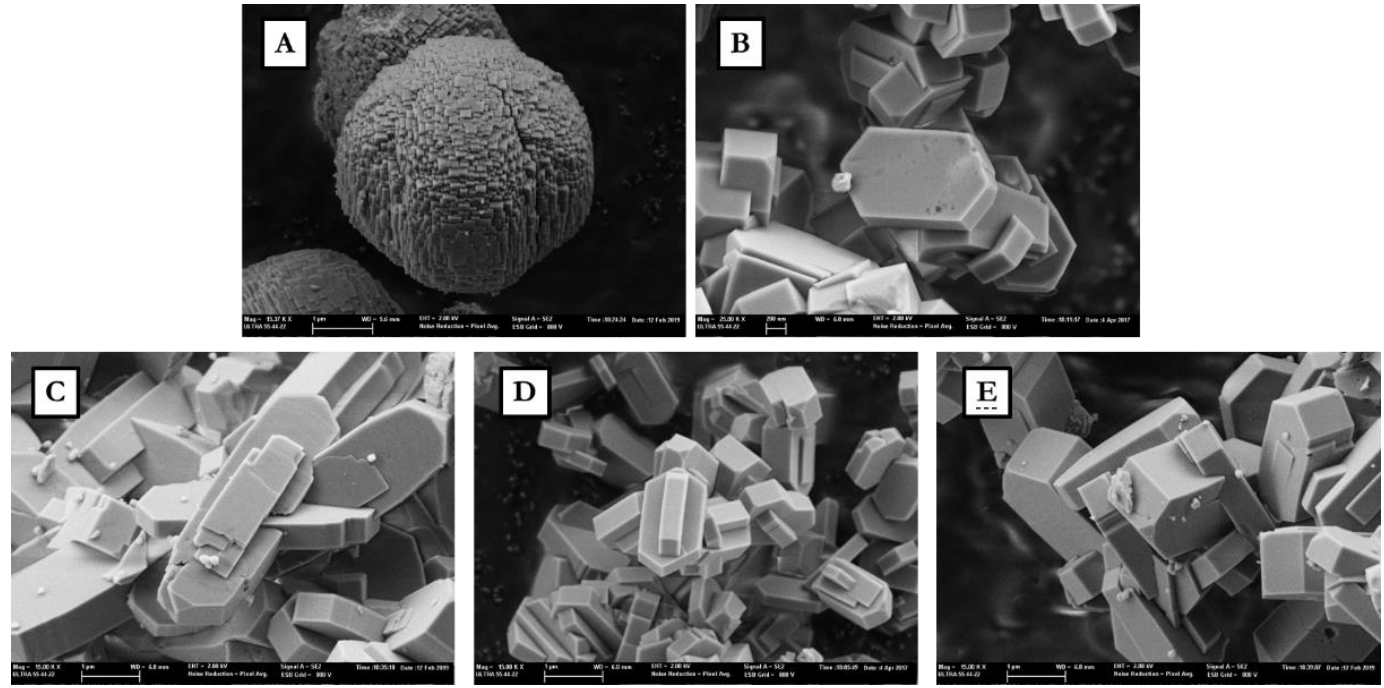

Figure 4.2 FESEM images of ZSM-5 samples synthesized with different alcohols as OSDAs, Z5TPA (A); Z5-PDO(B); Z5-PDO(C); Z5-TME(D); Z5-PET(E).

Using the adsorption/desorption of pyridine combined with infrared spectroscopy, it is possible to calculate amount of Brønsted acid sites according to peak areas of remaining adsorbed pyridine after being treated at different temperatures using the molar extinction coefficients given by Emeis. ${ }^{19}$ Brønsted acid amount was calculated based on the adsorption peak at centered at 1540 $\mathrm{cm}^{-1}$ while Lewis acid amount was calculated based on the peak centered at 1450 $\mathrm{cm}^{-1}$ that correspond to pyridine coordinated to the Lewis acid sites. The calculated amount of Brønsted and Lewis acid sites for the different ZSM-5 materials (see Table 4.1) would allow comparing their catalytic activity for acid catalyzed reactions. However, it is also important to confirm the absence of extraframework aluminum (EFAl) species, since it will generate Lewis acidity, which could facilitate hydrogen transfer reactions, drastically influencing the product distribution. From ${ }^{27} \mathrm{Al}$ MAS NMR, it is clear that the aluminum is solely 
tetrahedrally coordinated in the framework (see Figure 4.3), and no band at $\sim 0$ ppm is observed. This allows to conclude that if EFAL present, it is below detection limit.

Table 4.1 Physicochemical properties and chemical compositions of ZSM-5 samples synthesized with different alcohols as OSDA.

\begin{tabular}{|c|c|c|c|c|c|c|c|c|}
\hline \multirow[t]{2}{*}{ Sample } & \multirow[t]{2}{*}{$\mathrm{Si} / \mathrm{Al}^{\mathrm{a}}$} & \multirow[t]{2}{*}{$\mathrm{Si} / \mathrm{Na}^{a}$} & \multirow[t]{2}{*}{$\begin{array}{l}\mathrm{S}_{\mathrm{BET}} \mathrm{b}^{2} \\
\left(\mathrm{~m}^{2} / \mathrm{g}\right)\end{array}$} & \multirow[t]{2}{*}{$\begin{array}{l}\mathrm{V}_{\text {micro }} \mathrm{b} \\
\left(\mathrm{cm}^{3} / \mathrm{g}\right)\end{array}$} & \multirow[t]{2}{*}{$\begin{array}{l}\mathrm{S}_{\text {ext }}^{\mathrm{b}} \\
\left(\mathrm{m}^{2} / \mathrm{g}\right)\end{array}$} & \multicolumn{3}{|c|}{$\begin{array}{c}\text { Brønsted acid amount }^{\mathrm{c}} \\
(\mu \mathrm{mol} / \mathrm{g})\end{array}$} \\
\hline & & & & & & $150^{\circ} \mathrm{C}$ & $250^{\circ} \mathrm{C}$ & $350^{\circ} \mathrm{C}$ \\
\hline Z5-TPA & 23.0 & 2103 & 423 & 0.19 & 38 & 487 & 451 & 367 \\
\hline Z5-PDO & 21.2 & 782 & 408 & 0.17 & 51 & 513 & 479 & 353 \\
\hline Z5-HDO & 20.8 & 1312 & 370 & 0.16 & 47 & 561 & 500 & 357 \\
\hline Z5-TME & 19.2 & 987 & 382 & 0.17 & 44 & 500 & 498 & 367 \\
\hline Z5-PET & 22.7 & 1457 & 398 & 0.17 & 49 & 491 & 465 & 354 \\
\hline
\end{tabular}

a Samples after calcination and acid treatment, measured by ICP-AES

b Samples after calcination and acid treatment, mMeasured by $\mathrm{N}_{2}$ adsorption/desorption measurement

c Measured by FT-IR combined with pyridine adsorption and desorption

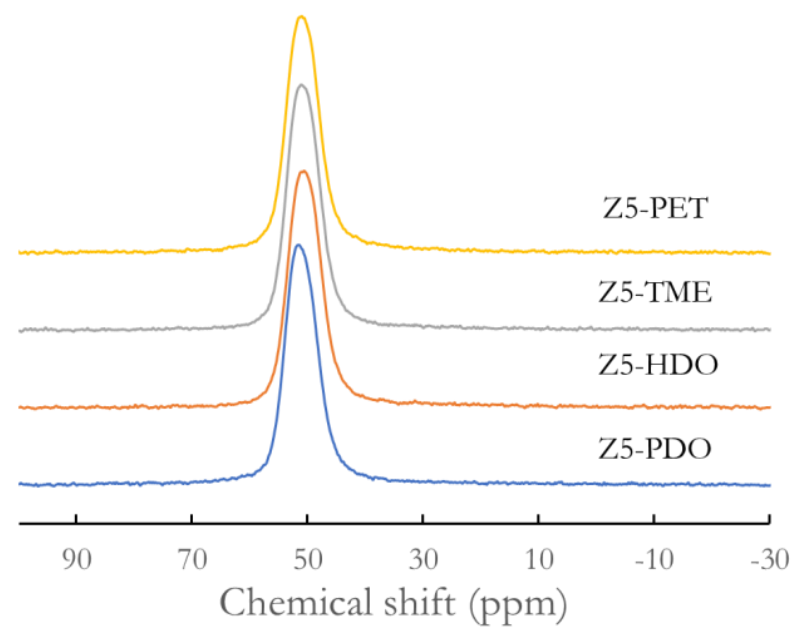


Figure 4.3 ${ }^{27} \mathrm{Al}$ MAS NMR spectra of calcined ZSM-5 samples synthesized with different alcohols as OSDA.

So far, all the samples were characterized to have analogous crystallinity, crystal size and morphology, chemical composition and acidity. Hence, the following step is to investigate the aluminum distribution of these samples. It has been reported that aluminum at different $\mathrm{T}$ sites have different chemical shifts in the ${ }^{27} \mathrm{Al}$ MAS NMR spectra, and thus different aluminum distribution could be examined by deconvolution of the spectra. However, it is important to keep in mind that in MFI structure there are at least 12 distinguishable T-sites which means that if one wants to identify aluminum at different $T$ sites in MFI structure there should be 12 sub-peaks. According to Yokoi et al., the peak in Al-NMR spectra could be deconvoluted into 5 sub-peaks, two of which are possibly related to aluminum located at intersection. It is able to observe different shapes of the peaks for all samples but the resolution is too low to be deconvolved to reveal the aluminum distribution (see Figure 4.3). Thus, it is necessary to find another way to distinguish aluminum at different location.

\subsubsection{Development of an indicator for Al location}

A reasonable way to evaluate the aluminum distribution would be feeding one reactant that could undergo several different reaction pathways that have transition-states with different shapes and configurations, resulting in different product distributions. In this sense, we thought that cracking of olefins could be a promising candidate reaction, since it can proceed faster than paraffins by around 200 times and could be therefore performed at lower temperature than paraffin cracking already with an observable activity ${ }^{17}$ In addition, the cracking of olefin can occur through a monomolecular and a bimolecular mechanism, involving different size transition states. ${ }^{18}$

In the monomolecular mechanism, olefin is directly protonated by an acid site and form a carbenium ion, which then undergoes $\beta$-scission and produce lighter 
products (see Scheme 4.4). The reaction is triggered by acid catalyzed formation of carbenium and then two reaction pathways arise for monomolecular cracking. The first possible pathway is isomerization of the linear carbenium followed by $\beta$-scission to yield propene. The second is direct $\beta$-scission of the linear hexyl carbenium to produce smaller olefins. The second pathway is less favorable since it involves secondary-primary carbenium ions, while the first one involves secondary-secondary carbocations. Regardless the pathway, the monomolecular mechanism only involves one n-hexene molecule as reactant and shows little difference of size in transition state. The only transition state that has larger size than reactant $n$-hexene is the branched hexyl carbenium, which is still smaller than any part of the channel in the MFI framework. Then, monomolecular mechanism should not be significantly influenced whether acid site is in the channel or in the intersection. Thus, it is expected that if n-hexene cracking is going solely through monomolecular mechanism, and side reactions are neglected, the main product should be propene.

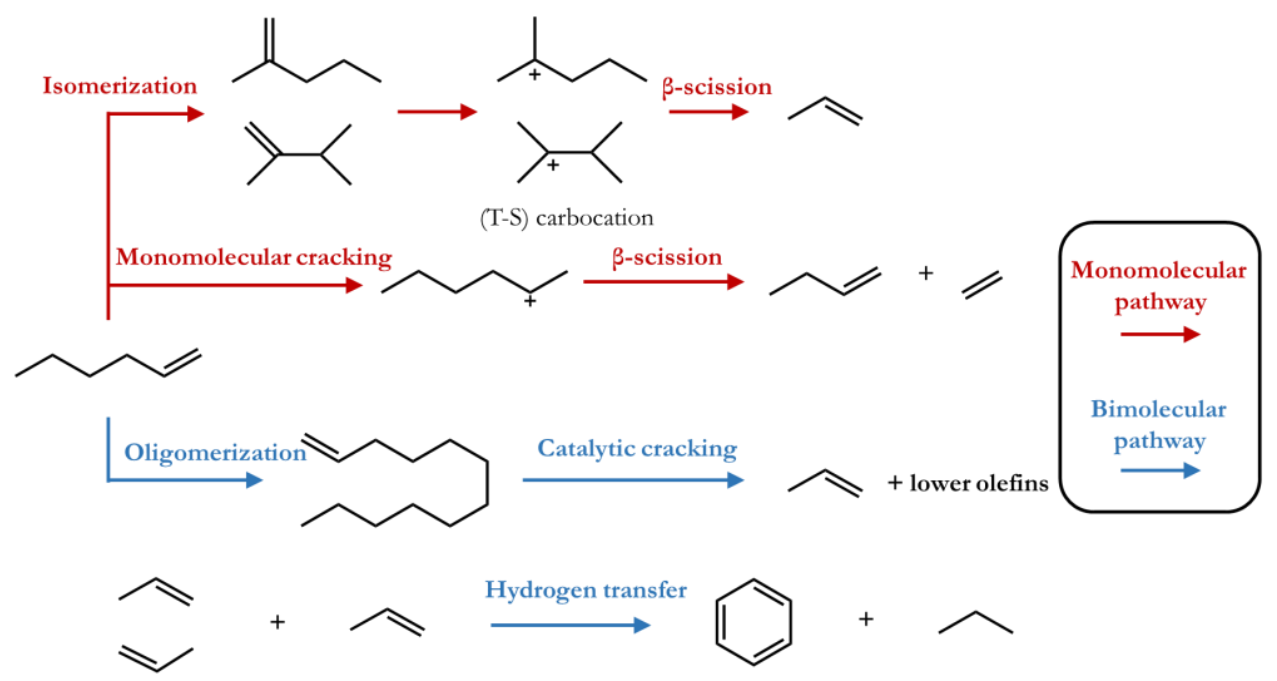

Scheme 4.4 A brief illustration of monomolecular and bimolecular pathways in 1-hexene cracking. 
In the bimolecular mechanism, one olefin molecule would first dimerize with another olefin forming a higher olefin and then go through protonation and $\beta$ scission. First, one $\mathrm{n}$-hexene molecule reacts with other short cationic species, usually propyl cations, generated in monomolecular mechanism, forming a $\mathrm{C}_{9}{ }^{+}$ carbenium. Then, the $\mathrm{C}_{9}{ }^{+}$carbenium will undergo $\beta$-scission in a similar way as it was described by monomolecular cracking mechanism of hexene (see Scheme 4.4, blue pathway). Due to the large size, $\mathrm{C}_{9}{ }^{+}$carbenium can isomerize into various products, which can produce various olefin products $\left(\mathrm{C}_{2}{ }^{-}-\mathrm{C}_{6}{ }^{ }\right)$. It is clear that the bimolecular mechanism should be more influenced by spatial confinement than monomolecular mechanism, since, firstly, it involves two molecules to form higher olefins, and, secondly, the intermediates in isomerization of the higher olefins are bulky. Both of these processes require large void space, and therefore, the bimolecular pathway should be more favored at channel intersection.

It is important to point out that the tendency toward either monomolecular or bimolecular mechanisms would be mainly affected by the number of carbon contained in the substrate molecule itself. Olefins with less than six carbons preferably follow bimolecular mechanism due to the high stability of short chain carbocations. In contrast, olefins larger than six carbons generally favor the monomolecular route. However, n-hexene is on the boundary, which means that it can crack through both mono- and bimolecular mechanisms and have no strong preference toward either of them. Thus, in this study, the selectivity toward each mechanism should not be limited by the intrinsic properties of reactants, and the ability of the zeolite framework to confine and stabilize the intermediates and transition states involved in each mechanism could thus be revealed.

Aside from the main reaction, catalytic cracking is always accompanied by a number of side reactions that could drastically affect the product distribution, such as olefin oligomerization, olefin thermal cracking, cyclization of short olefins, hydrogen transfer, etc. One of the important side reactions is hydrogen transfer, which is important in this study for several reasons. First, hydrogen transfer reaction happens between three olefin molecules, where each one of 
two olefins molecules transfer one hydrogen to the third olefin, forming an aromatic ring and a paraffin (see Scheme 4.4). This is clearly a reaction that requires large space and should occur only at the inersection. Second, this reaction consumes three molecules of olefins which are mostly propene in hexene cracking, and it is important to note that propene can be more desired in some cases than the achieved aromatics and much more than the paraffins.

Therefore, if one summarizes the mechanistic analysis above, it is reasonable to sketch the product distribution. If the reaction is not strictly limited by spatial confinement, monomolecular and bimolecular mechanisms should be more dependent on the intrinsic property of the substrate. In the case of n-hexene cracking, should be more equally happening. Then, the product should have mostly propene as it can be produced from both mechanisms. The other olefins formed should show an average distribution. Also, aromatics and paraffins should be observable in a large scale. On the other hand, if the reaction is limited within the 10-ring channel of MFI, bimolecular mechanism of n-hexene cracking and bimolecular side reactions should be less favored than when the reaction will occur in the crossing of the 10-ring channels. Therefore, if the reaction occurs mainly in the 10-ring channel, propene should still be the main product and the selectivity toward propene should be higher since less has been consumed by hydrogen transfer reactions. The selectivity toward other olefins, aromatics and paraffins should be significantly reduced.

Following the idea described above, the ZSM-5 samples prepared with different alcohols were tested in $n$-hexene catalytic cracking at $773 \mathrm{~K}$. The product distribution is listed in Table 4.2. It can be seen there that the main products in all cases are ethene, propene, butenes and pentenes, followed by small amounts of paraffins and aromatics. Although the molar yield of each product between samples are different in small scale, it cannot be used directly to interpret the mechanism since the olefins can be both products and reactants for further reactions. For such a complex reaction network, a proper simplification of the system studied is required, acquiring representative indicators for monomolecular and bimolecular reactions. Following the reaction scheme 4.4, it is noteworthy that the ratio of $\mathrm{C}_{2}{ }^{=} / \mathrm{C}_{4}{ }^{=}$is very low. In fact, this ratio is an 
important indicator. If one considers monomolecular cracking mechanism, the only possibility to obtain ethene and butenes is through direct $\beta$-scission since in isomerization followed by cracking the product shall be two propene molecules. In direct cracking, ethene and butenes should be produced in equal amount and the $\mathrm{C}_{2}{ }^{\circ} / \mathrm{C}_{4}{ }^{=}$ratio should be close to 1 .

Table 4.2 Conversion and product distribution of 1-hexene cracking on ZSM-5 samples synthesized with different alcohols as OSDA

\begin{tabular}{|c|c|c|c|c|c|}
\hline Sample & $\begin{array}{l}\text { Z5- } \\
\text { TPA }\end{array}$ & $\begin{array}{l}\text { Z5- } \\
\text { PDO }\end{array}$ & $\begin{array}{l}\text { Z5- } \\
\mathrm{HDO}\end{array}$ & $\begin{array}{l}\text { Z5- } \\
\text { TME }\end{array}$ & $\begin{array}{l}\text { Z5- } \\
\text { PET }\end{array}$ \\
\hline Contact time (s) & 2.52 & 2.52 & 2.53 & 2.48 & 2.54 \\
\hline Conv.n-hexene (\%) & 79.6 & 82.0 & 84.8 & 77.8 & 79.7 \\
\hline \multicolumn{6}{|l|}{ Molar yields (\%) } \\
\hline Ethene & 14.9 & 14.3 & 14.6 & 12.2 & 12.7 \\
\hline Propene & 70.4 & 79.5 & 78.8 & 74.9 & 75.1 \\
\hline $\mathrm{C}_{4}=$ & 37.3 & 33.1 & 35.3 & 30.6 & 32.3 \\
\hline $\mathrm{C}_{5}=$ & 11.8 & 18.1 & 20.0 & 18.2 & 19.1 \\
\hline BTX & 0.81 & 0.77 & 0.94 & 0.65 & 0.78 \\
\hline Paraffins & 3.70 & 4.01 & 4.42 & 3.52 & 4.0 \\
\hline \multicolumn{6}{|l|}{ Molar yield ratios } \\
\hline $\mathrm{C}_{2}=/ \mathrm{C}_{4}=$ & 0.40 & 0.43 & 0.41 & 0.40 & 0.39 \\
\hline $\mathrm{C}_{4}=/ \mathrm{C}_{3}=$ & 0.53 & 0.42 & 0.45 & 0.41 & 0.43 \\
\hline
\end{tabular}

However, in all cases, this ratio is by far less than 1, indicating that direct cracking of hexene is not the dominant monomolecular reaction. This observation then give rise to two conclusions. First, when the monomolecular mechanism occurs on these samples, it should be dominantly via isomerization- $\beta$-scission pathway. 
Second, butenes should be produced mainly through bimolecular mechanism, since the only monomolecular pathway to produce butene is by $\beta$-scission of hexene which will give a butene/ethene molar ratio of 1:1. Then, the molar yield of butenes should be able to indicate the degree of bimolecular reactions. Under such circumstance, the ratio of $\mathrm{C}_{4}{ }^{2} / \mathrm{C}_{3}{ }^{=}$could be used as a comparative basis to discuss the relative extension of bimolecular reactions with respect to all cracking. The higher this ratio, the higher proportion of bimolecular cracking. As is shown in Table 4.2, Z5-TPA, being the representative of standard ZSM-5, shows a $\mathrm{C}_{4}=/ \mathrm{C}_{3}=$ ratio of 0.53 , while other samples showed this ratio between 0.41 and 0.45 . The lower values of the ZSM-5 samples prepared with alcohols as porefilling agents mean that bimolecular reactions are slightly less favored, in comparison with ZSM-5 prepared using TPA as OSDA, further indicating higher portion of aluminum sited in the 10-ring channel than in the latter case.

At this point, it is possible to say that using $n$-hexene cracking as probe reaction, under proper conditions, the molar yield ratio of butenes and propene could reflect the monomolecular and bimolecular reaction in zeolite framework. Considering that the zeolites present similar physiochemical properties, it is likely to conclude that the difference observed could be the result of different location of aluminum in zeolites. Thus, the n-hexene cracking could be an effective probe reaction to evaluate the aluminum distribution in zeolite framework and could be further utilized to evaluate other synthetic attempts to tune the aluminum distribution.

\subsection{Boron-assisted synthesis of ZSM-5}

In order to develop a synthesis strategy that could tune aluminum distribution in zeolites, it is necessary to think about the driving force of aluminum incorporation in the zeolite framework. In a zeolite, aluminum tends to be located near the positive charges, either organic ammonium cations in OSDAs or alkaline cations, to balance the negative charge of the $\mathrm{AlO}_{4}{ }^{-}$tetrahydron. Then, it becomes reasonable that this affinity to positive charges should not be limited to only aluminum but should apply to other $\mathrm{T}^{\mathrm{III}}$ atoms. If this is true, one way to control the aluminum distribution through incorporation of a second trivalent 95 
heteroatom, which could compete with aluminum during nucleation and crystallization. Boron is taken as the example here to illustrate the idea due to three advantages. One of the advantages is that it is the nearest IIIA element to aluminum and it could form stable hydrate anions in water solution, which could effectively participate in zeolite nucleation. Another advantage is the high tendency of boron to be incorporated into zeolite framework. In fact, boron alone can already serve as $\mathrm{T}^{\mathrm{III}}$ source and facilitate nucleation of various zeolites, whose boron content is high, indicating that boron could not only enable the nucleation but also be incorporated in the zeolite framework. ${ }^{20-22}$ The third advantage of introducing boron in zeolite framework is the instability of boron in a silicate structure and the possibility to be fully removed from the framework position by post-synthesis methods. Indeed, the small atomic diameter of boron significantly reduces the stability of B-O-Si connection and during a postsynthetic calcination it can be eliminated in a large scale, leaving vacancies in its original position. In fact, this property of boron has been previously utilized to synthesize boron-containing zeolite as precursor for second step insertion of other heteroatoms that are difficult to introduce in zeolite framework by direct synthesis. ${ }^{23,24}$ Considering the above advantages, we though it should be possible to prepare ZSM-5 with different aluminum distribution by synthesizing ZSM-5 with the presence of both aluminum and boron and then eliminate boron through post-synthesis calcination followed by washing with water solution (see Scheme 4.5) provided that there is a different preference of aluminum and boron for different $T$ positions. The hypothesis is based on the following reasoning. Since boron, as a trivalent species, has a high tendency to be incorporated in zeolite framework when forming zeolite nucleus, the $\mathrm{BO}_{4}^{-}$should approach the cations similarly as $\mathrm{AlO}_{4}^{-}$, either toward ammonium in OSDA or alkaline cations. Then, if the total amount of cations is lower than the total amount of $\mathrm{BO}_{4}^{-}$and $\mathrm{AlO}_{4}$, there should inevitably be a competition between boron and aluminum in approaching those cations and be finally incorporated in the zeolite framework. In this sense, boron should occupy the location of part of aluminum that originally would be incorporated in the zeolite. At this point, it is still not clear whether boron or aluminum is more preferred by zeolite framework, but it is reasonable to assume that such replacement would be non-random since 
different $\mathrm{T}$ sites would show different bond angles and bond energies, which would mean different stability. Although trivial, such difference should influence the relative stabilities of boron located in different $\mathrm{T}$ sites, resulting in preferential positioning of boron, which is likely to further influence the aluminum location (boron regioselectivity). Moreover, due to its instability in zeolite framework, boron should be easily removed from the ZSM-5 prepared in such way, resulting in a ZSM-5 with controlled aluminum distribution.

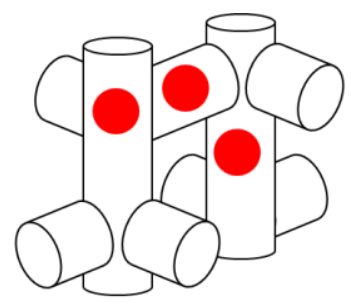

Boron

Aluminum

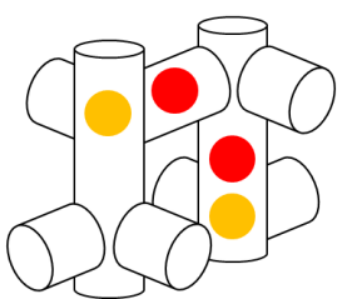

Deboronation

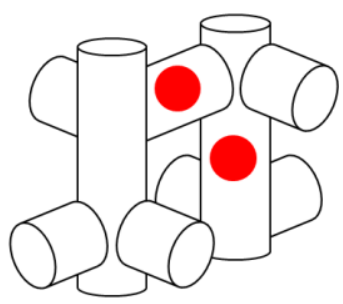

Scheme 4.5 Schematic illustration of the concept of introducing boron in the ZSM-5 synthesis and its influence on aluminum siting.

In fact, the incorporation of boron in the synthesis of aluminosilicate zeolites is not a novel concept and it has been reported for instance, to enhance stability against coke formation within ZSM-5. ${ }^{25-28}$ The improvement of such resistance to coke was mainly attributed to either weak acidity introduced or weakening of aluminum acidity caused by presence of boron. Nevertheless, as discussed previously, boron is not stable when incorporated in zeolite framework and can be eliminated in a large scale by post-synthesis calcination. Then, the amount of boron that remained in zeolite should be much less than in the as-prepared 97 
materials and the weak acidity caused by the bridge hydroxyl group directly connected to boron site should be limited as well. Meanwhile, the weak acidity of boron is hardly capable of catalyzing carbocation-based reactions since the acid strength is too low to initiate the formation of carbocations. Thus, there must be other explanation for such improvement of catalytic performance of the zeolite.

\subsubsection{Competitive occupation of boron and aluminum in MFI unit- cell}

Before applying the idea of boron-assisted synthesis into action, it is necessary to first test the possibility that boron can potentially present a preferential incorporation in some $\mathrm{T}$ positions when compared with aluminum. There is limited number of techniques that could be employed to investigate this competition experimentally. Thus, a DFT calculation was performed to investigate this hypothesis in prior to experimental attempts.

Among all 12 crystallographically distinguishable T-sites in MFI structure, 8 of them are located facing intersections, being only T4 and T10 located in the sinusoidal 10-ring channel, while T8 and T11 are located in the straight 10-ring channel. 


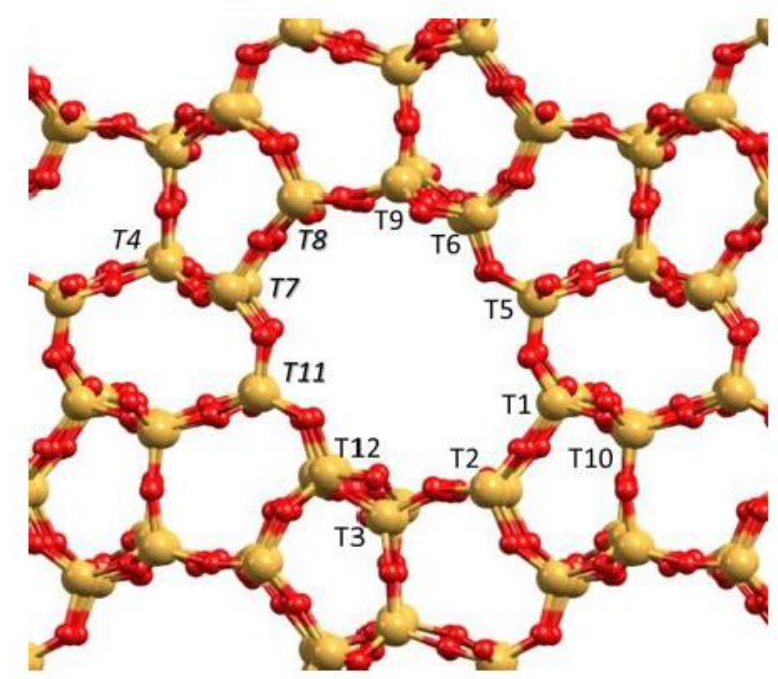

Scheme 4.6 Illustration of 12 different T-sites locations in MFI framework

Previous studies have reported that the energetic differences are not significant among these $\mathrm{T}$ sites, being only $9 \mathrm{kcal} / \mathrm{mol}$ between the highest and the lowest. Thus, one could not expect a large difference in stabilization energy when comparing crystal structures with different composition. To begin with, a MFI unit cell with either aluminum or boron as the only heteroatom was considered to study the individual influence of these two elements on the stability of the framework and whether there is preferential locations for each one of them. The calculation was performed on a typical MFI unit cell whose composition was set as $\mathrm{Al}_{\mathrm{x}} \mathrm{Si}_{96-\mathrm{x}} \mathrm{O}_{192}$ and $\mathrm{B}_{\mathrm{x}} \mathrm{Si}_{96-\mathrm{x}} \mathrm{O}_{192}$, where the value of $\mathrm{x}(1,2,4)$ correspond to $\mathrm{T}^{\mathrm{IV}} / \mathrm{T}^{\mathrm{III}}(95,47,23)$. Each channel intersection was filled with tetraethylammonium to simulate the positive charge of the OSDA. The potential locations of each element at different $\mathrm{T}$ sites were first investigated. The calculation was performed simulating the system in where ammonium is the only source of positive charge, which corresponds to $\mathrm{Na}$-free synthesis. The relative stabilities of all distributions with respect to the most stable distribution are summarized in Table 4.3. 
The results are in agreement with the previous reported studies suggesting that the energies of each state are not significantly different when aluminum is the heteroatom. The difference is within $4 \mathrm{kcal} / \mathrm{mol}$ at high $\mathrm{Si} / \mathrm{Al}$ ratio and 8 $\mathrm{kcal} / \mathrm{mol}$ at lower $\mathrm{Si} / \mathrm{Al}$. The only exception is when the unit cell has four $\mathrm{Al}$, equal to $\mathrm{Si} / \mathrm{Al}=23$, and all of them are located at $\mathrm{T} 7$ position. In such case, the relative stabilization energy is $16.3 \mathrm{kcal} / \mathrm{mol}$, indicating a clearly unstable composition of the system. This result indicates that aluminum has no preference in locating in each $\mathrm{T}$ sites when it is the only heteratom, in accordance with the proposal that the location of aluminum should be more determined by the synthesis procedure. ${ }^{29-31}$ Although $\mathrm{T} 7$ seems unfavored by $\mathrm{Al}$, considering that this is merely one of the eight $\mathrm{T}$ sites located in intersection, it is not influencing the conclusion. Indeed, at the highest aluminum content, there are six different positions differing in relative stability by less than $3 \mathrm{kcal} / \mathrm{mol}$ : T1T3 and T12 at the channel intersections and T4 and T11 within the 10-ring channels.

Table 4.3 Relative stability of aluminum and B distributions (in $\mathrm{kcal} / \mathrm{mol}$ ) of Al-ZSM-5 and BZSM-5 zeolite models with different $\mathrm{Si} / \mathrm{Al}$ and $\mathrm{Si} / \mathrm{B}$ ratios

\begin{tabular}{|c|c|c|c|c|c|c|}
\hline & \multicolumn{3}{|c|}{$\mathrm{Si} / \mathrm{Al}$} & \multicolumn{3}{|c|}{$\mathrm{Si} / \mathrm{B}$} \\
\hline & 95 & 47 & 23 & 95 & 47 & 23 \\
\hline $\mathrm{T} 1$ & 0.0 & 1.2 & 1.6 & 3.4 & 3.0 & 9.0 \\
\hline T2 & 3.1 & 6.4 & 2.6 & 4.9 & 9.3 & 7.4 \\
\hline T3 & 2.6 & 5.7 & 0.4 & 6.4 & 11.4 & 13.2 \\
\hline T4 & 1.4 & 0.6 & 2.8 & 5.9 & 7.8 & 22.5 \\
\hline T5 & 1.7 & 0.9 & 5.4 & 0.7 & 0.0 & 6.7 \\
\hline T6 & 4.0 & 8.0 & 6.4 & 2.1 & 2.1 & 0.0 \\
\hline $\mathrm{T} 7$ & 3.3 & 8.3 & 16.3 & 3.4 & 6.6 & 17.4 \\
\hline
\end{tabular}




\begin{tabular}{lllllll} 
T8 & 1.9 & 3.6 & 4.6 & 5.4 & 9.5 & 22.0 \\
T9 & 3.1 & 5.8 & 5.3 & 3.5 & 6.1 & 6.1 \\
T10 & 1.5 & 4.5 & 5.4 & 0.0 & 0.5 & 2.2 \\
T11 & 1.3 & 0.0 & 0.9 & 1.9 & 1.4 & 7.8 \\
T12 & 0.1 & 0.1 & 0.0 & 3.5 & 5.1 & 8.6 \\
\hline
\end{tabular}

On the other hand, in the boron containing model, the energetic differences become much higher. In the case of a Si-rich model the difference can reach 6.4 $\mathrm{kcal} / \mathrm{mol}$, whereas when increasing boron content in the unit cell, the stabilization energy was significantly different. In the model of $\mathrm{Si} / \mathrm{B}=47, \mathrm{~T} 1$, T5, T6, T9 and T10 remain energetically similar to the high-Si model, while the other sites are less stable, presenting a doubled energetical difference. In the model of $\mathrm{Si} / \mathrm{B}=23$, the difference among the different $\mathrm{T}$ sites is even larger, being T4 and T8 the most unstable sites $(22.5$ and $22.0 \mathrm{kcal} / \mathrm{mol}$ less stable than T7). In the other sites, T6, T9 and T10 barely changed compared to Si-rich models. The energetic difference among $\mathrm{T}$ sites in low-Si models is obviously larger in the $\mathrm{Si}-\mathrm{B}$ system than the $\mathrm{Si}-\mathrm{Al}$ system. This indicates that boron, contrary to $\mathrm{Al}$, has prefered positions within the MFI framework. It is noteworthy that the most unstable sites for boron (T4 and T8) are both in the 10-ring channel. If this is true, it is reasonable to think that in a borosilicate MFI, boron should have a tendency to avoid occupancy in the 10-ring channels and should be more preferentially located in the intersections.

If one put together the results obtained above, it becomes obvious that the preferential positioning of aluminum and boron varies along changing the $\mathrm{T}^{\mathrm{IV}} / \mathrm{T}^{\mathrm{III}}$ ratio. In Si-rich models, either aluminum or boron could freely be located in all sites, being the other sites occupied by Si. Since Si-O-Si is more stable than $\mathrm{T}^{\mathrm{III}}-\mathrm{O}-\mathrm{Si}$, the overall framework is stabilized anyway. When more $\mathrm{T}^{\mathrm{III}}$ heteroatoms are introduced, the percentage of heteroatoms in the unit cell is increased, which will decrease the stability by the presence of more $\mathrm{T}^{\mathrm{III}}$-O-Si bonds. Moreover, the presence of more than one $\mathrm{T}^{\mathrm{III}}$ atoms will generate 
competition between them. Since each intersection would have only one positive charge and $\mathrm{T}^{\mathrm{III}}$ should always tend to be located near this positive charge, the incorporation of other $\mathrm{T}^{\mathrm{III}}$ atoms would be forced to be located at thermodynamically unfavored $\mathrm{T}$ sites, resulting in high energetic instability.

This preliminary investigation supports the hypothesis that boron and aluminum should have preference toward different $\mathrm{T}$ sites in the unit cell. It is then reasonable to consider the system where both aluminum and boron are introduced. In order not to be confused by energetic differences caused by different aluminum and boron amounts, two aluminum and two boron were introduced into the system with a fixed $\mathrm{T}^{\mathrm{IV}} / \mathrm{T}^{\mathrm{III}}$ ratio of 23 . Four $\mathrm{T}^{\mathrm{III}}$ atoms in one unit-cell will produce a huge number of possibilities of locating situations that will be difficult to enumerate. Thus, only those possibilities with representative values are listed in Table 4.4. As it is shown in the table, the most stable systems (within $\sim 4 \mathrm{kcal} / \mathrm{mol}$ ) contain boron mostly located either in T6 or T10, with no obvious preferences for aluminum. Compared with previous results of individual substitution of silicon by only aluminum or boron (see Table 4.3), it is generally possible to say that by replacing part of aluminum by boron, the most stable configurations always led to a destablization of the system by several $\mathrm{kcal} / \mathrm{mol}$. It is also important to notice that three out of six most stable distributions of $\mathrm{Al}$, whose relative energy differ by less than $3 \mathrm{kcal} / \mathrm{mol}$, have aluminum located at T4, T8 and T11, all within the 10-ring channel.

Table 4.4 Relative stability of aluminum and boron distributions (in $\mathrm{kcal} / \mathrm{mol}$ ) of Al-B-ZSM-5 zeolite models with $\mathrm{Si} /(\mathrm{Al}+\mathrm{B})=23$ and $\mathrm{Al} / \mathrm{B}=1$

\begin{tabular}{ccc|ccc|lll}
\hline $\mathrm{Al}$ & $\mathrm{B}$ & $\mathrm{E}_{\text {rel }}$ & $\mathrm{Al}$ & $\mathrm{B}$ & $\mathrm{E}_{\text {rel }}$ & $\mathrm{Al}$ & $\mathrm{B}$ & $\mathrm{E}_{\text {rel }}$ \\
\hline $\mathrm{T} 1$ & $\mathrm{~T} 1$ & 3.6 & $\mathrm{~T} 4$ & $\mathrm{~T} 5$ & 5.3 & $\mathrm{~T} 11$ & $\mathrm{~T} 6$ & 3.2 \\
$\mathrm{~T} 2$ & $\mathrm{~T} 2$ & 6.5 & $\mathrm{~T} 4$ & $\mathrm{~T} 6$ & 1.7 & $\mathrm{~T} 11$ & $\mathrm{~T} 10$ & 4.6 \\
$\mathrm{~T} 3$ & $\mathrm{~T} 3$ & 6.8 & $\mathrm{~T} 4$ & $\mathrm{~T} 10$ & 1.9 & $\mathrm{~T} 12$ & $\mathrm{~T} 5$ & 5.9 \\
$\mathrm{~T} 4$ & $\mathrm{~T} 4$ & 8.7 & $\mathrm{~T} 4$ & $\mathrm{~T} 11$ & 7.9 & $\mathrm{~T} 12$ & $\mathrm{~T} 6$ & 1.2 \\
$\mathrm{~T} 5$ & $\mathrm{~T} 5$ & 5.1 & $\mathrm{~T} 5$ & $\mathrm{~T} 6$ & 10.5 & $\mathrm{~T} 12$ & $\mathrm{~T} 10$ & 3.3
\end{tabular}




\begin{tabular}{ccc|ccc|ccc} 
T6 & T6 & 3.6 & T5 & T10 & 4.8 & T12 & T11 & 7.3 \\
T7 & T7 & 15.9 & T5 & T11 & 7.2 & T6 & T4 & 16.2 \\
T8 & T8 & 13.8 & T8 & T5 & 10.7 & T6 & T5 & 11.9 \\
T9 & T9 & 7.5 & T8 & T6 & 1.4 & T6 & T8 & 13.3 \\
T10 & T10 & 3.2 & T8 & T10 & 7.9 & T6 & T10 & 3.6 \\
T11 & T11 & 7.0 & T8 & T11 & 9.0 & T6 & T11 & 8.2 \\
T12 & T12 & 8.4 & T10 & T5 & 9.7 & T6 & T12 & 9.8 \\
T1 & T5 & 5.5 & T10 & T6 & 9.5 & T2 & T6 & 0.0 \\
T1 & T6 & 7.2 & T10 & T11 & 8.5 & T3 & T6 & 3.2 \\
T1 & T10 & 1.3 & T10 & T4 & 11.9 & T7 & T6 & 10.7 \\
T1 & T11 & 4.1 & T11 & T5 & 9.5 & T9 & T6 & 3.8 \\
\hline
\end{tabular}

So far, the preliminary investigation of aluminum and boron siting through DFT calculation suggested that, from thermodynamic point of view, aluminum is nonselective to be located among all $\mathrm{T}$ sites, while boron has a tendency to avoid occupying $\mathrm{T}$ sites in 10-ring channels and concentrates in intersections. If this is true, and considering the case where OSDA is the only source of positive charges, the percentage of aluminum being located in the channel should be higher due to the preferential occupation of boron in the intersection. Then, it could be possible to rationalize the synthesis of ZSM-5 based on this preliminary understanding.

\subsubsection{Materials synthesis}

When attempting the synthesis of ZSM-5, several aspects need to be taken into account if one intends to apply the results from DFT calculation into practice. First, the selection of $\mathrm{Si} / \mathrm{Al}$ molar ratio for synthesis gels and resultant material must be considered. From the previous calculations, $\mathrm{T}^{\mathrm{IV}} / \mathrm{T}^{\mathrm{III}}$ ratio is significantly influencing the relative stability, and only under low $\mathrm{T}^{\mathrm{IV}} / \mathrm{T}^{\mathrm{III}}$ ratios is it possible 
to observe differences in relative stability. Thus, the overall $\mathrm{T}^{\mathrm{IV}} / \mathrm{T}^{\mathrm{III}}$ in the synthesis gel should be equal or lower than 23 . Second, the presence/absence of $\mathrm{Na}^{+}$should play a critical role. Although $\mathrm{Na}^{+}$could favor the zeolite nucleation and it is considered as important component in ZSM-5 synthesis, it would introduce extra positive charges that would inevitably interfere with siting of $\mathrm{T}^{\mathrm{III}}$ atoms. Third, the selection of the starting silica and alumina sources must also be rationalized. Since siting of aluminum includes an atomic-level structure manipulation, it should be better if the starting silica source could form highly dispersed $\mathrm{SiO}_{4}{ }^{-}$species without potential presence of dimers or polymers.

For these reasons, the synthesis conditions are set as follows. TEOS, $\mathrm{Al}(\mathrm{OH})_{3}$ and boric acid are adopted as starting sources. The slow hydrolysis of TEOS in water solution will release isolated single $\mathrm{Si}$ tetrahydron, which can freely affiliate toward OSDA to form OSDA-Si species. While in other pre-aggregated starting materials such as silica sol, sodium silicate or amorphous silica, Si is already forming dimers and polymers, which could either go through dissemble or directly coordinated to OSDA, issues that can generate uncertainty on the heteroatom incoporation.

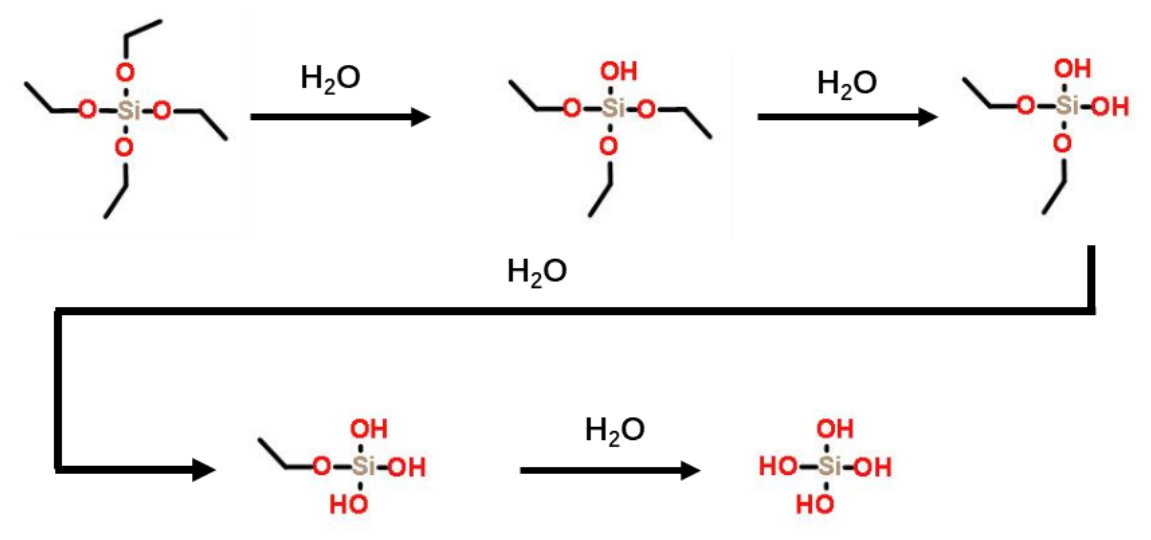

Scheme 4.7 Stepwise hydrolysis of TEOS generates single $\mathrm{SiO}_{4}$ tetrahydron

The synthesis gel contains $\mathrm{Si} /(\mathrm{Al}+\mathrm{B})$ ratio of 23 and $\mathrm{Al} / \mathrm{B}$ of 1 in order to force an equilibrated competition between aluminum and boron. In the as-synthesized 
materials, both aluminum and boron should be coordinated, while postsynthesis calcination treatment should facilitate efficient elimination of boron. For comparison purpose, two ZSM-5 samples with only aluminum and B as T $\mathrm{T}^{\mathrm{III}}$ atoms were also prepared following the same procedure. To further compare the influence of aluminum and boron content, a series of samples were synthesized using similar methodology with various $\mathrm{Si} / \mathrm{Al}$ and $\mathrm{Si} / \mathrm{B}$ molar ratios (see Table 4.5).

\subsubsection{Materials characterization}

From PXRD patterns, it is confirmed that all samples possess pure phase of MFI without presence of impurities and/or amorphous phases (see Figure 4.4). This has been further confirmed by the similar microporous volumes measured by $\mathrm{N}_{2}$ adsorption/desorption characterization, being all between $0.16-0.17 \mathrm{~cm}^{3} / \mathrm{g}$ (see Table 4.6).

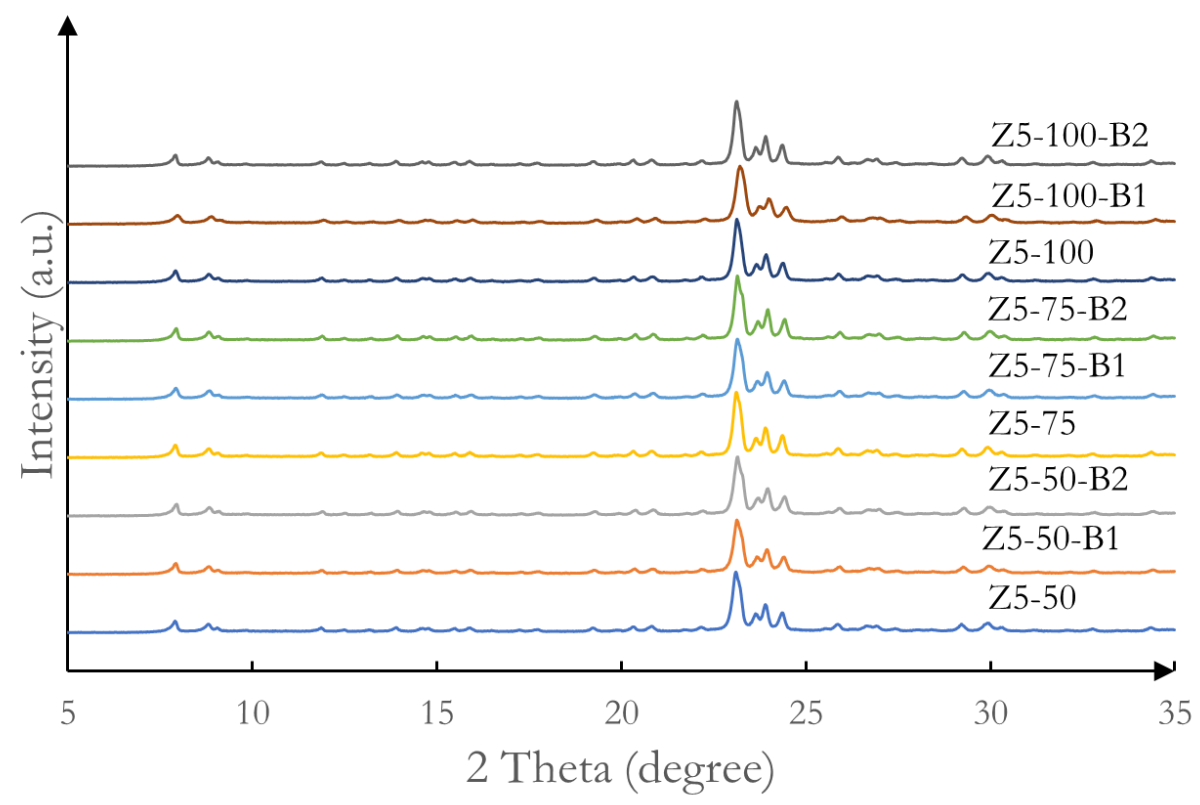


Figure 4.4 PXRD patterns of the ZSM-5 samples synthesized with different $\mathrm{Si} / \mathrm{Al}$ and $\mathrm{Si} / \mathrm{B}$ molar ratios.

The crystal morphologies of all samples are sphere-like with particle sizes around $100 \mathrm{~nm}$ (see Figure 4.5). However, the presence of small particles on the external surface of Z5-50-B1 and Z5-50-B2 samples are observed (see Figure 4.5, b, c). If this represents a decrease of the crystal sizes in these samples, then they would not be proper for comparison studies. Thus, the internal sections of these samples have been analyzed by FIB-SEM (see Figure 4.5, j, k). After exposing the internal part, the crystals are confirmed to be solid inside, which means that the crystals could be considered with a size of $100 \mathrm{~nm}$, and the small particles are only substructures on the external surface. Indeed, such substructures inevitably increased the external surface area of the samples from around 50 to $80 \mathrm{~m}^{2} / \mathrm{g}$. However, this difference is not observed in other cases and should not be influencing significantly the catalytic test, since the bulk particle size is merely $100 \mathrm{~nm}$ which is small enough to eliminate intracrystal diffusion limitations. Thus, it is possible to say that crystallographically all samples are analogous for further studies. 

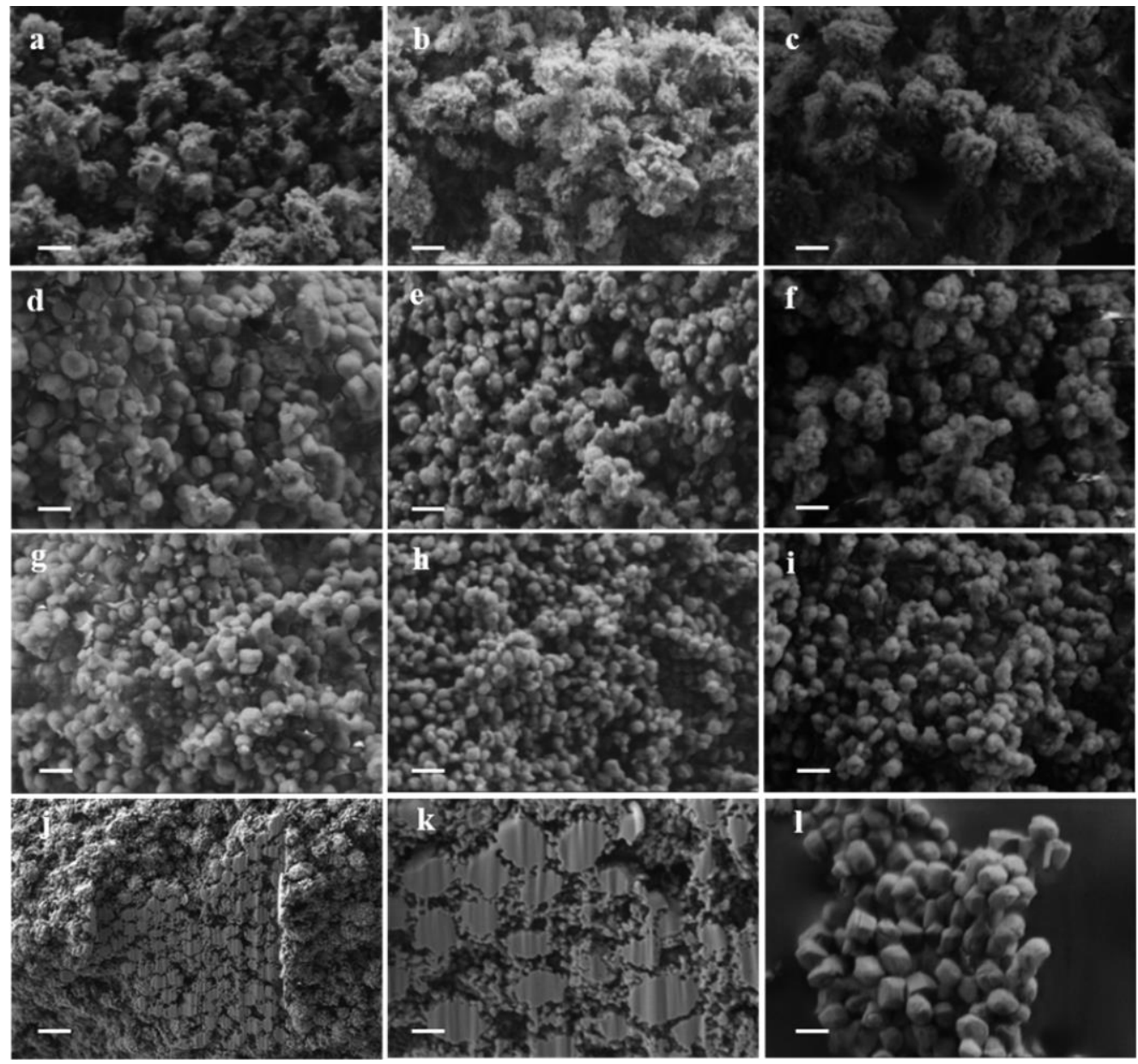

Figure 4.5 SEM images of ZSM-5 samples: (a) Z5-50; (b) Z5-50-B1; (c) Z5-50-B2; (d) Z5-75; (e) Z5-75-B1; (f) Z5-75-B2; (g) Z5-100; (h) Z5-100-B1; (i) Z5-100-B2; (j, k) Z5-50-B1; (l) Z5-pureB.

The scale bar in the images represents a length of $200 \mathrm{~nm}$.

The composition of as-synthesized samples has been analyzed by elemental and chemical analyses. From elemental analysis, the organic part of the material has a $\mathrm{C} / \mathrm{N}$ atomic ratio of 12 , which implies that the OSDA is well-preserved in the zeolites. The OSDA contents of all samples are in the range of $11-12 \%$ (see Table 4.5), equal to four OSDAs per unit cell. This indicates that the amount of 
OSDA per unit-cell is the same as the model adopted in the previous DFT calculations.

Table 4.5 OSDA content and textural properties of ZSM-5 samples synthesized with different $\mathrm{Si} / \mathrm{Al}$ and $\mathrm{Si} / \mathrm{B}$

\begin{tabular}{llllll}
\hline Sample & $\begin{array}{l}\text { OSDA } \\
\left(\mathrm{wt}^{\%} \%\right)\end{array}$ & $\begin{array}{l}\mathrm{T}_{\text {total }} / \text { OSDA } \\
\text { Z5-pureB }\end{array}$ & $\begin{array}{l}\mathrm{S}_{\text {BET }} \\
\left(\mathrm{m}^{2} / \mathrm{g}\right)\end{array}$ & $\begin{array}{l}\mathrm{V}_{\text {micro }} \\
\left(\mathrm{cm}^{3} / \mathrm{g}\right)\end{array}$ & $\begin{array}{l}\mathrm{S}_{\text {ext }} \\
\left(\mathrm{m}^{2} / \mathrm{g}\right)\end{array}$ \\
Z5-50 & 11.47 & 24.0 & 401 & 0.17 & 53 \\
Z5-50-B1 & 11.28 & 24.4 & 364 & 0.17 & 49 \\
Z5-50-B2 & 11.34 & 24.3 & 400 & 0.16 & 83 \\
Z5-75 & 11.57 & 23.7 & 378 & 0.16 & 41 \\
Z5-75-B1 & 11.14 & 24.8 & 391 & 0.17 & 61 \\
Z5-75-B2 & 11.62 & 23.6 & 395 & 0.17 & 44 \\
Z5-100 & 11.45 & 24.0 & 375 & 0.16 & 43 \\
Z5-100- & 11.31 & 24.4 & 390 & 0.17 & 38 \\
B1 & & & & & 41 \\
Z5-100- & 11.78 & 23.3 & 388 & 0.17 & 47 \\
B2 & & & & &
\end{tabular}

According to the aluminum and boron content measured by ICP, in all samples both the two $\mathrm{T}^{\mathrm{III}}$ atoms were successfully incorporated in reasonable amount. In the case of Z5-50-B1, Z5-50-B2, Z5-75-B2 and Z5-100-B2, the overall Si/ (Al+B) is close to 23 (see Table 4.6). In other samples, due to the lack of total $\mathrm{T}^{\mathrm{III}}$ atoms in the synthesis gel, the $\mathrm{Si} /(\mathrm{Al}+\mathrm{B})$ is higher than 23 , being proportional to the ratio introduced in the synthesis gels. The composition of the samples suggests that in the case of those samples synthesized with total $\mathrm{Si} /(\mathrm{Al}+\mathrm{B})$ lower than 23, the amount of $\mathrm{T}^{\mathrm{III}}$ incorporated in the final solids is limited by the amount of OSDA incorporated while in those gels with $\mathrm{Si} /(\mathrm{Al}+\mathrm{B})$ higher than 23 , all $\mathrm{T}^{\mathrm{III}}$ 
atoms could be incorporated in the crystal without strong competition. Importantly, in those samples with low $\mathrm{Si} /(\mathrm{Al}+\mathrm{B})$, both aluminum and boron could be incorporated in the framework without either being dominant. In Z550-B1 and Z5-50-B2, the as-synthesized zeolites possess equal amount of aluminum and boron, while Z5-75-B2 and Z5-100-B2 have higher percentage of boron than aluminum, which could be a result of the high $\mathrm{B} / \mathrm{Al}$ ratio in synthesis gel.

Table 4.6 Chemical compositions of ZSM-5 samples synthesized with different $\mathrm{Si} / \mathrm{Al}$ and $\mathrm{Si} / \mathrm{B}$

\begin{tabular}{llll|lll|ll}
\hline \multicolumn{5}{c|}{ Composition gel } & \multicolumn{2}{c|}{ As-synthesized sample } & \multicolumn{2}{c}{ Deboronated } \\
Sample & Si/Al & Si/B & $\mathrm{T}^{\mathrm{IV}} / \mathrm{T}^{\mathrm{III}}$ & $\mathrm{Si} / \mathrm{Al}$ & $\mathrm{Si} / \mathrm{B}$ & $\mathrm{T}^{\mathrm{IV}} / \mathrm{T}^{\mathrm{III}}$ & $\mathrm{S} / \mathrm{Al}$ & $\mathrm{Si} / \mathrm{B}$ \\
\hline Z5-pureB & - & 50 & 50 & - & 45 & 45 & - & 107 \\
Z5-50 & 50 & - & 50 & 43 & - & 43 & 44 & - \\
Z5-50-B1 & 50 & 50 & 25 & 44 & 49 & 23.2 & 46 & 82 \\
Z5-50-B2 & 50 & 15 & 11.5 & 47 & 49 & 24.0 & 48 & 96 \\
Z5-75 & 75 & - & 75 & 58 & - & 58 & 58 & - \\
Z5-75-B1 & 75 & 50 & 30 & 60 & 67 & 31.7 & 61 & 117 \\
Z5-75-B2 & 75 & 15 & 12.5 & 72 & 40 & 25.7 & 70 & 64 \\
Z5-100 & 100 & - & 100 & 86 & - & 86 & 86 & - \\
Z5-100-B1 & 100 & 50 & 33.3 & 87 & 77 & 40.8 & 90 & 149 \\
Z5-100-B2 & 100 & 15 & 13.0 & 90 & 39 & 27.2 & 92 & 78 \\
\hline
\end{tabular}

After confirming the analogous physicochemical properties of all samples, it is necessary to characterize the state of aluminum in the materials. ${ }^{27} \mathrm{Al}$ MAS NMR spectra of all samples showed only appearance of the peak corresponding to tetrahydrally coordinated aluminum (45-65ppm), without presence of EFAl (0 109 
ppm) (see Figure 4.6). In order to see qualitatively the distribution of aluminum, deconvolution of aluminum spectra was performed, selecting five different peaks at 52, 53, 54, 56 and $58 \mathrm{ppm}$, as it has been previously described in the literature. ${ }^{16}$
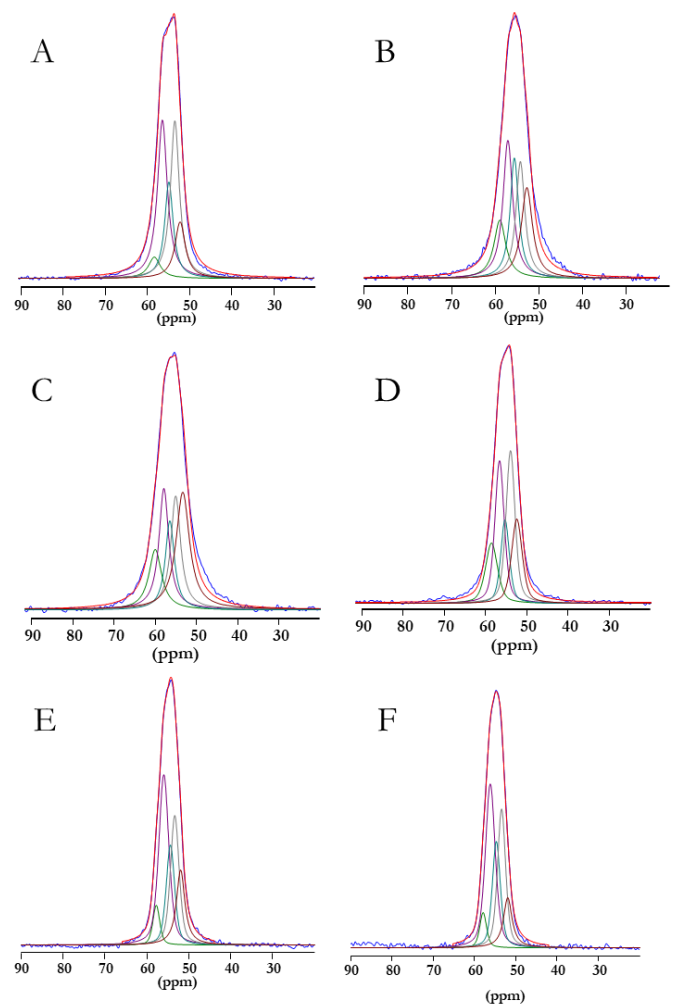

Figure 4.6 Deconvolution of the ${ }^{27} \mathrm{Al}$ MAS NMR spectra of (A) Z5-50, (B) Z5-50-B1, (C) Z5-75, (D) Z5-75-B1, (E) Z5-100, and (F) Z5-100-B1.

Table 4.8 Relative peak areas of the ${ }^{27} \mathrm{Al}$ MAS NMR spectra of different ZSM-5 samples 


\begin{tabular}{llllll}
\hline & $\begin{array}{l}\mathrm{Al}(\mathrm{a}) \\
{[52]^{\mathrm{a}}}\end{array}$ & $\begin{array}{l}\mathrm{Al}(\mathrm{b}) \\
{[53]^{\mathrm{a}}}\end{array}$ & $\begin{array}{l}\mathrm{Al}(\mathrm{c}) \\
{[54]^{\mathrm{a}}}\end{array}$ & $\begin{array}{l}\mathrm{Al}(\mathrm{d}) \\
{[56]^{\mathrm{a}}}\end{array}$ & $\begin{array}{l}\mathrm{Al}(\mathrm{e}) \\
{[58]^{\mathrm{a}}}\end{array}$ \\
\hline Z5-50 & 13 & 30 & 18 & 33 & 6 \\
Z5-50-B1 & 21 & 20 & 20 & 26 & 13 \\
Z5-75 & 28 & 21 & 15 & 22 & 14 \\
Z5-75-B1 & 17 & 28 & 13 & 30 & 12 \\
Z5-100 & 15 & 24 & 19 & 36 & 6 \\
Z5-100- & 12 & 26 & 20 & 36 & 5 \\
B1 & & & & & \\
\hline
\end{tabular}

${ }^{a}$ The numbers in brackets represent the chemical shift (ppm) for each peak

The curve fittings and relative peak areas reveal that the relative concentration of the five peaks differs noticeably from each other. The only spectra showing similar peak concentrations are Z5-100 and Z5-100-B1. This is likely to be caused by the low amount of aluminum introduced in the synthesis, which resulted in free siting of aluminum and boron since they can barely give an influence. In the case of other samples, although clear differences are observed, there is no definitive trend among the samples associated to the presence of boron in Z5-50 and Z5-75 series. Furthermore, as discussed previously, the 12 non-equivalent tetrahedral T-sites in MFI structure raised difficulty in assigning the five peaks to their exact locations. Then, it is reasonable to conclude that there are possible differences in the aluminum siting in the samples, but the current limitation of ${ }^{27} \mathrm{Al}$ MAS NMR does not allow to achieve certain conclusions on how aluminum atoms are distributed. 


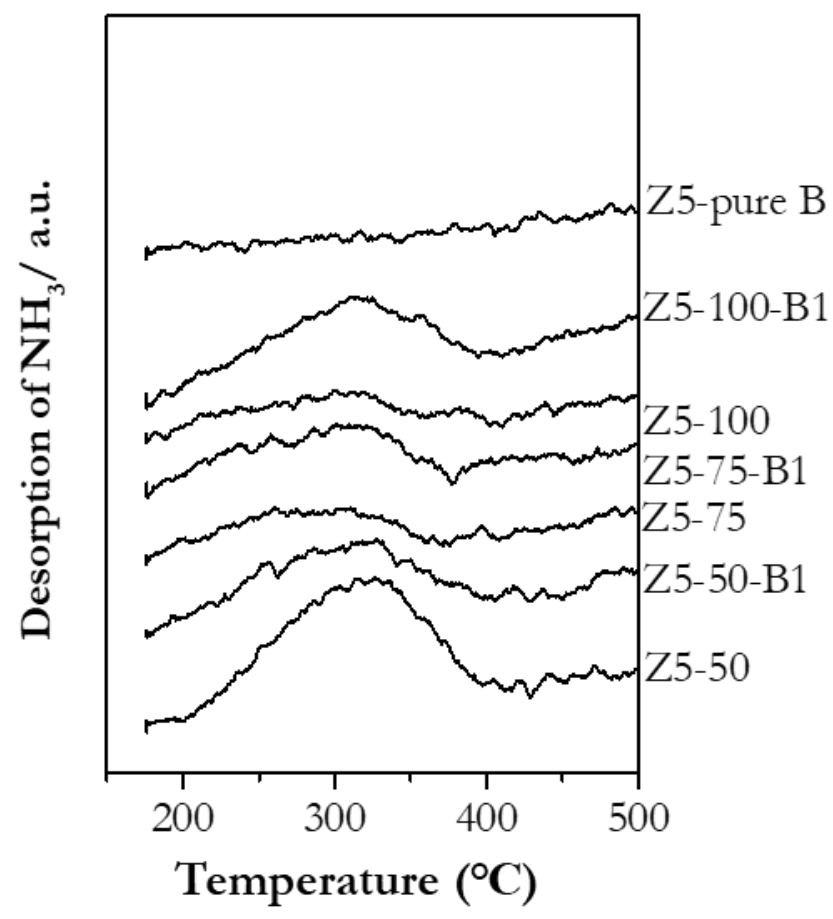

Figure 4.7 $\mathrm{NH}_{3}$-TPD profiles for different ZSM-5 samples synthesized with different $\mathrm{Si} / \mathrm{Al}$ and $\mathrm{Si} / \mathrm{B}$ molar ratios.

Acidity of all samples after deboronation has been investigated by $\mathrm{NH}_{3}$-TPD and FT-IR combined with pyridine adsorption/desorption measurements (see Figure 4.7 and 4.8). The total amount of acid sites is proportional to the aluminum content in the samples (see Table 4.7). The absence of pyridine adsorption in Si-B MFI zeolite confirmed that the residual of boron in the framework does not contribute to the measured acidity after removal of $\mathrm{B}$. 


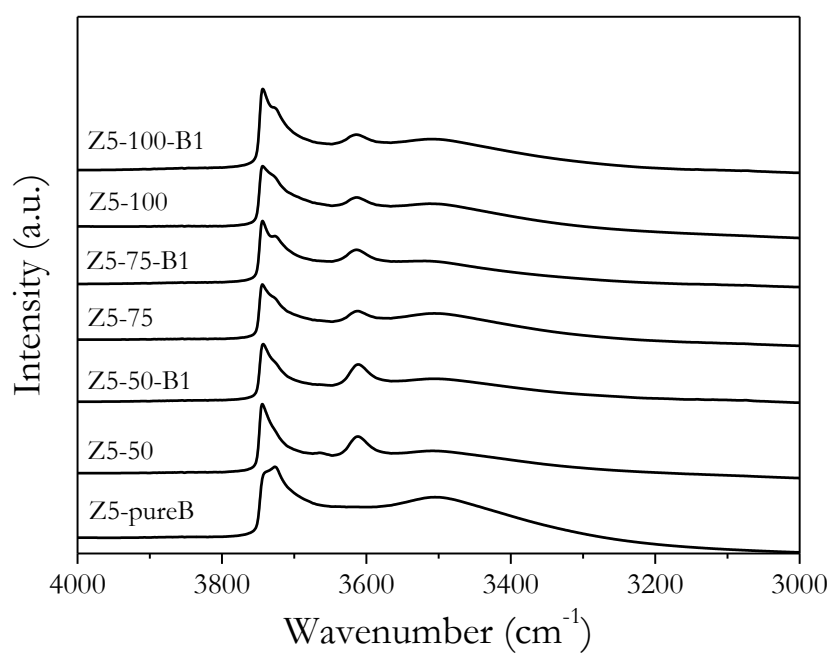

Figure 4.8 FT-IR spectra of different ZSM-5 samples synthesized with different $\mathrm{Si} / \mathrm{Al}$ and $\mathrm{Si} / \mathrm{B}$ molar ratios.

Table 4.7 Brønsted (B) and Lewis (L) acidity (mmol pyridine/g) of different ZSM-5 samples measured by FT-IR combined with pyridine adsorption and desorption at $350^{\circ} \mathrm{C}$.

\begin{tabular}{llllll}
\hline & $\mathrm{Si} / \mathrm{Al}$ & $\mathrm{Si} / \mathrm{B}$ & $\mathrm{B}^{\mathrm{a}}$ & $\mathrm{L}^{\mathrm{b}}$ & Total \\
\hline Z5-50 & 44 & - & 0.11 & 0.02 & 0.13 \\
Z5-50-B1 & 46 & 82 & 0.08 & 0.04 & 0.12 \\
Z5-75 & 58 & - & 0.09 & 0.02 & 0.11 \\
Z5-75-B1 & 61 & 117 & 0.10 & 0.00 & 0.10 \\
Z5-100 & 86 & - & 0.07 & 0.02 & 0.09 \\
Z5-100-B1 & 90 & 149 & 0.07 & 0.01 & 0.08 \\
Z5-pureB & - & 107 & 0.00 & 0.00 & 0.00 \\
\hline
\end{tabular}

a Determined by the adsorption peak at $1540 \mathrm{~cm}^{-1}$ in IR spectra.

${ }^{b}$ Determined by the adsorption peak at $1450 \mathrm{~cm}^{-1}$ in IR spectra.

113 
As described in the background introduction, when considering aluminum distribution, it should be never ignored the influence of the state of aluminum in isolated and paired forms. Thus, the measurement of aluminum pairs using UV-Vis spectra on Co-exchanged samples has been performed on Z5-50 and Z5-50-B1, the two materials possessing the lowest $\mathrm{Si} / \mathrm{Al}$ ratios, and therefore, the two samples with the highest chance of having aluminum pairs. The samples were exchanged first by $\mathrm{Na}^{+}$and then by $\mathrm{Co}^{2+}$ in order to quantify the total amount of aluminum in isolated and paired forms following the procedures described in the literature. ${ }^{32-35}$ The results are summarized in Table 4.9.

Table 4.9 $\mathrm{Co}^{2+}$-exchange experiment results of different ZSM-5 samples

\begin{tabular}{llllllll}
\hline Sample & \multicolumn{2}{c}{ Composition } & \multicolumn{6}{c}{ Co-exchange experiments (\%) } \\
& $\mathrm{Si} / \mathrm{Al}$ & $\mathrm{Si} / \mathrm{B}$ & $\mathrm{Al}_{\text {isol }}{ }^{\mathrm{b}}$ & $\mathrm{Al}_{\text {pair }}{ }^{\mathrm{c}}$ & $\mathrm{Al}_{\alpha}{ }^{\mathrm{d}}$ & $\mathrm{Al}_{\beta}{ }^{\mathrm{d}}$ & $\mathrm{Al}_{\gamma}{ }^{\mathrm{d}}$ \\
\hline Z5-50 & 44 & - & 45 & 55 & 32 & 65 & 3 \\
Z5-50-B1 & 46 & 82 & 30 & 70 & 45 & 55 & $<1$ \\
\hline
\end{tabular}

${ }^{a}$ Measured by ICP-AES.

${ }^{\mathrm{b}}$ Calculated according to the equation $\mathrm{n}\left(\mathrm{Al}_{\text {isol }}\right)=\mathrm{n}\left(\mathrm{Al}_{\text {total }}\right)-\mathrm{n}\left(\mathrm{Al}_{\text {pair }}\right)$.

$\mathrm{c}_{\mathrm{n}}\left(\mathrm{Al}_{\text {pair }}\right)=\mathrm{n}\left(\mathrm{Co}^{2+}\right)$.

dMeasured by deconvolution of UV-vis spectra of dehydrated ZSM-5.

First of all, Z5-50 showed higher percentage of isolated aluminum than Z5-50B1, regardless the position of the paried aluminum sites. Z5-50 has $45 \%$ of aluminum in isolated form, while Z5-50-B1 has only 30\%. With regard to the relative concentration of the different types of aluminum pairs in the two samples, namely $\alpha$ (at the straight 10-ring channel), $\gamma$ (at the intersection) and $\beta$ (at the sinusoidal channels), the results revealed that Z5-50 has slightly more aluminum pairs located at intersection, while Z5-50-B1 possesses more aluminum pairs in the straight channel. Aluminum pairs in sinusoidal channels can rarely be observed in both cases. One should take into account that aluminum pairs should facilitate bimolecular reactions by stabilizing better bulky intermediates. Then, when discussing only the influence of aluminum pairs, Z5- 
50-B1 should favor more bimolecular reactions. This preliminary conclusion will be included in the later discussion on the catalytic performance of the samples. In terms of the information of aluminum location from Co-exchange experiment, although the location of aluminum pairs can be characterized, the location of isolated aluminum remains unsolved. Taking into consideration the high dispersion of isolated aluminum sites, where nearly half of the aluminum are isolated species in both samples, their distribution should significantly influence the catalytic performance since each one should be effective active sites for reactants. Thus, although the location of part of aluminum could be identified, it is still required a methodology that fully identifies aluminum atoms in the intersection and in the channel.

At this point, the information acquired so far on the characterization of the ZSM-5 samples could be summarized as follows. All the samples possess high crystallinity without presence of impurities and/or amorphous phases. Although slightly different in external surface area caused by presence of substructures on external of crystals, the textural properties and crystal morphologies are similar. The acidity is comparable among samples with similar Si/Al. aluminum distributions are seemingly different according to ${ }^{27} \mathrm{Al}$ MAS NMR, but the resolution is far from being enough to give clear assignments. The distribution of aluminum between isolated and paired forms is effectively characterized using Co-exchanged experiments and the location of aluminum pairs in channel and intersection is quantified. However, the entire location of the aluminum species in the materials still remains unclear due to the lack of techniques to properly characterize isolated aluminum sites. At this point, it would be possible to adopt catalytic reactions to characterize the aluminum distributions, as previously described in the case of ZSM-5 samples synthesized with alcohols.

\subsubsection{Study on aluminum distribution via catalytic tests}

Similar as previous study of alcohol-assisted synthesized ZSM-5 samples, 1hexene cracking was conducted at $500^{\circ} \mathrm{C}$ under various contact times. Table 4.10 summarizes two experiments under which Z5-50 and Z5-50-B1 gave similar level of conversion. 
Table 4.10 Conversion and product distribution of 1-hexene cracking on Z5-50, Z5-50-B1

\begin{tabular}{|c|c|c|}
\hline Sample & Z5-50 & Z5-50-B1 \\
\hline Contact time (s) & 9.96 & 14.94 \\
\hline Conv. n-hexene (\%) & 84.3 & 84.7 \\
\hline \multicolumn{3}{|l|}{ Molar yield (\%) } \\
\hline Ethene & 13.3 & 12.9 \\
\hline Propene & 78.3 & 86.2 \\
\hline $\mathrm{C}_{4}=$ & 33.8 & 30.9 \\
\hline $\mathrm{C}_{5}=$ & 12.6 & 11.8 \\
\hline BTX & 0.63 & 0.34 \\
\hline Paraffins & 3.91 & 2.66 \\
\hline \multicolumn{3}{|l|}{ Molar yield ratios } \\
\hline $\mathrm{C}_{2}=/ \mathrm{C}_{4}=$ & 0.39 & 0.42 \\
\hline $\mathrm{C}_{4}=/ \mathrm{C}_{3}=$ & 0.43 & 0.36 \\
\hline $\mathrm{C}_{5}{ }^{=} / \mathrm{C}_{3}=$ & 0.16 & 0.14 \\
\hline
\end{tabular}

Conversion of 1 -hexene in both cases is around $85 \%$, which is normally considered too high for analyzing reaction mechanism. It should be pointed out that the target is not to maximize main reaction while minimize side reactions in order to study the mechanism of the former. On the contrary, the condition is set to maximize both main reaction and side reactions in order to distinguish preference of the catalyst toward certain reactions, especially between monomolecular and bimolecular reactions. According to the product distributions summarized in Table 4.10, the main obtained products are ethene, propene, butenes and pentenes, followed by small amounts of paraffins and aromatics. 
The $\mathrm{C}_{2}{ }^{2} / \mathrm{C}_{4}{ }^{=}$was determined to be far less than 1 , indicating that the yield of butene mainly follows the bimolecular mechanism. Then, $\mathrm{C}_{4}{ }^{=}$molar yield could be used to indicate the scale of bimolecular cracking. Due to the low yield of ethene, propene could be considered mainly produced through isomerization- $\beta$ scission route. In this sense, the $\mathrm{C}_{4}{ }^{2} / \mathrm{C}_{3}{ }^{=}$ratio could be used to compare the bimolecular to monomolecular cracking in the different samples, being the $\mathrm{C}_{4}{ }^{=} / \mathrm{C}_{3}{ }^{=}$value 0.43 in Z5-50 and 0.36 in Z5-50-B1, respectively. Although less pronounced, the ratio of $\mathrm{C}_{5}{ }^{=} / \mathrm{C}_{3}{ }^{=}$ratio showed similar trend. Since pentenes are produced via similar route as butenes, such ratio should be indicating similar preference of the materials toward bimolecular and monomolecular reactions.

Also illustrated in Table 4.10, to achieve similar conversion of 1-hexene, Z5-50B1 requires longer contact time, indicating a relatively lower activity. Taking into account that the acidity of Z5-50 and Z5-50-B1 is identical, it is possible to attribute such difference to the high spatial hinderance of aluminum in channel compared to aluminum in intersections. Moreover, the aromatic and paraffin yield in the case of Z5-50-B1 is significantly lower than in Z5-50, indicating a lower extension of the bimolecular hydrogen transfer reaction. At this point, the influence of aluminum pair could be discussed. According to Co-exchange experiment, Z5-50-B1 possess $70 \%$ aluminum in pairs while Z5-50 only $55 \%$. If aluminum pairs are presenting significant influence in this case, the hydrogen transfer reaction should be enhanced when Z5-50-B1 is used and give higher yield of aromatics and paraffins. However, the experimental results showed the opposite. This implies that although aluminum distribution of pair and isolated forms may have an influence on the catalytic activity of the catalyst toward bimolecular and monomolecular reactions, in this work, particularly, there are other factors that are contributing more to the reaction. 


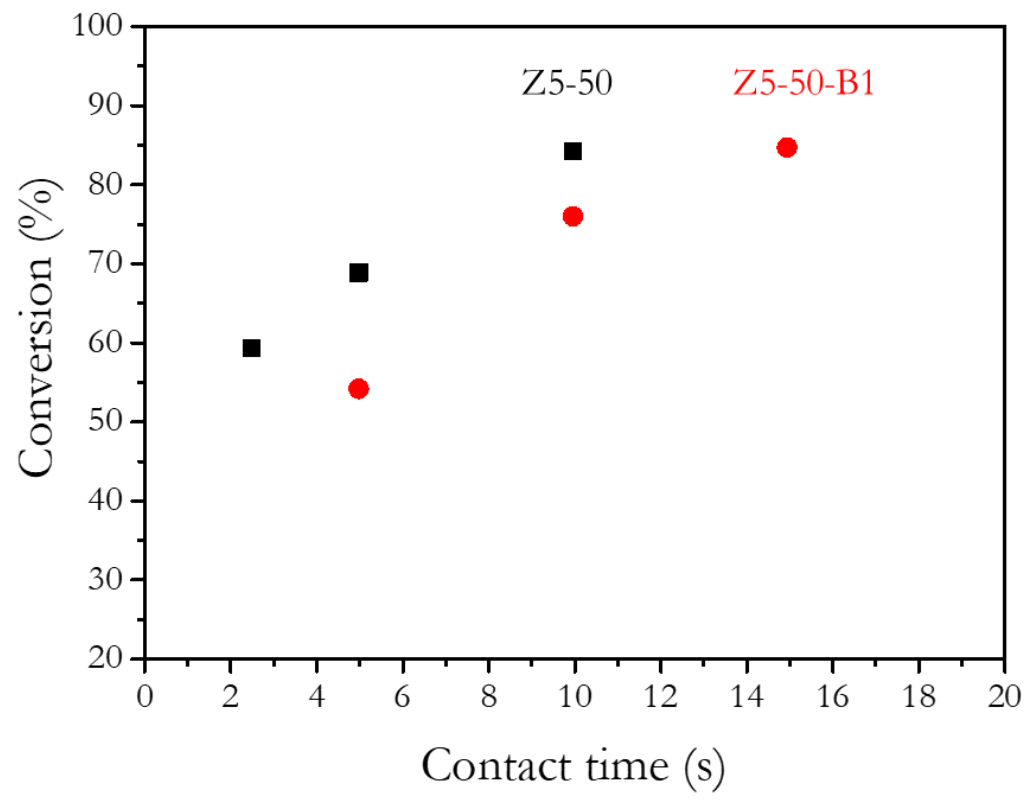

Figure 4.9 Initial conversion of 1-hexene vs contact time in 1-hexene cracking on Z5-50 (black square), Z5-50-B1 (red circle)

It is clear that Z5-50 always shows lower conversion of 1-hexene under same contact time. Considering that the particle sizes of both samples are as small as $100 \mathrm{~nm}$, there should be no significant influence of diffusion limitation. In fact, Haag et al. have systematically studied the diffusion of n-olefin inside MFI framework and proved that for zeolites with particle size equal or below $100 \mathrm{~nm}$, the diffusion of 1-hexene is barely influenced. ${ }^{17}$ If diffusion is not playing a role, then it must be an intrinsic property of the zeolite that is influencing the activity. From the above characterizations, the two samples are equivalent in terms of physical, textural and physicochemical properties. Then, the only variable that can influence activity will be the aluminum distribution. Respect to the possible role played by activity at the external surface of the crystallites, one may consider that the acid sites on the external surface should not be considered similar as those inside the crystal, since regardless the location of those aluminum sites, 
they should be facing limited spatial constraint and show little preference toward monomolecular and bimolecular reactions. In order to address this concern, cracking of 1-hexene was also performed in presence of 2,4-dimethylquinolidine (2,4-DMQ), which selectively blocks the acid sites on the external surface while having no access to internal acid sites.

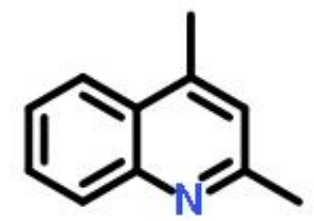

Scheme 4.8 Molecule of 2,4-dimethylquinoline

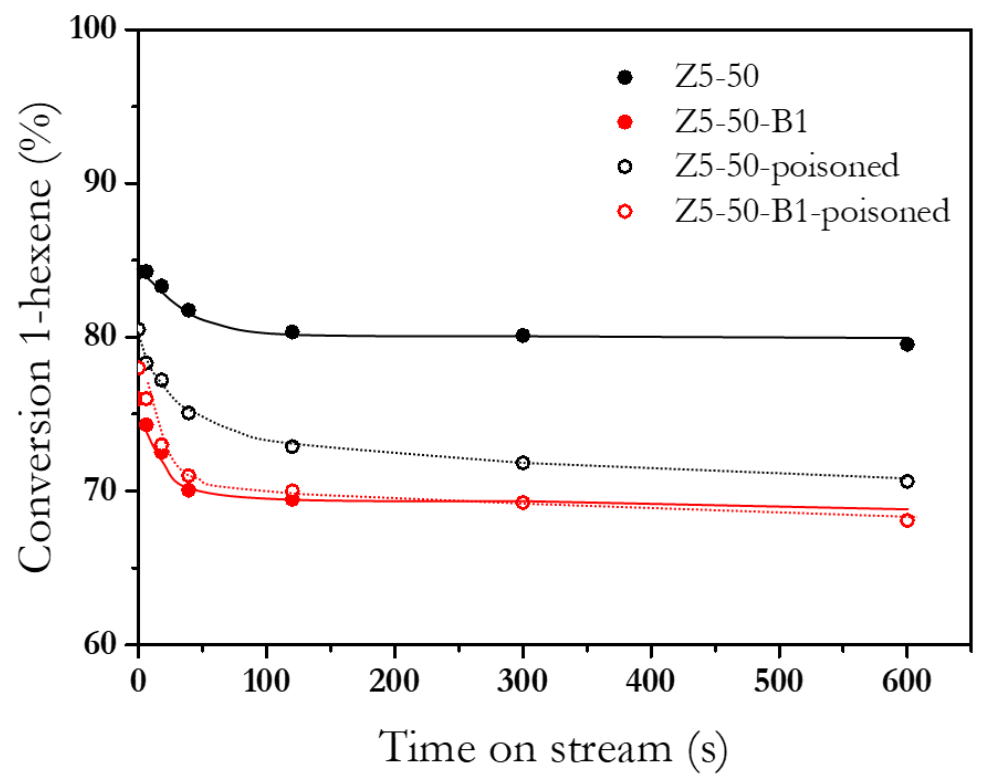

Figure 4.10 Conversion of 1-hexene along Time on Stream (TOS) on Z5-50 and Z5-50-B1 samples in the absence and presence of 2,4-dimethylquinoline as poisoning agent. 
As shown in Figure 4.10, the initial conversion of 1-hexene decreased by $\sim 5-10 \%$ due to the partial poisoning of the acid sites by 2,4-DMQ in the case of Z5-50. Indeed, the decrease of the initial activity was nearly proportional to the ratio of external surface to BET surface (13.1\%). This indicates that the acid sites on external surface are almost equally active as the internal acid sites, implying a homogeneous distribution of acid sites, both on external and internal parts of the crystals. On the contrary, no significant influence on activity was observed in the case of Z5-50-B1, where the conversion of 1-hexene with and without presence of 2,4-DMQ was $78.0 \%$ and $78.3 \%$, correspondingly. This might indicate that the activity of Z5-50-B1 is mainly inside the crystal. When comparing the activity of Z5-50 and Z5-50-B1 after poisoning, they showed more similar activity for cracking of 1 -hexene.

Table 4.11 Comparison of product distribution obtained for cracking of 1-hexene on Z5-50 and Z5-50-B1 samples in the absence and presence of 2,4-dimethylquinoline as poisoning agent. Reaction condition: temperature, $500^{\circ} \mathrm{C}$; contact time, $9.98 \mathrm{~s}$; 1-hexene partial pressure, 0.251 .

\begin{tabular}{lllll}
\hline & Z5-50 & \multicolumn{3}{c}{ Z5-50-B1 } \\
2,4-DMQ & no & yes & no & Yes \\
\hline 1-hexene conversion $(\%)$ & 84.3 & 80.0 & 78.0 & 78.3 \\
Propene molar yield (\%) & 78.3 & 82.6 & 79.2 & 92.2 \\
$\mathrm{C}_{4}{ }^{=} / \mathrm{C}_{3}{ }^{=}$molar yield ratio & 0.43 & 0.35 & 0.32 & 0.27 \\
HTI $\left(\mathrm{C}_{3}+\mathrm{C}_{4}\right) /\left(\mathrm{C}^{3}{ }^{=}+\mathrm{C}_{4}{ }^{*}\right)$ & 0.020 & 0.010 & 0.006 & 0.006 \\
\hline
\end{tabular}

The selectivity toward propene was also influenced by introducing 2,4-DMQ. Both samples show an increase in propene selectivity, being Z5-50 increased from $78.3 \%$ to $82.6 \%$ and Z5-50-B1 from $79.2 \%$ to $92.2 \%$. Two information can be extracted from these results. First, the selectivity to propene should be revealing the "real" catalytic performance of the catalysts after the poisoning of external acid sites. In such case, the difference between Z5-50-B1 and Z5-50 has enlarged after poisoning with 2,4-DMQ. Second, the higher increase in the Z5- 
50-B1 indicates that in the experiment without poisoning external acid sites, nearly $20 \%$ of propene was consumed by hydrogen transfer reactions, while in the case of Z5-50 less than 5\% was consumed.

Combining the information extracted from results of 2,4-DMQ poisoning,a picture could be drawed on how the reaction has taken place with and without external surface poisoning. Without poisoning of external surface, 1-hexene is cracked indifferently in Z5-50 either on external surface or internal surface, where aluminum atoms are non-selectively located. Since in this case aluminum sites face less spatial hinderance, the initial activity is high. In the case of Z5-50B1, 1-hexene mainly cracks inside the crystal and since there are fewer aluminum atoms located at the channel intersection inside the zeolite, the reaction undergoes mainly monomolecular pathways. Therefore, the selectivity toward propene is intrinsically high yet the 1-hexene conversion is low due to spatial hinderance. Meanwhile, there are less bimolecular side reactions that consume propene inside crystal and, therefore, most bimolecular reactions take place on the external surface. When external surface is poisoned, the 1 -hexene conversion of Z5-50 decreased together with slight increase in propene selectivity.

Through the comparisons above, it is reasonable to conclude that introducing boron in the synthesis of ZSM-5 is an effective way to direct aluminum to be located in the channel and could further influence its preference toward reaction pathways with different size of intermediates. If one think on a ZSM-5 with aluminum located in 10-ring channel, it should resemble to unidimensional 10ring zeolites. Therefore 1 -hexene cracking has been also carried out with Theta1 and mesoporous Theta- 1 prepared by post-synthesis desilication. The Theta- 1 sample is prepared using diethanolamine as template in alkaline media. The resultant material has a $\mathrm{Si} / \mathrm{Al}$ of 44 , comparable to the ZSM-5 samples. 
Table 4.12 Conversion and product distribution of 1-hexene cracking on Z5-50, Z5-50-B1, and Theta-1

\begin{tabular}{|c|c|c|c|c|c|}
\hline Sample & $\mathrm{Z} 5-50$ & Z5-50-B1 & Theta-1 & Theta-1 & $\begin{array}{l}\text { Theta-1- } \\
\text { treated }\end{array}$ \\
\hline Contact time (s) & 9.96 & 14.94 & 39.8 & 10.0 & 10.0 \\
\hline Conv. 1-hexene (\%) & 84.3 & 84.7 & 82.9 & 56.8 & 68.8 \\
\hline \multicolumn{6}{|l|}{ Molar yield $(\%)^{*}$} \\
\hline Ethene & 13.3 & 12.9 & 8.5 & 3.5 & 4.8 \\
\hline Propene & 78.3 & 86.2 & $122.1 *$ & 95.5 & $110.3^{*}$ \\
\hline $\mathrm{C}_{4}=$ & 33.8 & 30.9 & 13.9 & 4.3 & 6.9 \\
\hline $\mathrm{C}_{5}=$ & 12.6 & 11.8 & 4.4 & 0.5 & 2.0 \\
\hline BTX & 0.63 & 0.34 & 0.44 & 0.08 & 0.3 \\
\hline Paraffins & 3.91 & 2.66 & 3.0 & 0.30 & 1.21 \\
\hline \multicolumn{6}{|l|}{ Molar yield ratios } \\
\hline $\mathrm{C}_{2}=/ \mathrm{C}_{4}=$ & 0.39 & 0.42 & 0.61 & 0.81 & 0.70 \\
\hline $\mathrm{C}_{4}=/ \mathrm{C}_{3}=$ & 0.43 & 0.36 & 0.11 & 0.05 & 0.06 \\
\hline $\mathrm{C}_{5}=/ \mathrm{C}_{3}=$ & 0.16 & 0.14 & 0.04 & 0.01 & 0.02 \\
\hline
\end{tabular}

* Molar yield to a product is defined as the number of moles produced by moles of olefin fed. 


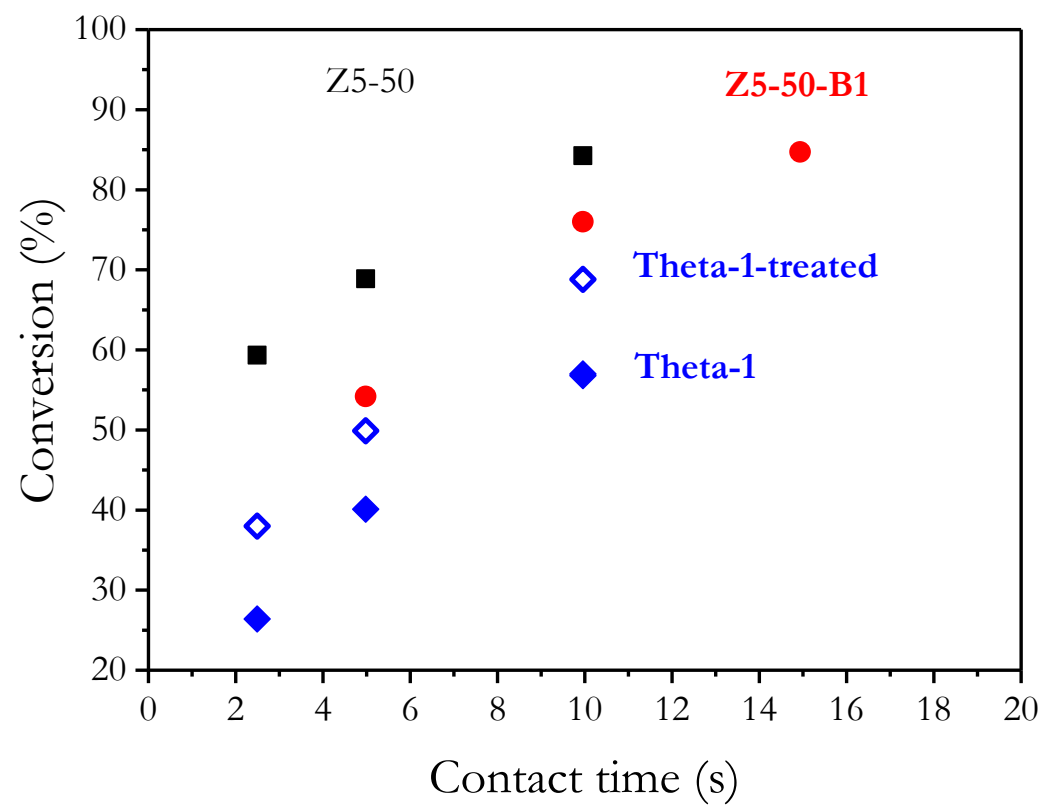

Figure 4.11 Initial conversion of 1-hexene vs. contact time in 1-hexene cracking on Z5-50 (black square), Z5-50-B1 (red circle), Theta-1 (blue diamond) and treated Theta-1 (hollow blue diamond) samples

The Theta-1 samples have been tested in 1-hexene cracking under the same conditions as ZSM-5 samples. The results in Table 4.12 reveal that at a 1 -hexene conversion of $82.9 \%$, the propene molar yield of Theta- 1 is $122.1 \%$ with lower amount of butene pentene and ethene. Molar yield to a product is defined as the number of moles produced by per mole of 1 -hexene reacted. For this reason, the lower olefins could reach a molar yield higher than $100 \%$. The $\mathrm{C}_{4}{ }^{2} / \mathrm{C}_{3}{ }^{=}$value is 0.11 , which is much lower than values obtained with Z5-50 and Z5-50-B1. Meanwhile, the activity of Theta- 1 is lower than both ZSM- 5 samples. In order to achieve a 1 -hexene conversion of $82.9 \%$, it requires a contact time as high as $39.8 \mathrm{~s}$, which is 2.7 and 4 times higher than Z5-50-B1 and Z5-50, respectively. 
This has been further proved in Figure 4.11. It is clear that one-dimensional zeolite should suffer significantly from diffusion limitation. Then, a post synthesis desilication was adopted to increase mesoporosity in the sample and decrease diffusion pathways for molecules inside the channels (see description in experimental). After such treatment, activity of Theta-1 has increased to a level similar to Z5-50-B1 (see Figure 4.11).

To sum up, in all aspects of catalytic reactions including 1-hexene conversion, product selectivities, molar yield ratios and activity against contact time, Z5-50B1 is resembling Theta-1. However, it is not realistic to expect that ZSM-5 would have similar properties as one-dimensional zeolites, even when aluminum sites are located in 10-ring channels, since the two-dimensional channel system of MFI will significantly improve diffusion even without active sites. However, on the base of the selectivities obtained and the behavior observed when comparing the results with the $\mathrm{Al}$ and $\mathrm{Al}-\mathrm{B}$ ZSM-5 and Theta-1, it is possible to conclude that the presence of boron in the synthesis of ZSM- 5 could direct aluminum to be more preferentially located in 10-ring channels, and such aluminum distribution could favor more monomolecular reactions than bimolecular reactions. If this is true, we should now be able to design better catalysts for other processes in where location of acid sites could have an important impact. Hereby, methanol to hydrocarbons reaction has been selected as the target reaction since a preferential location of acid sites in the 10-ring channels with respect to channel crossing location, should give a higher selectivity to olefins and lower selectivity to aromatics and coke.

\subsubsection{Impact of aluminum distribution on Methanol to Hydrocarbons (MTH) reactions}

MTH is an industrially relevant process in where olefins are produced through a series of alkylation, dealkylation, hydrogen transfer-cyclization, ring contraction and ring expansion. ${ }^{36}$ The complex reaction will be explained in detail in chapter 5. Hereby the reaction mechanism is briefly described.

In general, during a typical MTH reaction, light olefins are first formed during an induction period, and the exact reaction mechanism is still under debate. Then, 
the olefins, when formed, could either be methylated to produce higher olefins and, eventually, they can crack to produce light olefins through an "olefin-based cycle" or via hydrogen transfer-cyclization reaction to form aromatic based intermediates that will follow the so-called "aromatic-based cycle".

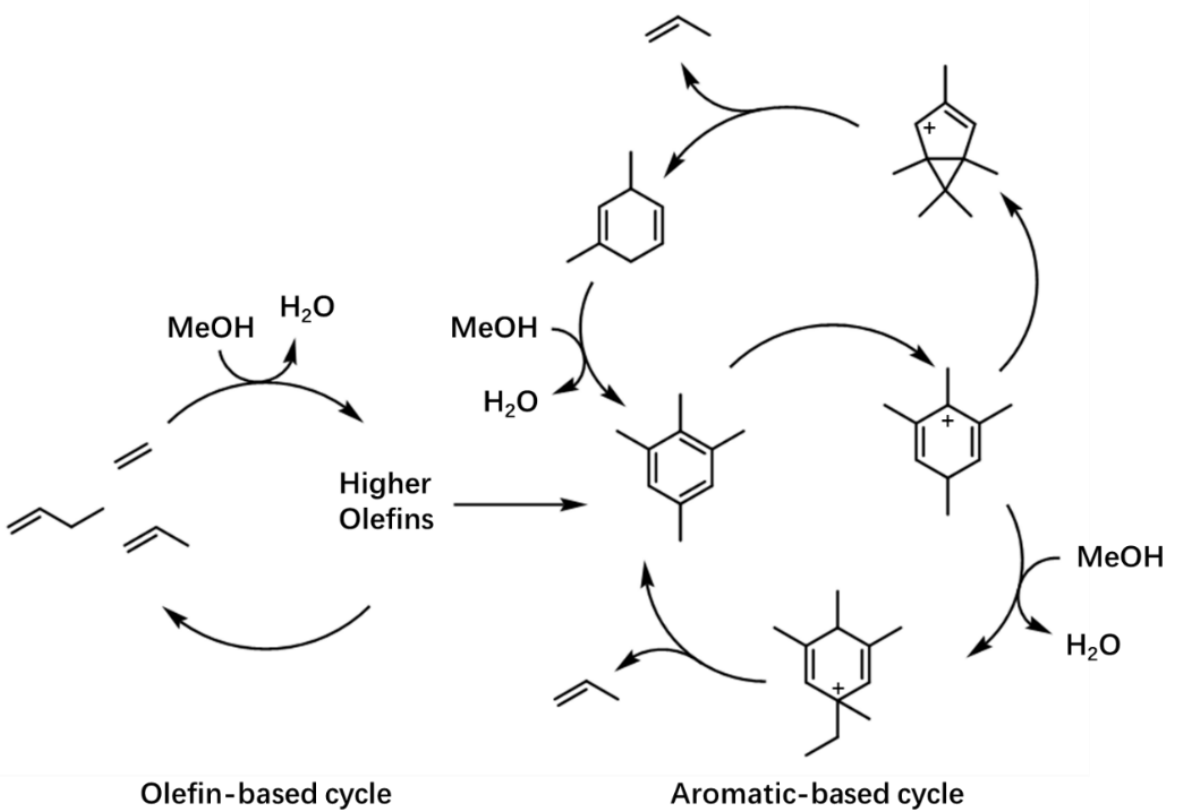

Scheme 4.9 Illustration of dual-cycle mechanism of MTH reaction.

Despite the complicated reaction pathways, the reactions occuring in the mechanism of MTH reaction can be classified according to the size of the reaction intermediates. In general, all the molecules in the olefin-based mechanism are linear or with a low-level of branching, and could be considered as small intermediates. The reaction in this mechanism are basically alkylation and dealkylation between small molecules, which does not require large space and should be able to occur inside 10-ring channels of ZSM-5. When two or three olefin molecules go through oligomerization-cyclization-hydrogen transfer reaction, it forms an aromatic and paraffin by saturation of olefins. Then, the 125 
formation of aromatics plus paraffins involve multiple olefin molecules as reactant as well as the formation of bulky intermediates. Thus, this step should be considered to occur mainly in the intersection of ZSM-5 and at the external surface. On the other hand, in aromatic-based cycle, since all reactions involve one molecule of aromatic or cyclopentenyl intermediate, they all should be classified as large molecule reactions and should occur exclusively at channel intersections or external surface of ZSM-5. Through a brief classification of reactions, it is clear that if aluminum is preferentially located in the 10-ring channel of ZSM-5, olefin cycle should be enhanced and side reactions that consumes olefins and form aromatics and paraffins should be prevented. Then, there is no doubt that the ZSM-5 samples that have been presented above and that we considered to have aluminum concentrated in 10-ring channels, should improve the selectivity to propene when feeding methanol, when compared with the zeolite in where active sites pointing to intersections.

During the preparation of catalysts for MTH the objective is to maximize the conversion of methanol into propene. Industrially, the product distribution is altered by using zeolite catalysts with proper structure. ZSM-5 is the current catalyst for MTH processes that maximizes yield of propene and aromatics due to its channel-based structure with 10-ring pore opening. Depending on the main product, the process could be called either MTP (methanol to propene), MTA (methanol to aromatics) or MTG (methanol to gasoline).

When designing a ZSM-5 catalyst for MTP, the objective is to maximize the selectivity to propene while minimizing those secondary reactions that can consume propene, including oligomerization, cyclization and hydrogen transfer reactions, which yield aromatics and paraffins. It is generally accepted that the density of acid sites, represented by the framework $\mathrm{Si} / \mathrm{Al}$ ratio, is the main compositional parameter that allows controlling the extent of such secondary side reactions. The selectivity toward aromatics and alkanes is higher when the framework $\mathrm{Si} / \mathrm{Al}$ ratio is low. For this reason, industrial ZSM-5 catalysts for MTP process usually possess high $\mathrm{Si} / \mathrm{Al}$ ratio, being the selectivity to propene higher and the catalyst deactivation by coke faster than in the ZSM-5 catalysts with lower $\mathrm{Si} / \mathrm{Al}$ ratios. However, although the selectivity to propene could be 
effectively improved, the low acid amount will limit the methanol processing capacity of the catalyst. For this reason, if a ZSM-5 with higher amount of acid sites could maintain high propene selectivity and resistance against coke formation, it should have an important industrial impact.

In low-Si ZSM-5, when aluminum is occupying various positions in a unit cell, the chance of forming aromatics and heavy products is high since aluminum sites can be distributed either in the channel or in the intersection of the channels, as isolated or paired form. Thus, by simply decreasing their amount, aluminum sites should be more separated from each other and decrease the chance of forming aluminum pairs. Meanwhile, it will also decrease the amount of alumium located at channel intersections, which are responsible of bimolecular reactions. However, decreasing aluminum content will decreases both amount of aluminums in intersection and in channel. If a ZSM- 5 sample could be prepared with more aluminum in channels and less at the intersections, then without decreasing its aluminum content, the selectivity toward propene as well as resistance against coke formation should increase.

Following this thought, samples with various $\mathrm{Si} / \mathrm{Al}$ and $\mathrm{Si} / \mathrm{B}$, all of which possess higher amount of aluminum than industrially used ZSM- 5 catalysts, were tested in MTP reactions under high WHSV to obtain an observable deactivation. Similar as in $\mathrm{n}$-hexene cracking, Theta- 1 was also tested under the same experimental conditions as a reference catalyst to see how aluminum in channel would behave. 


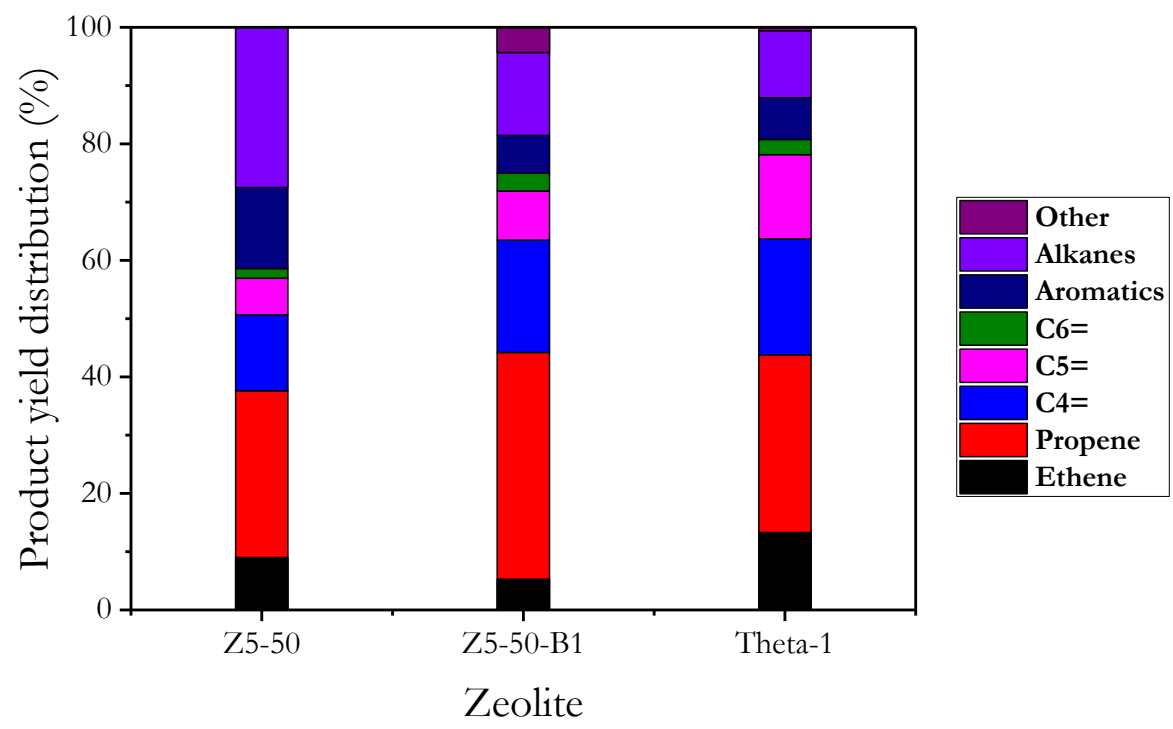

Figure 4.12 Product yield distribution of methanol to propene over different zeolites. Reaction condition: temperature, $450^{\circ} \mathrm{C}, \mathrm{WHSV}_{\mathrm{MeOH}}=10 \mathrm{~h}^{-1}$.

Figure 4.12 summarizes the product distribution of Z5-50, Z5-50-B1 and Theta1 in MTP reaction. Compared to Z5-50, Z5-50-B1 with a higher proportion of $\mathrm{Al}$ in the channel shows a higher selectivity toward $\mathrm{C}_{3}{ }^{2}-\mathrm{C}_{5}{ }^{=}$together with a lower selectivity toward aromatics and paraffins. This is in accordance to previous expectation as well as to the results of $\mathrm{n}$-hexene cracking. In fact, in terms of the product selectivity of MTP reaction, Z5-50-B1 resembles more to Theta-1 than to Z5-50 in terms of product selectivity. 

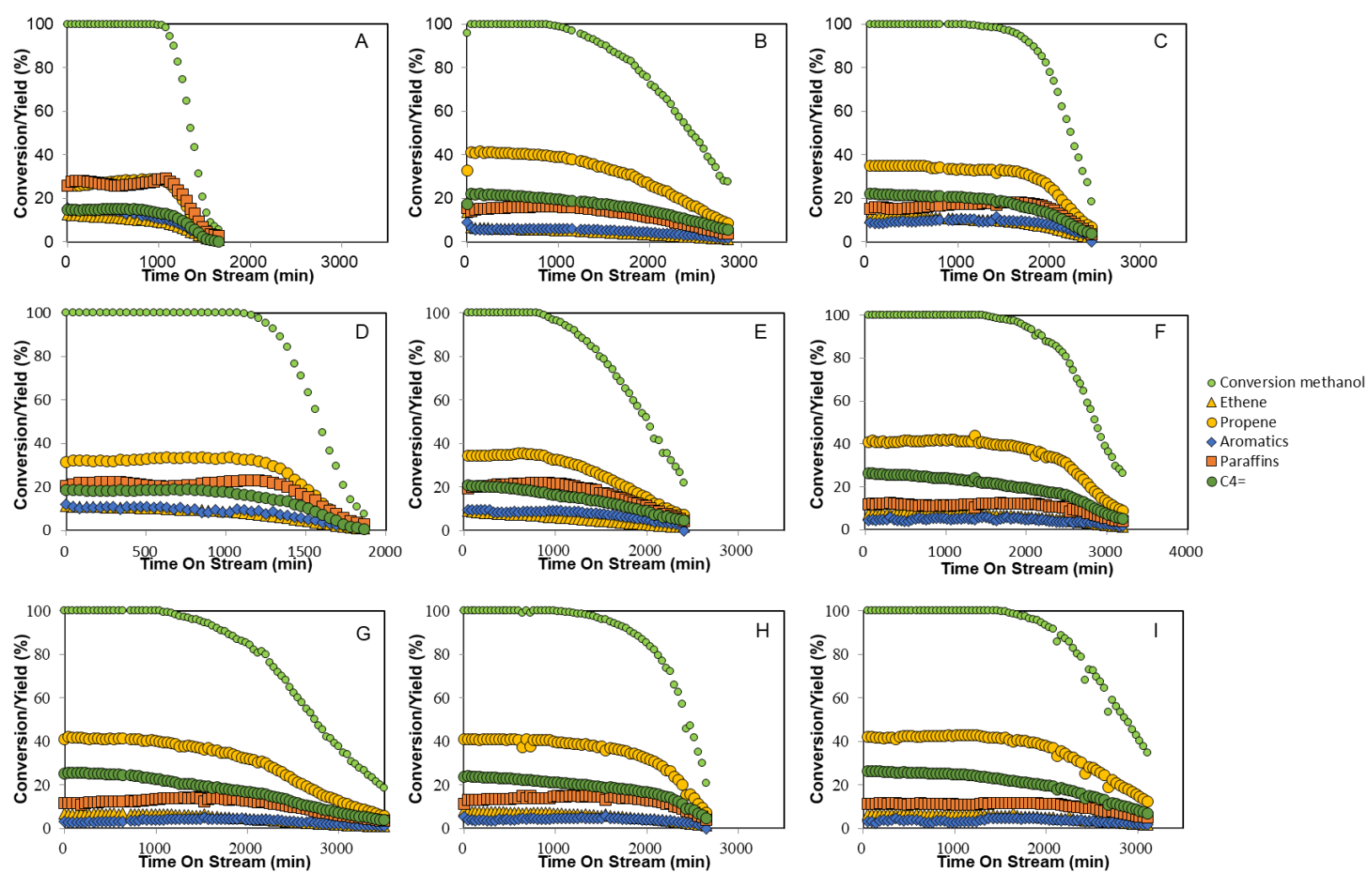

Figure 4.13 Product distribution of methanol to propene over different ZSM-5 samples (A) Z5-50,

(B) Z5-50-B1, (C) Z5-50-B2, (D) Z5-75, (E) Z5-75-B1, (F) Z5-75-B2, (G) Z5-100, (H) Z5-100-B1

and (I) Z5-100-B2; Reaction conditions: catalyst amount, 50mg; temperature, $450^{\circ} \mathrm{C}$, WHSV $=10$

$\mathbf{h}^{-1}$.

The main products in all cases are propene, butenes and pentenes, with very low amounts of aromatics and paraffins (see Figure 4.13). Among those samples synthesized without boron, the lifetime and selectivity toward propene increased along with increasing of the Si/Al, while selectivity toward aromatics and paraffins as well as deactivation rate decrease in the same order. Compared to their boron-free counterparts, the samples synthesized in presence of boron show much higher selectivity toward propene, butenes and pentenes while the 
selectivity toward ethene, aromatics and paraffins is lower. The differences between samples with and without boron diminishes when the overall $\mathrm{Si} / \mathrm{Al}$ molar ratio increases. In the case of Z5-50 and Z5-50-B1, the lifetime for methanol conversion defined as the time for conversion drop to $50 \%$ of the starting value, has been doubled, while the selectivity toward propene has been increased from less than 30\% to 42\%. In comparison, Z5-100 and Z5-100-B1 show nearly identical time to reach a $50 \%$ methanol conversion and the product selectivity barely changed. Only a slight increase of the butenes yield and a decrease of paraffin yield are observed for Z5-100-B2. Even though, the improvement of Z5-100-B2 compared to Z5-100 is not as large as of Z5-50-B1 compared to Z5-50. This could prove the hypothesis above that in high-Si ZSM5 , the aluminum is readily separated from each other, preventing the catalyst from fast deactivation by coke. Then, when the location of aluminum sites is more concentrated in the channel in the case of Z5-100-B2, the influence on catalyst deactivation will be smaller.

In conclusion, we have showed the relationship between acid site locations in zeolites with different confinement and catalytic activity, selectivity and catalyst deactivation in different carbocation-based reactions. This has been illustrated in the case of ZSM- 5 by taking advantage of the different preference of boron and aluminum to occupy different locations within 10-ring channels and/or intersections. According to the results, boron prefers to be located at the intersections, while no preference was found for aluminum. As a result of competitive locating between aluminum and boron, the ZSM-5 prepared in presence of boron had more aluminum species located in the channels. The effect of such preferential siting of aluminum has been illustrated by 1-hexene and MTP reactions, where a clear enhancement of the monomolecular reactions, which require smaller reaction space, has been demonstrated. In contrast, the bimolecular reactions, which require large void space for the intermediates, are mostly prevented. 


\subsection{Conclusion and perspectives}

In this chapter, the positions of aluminum in ZSM-5 zeolite were studied as an illustration of how such delicate control of acid sites could generate impact on the material and the catalyzed reactions.

As was described in the introduction, the distribution of aluminum in zeolite framework is not a single issue but rather a combination of three concepts: the zoning of aluminum in part of the crystals, the distribution of aluminum in paired and isolated form, and the position of aluminum at certain T-sites in the zeolite framework. The location of aluminum in MFI structure, in particular, is difficult to identify due to the large number of crystallographic distinguishable T-sites. For this reason, instead of using single technique for locating the aluminum, a combination of ${ }^{27} \mathrm{Al}$ MAS NMR, catalytic cracking and DFT calculations was employed to study the positioning of aluminum.

In the catalytic cracking of $\mathrm{n}$-hexene, the monomolecular and bimolecular mechanisms are sensitive to the spatial confinements of the acid sites. When $\mathrm{C}_{2}=/ \mathrm{C}_{4}{ }^{=}$is low, butene is mainly produced via bimolecular mechanism and its yield could indicate the extension of the bimolecular reaction. Then the molar yield ratio of $\mathrm{C}_{4}{ }^{=} / \mathrm{C}_{3}{ }^{=}$could effectively reflect the preference between monomolecular and bimolecular reactions, achieving an indicator to evaluate the aluminum position in ZSM- 5 samples. The aluminum distribution reflected by this indicator is consistent with those results from ${ }^{27} \mathrm{Al}$ MAS NMR, although the latter is not conclusive.

In order to tune the $\mathrm{Al}$ distribution, boron was introduced as a secondary heteroatom to generate competitive positioning with aluminum. This competitive positioning was proved thermodynamically by DFT calculations. The aluminum distribution in the ZSM-5 samples synthesized with various $\mathrm{Si} / \mathrm{Al}$ and $\mathrm{Si} / \mathrm{B}$ were evaluated using various techniques as well as the indicator developed in this work. The results obtained indicated that boron could influence the position of aluminum. When applied in MTO reaction where spatial confinement plays an important role in catalytic activity and product selectivity, the sample prepared in presence boron showed outstanding catalytic 
lifetime, resistance against coke formation as well as high selectivity toward propene in MTO reaction.

Although the resultant zeolites showed differences, the boron-assisted synthesis approach still lacks mechanistic explanation. The reason for the competitive incorporation between boron and aluminum is still unclear. According to the results obtained in this study, the positioning of aluminum in zeolite framework is determined by the interaction between cations and $\mathrm{T}^{\mathrm{III}} \mathrm{O}_{4}{ }^{-}$tetrahydrons. This interaction should be mostly influenced during nucleation where the OSDAs and inorganic cations capture $\mathrm{T}^{\mathrm{IV}} \mathrm{O}_{4}$ and $\mathrm{T}^{\mathrm{III}} \mathrm{O}_{4}^{-}$to form the nucleus. Thus, further mechanistic studies to unravel the competitive incorporation of boron and aluminum should focus on the colloidal chemical nature of the synthesis gel. 


\subsection{Reference}

1. J. Jones, E. Iglesia, ACS Catal., 2015, 5, 5741.

2. E. G. Derouane, J. Mol. Catal. A, 1998, 134, 29.

3. B. C. Knott, C. T. Nimlos, D. J. Robichaud, N. R. Nimlos, S. Kim, R. Gounder, ACS Catal., 2018, 8, 770.

4. R. Gounder, E. Iglesia, Chem. Commun., 2013, 49, 3491.

5. A. J. Jones, E. Iglesia, Angew. Chem. Int. Ed., 2014, 53, 12177.

6. S. Wang, E. Iglesia, J. Catal., 2017, 352, 415.

7. J. Dedecek, D. Kaucky, B. Wichterlova, O. Gonsiorova, Phys. Chem. Chem. Phys., 2002, 4, 5406.

8. A. B. Pinar, C. Marquez-Alvarez, M. Grande-Casas, J. Perez-Pariente, J. Catal., 2009, 263, 258.

9. Y. Román-Leshkov, M. Moliner, M. E. Davis, J. Phys. Chem. C, 2011, 115, 1096.

10. J. R. Di Iorio, R. Gounder, Chem. Mater., 2016, 28, 2236.

11. J. R. Di Iorio, C. T. Nimlos, R. Gounder, ACS Catal., 2017, 7, 6663.

12. M. Liu, T. Yokoi, M. Yoshioka, H. Imai, J. N. Kondoa, T. Tatsumi, Phys. Chem. Chem. Phys., 2014, 16, 4155.

13. A. Ghorbanpour, J. D. Rimer, L. C. Grabow, Catal. Commun., 2014, 52, 98.

14. S. M. Sharada, P. M. Zimmerman, A. T. Bell, J. Phys. Chem. C, 2013, 117, 12600.

15. A. Janda, A. T. Bell, J. Am. Chem. Soc., 2013, 135, 19193.

16. T. Yokoi, H. Mochizuki, S. Namba, J. N. Kondo, T. Tatsumi, J. Phys. Chem. C, 2015, 119, 15303.

17. W. O. Haag, R. M. Lago, P. B. Weisz, Faraday Discuss. Chem. Soc., 1981,72, 317. 
18. A. Corma, A. V. Orchilles, Micropor. Mesopor. Mater, 2000, 35, 21.

19. C. A. Emeis, J. Catal., 1993, 141, 347.

20. C. Fild, D. F. Shantz, R. F. Lobo, H. Koller, Phys. Chem. Chem. Phys., 2000, 2, 3091.

21. M. G. Howden, Zeolites, 1985, 5, 334.

22. S. I. Zones, S.-J. Hwang, Micropor. Mesopor. Mater., 2011, 146, 48.

23. P. Wu, T. Tatsumi, K. Takayuki, Y. Tatsuaki, J. Phys. Chem. B, 2001, 105, 2897.

24. P. Wu, T. Tatsumi, Chem. Commun., 2002, 1026.

25. Q. Zhu, J. N. Kondo, T. Yokoi, T. Setoyama, M. Yamaguchi, T. Takewaki, K. Domen, T. Tatsumi, Phys. Chem. Chem. Phys., 2011, 13, 14598.

26. Y. Yang, C. Sun, J. Du, Y. Yue, W. Hua, C. Zhang, W. Shen, H. Xu, Catal. Commun., 2012, 24, 44.

27. Z. Hu, H. Zhang, L. Wang, H. Zhang, Y. Zhang, H. Xu, Catal. Sci. Technol., 2014, 4, 2891.

28. F. Yaripour, Z. Shariatinia, S. Sahebdelfar, A. Irandoukht, Micropor. Mesopor. Mater., 2015, 203, 41.

29. O. H. Han, C. S. Kim, S. B. Hong, Angew. Chem. Int. Ed., 2002, 41, 469.

30. S. Sklenak, J. Dedecek, C. Li, B. Wichterlová, V. Gabova, M. Sierka, J. Sauer, Angew. Chem. Int. Ed., 2007, 46, 7286.

31. S. Sklenak, J. Dedecek, C. Li, B. Wichterlová, V. Gabova, M. Sierka, J. Sauer, Phys. Chem. Chem. Phys., 2009, 11, 1237.

32. J. Dedecek, V. Balgova, V. Pashkova, P. Klein, B. Wichterlová, Chem. Mater., 2012, 24, 3231.

33. V. Pashkova, P. Klein, J. Dědeček, V. Tokarova, B. Wichterlová, Micropor. Mesopor. Mater., 2015, 202, 138. 
34. V. Pashkova, S. Sklenak, P. Klein, M. Urbanova, J. Dedecek, Chem. Eur. J., 2016, 22, 3937.

35. T. Yokoi, H. Mochizuki, T. Biligetu, Y. Wang, T. Tatsumi, Chem. Lett., 2017, 46, 798.

36. V. Van Speybroeck, K. De Wispelaere, J. Van der Mynsbrugge, M. Vandichel, K. Hemelsoet, M. Waroquier, Chem. Soc. Rev., 2014, 43, 7326. 



\section{Chapter 5}

\section{"Ab-initio" synthesis of}

zeolites for catalytic reactions 


\subsection{Introduction}

In the previous part of the thesis, attempt was made to locate the active sites in the adequated pore or cavity of the zeolite for catalyzing a given reaction. Here we will present how it is possible to synthesize the zeolite with the adequate pore or cavity size and shape for a pre-established reaction. In this way, from the work presented here, one should be able to follow the synthesis of optimum zeolite for a preestablished reaction by an "ab-initio" method. The selection of a zeolite catalyst for a certain reaction is normally carried out by trial and error. Zeolites with different topology, composition or physicochemical properties are tested one after another as catalysts in the target reaction. Then, the catalyst is selected according to their catalytic performance in terms of conversion, selectivity and resistance against deactivation. One obvious shortcoming of this trial and error methodology is that the synthesis of these zeolite materials is time-consuming and labor intensive together with the difficulty to obtain structures with proper physicochemical properties for this target reaction, which could have very narrow synthesis condition window. As a compromise to this labor-intense way of exploring catalysts for reactions, industries now often utilize those wellestablished zeolites such as Y, ZSM-5, Beta, mordenite and MCM-22, which are currently involved as the majority of catalyst market and cover a variety of chemical processes. The reasons are not difficult to understand. First, the properties of these materials have been widely studied and their composition and physicochemical properties can be tuned in a relatively wide range, leading to significant different catalytic performances. Second, the cost of development of new catalysts is expensive and, therefore, it is not guaranteed the finding of competitive catalysts to these pre-established zeolites at reasonable cost.

At this point, it is demanded to develop a synthesis strategy that can efficiently generate proper zeolite catalysts for target reactions. In fact, during a catalytic process, the zeolite channel/cavity shows shape selectivity by providing spatial hinderance to reaction intermediates or transition states and further lead to certain reaction pathways. Actually, this commonly mentioned terminology "shape selectivity" is mostly realized through selecting the size instead of the shape of the target reaction. This would explain why the most commonly used 
zeolite catalysts in current industries were synthesized decades ago, such as $\mathrm{Y}$, ZSM-5, mordenite or beta: they combine the proper channel size and internal diffusion, which are not very different from newly synthesized structures. However, if we think deeper into the mechanism of the catalyzed reaction, the stablization of the transition state would directly influence the activation energy (Ea), which will ultimately be reflected in the final reaction rate and catalyst activity. Thus, zeolites that could better stabilize the transition state should effectively minimize its free energy $(\Delta G)$ and, then, decrease the energy barrier for the reaction.

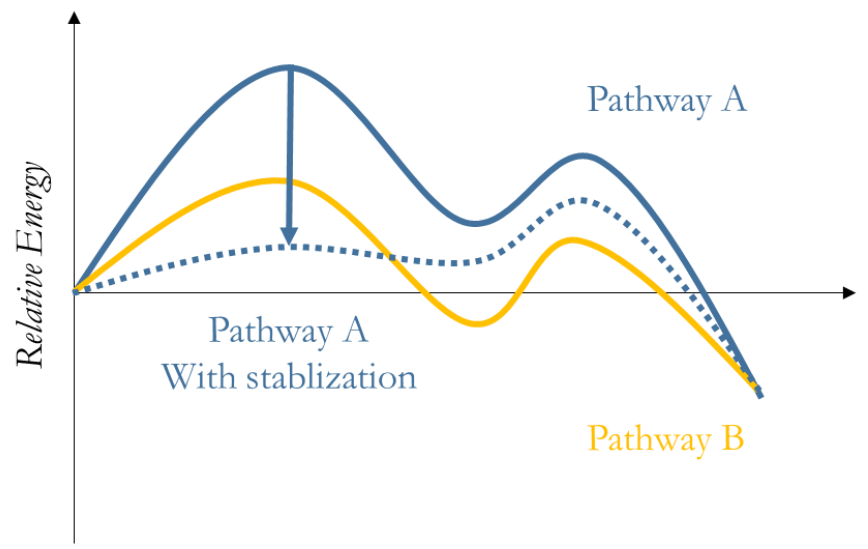

Scheme 5.1 A schematic illustration of how stabilization of an intermediate by zeolite could alter reaction pathways

The methodology of directing formation of cavity with shape that adopted from reaction intermediate is connected with the field of "molecular imprinting" in amorphous silica. ${ }^{1,2}$ However, due to lack of short range order, the imprinting of amorphous silica is easy to change the shape of cavity upon calcination and regeneration, disturbing the imprinted shapes and terminal groups. ${ }^{3}$ Then, if the concept of "molecular imprinting" could be adopted in the synthesis of zeolites, their crystalline nature should allow maintaining of imprinted cavity during calcination, catalytic reaction as well as regeneration. The OSDAs adoped in zeolite synthesis are usually ammonium or phosphonium. A proper designed 
OSDAs that could mimic the shape and configuration of reaction intermediates should lead to formation of zeolites that better stabilize the corresponding reaction transition states and thus favor the target reaction.

Considering this concept, Corma et al. have recently developed an "ab initio" zeolite synthesis methodology using OSDAs that mimick the transition state of pre-established chemical reactions. ${ }^{1}$ In the work, several reactions are set as target reactions including disproportionation of toluene, isomerization of ethylbenzene and adamantane synthesis through isomerization of endotricyclodecane. By preparing OSDAs that mimick the transition-states, the researchers obtained ITQ-27, ITQ-64 and MWW-type zeolites, correspondingly. The obtained materials showed outstanding activity in the target reactions and high selectivity toward main products. These materials had not been previously reported or considered to be effective catalysts in said reactions. In this pioneer work, the researchers demonstrated the potential correlation between OSDA, zeolite framework and reaction transition state for a target chemical process.

In this part of thesis, the effort will be put on investigating the mechanistic insight to the mimic synthesis strategy. Specifically, the study will focus on exploring zeolite formation using the mimic synthesis, the status of the OSDA that remains in the zeolite framework and how it is affecting its structure, followed by the catalytic evaluation of the zeolite together with mechanistic explanations. Also, the strategy of mimic synthesis will be expanded to complex reactions that include multiple parallel and continuous pathyways, such as the case of MTO reaction.

\subsection{Ethylbenzene (EB) related chemical processes}

In the previous work done by Corma et al., ITQ-27 was obtained by employing diarylphosphonium OSDA in a fluoride media. ${ }^{214}$ In this case, the template was used as a mimic of the transition state species in toluene disproportionation to produce Xylenes (see Scheme 5.2). The catalyst showed superior activity per aluminum compared with mordenite, beta and ZSM-5 with similar Si/Al. 
If one observes the transition state of toluene disproportionation, this is not very different from the transalkylation between diethylbenzene (DEB) and benzene, which is an important chemical process to produce EB (see Scheme 5.3).

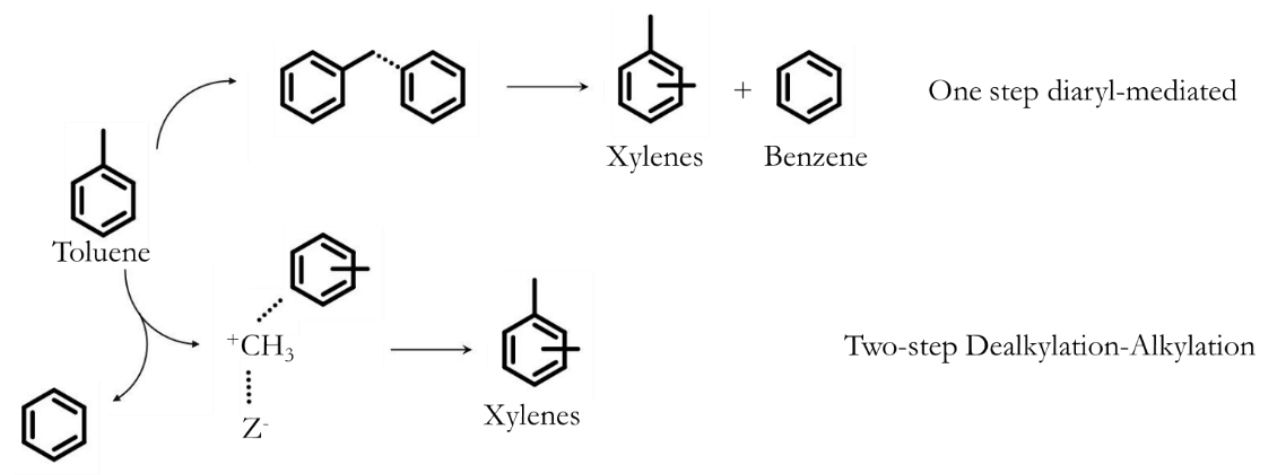

Benzene

Scheme 5.2 Illustration of the two reaction pathways in toluene disproportionation.

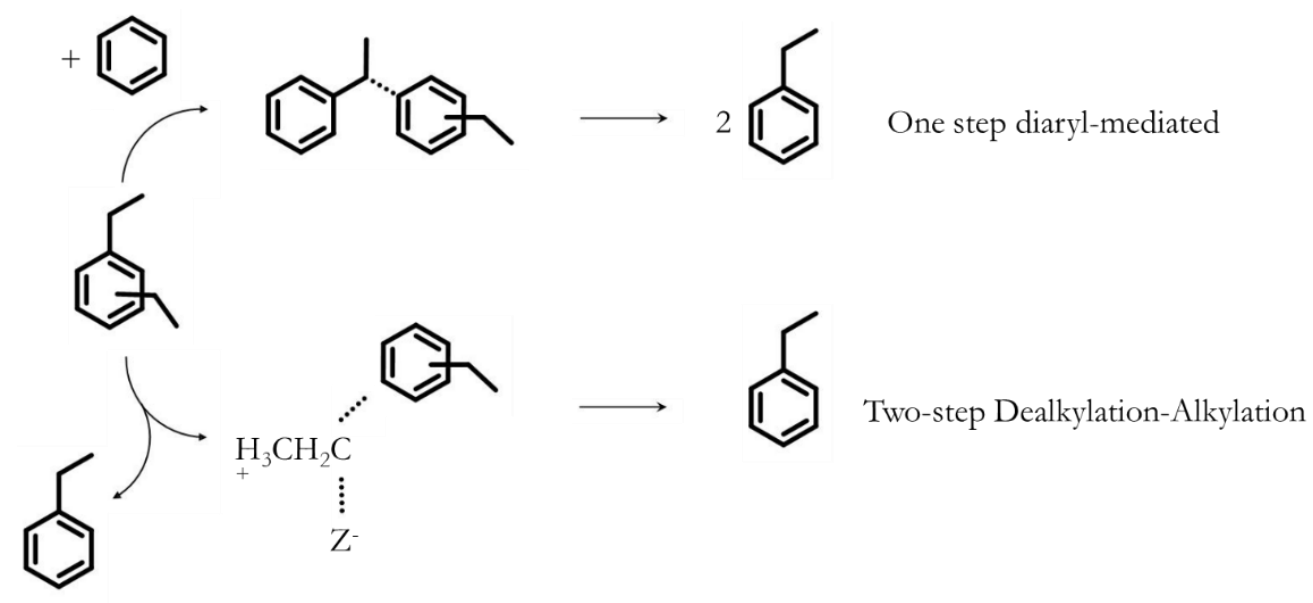

Scheme 5.3 Illustration of the two reaction pathways in transalkylation between DEB and benzene.

Current production of EB is mainly through alkylation of benzene with ethene. To avoid the formation of polyalkylated products, such as DEB and triEB, the benzene is fed exceeding stoichiometric ratio (1:1). Theoretically, the higher the 
benzene to ethene ratio in the feed, the less polyalkylated products will be produced. However, this ratio cannot be very high since overfeeding benzene will inevitably decrease the throughput and cause a higher recirculation of benzene. As a compromise, the benzene to ethene ratio is selected between 2:1 - 6:1 in current industrial plants. Although the conditions are optimized to increase the yield of EB in these plants, the formation of polyalkylated products, mainly DEB and a little amount of triEB, cannot be avoided. Then, following the main unit of benzene alkylation, EB is separated from the product and polyalkylated products are further reacted with benzene in a transalkylation unit to eliminate polyEB and further increase the yield of EB (see Scheme 5.4).

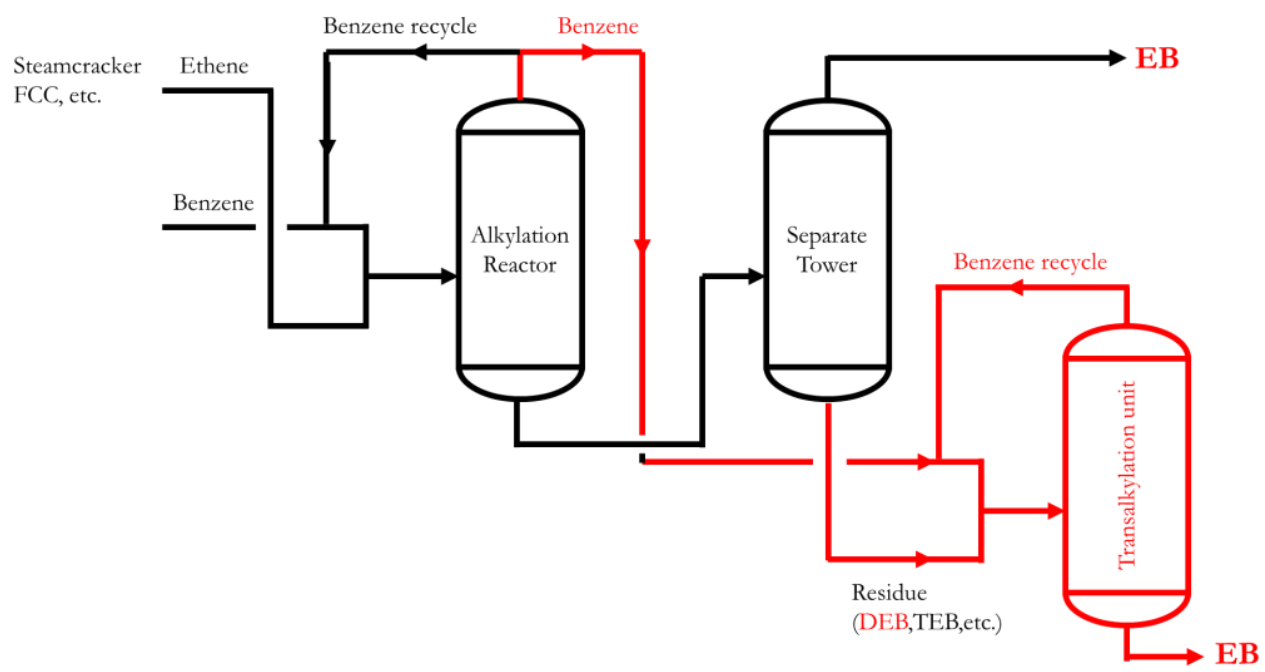

Scheme 5.4 Scheme of an industrial process to produce EB via combination of benzene alkylation and DEB transalkylation.

The catalysts used in current processes are mainly large pore zeolites like USY, Beta and mordenite or medium pore zeolites with large internal voids, such as MCM-22. ${ }^{5,6}$ It is quite clear that the selection of these catalysts has been mainly based on their channel size, cavity size and dimensionality. The most active catalyst so far is $\mathrm{Y}$ zeolite with three-dimensional 12-ring pores and supercage 
(see Scheme 5.5). Beta (BEA) contains a three dimensional 12-ring channel with no cage while MCM-22 (MWW) has 10-ring channels with a supercage with size equal to 12-ring and 12-ring cups open to the exterior. It has also been reported that mordenite (MOR), with unidimensional 12-ring channel, is also active in catalyzing transalkylation reactions. ${ }^{7}$

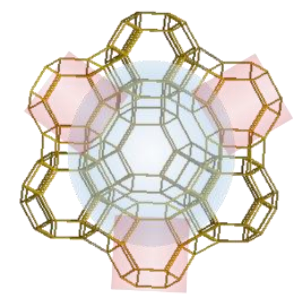

FAU

3D 12-ring

Supercage

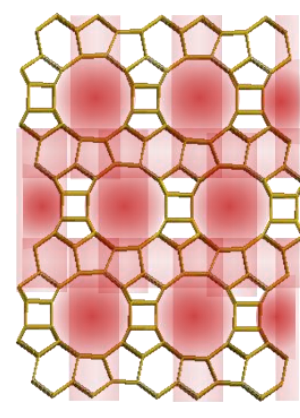

BEA

3D 12-ring

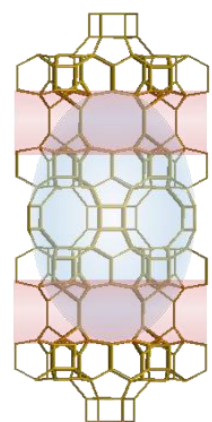

MWW

2D 10-ring

Supercage

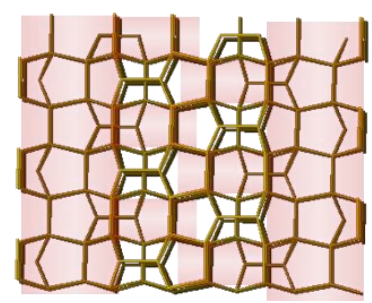

MOR

1D 12ring

Scheme 5.5 Structure and channel system of the zeolites used as catalyst in transalkylation of DEB. The parts shadered in red represent channel systems and the parts in blue represent cages.

\subsubsection{Materials synthesis and characterization}

Following the concept of mimicking synthesis approach mentioned above, a diphenyldimethylphosphonium (DPDMP) OSDA (see Figure 5.1) was proposed to mimic the transition state in the diaryl-mediated mechanism (see Scheme 5.3). 

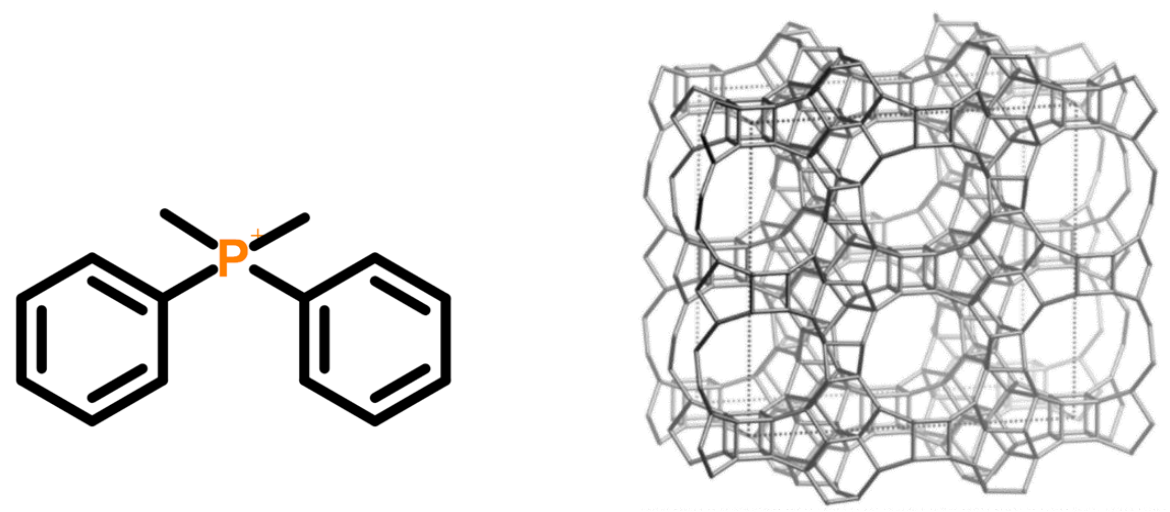

Figure 5.1 Proposed diphyneldimethylphosphonium OSDA (left) and the structure of IWV framework (right).

Using this template, a crystalline phase with IWV structure could be selectively synthesized in fluoride media and is named IWV-M. According to the PXRD pattern, IWV-M has high crystallinity with no presence of impurity or amorphous phases (see Figure 5.2). The high crystallinity is also reflected by the high microporous volume (see Table 5.1). The inspection of the sample by FEMSEM reveals the formation of plate like crystals with average sizes of 1-2 $\mu \mathrm{m}$ (see Figure 5.3). The chemical composition of IWV-M, measured by ICPAES shows that the Si/Al molar ratio is 23.8 , which is analogous to the ratio introduced in the starting synthesis gel. Efforts have been paid to broadening the $\mathrm{Si} / \mathrm{Al}$ range for the IWV materials obtained following the same mimicking approach, but the attempts starting with synthesis gels with lower $\mathrm{Si} / \mathrm{Al}$ resulted always in amorphous phase.

When knowing that IWV is a zeolite that can stabilize the TS for transalkylation reaction of diethylbenzene and benzene, other methods able to synthesize IWV zeolite are considered. For achieving this, synthesis was performed following a methodology recently described by Davis et al. using an imidazolium-based OSDA. ${ }^{8}$ A pure IWV product is obtained following this procedure (see IWV-D in Figure 5.2). The particle size is similar to IWV-M, being close to $1 \mu \mathrm{m}$ (see FESEM image in Figure 5.3B). The Si/Al of IWV-D is 13.4, similar to the 
starting material CBV720 used as silicon and aluminum source, being remarkably lower than the $\mathrm{Si} / \mathrm{Al}$ molar ratio obtained in the IWV-M sample.

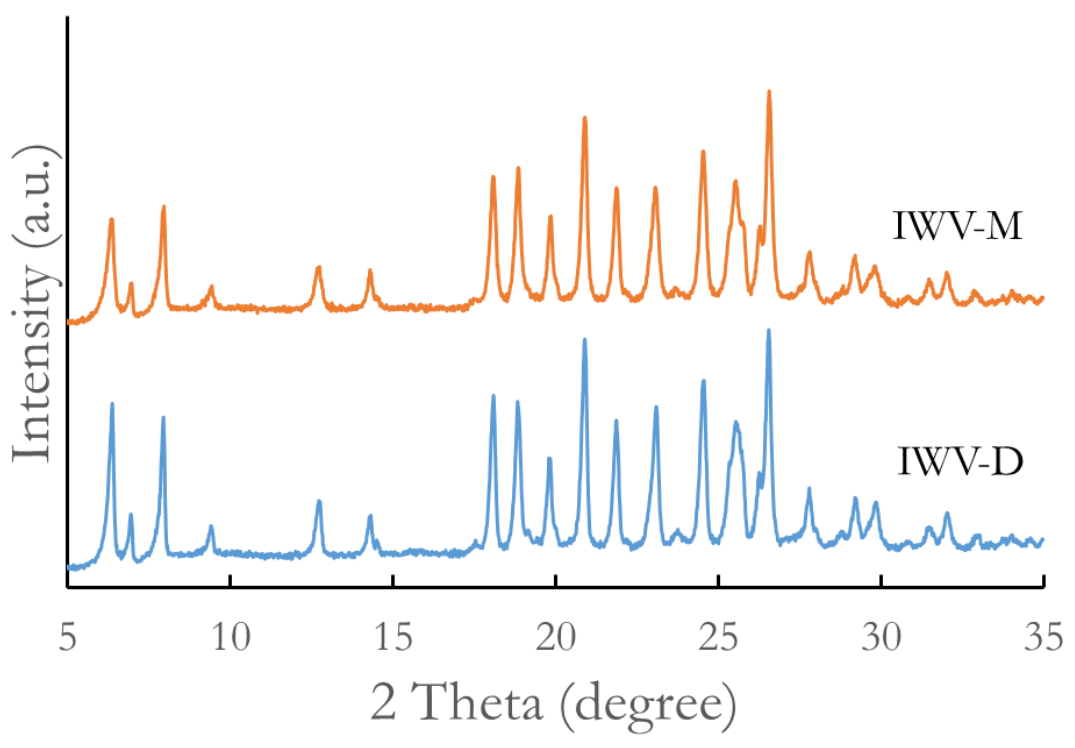

Figure 5.2 PXRD patterns of IWV-M and IWV-D samples
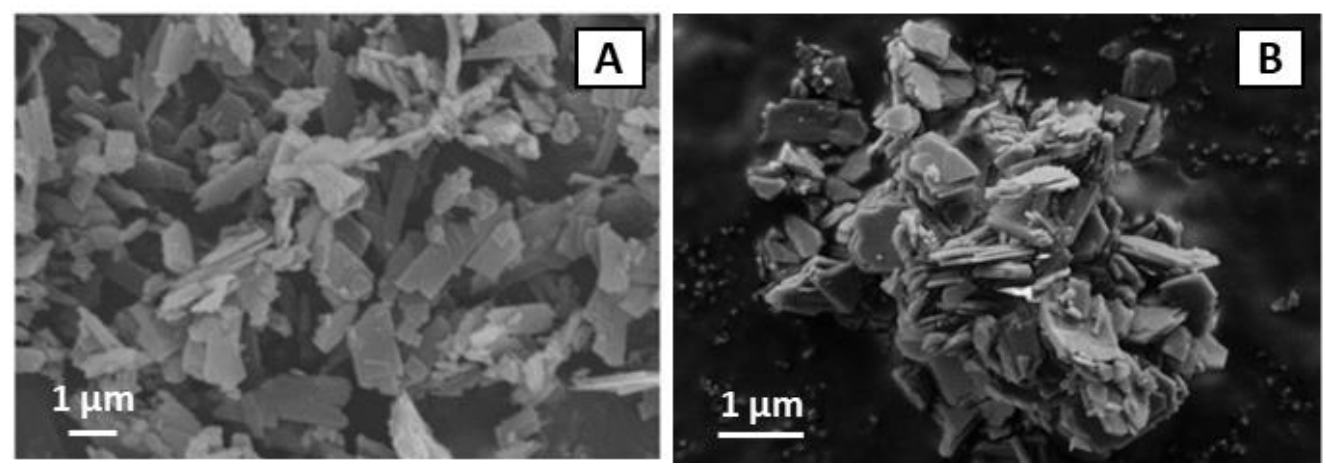

Figure 5.3 FESEM images of IWV-M (A) and IWV-D (B)

Table 5.1 Physicochemical properties of the IWV samples 


\begin{tabular}{lllllll}
\hline Sample & $\mathrm{Si} / \mathrm{Al}^{\mathrm{a}}$ & $\mathrm{Si} / \mathrm{Na}^{\mathrm{a}}$ & $\begin{array}{l}\mathrm{S}_{\mathrm{BET}}{ }^{\mathrm{b}} \\
\left(\mathrm{m}^{2} / \mathrm{g}\right)\end{array}$ & $\begin{array}{l}\mathrm{V}_{\text {micro }} \mathrm{b}^{\mathrm{b}} \\
\left(\mathrm{cm}^{3} / \mathrm{g}\right)\end{array}$ & $\begin{array}{l}\mathrm{S}_{\text {ext }} \mathrm{b}^{2} \\
\left(\mathrm{~m}^{2} / \mathrm{g}\right)\end{array}$ & $\begin{array}{l}\text { Brønsted acididy } \\
(\mathrm{mmol} / \mathrm{g})^{\mathrm{c}}\end{array}$
\end{tabular}

$150^{\circ} \mathrm{C} \quad 350^{\circ} \mathrm{C}$

\begin{tabular}{llllllll}
\hline IWV-M & 23.8 & - & 460 & 0.23 & 20 & 309 & 175 \\
IWV-D & 13.4 & $>500$ & 566 & 0.26 & 29 & 453 & 279 \\
\hline
\end{tabular}

${ }^{a}$ Measured by ICP-AES

${ }^{\mathrm{b}}$ Measured by $\mathrm{N}_{2}$ adsorption measurement

cMeasured by infrared spectra combined with adsorption of pyridine

The successful synthesis of two IWV samples with different Si/Al molar ratios allows studing the catalytic properties of such zeolites. To compare, FAU, Beta, MCM-22 and MOR, zeolites industrially used as catalysts for DEB transalkylation process have been selected to benchmark the catalytic activity of the two IWV materials. ${ }^{910}$ In this case, two commercially available USY zeolites, CBV760 ( $\mathrm{Si} / \mathrm{Al}=24.8)$ and $\mathrm{CB} 720(\mathrm{Si} / \mathrm{Al}=13.1)$, have been selected since they possess $\mathrm{Si} / \mathrm{Al}$ similar to the two IWV samples. These two zeolites present average particle sizes in the range of 400-500 nm (see Figure $5.5 \mathrm{~A}$ and B). For Beta zeolite, the commercial-available CP814C sample has been selected, with a $\mathrm{Si} / \mathrm{Al}$ of 16.4. This sample presents aggregates of $1 \mu \mathrm{m}$ that are composed of primary particles smaller than $100 \mathrm{~nm}$ (see Figure 5.5 D). The MWW zeolite has been home-made following the typical synthesis procedure using hexamethyleneimine (HMI) as template. ${ }^{11}$ The resultant sample shows pure MWW phase, according to PXRD patterns (see MWW in Figure 5.4). The sample presents plate-like crystals with average sizes of $400-500 \mathrm{~nm}$ (see FESEM image in Figure 5.5). 


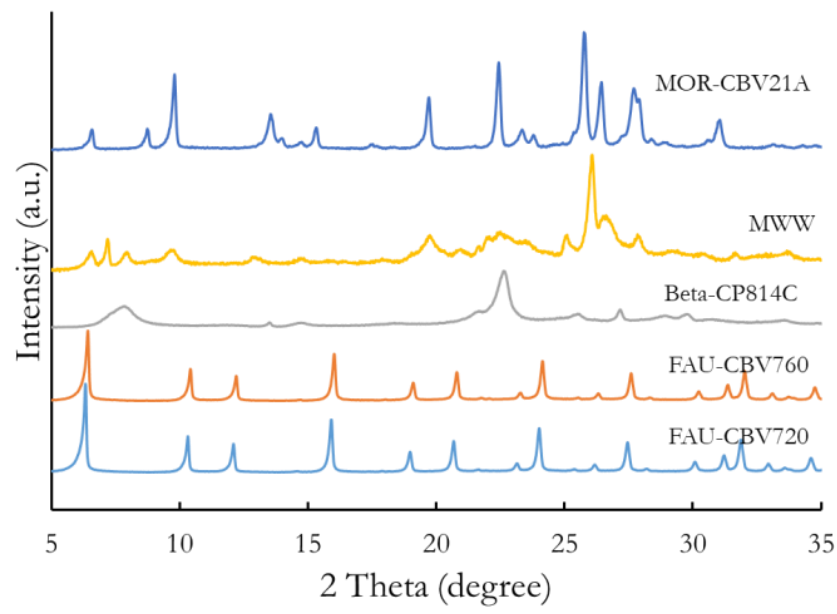

Figure 5.4 PXRD patterns of the samples employed in this study
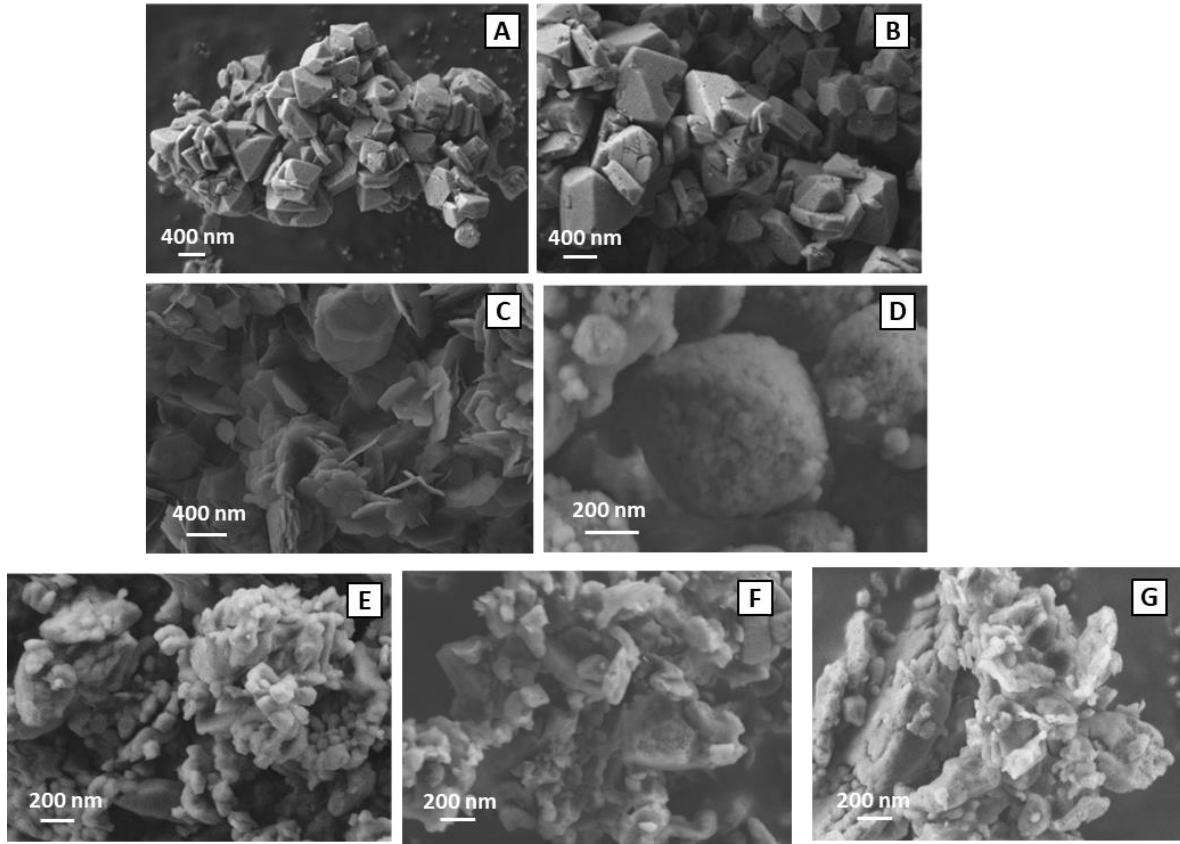

Figure 5.5 FESEM images of CBV720 (A), CBV760 (B), MWW (C), CP814C (D), CBV21A (E), CBV21A_DeAl (F) and CBV21A_meso (G). 
The Si/Al ratio of this MWW is around 20.4, similar to that of other samples presented above. Finally, a commercially available MOR, CBV21A has also been selected. The chemical analysis of this sample indicates a Si/Al molar ratio of 10 . This sample shows a nanosized morphology with primary particle size smaller than $100 \mathrm{~nm}$ (see Figure $5.5 \mathrm{E}$ ). Since the synthesis of mordenite zeolite with $\mathrm{Si} / \mathrm{Al}$ over 20 by direct synthesis is difficult, a dealumination by nitric acid was performed with CBV21A, resulting in a mordenite with Si/Al of 29.4 (see Table 5.2). The dealumination did not increase observable mesoporosity. Thus, this dealuminated mordenite is proper to compare with the other catalysts and is named CBV21A_DeAl.

Table 5.2 Physicochemical properties of the different samples

\begin{tabular}{|l|l|l|l|l|l|l|l|}
\hline Sample & $\mathrm{Si} / \mathrm{Al}^{\mathrm{a}}$ & $\mathrm{Si} / \mathrm{Na}^{\mathrm{a}}$ & $\begin{array}{l}\mathrm{S}_{\mathrm{BET}}{ }^{\mathrm{b}} \\
\left(\mathrm{m}^{2} / \mathrm{g}\right)\end{array}$ & $\begin{array}{l}\mathrm{V}_{\text {micro }}{ }^{\mathrm{b}} \\
\left(\mathrm{cm}^{3} / \mathrm{g}\right)\end{array}$ & $\begin{array}{l}\mathrm{S}_{\text {ext }}{ }^{\mathrm{b}} \\
\left(\mathrm{m}^{2} / \mathrm{g}\right)\end{array}$ & $\begin{array}{l}\text { Brønsted acid } \\
\text { amount } \\
(\mathrm{mmol} / \mathrm{g})^{\mathrm{c}}\end{array}$ \\
\hline CBV720 & 13.1 & - & 723 & 0.32 & 75 & & 287 \\
\hline CBV760 & 24.8 & - & 753 & 0.33 & 85 & 372 & 159 \\
\hline MWW & 20.4 & - & 424 & 0.16 & 81 & 348 & 225 \\
\hline CP814C & 16.4 & - & 577 & 0.25 & 73 & 300 & 201 \\
\hline CBV21A & 10 & - & 451 & 0.20 & 26 & 472 & 225 \\
\hline CBV21A_DeAl & 29.4 & - & 452 & 0.20 & 24 & 271 & 95 \\
\hline CBV21A_meso & 26.1 & 348 & 488 & 0.13 & 218 & 328 & 169 \\
\hline
\end{tabular}

${ }^{a}$ Measured by ICP-AES

${ }^{b}$ Measured by $\mathrm{N}_{2}$ adsorption measurement 
${ }^{\mathrm{c}}$ Measured by infrared spectra combined with adsorption of pyridine

To summarize, two IWV samples with different $\mathrm{Si} / \mathrm{Al}$ molar ratios have been obtained together with other industrially relevant zeolites for the transalkylation reactions, which possess similar physicochemical properties to IWV samples but different pore topologies. Thus, it is possible to evaluate the catalytic activity of these materials for the transalkylation reaction between DEB and benzene.

\subsubsection{Catalytic evaluation}

The optimized conditions optimized for transalklylation reaction of DEB and benzene vary among the different technologies. In general, WHSV is in the range between $1-10 \mathrm{~h}^{-1}$, pressure between $0.4-4.0 \mathrm{MPa}$ and temperature in the range of $180-260^{\circ} \mathrm{C}$. Based on literature, the following conditions to carry out the $\mathrm{DEB}$ transalkylation reaction was selected: temperature $250^{\circ} \mathrm{C}$, pressure $3.5 \mathrm{MPa}$ and $\mathrm{WHSV}_{\mathrm{DEB}} 10 \mathrm{~h}^{-1}$. It is important to note that under these conditions, the reaction will proceed in liquid phase, which means that the fast deactivation by coke formation will be mostly prevented.

First, zeolite samples with different structure and Si/Al ratio between 20 and 25 have been tested under the above reaction conditions and the results are shown in Figure 5.6. 

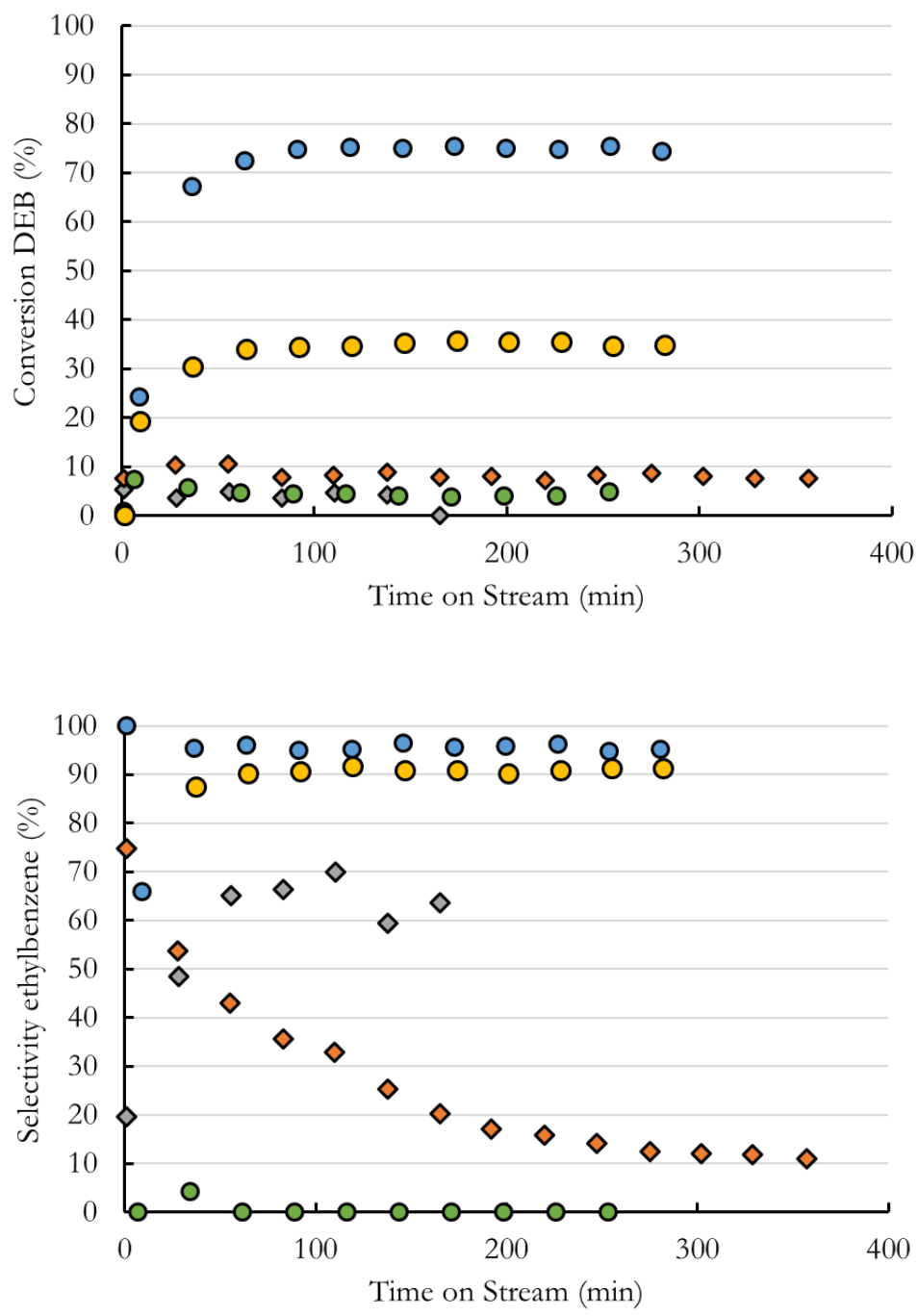

oIWV-M $\diamond \operatorname{Beta(CP814C)~OFAU(CBV760)~} \diamond \mathrm{MWW} \quad$ OCBV21A-DeAl

Figure 5.6 Conversion of DEB (top) and EB selectivity (bottom) along Time-On-Stream over different catalysts. Reaction conditions: $\mathrm{T}=250^{\circ} \mathrm{C} ; \mathrm{P}=3.5 \mathrm{MPa}, \mathrm{WHSV}_{\mathrm{DEB}}=10 \mathrm{~h}^{-1} ; \mathrm{Bz} / \mathrm{DEB}=$ $3: 1(w t)$. 
It can clearly be observed that the IWV-M catalyst shows the highest steadystate DEB conversion, reaching 75\% (see Figure 5.6 top). Considering the industrially relevant catalysts, the best performance was achieved with FAU (CBV760) with a steady-state DEB conversion of 35\%. In the case of Beta and MWW, the steady state DEB conversions are much lower, both being around 8\%. The lowest conversion has been obtained using CBV21A_DeAl, presenting a DEB conversion close to $5 \%$. In terms of selectivity to EB, IWV-M also shows a substantial difference compared to the other catalysts (see Figure 5.6 bottom). Among the commercial catalysts, only FAU and Beta maintain steady selectivities along Time-On-Stream, being 90\% for FAU and $60 \%$ for Beta. MWW reaches a high selectivity at the beginning $(\sim 75 \%)$. However, an obvious deactivation is observed along Time-On-Stream. In the case of mordenite zeolite, the selectivity to $\mathrm{EB}$ is always near $0 \%$ and the main products were heavier products from dealkylation, such as triEB and tetraEB. Among the commercial zeolites, it seems that those with tri-dimensional channel system (FAU and Beta) could gave steady selectivity, while the bidimensional zeolite MWW showed high EB selectivity with fast deactivation and little yield of EB could be observed for unidimensional mordenite zeolite. IWV, though being bidimensional, showed superior selectivity to EB than all the zeolites studied here and could maintain steady conversion throughout the reaction.

The limited DEB conversion as well as low selectivity of mordenite zeolite could be ascribed to its unidimensional channel system which could cause severe diffusion limitations to both reactants and products. For this reason, a mordenite zeolite sample has been prepared via a desilication followed by dealumination of commercial CBV21A to obtain reasonable mesoporosity. The sample obtained by this method was named CBV21A_meso. CBV21A_meso has a Si/Al of 26.1, which is similar to CBV21A_DeAl and other materials included in this study. Meanwhile, the external surface area has increased from $26 \mathrm{~m}^{2} / \mathrm{g}$ to $218 \mathrm{~m}^{2} / \mathrm{g}$ (see Table 5.2) as a result of the generation of mesopores (see CBV21A_meso in Figure 5.7). In order to obtain an observable activity, the temperature of transalklylation reaction over mordenite samples was increased to $300^{\circ} \mathrm{C}$ to increase reaction rate. 

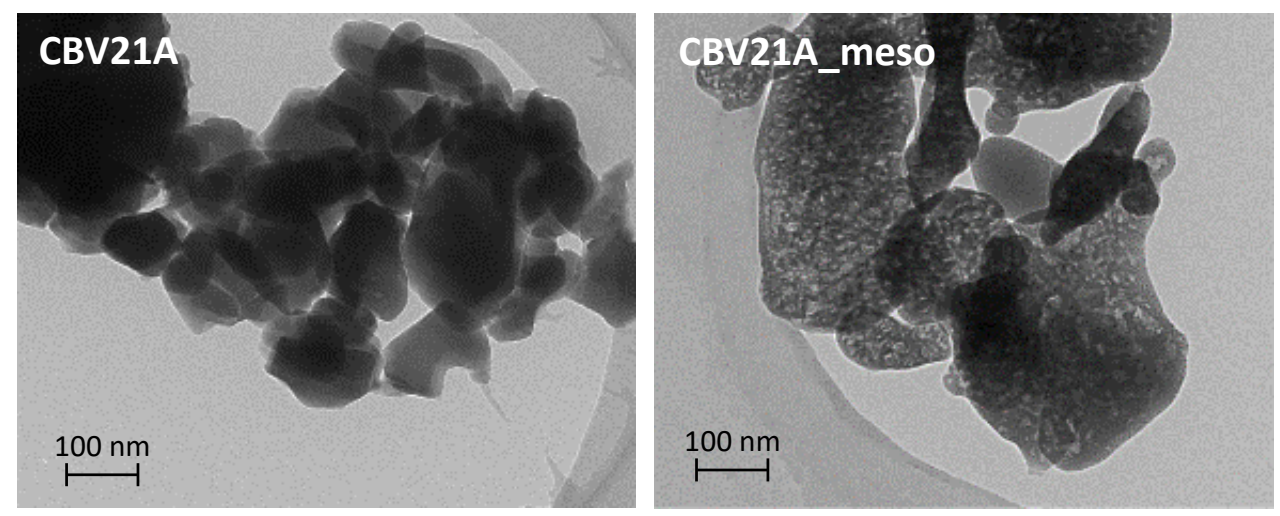

Figure 5.7 TEM images of CBV21A and CBV21A_meso samples
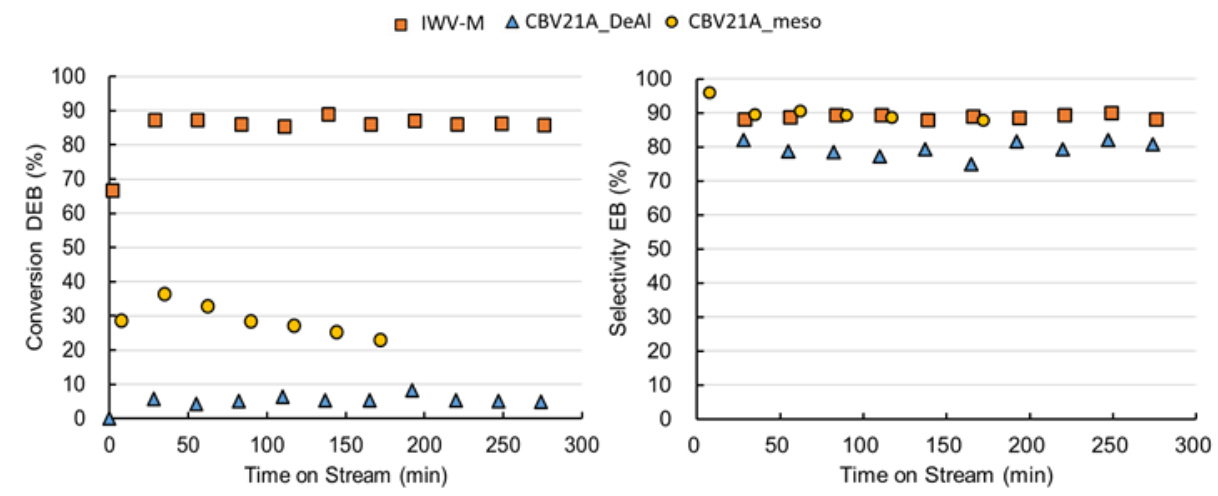

Figure 5.8 Conversion of DEB (left) and EB selectivity (right) along Time-On-Stream over different catalysts. Reaction conditions: $\mathrm{T}=300^{\circ} \mathrm{C} ; \mathrm{P}=3.5 \mathrm{MPa}, \mathrm{WHSV}_{\mathrm{DEB}}=10 \mathrm{~h}^{-1} ; \mathrm{Bz} / \mathrm{DEB}=$ $3: 1(w t)$.

At $300^{\circ} \mathrm{C}$, CBV21A_DeAl still shows low DEB conversion of $\sim 5 \%$ but the selectivity to $\mathrm{EB}$ has increased to $80 \%$ (see Figure 5.8). This could be a result of better diffusion caused by higher temperature. As a result, the reaction could take place inside the 12-ring pores of MOR, explaining its higher EB selectivity. CBV21A_meso, the mesopore-containing counterpart of CBV21A_DeAl, i.e., 
shows a six-fold increase of DEB conversion compared to CBV21A_DeAl, while maintaining a selectivity to $\mathrm{EB}(\sim 90 \%$, see Figure 5.8$)$. This fact is clearly suggesting that higher accessibility caused by generation of mesoporosity could optimize the catalytic activity of mordenite. However, it is important to remark that under the same conditions, IWV-M showed a DEB conversion of $84 \%$ with EB selectivity higher than $98 \%$ (see Figure 5.8), which is much higher than the two mordenites studied in this work.

Therefore, it is possible to conclude that among the different structures tested under this preliminary reaction conditions, IWV is the most active catalyst with the highest selectivity to EB. The second most active material is FAU, presenting relatively lower DEB conversion and EB selectivity. Since the other zeolites prepared with similar physicochemical properties to IWV-M (i.e. crystal size and $\mathrm{Si} / \mathrm{Al}$ molar ratio) show much lower catalytic activity, further catalytic studies will be focus on IWV and FAU zeolites.

Acidity plays an important role in zeolite catalysis and, for this reason, samples with different $\mathrm{Si} / \mathrm{Al}$ should be compared to eliminate its influence before to draw a final conclusion on the impact of structures. Considering this, IWV-D and CBV720, both with lower Si/Al, than IWV-M and CBV760, have been also tested as catalysts in the transalkylation reactions. It is necessary to point out that under the above described conditions, IWV-M and CBV760 have already reached DEB conversion of between $75 \%$ and $35 \%$. If the DEB reaches conversion as high as $80 \%$, then the reaction can be controlled by thermodynamic equilibrium and cannot reveal the real capacity of the catalyst. Thus, we decided to work at experimental conditions to obtain conversions well below the thermodynamic equilibrium. To do that, the WHSV has been increased to $40 \mathrm{~h}^{-1}$, which is four times higher than in previous experiments, to assure lower DEB conversion values for all samples. The catalytic test results of the four zeolites are shown in Figure 5.9. 


\section{OITQ27-mimic OFAU(CBV760) OITQ27-Davis OFAU(CBV720)}
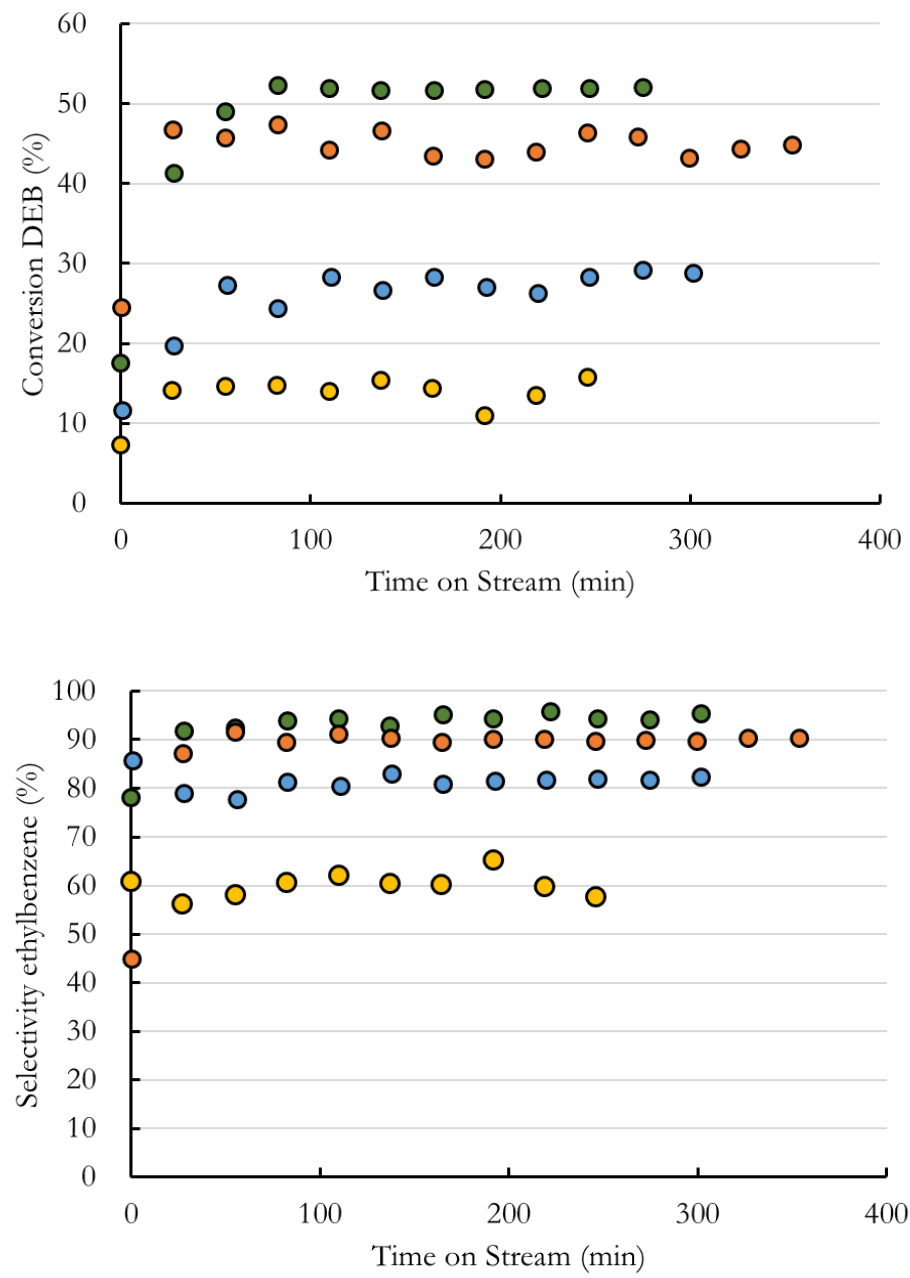

Figure 5.9 Conversion of DEB (top) and EB selectivity (bottom) along Time-On-Stream over different catalysts. Reaction conditions: $\mathrm{T}=250^{\circ} \mathrm{C} ; \mathrm{P}=3.5 \mathrm{MPa}, \mathrm{WHSV}_{\mathrm{DEB}}=40 \mathrm{~h}^{-1} ; \mathrm{Bz} / \mathrm{DEB}=$ 3:1 (wt).

Under these reaction conditions, the DEB conversion values of IWV-M and CBV760 have dropped to $\sim 29 \%$ and $\sim 15 \%$, respectively (see Figure 5.9 top). 
IWV-D, with a higher $\mathrm{Si} / \mathrm{Al}$ of 13.4 , shows a steady-state $\mathrm{DEB}$ conversion of $52 \%$, which is twice as much as IWV-M, being this difference linearly correlated to the aluminum content. On the other hand, CBV720, with Si/Al of 13.1, showed a DEB conversion of $45 \%$. The fact that the conversion values are below $50 \%$, can guarantee that equilibrium has not been reached in this case. Both materials with lower $\mathrm{Si} / \mathrm{Al}$, showed around $90 \% \mathrm{~EB}$ selectivity while IWV$\mathrm{M}$ and CBV720 gave $80 \%$ and $60 \%$, respectively (see Figure 5.9 bottom). Then, regardless of the $\mathrm{Si} / \mathrm{Al}$ ratio studied here, IWV materials present superior DEB conversion capability than FAU materials, which means that the acidic properties are not the reason for the higher activity showed by IWV materials compared to other materials. Combined with the fact that IWV is a bidimensional zeolite which showed superior activity than both unidimensional and tri-dimensional zeolites, it is possible to draw a preliminary conclusion that the framework structure of IWV should facilitate the transalkylation reaction and this can be due to a better stabilization of the reaction transition state, as a consequence of the TS mimic used for the zeolite synthesis.

In order to further investigate the catalytic behavior of the IWV and FAU materials, the transalkylation reaction was performed at different contact in order to obtain the initial reaction rate. Since diethylbenzene can be converted by transalkylation with either benzene or another diethylbenzene, the conversion data is a comprehensive result of these parallel reactions. Thus, the initial reaction rate is measured on the basis on ethylbenzene yield since at lower level of yield, secondary reaction such as disproportionation and dealkylation can be considered in a very low scale and transalkylation reaction could be measured as an elementary step. This can be reflected by the linear correlation between ethylbenzene yield and contact time in Figure 5.12 when the yield is below 50\%. Based on the data, initial reaction rates were calculated for the IWV and FAU materials and the results are listed in Table 5.5. It is obvious that compared to FAU, IWV with similar $\mathrm{Si} / \mathrm{Al}$ shows superior initial reaction rate as well as when normalized by aluminum amount. 


\section{OITQ27-mimic OFAU(CBV760) OITQ27-Davis OFAU(CBV720)}

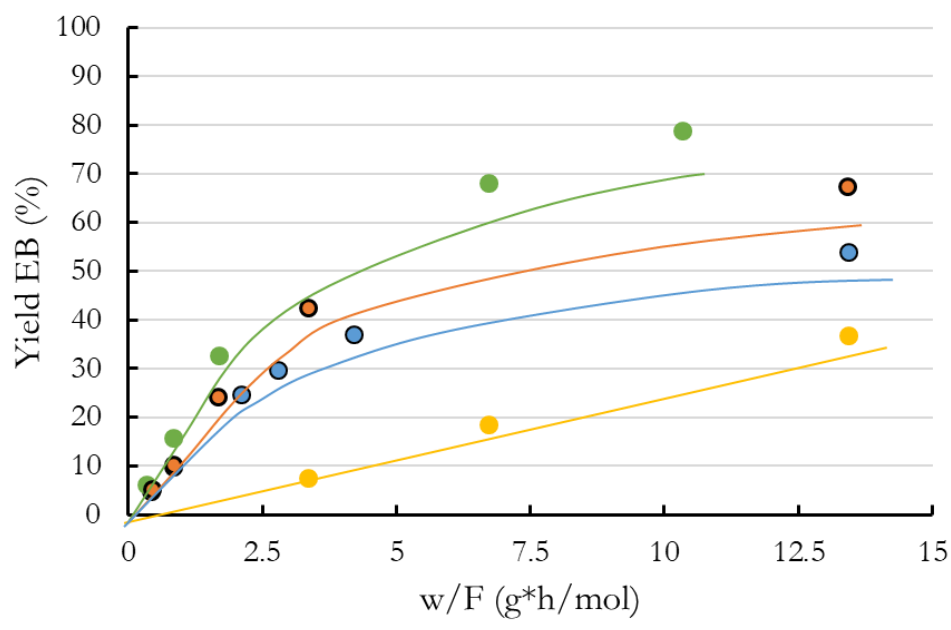

Figure5.10 Yield of ethylbenzene in transalkylation reaction of diethylbenzene and benzene at different contact time. Reaction condition: temperature, $250^{\circ} \mathrm{C}$; pressure, $3.5 \mathrm{MPa}$.

Table 5.3 Initial reaction rate of ethylbenzene yield in transalkylation reaction of diethylbenzene and benzene, turnover frequencies and their corresponding value normalized by $\mathrm{Al}$ amount.

\begin{tabular}{cccc}
\hline & Si/Al & $\begin{array}{c}\text { Initial reaction rate } \\
(\mathrm{mol} \mathrm{EB} /(\mathrm{mol} \\
\mathrm{cat*})\end{array}$ & $\begin{array}{c}\text { TOF per } \mathrm{Al} \\
\left(\mathrm{h}^{-1}\right)\end{array}$ \\
\hline IWV-M & 23.8 & 7.1 & 168.5 \\
IWV-D & 13.4 & 11.7 & 156.8 \\
CBV760 & 24.8 & 1.7 & 41.7 \\
CBV720 & 13.1 & 8.6 & 113.2 \\
\hline
\end{tabular}




\subsection{Methanol to Olefin reactions}

The previous illustration of utilizing IWV materials in EB-related reactions inspired from synthesis using OSDA mimicking reaction transition state, it can effectively prove the idea that proper OSDAs can facilitate the formation of cavities with particular shape/size that could favor selected reaction pathways. The reaction mechanisms of aromatic transalkylation, alkylation and disproportionation are well-established, and the network is centered at EB with no interferences between each reaction (see Scheme 5.3). Thus, in a reaction network that have one species in the center, in this case EB, the reaction pathway could be preferentially altered by favoring the transition state using material acquired from mimic synthesis strategy.

Herein, in this part of the thesis, will attempt to extend this mimic methodology into reactions with more complex reaction networks, involving various intermediates that could lead to different product distributions. To this extent, MTO has been proposed as an example of complex reaction, in which various transition states or intermediates are involved.

\subsubsection{Understanding of the reaction mechanism}

The MTO reaction is a commercial process that convert syngas to light olefins via methanol using zeolite or zeotype materials as catalysts. ${ }^{18,19}$ Methanol can be used as a key molecule to establish the bridge between methane and $\mathrm{CO}_{2} / \mathrm{CO}$ and production of olefinic and aromatic hydrocarbon products or as an effective hydrogen storage molecule. Current processes for converting methanol to hydrocarbons are conducted under high temperature $\left(350-450^{\circ} \mathrm{C}\right)$ at atmospheric pressure in presence of acid catalysts, usually aluminosilicate zeolites or zeotype silicoaluminophosphates. ${ }^{19}$ The conversion of methanol to olefins has been readily developed industrially and commercialized worldwide though its reaction mechanism is still under debate,and different reaction mechanism are involved. ${ }^{20}$ This is due to the high complexity of the process in where the products contain numerous paraffins, olefins and aromatics, ranging from $\mathrm{C}_{1}$ (methane) to $\mathrm{C}_{14+}$ (polialkylated naphtalene), and their distribution could 
be very different according to the reaction conditions and, more importantly, the acidity, pore size and cavity shape of the zeolite catalyst.

The active $\mathrm{C}-\mathrm{OH}$ bond rendered methanol the ability to be activated under elevated temperatures or facing acid catalysts. Although it is still under debate what is the first molecule or intermediate and how it is formed, it is generally accepted that MTO reactions proceed through an indirect hydrocarbon pool (HP) mechanism (see a brief scheme in Scheme 5.6).

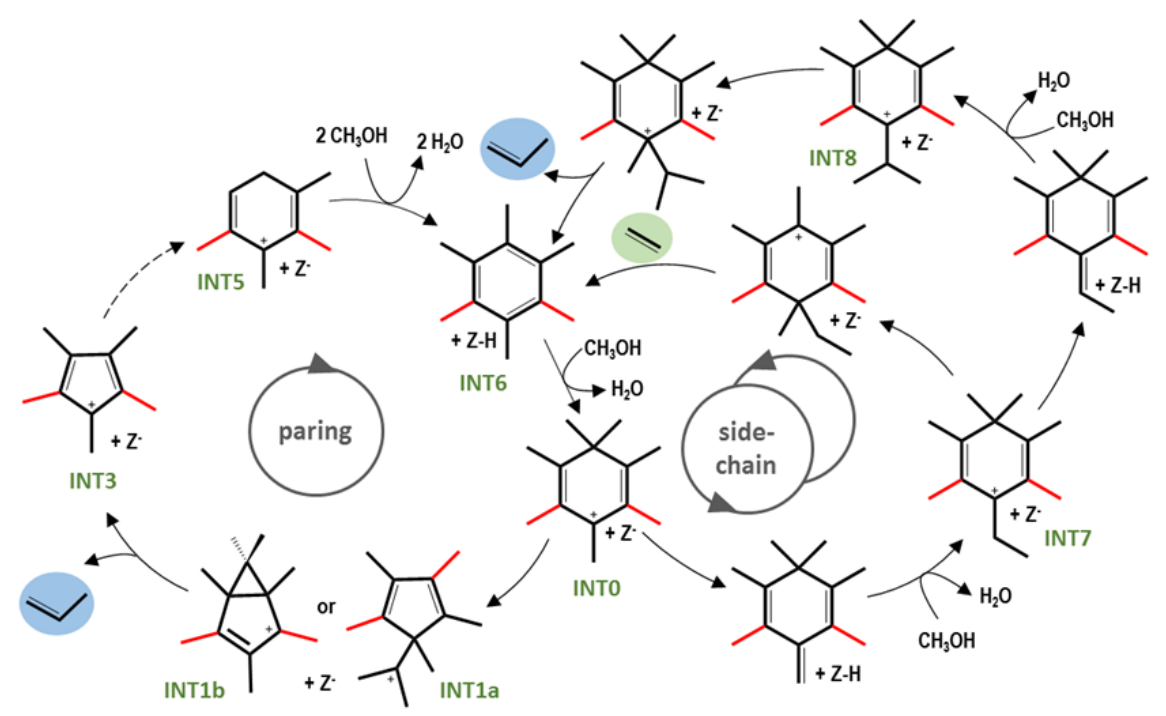

Scheme 5.6 Proposed hydrocarbon pool mechanisms for the MTO reaction, including the paring and side-chain routes. Figure adapted from ref.21,24

According to HP mechanism, starting at Time-On-Stream zero, MTO reactions first undergo an induction period in where after the formation of the first C-C bond, several hydrocarbon species are formed inside zeolite cavities and serve as reactive center molecules, which should be methylated by activated methanol to form the hydrocarbon pool (HP) species. 
In cage-based zeolites and zeotype materials, such as SAPO-34, SSZ-13 or SAPO-18, among others, the HP species are dominantly aromatics and cyclopentyl species. (see Scheme 5.6). The large void in cavities enables hydrogen transfer and cyclization of olefins, producing cyclic HP species. Depending on the shape of the cavity in zeolites and reaction conditions, the cyclic HP species could be polyalkylbenzenes (PABs) and polyalkylbenzenium cations $\left(\mathrm{PAB}^{+}\right)$, as well as polyalkylcyclopentyl cations $\left(\mathrm{PACP}^{+}\right)$. The methylation by activated methanol proceeds repeatedly and the degree of methylation of the TSs keeps increasing. Along with increasing methylation degree, the stability of the carbocation would decrease and shows higher tendency to produce light olefins by either dealkylation or ring-extraction. The remaining carbocation is then ready to be alkylated again, closing a catalytic cycle (see Scheme 5.6).

The aromatic-based cycle starts with formation of polymethylated benzene (PMB), which is the product of the aforementioned hydrogen transfercyclization of olefins. Then, the PMB could be easily methylated to have higher alkylated PMB molecules. At some point, the methylation will take place on a ring carbon that has already been methylated, forming a tetraalkylated carbon (INT0 in Scheme 5.6). ${ }^{14}$ This molecule could further undergo two possible pathways. One is a deprotonation to form stable neutrally charged PAB species, being the aromatic ring transformed to cyclohexadiene and an exocyclic double bond, which prones to be alkylated by methanol, forming an ethyl or an isopropyl group (see INT7 or INT8 in Scheme 5.6). With an elimination of the ethyl or isopropyl group to produce ethene and propene, respectively, the cyclohexadiene ring returns to a cyclohexyl carbocation and then is stabilized by deprotonation to form PMB, closing the catalytic cycle (see Scheme 5.6). Since in this mechanism the key step is the methylation on side-chain rather than ring methylation, the pathway is named side-chain pathway or side-chain mechanism. Another possibility is going through a ring contraction and form $\mathrm{PACP}^{+}$, where the carbocation could be either inside the ring (INT1b) or on the side group (INT1a) (see Scheme 5.6). Such ring contraction would push the tetraalkylated ring carbon out of the ring and form a tetraalkylated side group, which is prone to dealkylation, producing propene. Finally, the cyclopentacarbocation expands 
to $\mathrm{PAB}$ species and close the catalytic ring (see Scheme 5.6). Since this mechanism involves a step of pushing out one carbon followed by elimination, the mechanism is named paring as a metaphoric description of the elimination.

\subsubsection{OSDA selection for zeolite synthesis}

From the brief description of the mechanism on the MTO process, one can see that the transition states and intermediates of the mechanisms differ in molecular size and could be limited by the size of the channel or the shape of the cavity present in the zeolite catalyst used. It has been repeatedly reported that using small-pore cage-based zeolites, the product selectivity between different light olefins as well as their resistance against deactivation by coke can be influenced by the framework structure. ${ }^{25-27}$ In general, after trial and error screening of zeolite catalysts, the better catalysts focused so far are cage-based small pore zeolites with adequate cage sizes similar to the size of reaction intermediates. For instance, the CHA-type framework, being typical materials SSZ-13 and SAPO34 , is composed of a stacking of double six-member rings (D6R), forming a cage with dimensions of $11.7 \times 10.2 \AA$ (see Scheme 5.7 ). SAPO-34 is currently used in industry as one of the most successful catalysts for MTO processes. ${ }^{19}$ AEI type framework, being typical materials SSZ-39 and SAPO-18, is also composed of a stacking of D6Rs but in a different way than CHA (see Scheme 5.7). The cage in AEI framework $(12.6 \times 11.2 \AA)$ is similar in size to that in CHA framework. The proper size of the cage rendered the AEI materials good stability in the MTO reaction. ${ }^{16}$ However, the shape of cage in AEI is not symmetric but a basket-type shape(see Scheme 5.7). As a result, AEI zeolite shows higher selectivity to propene than ethene in MTO reaction than $\mathrm{CHA}$ zeolites $\left(\mathrm{C}_{3}{ }^{=} / \mathrm{C}_{2}{ }^{=}\right.$ratios of $\sim 2.4$ and $\sim 1.1$, respectively). ${ }^{16,17}$ 
CHA

$\mathrm{C}_{3}=/ \mathrm{C}_{2}=$ in MTO:

SSZ-13: 1.0

SAPO-34: 1.2

AEI

$\mathrm{C}_{3}=/ \mathrm{C}_{2}=$ in MTO:

SSZ-39: 2.6

SAPO-18: 2.2
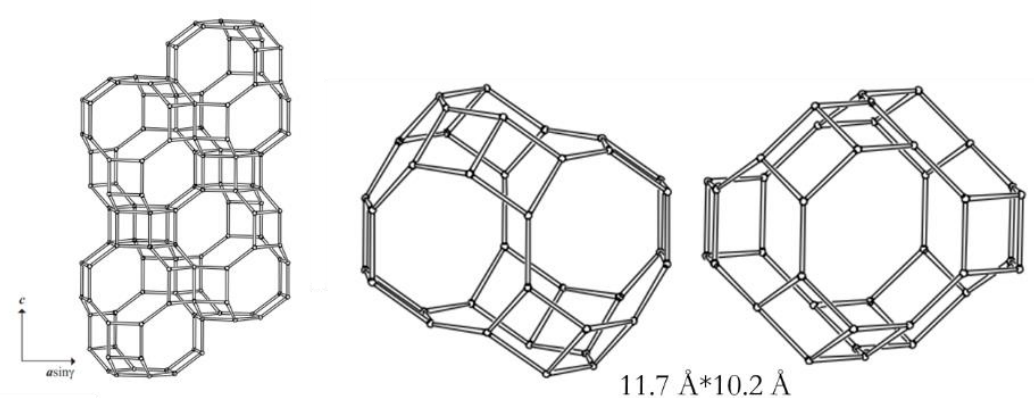

$11.7 \AA * 10.2 \AA$

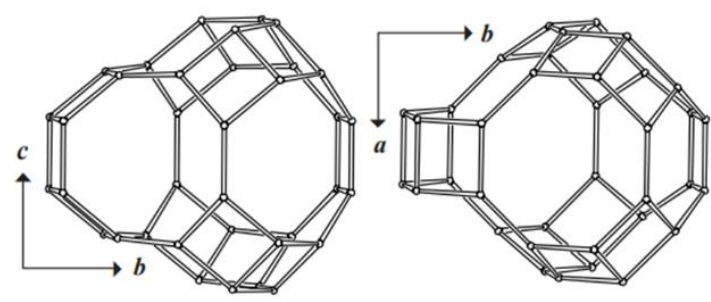

$12.6 \AA * 11.2 \AA$

Scheme 5.7 CHA and AEI type cages and their stacking patterns. Reaction conditions for

$$
\mathrm{C}_{3}=/ \mathrm{C}_{2}=\text { ratios, } \mathrm{T}=350^{\circ} \mathrm{C}, \mathrm{WHSV}_{\mathrm{MeOH}}=0.8 \mathrm{~h}^{-1} .16,17
$$

The comparison between CHA and AEI clearly illustrates that differences in cage shape could largely affect the catalytic activity of zeolites. Thus, it could be envisioned that if the shape of the cage could be tuned, even small differences shall influence the resultant catalytic activity. If so, it seems reasonable that if it is possible to design and manufacture the small-pore zeolite with a cage of proper size and shape to maximize the stabilization of particular HP intermediates, the catalytic performance of the resultant zeolite in terms of selectivity toward certain product, or resistance against deactivation by coke, could be significantly influenced. At this point, the mimic synthesis strategy seems promising to achieve such goal, since as previously illustrated in the case of $\mathrm{EB}$ reactions, this mimic strategy will facilitate the formation of zeolite cavities that could favor certain intermediates or transition states. Now that the reaction network for MTO reactions is pre-established, although still yet under debate, the general idea of side chain and paring pathways in HP mechanism can be used as a starting point. Moreover, if through this methodology the obtained materials 161 
are able to favor certain pathways, the still under debate HP mechanism could be further supported.

Similar to the case of EB centered reactions, in order to adopt mimic synthesis to obtain proper zeolites for MTO reactions, it is necessary to propose key molecules that could determine the reaction pathway. From the brief description of MTO mechanism above, it is important to remark that the intermediates in aromatic-based mechanism are rigid due to the presence of aromatic rings, thus the corresponding mimics based on ammonium should be ideal candidates to direct zeolite synthesis, considering that the positive charges could be properly introduced. Among the aromatic-based mechanisms, the most interesting should be the paring pathway since, according to the proposed mechanism, there is a ring contraction that forms isopropyl or tert-butyl groups and the formation of ethyl group is less probable. Thus, the olefins formed from the paring pathway are preferentially propene, butenes or pentenes. On the other hand, side-chain pathway produces both ethene and propene. Therefore, if the paring pathway could be enhanced by certain catalyst, it should increase the added value to methanol conversion since propene would be preferentially formed. For this reason, we have been focused here on zeolite synthesis using OSDAs mimicking intermediates and transition states within the paring mechanism.

According to the aromatic-based cycle in HP mechanism, one group of the key molecules is polymethylbenzenes (see for instance INT6 in Scheme 5.6). First, they are produced through aforementioned hydrogen transfer-cyclization of olefins, so they can be seen as the transfer step from olefin-based cycle to the aromatic-based cycle. Second, both side-chain and paring mechanisms start with INT6, since the first step of both cycles involves the methylation of INT6 to form INT0 (see Scheme 5.6). Both side chain and paring mechanisms will also finalize in INT6, either following ring expansion in paring mechanism or side chain dealkylation in side chain mechanism. Lastly, the structure of PMB contains one aromatic ring with methyl groups as the sole substituents. Such structure guarantees the rigidity of the molecule and the corresponding mimic organic ammonium should be stable in configuration under synthesis conditions. Thus, INT6, as a representative of the PMB species, should be considered a key 
molecule. At this point, it is important to keep in mind that the structure of OSDA should mimic not only the structure of reaction intermediate, but also its positive charge distribution. Considering these prerequisites, the following tetramethylpyridinium template (OSDA3) is proposed as potential mimic of the intermediate INT6 (see Scheme 5.8).
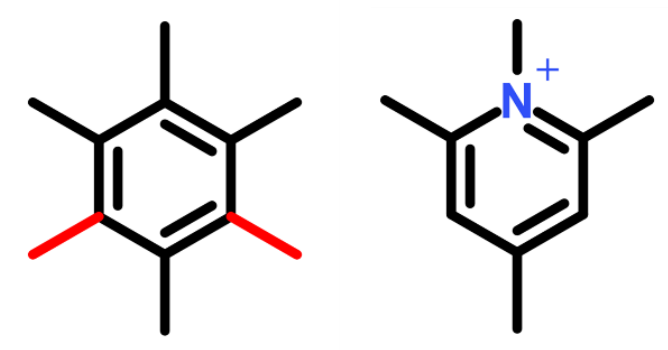

Scheme 5.8 Structure of INT6 (left) and OSDA3 (right) (bonds in red represent optional bond)

After the methylation to form INT0, the mechanism separates into paring and side-chain pathways. In the paring mechanism, the very first step after formation of INT0 includes the ring contraction and formation of five-member ring intermediates (INT1a and INT1b, see Scheme 5.6) Depending on the mechanism proposed, the five-member ring intermediates could have positive charges either on the side chain isopropyl group (INT1a, see Scheme 5.9) or inside the five-member ring (INT1b, see Scheme 5.10). Two OSDAs are designed to mimic each of those intermediates. OSDA1a is designed to have a five-member ring with an ammonium substituting one carbon atom, which is directly connected to an isopropyl and a methyl groups (see Scheme 9). On the other hand, when the positive charge of the intermediate is inside the fivemember ring (INT1b), the corresponding ammonium should be stable enough to have an ammonium in the same position as the carbocation in the intermediate. Thus, a mimic OSDA (OSDA1b) is also proposed and synthesized (see Scheme 5.10). 


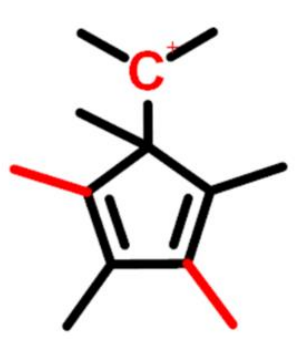

INT1a

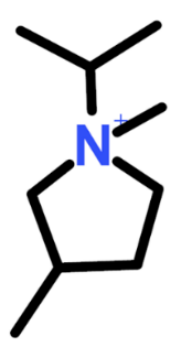

OSDA1a

Scheme 5.9 Structure of INT1a and OSDA1a. (bonds in red represent optional bond)

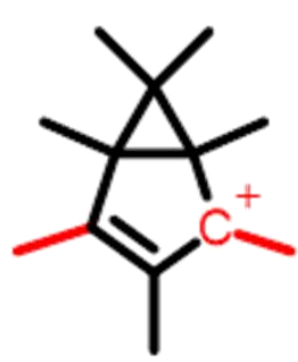

INT1b

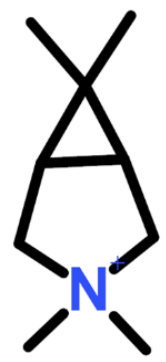

OSDA1b

Scheme 5.10 Structure of INT1b and OSDA1b. (bonds in red represent optional bond)

INT1a and INT1b intermediates are considered to be the precursor species for propene yielding step. Following the dealkylation to produce propene, both molecules will discard their bulky side-chain and return to methylated fivemember ring carbocation (INT3). It seems that if INT3 could be stabilized, its free energy should be lowered, generating larger energetic difference between before (INT1) and after (INT3), and then yielding propene (see Scheme 5.6). For this reason, a pentamethylimidazolium OSDA (OSDA2) was proposed and synthesized mainly considering its structural and configurational similarity to INT3. 


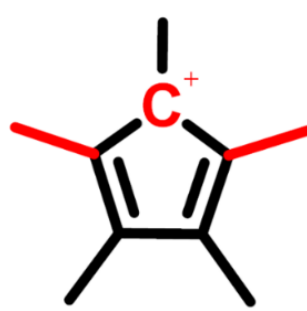

INT3

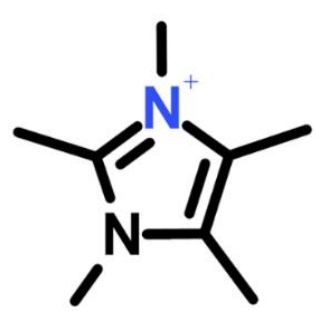

OSDA2

Scheme 5.11 Structure of INT3 and OSDA2 (bonds in red represent optional bond)

As a summary of the OSDA selection, several intermediates have been proposed as important molecules in THE paring pathway. The key intermediates of the paring pathway are mainly related with precursors and products of ring contraction and expansion. To each intermediate, one OSDA was proposed to best mimic its structure, shape, configuration and charge distribution. It is expected that through mimicking the intermediates of the paring pathway, the OSDAs could direct the formation of zeolites that would enhance this pathway and, therefore, promote the yield of propene and butenes.

\subsubsection{Materials synthesis, characterizations and catalytic evaluations}

After carefully selecting the OSDAs, the next step for zeolite synthesis would be to establish the synthesis conditions. There are various factors that could influence the product of zeolite synthesis, including starting materials of Si and $\mathrm{Al}$ sources, addition of OSDA, presence of alkaline cations, the alkalinity of the synthesis gel, the gel concentration or the presence of fluoride anions. Among these compositional factors, one should also consider crystallization temperature and time, as well as stirring. ${ }^{28}$ It has been reported repeatedly that starting with different $\mathrm{Si}$ and $\mathrm{Al}$ sources, either from amorphous materials or precrystallized zeolites, the crystallization of zeolites could be altered, not only in nucleation rate but also the framework structure of the resultant materials. ${ }^{29}$ For this reason, 
silica sol and aluminum hydroxide were selected as amorphous source materials and ultrastablized Y zeolite (CBV720 and CBV760) as precrystallized source materials. In order to avoid low phase selectivity caused by lack of OSDA, the ratio of OSDA/Si is set as $0.2-0.4$, a predominantly higher amount than normally incorporated in the resultant zeolites. The influence of alkaline cations is also considered. Thus, the syntheses were performed either with or without presence of $\mathrm{Na}^{+}(\mathrm{Na} / \mathrm{Si}=0-0.2)$. When $\mathrm{Na}$ is employed, the amount of OSDA is reduced in order to maintain the same $\mathrm{OH}^{-} / \mathrm{Si}$ in the gel. The water amount is adjusted to the range of $\mathrm{H}_{2} \mathrm{O} / \mathrm{Si} \sim 3-20$, considering that concentrated gels would facilitate nucleation and accelerate crystallization. Finally, the fluoride system is also investigated by introducing $\mathrm{NH}_{4} \mathrm{~F}$ as fluoride source, with the amount equal to total $\mathrm{OH}^{-}$in the gel. Thus, for zeolite synthesis, the conditions are set as $\mathrm{Si} / \mathrm{Al}$ [6-15], OSDA/Si [0.2-0.4], NaOH/Si [0-0.2], $\mathrm{H}_{2} \mathrm{O} / \mathrm{Si}$ [3-20].

Due to the pioneer examples of SAPO-34 and SAPO-18 as efficient catalysts for MTO reactions, the synthesis of silicoaluminophosphate materials are also included in the study. In general, SAPO materials are synthesized in mild alkalinity or neutral $\mathrm{pH}$ systems, using $\mathrm{H}_{3} \mathrm{PO}_{3}$ as $\mathrm{P}$ source and aluminum oxide as $\mathrm{Al}$ source. The gel compositions for $\mathrm{SAPO}$ syntheses are set as follows: $\mathrm{P} / \mathrm{Al}$ [0.8-0.9], OSDA/(Al+P) [0.2-0.4], $\mathrm{H}_{2} \mathrm{O} / \mathrm{Si}$ [3-20]. The first OSDAs that have been evaluated for zeolite and zeotype syntheses are OSDA1 a and OSDA1b and the achieved solids are summarized in Figure 5.12. 


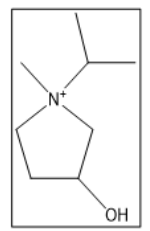

\begin{tabular}{|c|c|c|c|c|c|}
\hline \multirow{3}{*}{$\begin{array}{c}\text { (a) Zeolite } \\
\left(\mathrm{SiO}_{2}\right)\end{array}$} & & \multicolumn{2}{|c|}{$\mathrm{Si} / \mathrm{Al}=6$} & \multicolumn{2}{|c|}{$\mathrm{Si} / \mathrm{Al}=15$} \\
\hline & & $\mathrm{OSDA} / \mathrm{Si}=0.2$ & $\mathrm{OSDA} / \mathrm{Si}=0.4$ & $\mathrm{OSDA} / \mathrm{Si}=0.2$ & OSDA/Si=0.4 \\
\hline & & $\mathrm{NaOH} / \mathrm{Si}=0.2$ & $\mathrm{NaOH} / \mathrm{Si}=0$ & $\mathrm{NaOH} / \mathrm{Si}=0.2$ & $\mathrm{NaOH} / \mathrm{Si}=0$ \\
\hline \multirow{2}{*}{$\mathrm{H}_{2} \mathrm{O} / \mathrm{Si}$} & 3 & & & & \\
\hline & 15 & & & & \\
\hline
\end{tabular}

\begin{tabular}{|c|c|c|c|c|c|c|}
\hline \multirow{3}{*}{\multicolumn{2}{|c|}{$\begin{array}{l}\text { (b) Zeolite } \\
\text { (FAU) }\end{array}$}} & \multicolumn{2}{|c|}{ CBV712 (Si/Al=6) } & \multicolumn{2}{|c|}{ CBV720 (Si/Al=15) } & \multirow{5}{*}{$\begin{array}{l}\text { Amorphous } \\
\text { FAU } \\
\text { CHA (SSZ-13) }\end{array}$} \\
\hline & & OSDA $/ \mathrm{Si}=0.2$ & $\mathrm{OSDA} / \mathrm{Si}=0.4$ & OSDA $/ \mathrm{Si}=0.2$ & OSDA $/ \mathrm{Si}=0.4$ & \\
\hline & & $\mathrm{NaOH} / \mathrm{Si}=0.2$ & $\mathrm{NaOH} / \mathrm{Si}=0$ & $\mathrm{NaOH} / \mathrm{Si}=0.2$ & $\mathrm{NaOH} / \mathrm{Si}=0$ & \\
\hline \multirow{2}{*}{$\mathrm{H}_{2} \mathrm{O} / \mathrm{Si}$} & 3 & SSZ-13 & & & & \\
\hline & 15 & & & & & \\
\hline
\end{tabular}

\begin{tabular}{|c|c|c|}
\cline { 2 - 3 } (c) SAPOs & \multicolumn{2}{|c|}{$\mathrm{OSDA} /(\mathrm{Al}+\mathrm{P})=0.4$} \\
\cline { 2 - 3 } & \multicolumn{2}{|c|}{$\mathrm{H}_{3} \mathrm{PO}_{4}, \mathrm{Al}(\mathrm{OH})_{3}$} \\
\cline { 2 - 3 } & \multicolumn{2}{|c|}{$\mathrm{P} / \mathrm{Al}$} \\
\hline $\mathrm{H}$ & 0.8 & 0.9 \\
\hline 20 & & \\
\hline 20 & & \\
\hline
\end{tabular}
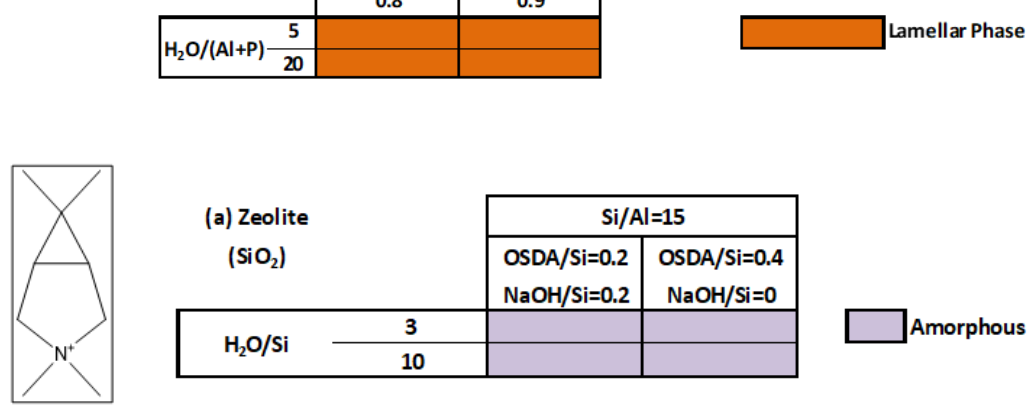

\begin{tabular}{|c|c|c|c|}
\hline \multirow{2}{*}{$\begin{array}{l}\text { (a) Zeolite } \\
\left(\mathrm{SiO}_{2}\right)\end{array}$} & & \multicolumn{2}{|c|}{$\mathrm{Si} / \mathrm{Al}=15$} \\
\hline & & OSDA $/ \mathrm{Si}=0.2$ & OSDA $/ \mathrm{Si}=\mathbf{0 . 4}$ \\
\hline \multirow{2}{*}{$\mathrm{H}_{2} \mathrm{O} / \mathrm{Si}$} & 3 & & \\
\hline & 10 & & \\
\hline
\end{tabular}

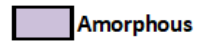

\begin{tabular}{|c|c|c|c|c|c|}
\hline \multirow{3}{*}{$\begin{array}{l}\text { (b) Zeolite } \\
\text { (FAU) }\end{array}$} & & \multicolumn{2}{|c|}{ CBV712 (Si/Al=6) } & \multicolumn{2}{|c|}{ CBV720(Si/Al=15) } \\
\hline & & $\mathrm{OSDA} / \mathrm{Si}=0.2$ & OSDA $/ \mathrm{Si}=0.4$ & OSDA $/ \mathrm{Si}=0.2$ & OSDA $/ \mathrm{Si}=0.4$ \\
\hline & & $\mathrm{NaOH} / \mathrm{Si}=0.2$ & $\mathrm{NaOH} / \mathrm{Si}=0$ & $\mathrm{NaOH} / \mathrm{Si}=0.2$ & $\mathrm{NaOH} / \mathrm{Si}=0$ \\
\hline \multirow{3}{*}{$\mathrm{H}_{2} \mathrm{O} / \mathrm{Si}$} & 3 & & & & SSZ-13 \\
\hline & 10 & & & & \\
\hline & 15 & & & & \\
\hline
\end{tabular}
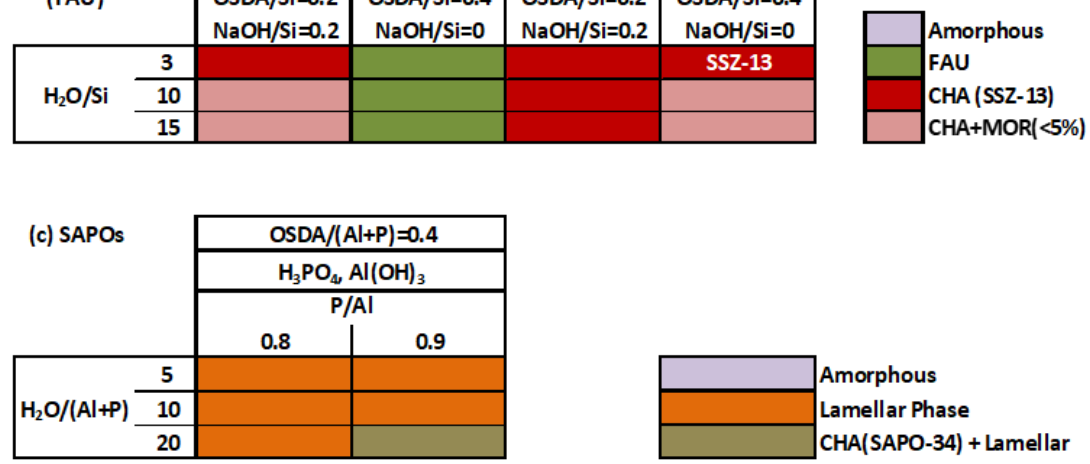

Figure 5.12 Zeolite synthesis phase diagram using OSDA1a (top) and OSDA1b (bottom) as template 
OSDA1a and OSDA1b favor in both cases the formation of the silicoaluminate form of CHA zeolite, i.e., SSZ-13 (see Figure 5.12). In the case of OSDA1a, SSZ-13 is only obtained using precrystallized $\mathrm{Y}$ zeolite as starting material in presence of $\mathrm{Na}^{+}$, with a high gel concentration $\left(\mathrm{H}_{2} \mathrm{O} / \mathrm{Si}=3\right.$, see Figure 5.12). All these conditions favor nucleation and accelerate crystallization, while under other conditions only amorphous or Y zeolite have been obtained. The limited conditions to achieve crystallize materials may indicate that this template lacks effectiveness for zeolite nucleation.

OSDA1b, on the other hand, allows crystallization of SSZ-13 with a relatively large range of conditions (see Figure 5.12). The most favored conditions for SSZ-13 are through interzeolite transformation from CBV720 in presence of $\mathrm{Na}$. Interestingly, in a concentrated gel, the transformation could be done without presence of $\mathrm{Na}$ (see SSZ-13 in Figure 5.12). It is generally accepted that the presence of $\mathrm{Na}$ in synthesis gel will influence the distribution of $\mathrm{Al}$ in the resultant zeolite. ${ }^{30,31}$ Thus, this $\mathrm{Na}$-free synthesis of $\mathrm{CHA}$ might give interesting catalytic performance for MTO reaction.

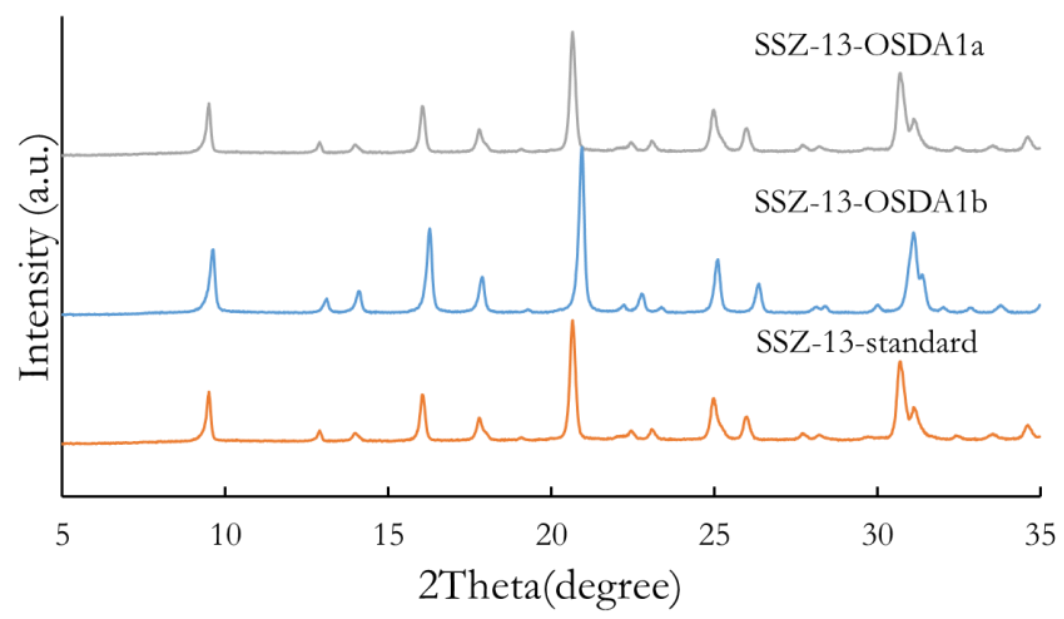

Figure 5.13 PXRD patterns of the different SSZ-13 synthesized using OSDA1a and OSDA1b as templates 

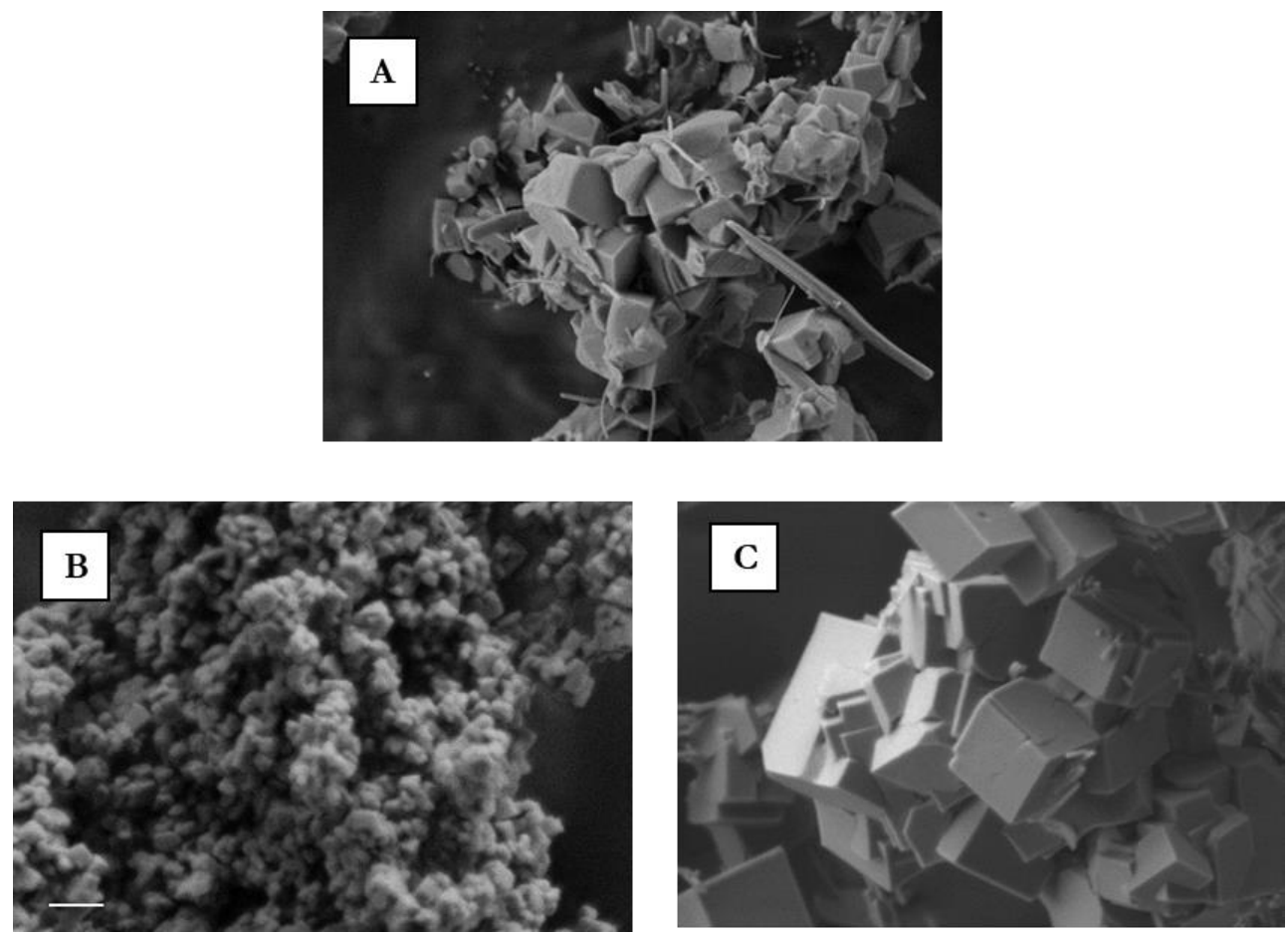

Figure 5.14 FESEM image of the SSZ-13 synthesized using OSDA1a (A), OSDA1b (B) and

TMAda (C) as template, scale bars in all images correspond to $200 \mathrm{~nm}$.

PXRD patterns of SSZ-13_OSDA1a and SSZ-13_OSDA1b confirm the crystallization of these two materials as pure crystalline CHA phase and without the presence of amorphous phase or impurities (see Figure 5.13). FESEM images also show uniform crystals for both materials, where SSZ-13_OSDA1a shows the classical cubic morphology of CHA with crystal sizes of around 400 $\mathrm{nm}$, while SSZ-13_OSDA1b presents considerably smaller crystal sizes below $100 \mathrm{~nm}$ (see Figure 5.14). Elemental analysis reveals that the $\mathrm{C} / \mathrm{N}$ molar ratios in these as-synthesized materials are the same as in their pure organic form, indicating that the OSDAs remain intact during the synthesis. This fact has been further proved by ${ }^{13} \mathrm{C} C \mathrm{CP}$ MAS NMR, where all peaks corresponding to the pure OSDA can be observed in the as-synthesized material with no extra peaks (see Figure 5.15). After calcination, the materials show similar textural properties 169 
compared to other CHA samples reported in the literature, presenting micropore volumes within $0.22 \sim 0.25 \mathrm{~cm}^{3} / \mathrm{g}$ (see Table 5.5). Si/Al ratios in the obtained zeolites are similar to those introduced in the starting synthesis mixtures, which are close to 6 and 15 for SSZ-13_OSDA1a and SSZ13_OSDA1b, respectively (see Table 5.5).

Table 5.5 Chemical composition and physicochemical properties of the sample

\begin{tabular}{|c|c|c|c|c|c|c|c|c|}
\hline & $\mathrm{Si} / \mathrm{Al}^{\mathrm{a}}$ & $\begin{array}{c}\mathrm{C}^{\mathrm{b}} \\
(\mathrm{wt} \%)\end{array}$ & $\begin{array}{c}\mathrm{N}^{\mathrm{b}} \\
(\mathrm{wt} \%)\end{array}$ & $\mathrm{C} / \mathrm{N}_{\text {real }}$ & $\mathrm{C} / \mathrm{N}_{\text {theo }}$ & $\begin{array}{l}\mathrm{S}_{\mathrm{BET}}{ }^{\mathrm{c}} \\
\left(\mathrm{m}^{2} / \mathrm{g}\right)\end{array}$ & $\begin{array}{c}V_{\text {micro }}{ }^{\mathrm{c}} \\
\left(\mathrm{cm}^{3} / \mathrm{g}\right)\end{array}$ & $\begin{array}{c}\mathrm{S}_{\text {ext }}{ }^{\mathrm{c}} \\
\left(\mathrm{m}^{2} / \mathrm{g}\right.\end{array}$ \\
\hline $\begin{array}{c}\text { SSZ-13 } \\
\text { OSDA1a }\end{array}$ & 5.9 & 13.77 & 1.63 & 7.8 & 8 & 468 & 0.22 & 13 \\
\hline $\begin{array}{c}\text { SSZ-13 } \\
\text { _OSDA1b }\end{array}$ & 14.0 & 12.85 & 1.75 & 8.6 & 8 & 532 & 0.24 & 40 \\
\hline $\begin{array}{c}\text { SSZ-13 } \\
\text { _std }\end{array}$ & 11.9 & - & - & - & - & 455 & 0.21 & 41 \\
\hline $\begin{array}{l}\text { SSZ-13 } \\
\text { _nano }\end{array}$ & 17.0 & - & - & - & - & 530 & 0.20 & 129 \\
\hline
\end{tabular}

${ }^{a}$ Measured by ICP-AES

b Measured by elemental analysis

c Measured by $\mathrm{N}_{2}$ adsorption/desorption measurement 


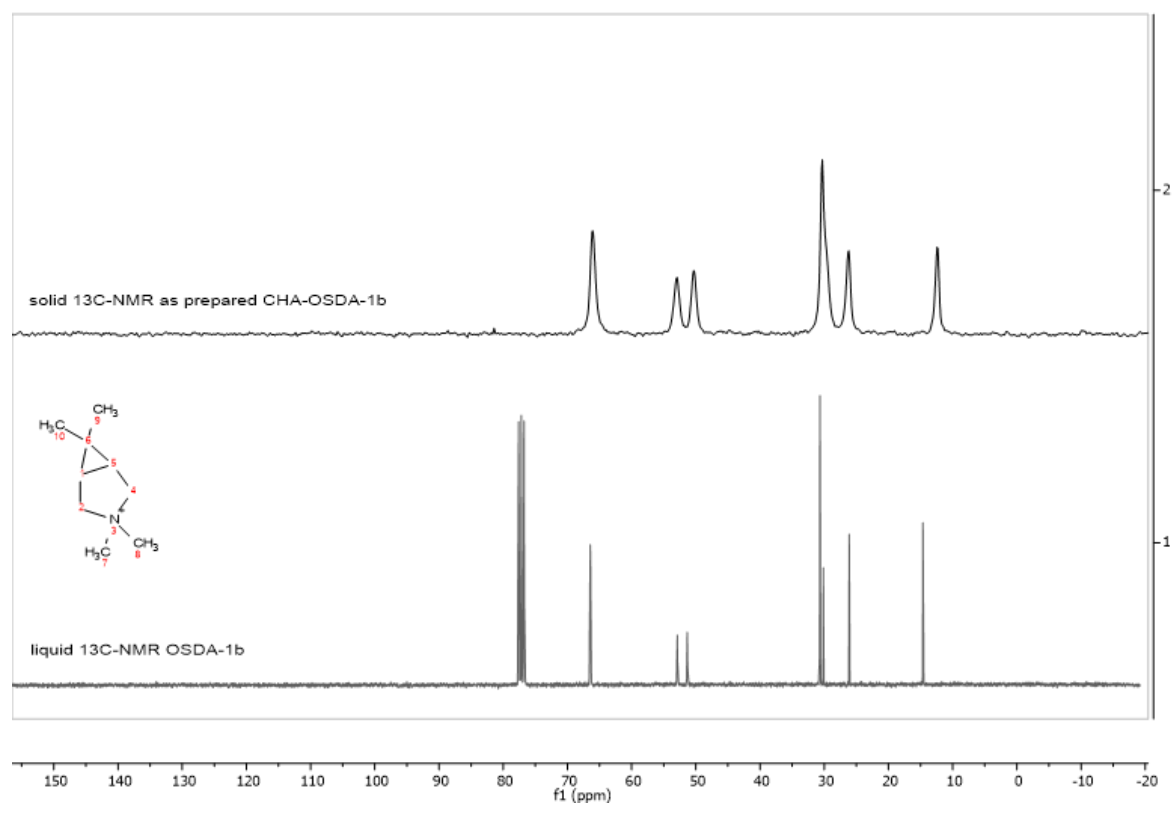

Figure 5.15 Liquid ${ }^{13} \mathrm{C}$ NMR spectrum of the OSDA1b molecule and solid ${ }^{13} \mathrm{C}$ MAS NMR spectrum of the as-prepared SSZ-13_OSDA1b material (*solvent peak)

After preliminary characterization of the two SSZ-13 samples, it can be confirmed that these two materials are pure CHA phases with good crystallinity, both crystalized due to the presence of OSDA1a and OSDA1b templates. For comparison purpose, two additional SSZ-13 samples have been synthesized using the calcined TMAda as OSDA (see experimental section in Chapter 3). It is easy to point out that the SSZ-13 samples synthesized from OSDA1a and OSDA1b are quite small compared to the normal cubic SSZ-13 obtained with TMAda with around 1-2 $\mu \mathrm{m}$ size (see Figure 5.15). Thus, to eliminate the possible influence of different crystal sizes, a SSZ-13 sample with nanosized crystal was synthesized using TMAda as OSDA together with a surfactant CTMA as modifier following a recipe from the literature. ${ }^{32}$ The crystal of this SSZ-13 is decreased to $50-150 \mathrm{~nm}$, in a range more comparable to SSZ- 
13_OSDA1a and SSZ-13_OSDA1b. ${ }^{32}$ The Si/Al ratios of these samples are 1217 , similar to the mimic-based SSZ-13 samples. Finally, the external surface of the nano-sized SSZ-13 is $129 \mathrm{~m}^{2} / \mathrm{g}$, much higher than the measured for the other SSZ-13 samples.

At this point, we have evaluated the catalytic performance of the different SSZ13 samples in MTO reactions. The reaction condistion used was set as similar values than the industrially used, i.e., under $350^{\circ} \mathrm{C}$ and a WHSV of $0.8 \mathrm{~h}^{-1}$. The results are summarized below.
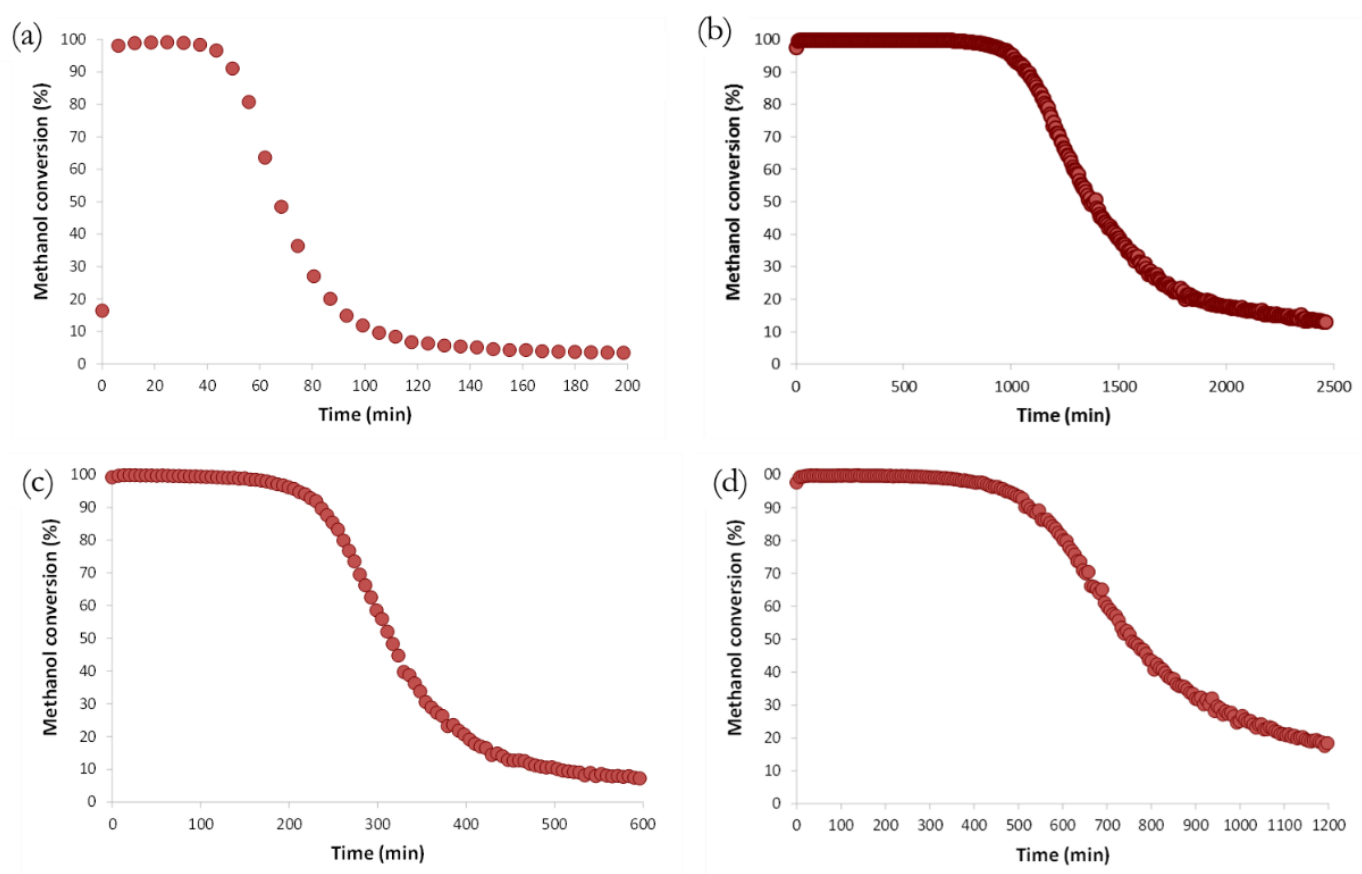

Figure 5.16 Methanol conversion along time on stream achieved using the SSZ-13_OSDA1a (a), SSZ-13_OSDA1b (b), SSZ-13_std (c) and SSZ-13_nano (d) as catalyst for the MTO reaction (reaction conditions: $\mathrm{T}=350^{\circ} \mathrm{C}$, WHSV $=0.8 \mathrm{~h}^{-1}, \mathrm{w}_{\mathrm{cat}}=50 \mathrm{mg}$ ) 


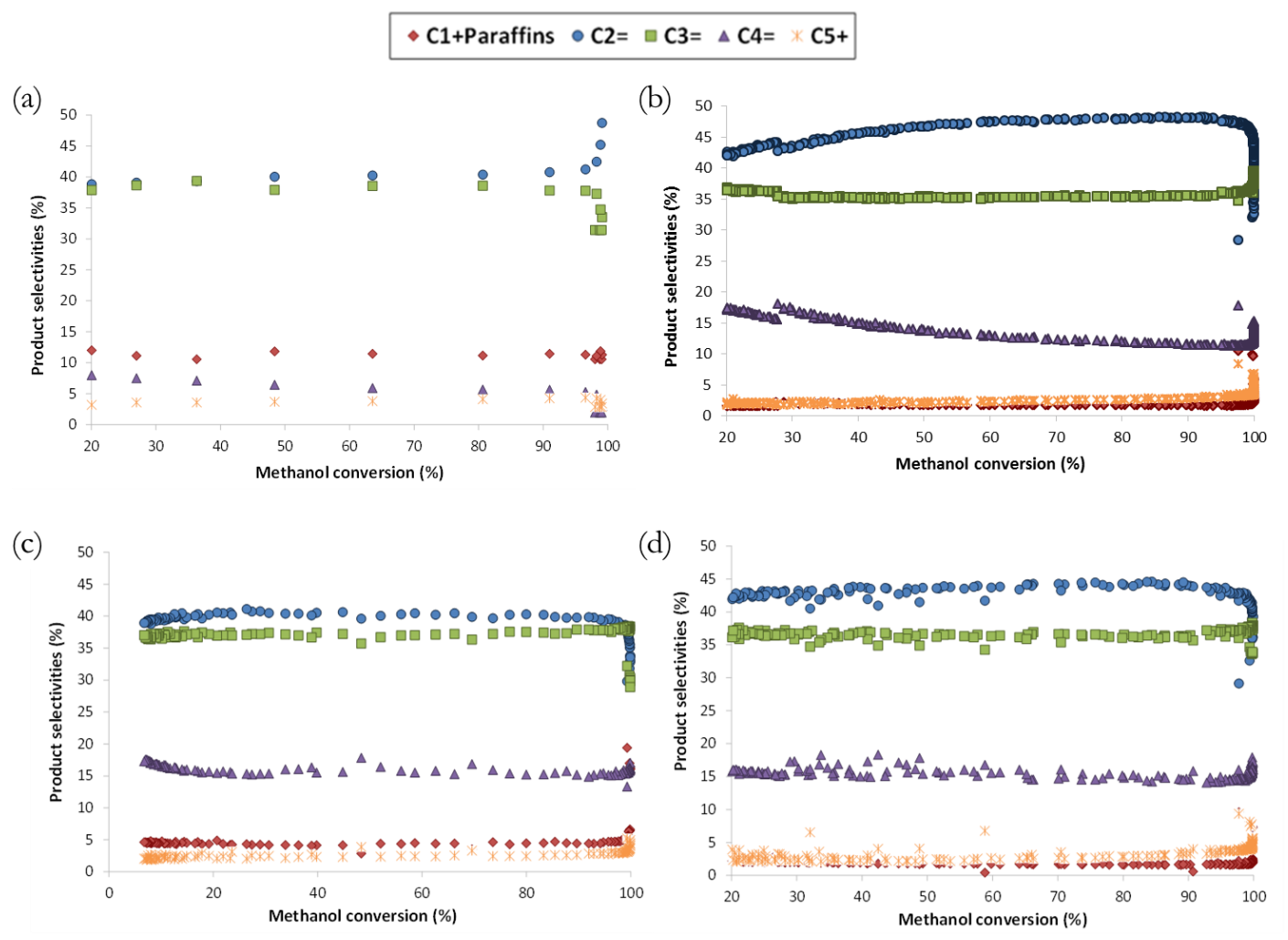

Figure 5.17 Product selectivity along methanol conversion achieved using the SSZ-13_OSDA1a (a), SSZ-13_OSDA1b (b), SSZ-13_std (c) and SSZ-13_nano (d) as catalyst for the MTO reaction (reaction conditions: $\mathrm{T}=350^{\circ} \mathrm{C}, \mathrm{WHSV}=0.8 \mathrm{~h}^{-1}, \mathrm{w}_{\mathrm{cat}}=50 \mathrm{mg}$ )

From Figure 5.16, which summarizes the methanol conversion along Time On Stream (TOS) for the CHA-type materials, it is clear that SSZ-13_OSDA1a material shows a fast deactivation. The conversion of methanol starts dropping after only 50 minutes time on stream (TOS) and at 75 minutes TOS the methanol conversion has dropped down to 50\% already (see Figure 5.16 a). The fast deactivation of SSZ-13_OSDA1a is very likely caused by the high Al content of this material. CHA structure is a pure cage-based structure that is composed of stacking of D6R form a large cage. In every unit cell there are $36 \mathrm{~T}$ atoms forming 3 cages, which means that every cage is formed by $12 \mathrm{~T}$ atoms. Considering a $\mathrm{Si} / \mathrm{Al}=6$, in average every cage should have two $\mathrm{Al}$ atoms. The 173 
presence of more than one $\mathrm{Al}$ would favor bimolecular reactions, such as hydrogen transfer reactions. It is well known that hydrogen transfer is a crucial step to form aromatic-based HP species, however excessive hydrogen transfer would form heavy aromatics including naphthalene or even coke, leading to a fast deactivation by coke.

Table 5.6 Catalytic properties for the different CHA zeolites for the MTO reaction.

\begin{tabular}{|c|c|c|c|c|c|c|c|}
\hline \multirow[b]{2}{*}{ Sample } & \multicolumn{2}{|l|}{ Lifetime } & \multicolumn{5}{|c|}{ Selectivity at Conv $95 \%$} \\
\hline & Conv $_{95 \%}$ & Conv $_{50 \%}$ & $\mathrm{C}_{2}=$ & $\mathrm{C}_{3}=$ & $\mathrm{C}_{4}=$ & $\mathrm{C}_{3}=/ \mathrm{C}_{2}=$ & $\mathrm{C}_{4}=/ \mathrm{C}_{2}=$ \\
\hline $\begin{array}{l}\text { SSZ- } \\
\text { 13_OSDA1a }\end{array}$ & 50 & 75 & 40.8 & 37.8 & 5.6 & 0.92 & 0.14 \\
\hline $\begin{array}{l}\text { SSZ- } \\
\text { 13_OSDA1b }\end{array}$ & 1005 & 1360 & 45.2 & 34.4 & 10.9 & 0.76 & 0.24 \\
\hline SSZ-13_std & 212 & 311 & 39.3 & 37.8 & 15.4 & 0.96 & 0.39 \\
\hline SSZ-13_nano & 472 & 757 & 43.2 & 37.4 & 14.2 & 0.86 & 0.33 \\
\hline
\end{tabular}

In contrast, the SSZ-13_OSDA1b catalyst, possessing a Si/Al similar to the other reference SSZ-13 materials, shows a significant longer lifetime (see Figure 5.16 b). The methanol conversion maintains 100\% for 1005 minutes and then progressively decreases to $50 \%$ at $1360 \mathrm{~min}$ TOS. This time is longer than not only standard SSZ-13 sample with larger crystallites (212 min TOS at 100\% conversion, see Figure $5.16 \mathrm{c}$ ), but also the nano-SSZ-13 prepared using CTMA as modifier (472 min TOS at 100\% conversion, see Figure $5.16 \mathrm{~d}$ ). This set of comparison illustrates that indeed the nanocrystalline form of the CHA material synthesized with TMAda can double the catalytic lifetime from 212 min to 472 min, the sample synthesized using the OSDA1b shows a considerably longer catalytic lifetime (1005 min) This higher catalytic activity cannot be only attributed to its nanosized crystals. Then, plausible reason for its substantially improved catalytic behavior could be assigned to the better aluminum 
distribution along the CHA crystals, as a consequence of avoiding the presence of $\mathrm{Na}$ in the preparation of this material. ${ }^{30,31}$

The successful crystallization of small-pore crystalline zeolites using OSDA1a and OSDA1b as templates indicates that the TS mimick OSDA synthesis methodology used in this study is proper to obtain zeolitic materials adequated for the "a priori" set reaction, i.e. MTO. At this point, the OSDA2 has also been evaluated under similar synthesis conditions and the results are summarized in Figure 5.18.
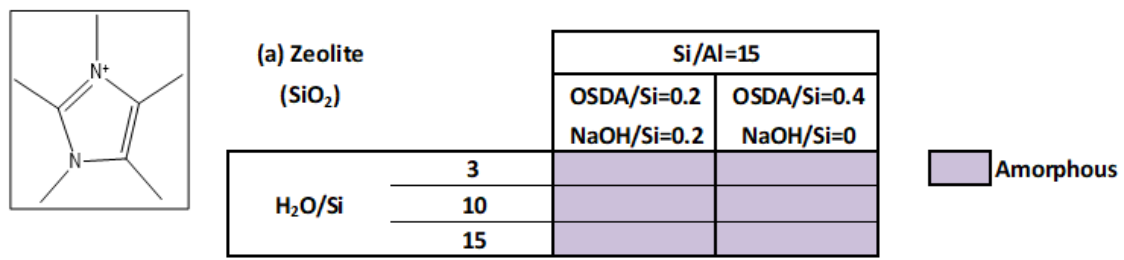

\begin{tabular}{|c|c|c|c|c|c|}
\hline \multirow{2}{*}{$\begin{array}{l}\text { (b) Zeolite } \\
\text { (FAU) }\end{array}$} & & \multicolumn{2}{|c|}{ CBV712 (Si/Al=6) } & \multicolumn{2}{|c|}{ CBV720 (Si/Al=15) } \\
\hline & & $\begin{array}{l}\mathrm{OSDA} / \mathrm{Si}=0.2 \\
\mathrm{NaOH} / \mathrm{Si}=0.2\end{array}$ & $\begin{aligned} \mathrm{OSDA} / \mathrm{Si} & =0.4 \\
\mathrm{NaOH} / \mathrm{Si} & =0\end{aligned}$ & $\begin{array}{l}\text { OSDA } / \mathrm{Si}=0.2 \\
\mathrm{NaOH} / \mathrm{Si}=0.2\end{array}$ & $\begin{array}{c}\mathrm{OSDA} / \mathrm{Si}=0.4 \\
\mathrm{NaOH} / \mathrm{Si}=0\end{array}$ \\
\hline \multirow{3}{*}{$\mathrm{H}_{2} \mathrm{O} / \mathrm{Si}$} & 3 & & & & \\
\hline & 10 & & & & RUB-13 \\
\hline & 15 & & & & \\
\hline
\end{tabular}
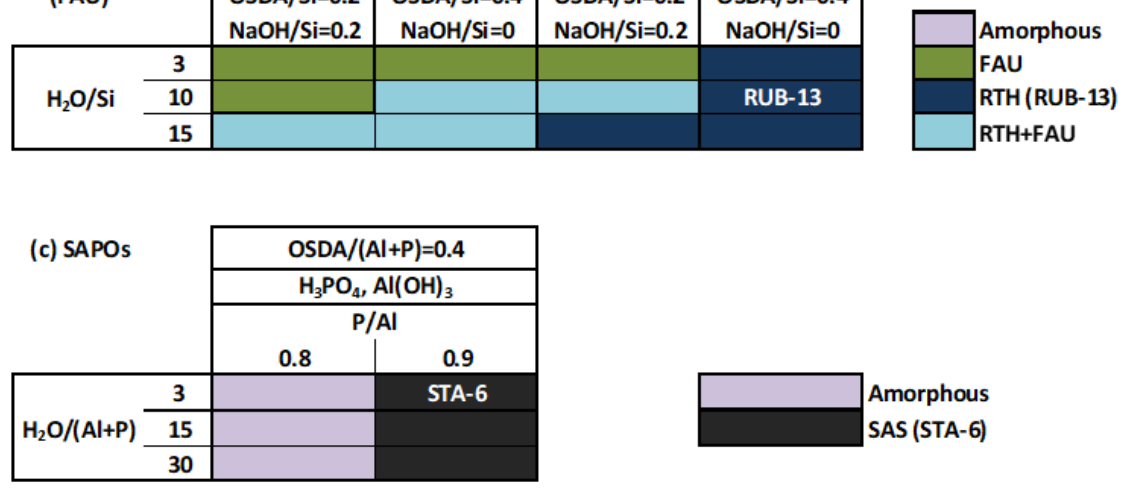

Figure 5.18 Phase diagram obtained with the OSDA2 as organic structure directing agent for the synthesis of: (a) silicoaluminates using amorphous silicon and aluminum sources, (b) silicoaluminates using FAU zeolites as silicon and aluminum sources, and (c) silicoaluminophosphate materials. Synthesis conditions: $T=175^{\circ} \mathrm{C} ; \mathrm{t}=10$ days. 
Interestingly, when using the OSDA2 as template, the preferred crystallized zeolite is the RTH structure. In fact, the pure RTH phase has been obtained independent of alkaline or fluoride media, and independent of the starting materials or gel composition. Such a high preference toward one particular structure using one OSDA usually indicates a strong compatibility of this organic molecule to direct into the resultant structure. On the other hand, in the case of SAPO synthesis, OSDA2 shows a selective formation of SAS structure, particularly when $\mathrm{P} / \mathrm{Al}$ in synthesis gel is 0.9 (see Figure 5.18).

\section{RTH}

$\mathrm{C}_{3}=/ \mathrm{C}_{2}=$ in MTO:

RUB-13: 3.1
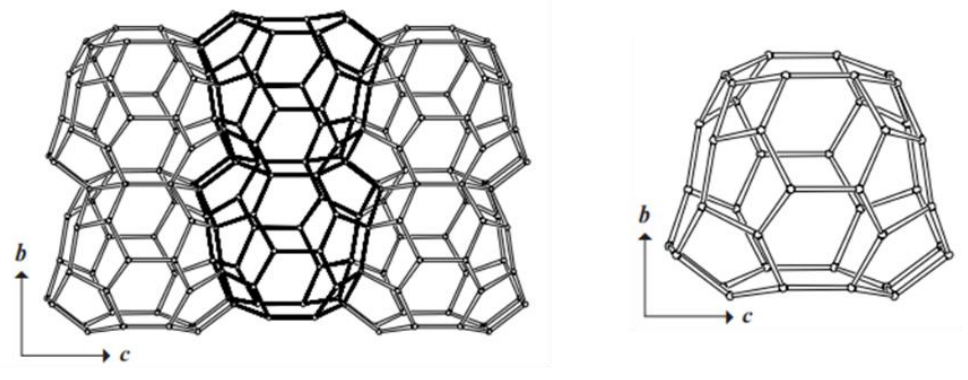

SAS

$\mathrm{C}_{3}=/ \mathrm{C}_{2}=$ in MTO:

No previous report

In this work:

STA-6: 2.0
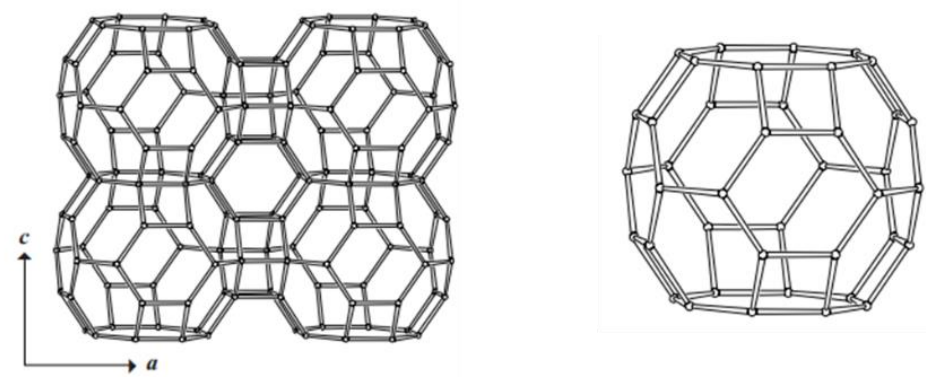

Scheme 5.12 RTH and SAS type cages and their stacking patterns. Reaction conditions for $\mathrm{C}_{3}=/ \mathrm{C}_{2}=$ ratios, $\mathrm{T}=350^{\circ} \mathrm{C}, \mathrm{WHSV}_{\mathrm{MeOH}}=0.8 \mathrm{~h}^{-1}$

Both RTH and SAS are small pore structures containing the presence of large cavities within their structures (see Scheme 5.12). These results show the high specificity of OSDA2 toward such cage-based small pore structures. 
To unravel the ability of the achieved materials as potential MTO catalysts, selected RTH and SAS materials have been first characterized to obtain their chemical and physicochemical properties. Since RTH has been obtained under various composition, the sample synthesized with a $\mathrm{Si} / \mathrm{Al}$ of $\sim 16$ using interzeolite transformation of CBV720 has been selected, since its synthesis conditions resemble the most to the previously mentioned SSZ-13 materials, facilitating further comparisons. So far, there is no report on SAS materials in application of MTO reaction.

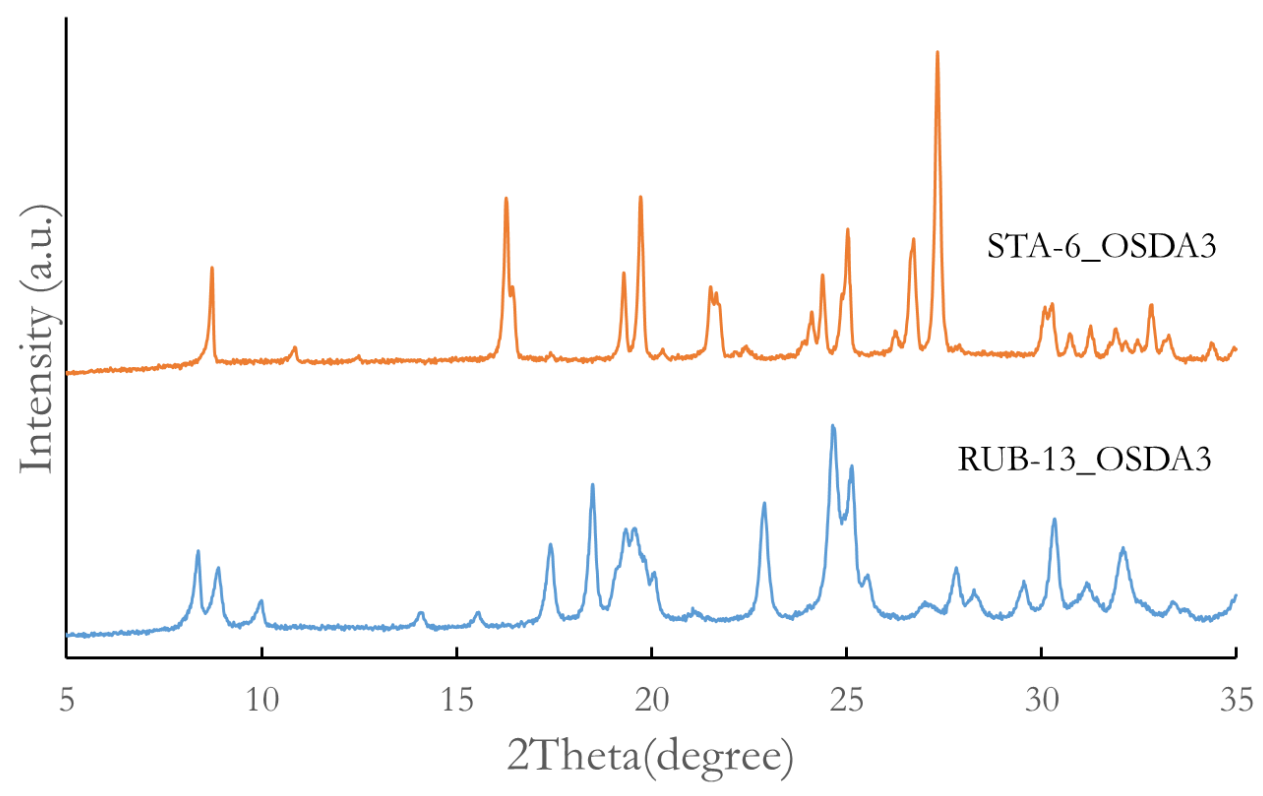

Figure 5.19 XRD pattern of RUB-13 and STA-6 synthesized using OSDA2 as template

The RUB-13_OSDA2 sample possesses an average particle size of 50-100 nm (see Figure 5.20). Such crystal size together with the two-dimensional channel in RTH structure should effectively avoid diffusion limitation when catalyzing MTO reactions. On the other hand, STA-6_OSDA2 sample shows orthorhombic crystals with size around $1 \times 4 \mu \mathrm{m}$ (see Figure 5.20). In such cases, the crystal tends to grow faster along the direction of the unidimensional channel and slower on the other dimensions, resulting in rod-like crystals. If this is true, 
the unidimensional channel should be along $4 \mu \mathrm{m}$ direction in STA-6_OSDA2, and, consequently, its catalytic activity should be strongly influenced by intracrystal diffusion limitations.
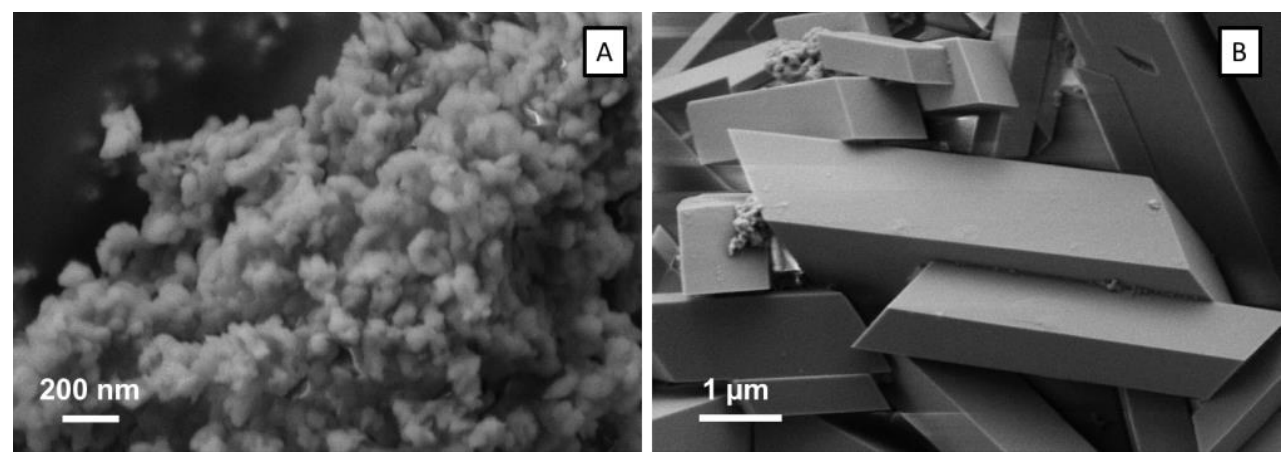

Figure 5.20 FESEM images of RUB-13_OSDA2 (A) and STA-6_OSDA2 (B)

Table 5.6 Chemical composition and physicochemical properties of samples synthesized using OSDA2

\begin{tabular}{|c|c|c|c|c|c|c|c|c|}
\hline & $\mathrm{Si} /(\mathrm{Al}+\mathrm{P})^{\mathrm{a}}$ & $\begin{array}{c}C^{b} \\
\left(w t^{0} \%\right)\end{array}$ & $\begin{array}{c}\mathrm{N}^{\mathrm{b}} \\
(\mathrm{wt} \%)\end{array}$ & $\mathrm{C} / \mathrm{N}_{\text {real }}$ & $\mathrm{C} / \mathrm{N}_{\text {theo }}$ & $\begin{array}{c}\mathrm{S}_{\mathrm{BET}} \mathrm{c}^{\mathrm{s}} \\
\left(\mathrm{m}^{2} / \mathrm{g}\right)\end{array}$ & $\begin{array}{c}\mathrm{V}_{\text {micro }}{ }^{\mathrm{c}} \\
\left(\mathrm{cm}^{3} / \mathrm{g}\right)\end{array}$ & $\begin{array}{c}\mathrm{S}_{\mathrm{ext}}^{\mathrm{c}} \\
\left(\mathrm{m}^{2} / \mathrm{g}\right)\end{array}$ \\
\hline $\begin{array}{l}\text { RUB-13 } \\
\text { _OSDA2 }\end{array}$ & 15.8 & 15.17 & 4.51 & 3.9 & 4 & 597 & 0.25 & 88 \\
\hline $\begin{array}{l}\text { STA-6 } \\
\text { _OSDA2 }\end{array}$ & 0.13 & 13.46 & 4.38 & 3.9 & 4 & 336 & 0.16 & 16 \\
\hline
\end{tabular}

a Measured by ICP-AES

b Measured by elemental analysis

c Measured by $\mathrm{N}_{2}$ adsorption/desorption measurement 
$\mathrm{N}_{2}$ adsorption measurements reveals that RUB-13_OSDA2 has a micropore volume of $0.25 \mathrm{~cm}^{3} / \mathrm{g}$, while that of STA-6_OSDA2 is $0.16 \mathrm{~cm}^{3} / \mathrm{g}$, being both comparable to previously reported materials in the literature. ${ }^{33,34}$ Chemical analyses indicate that the compositions of these two materials are similar to those of the initial synthesis gels, presenting RUB-13_OSDA2 a Si/Al of around 16 and STA-6_OSDA2 a Si/(Al+P) of around 0.13 (see Table 5.6).

The general characterizations of the achieved materials using OSDA2 confirm that they possess high crystallinity with no presence of amorphous or impurities, therefore, both materials have been tested in MTO reaction.
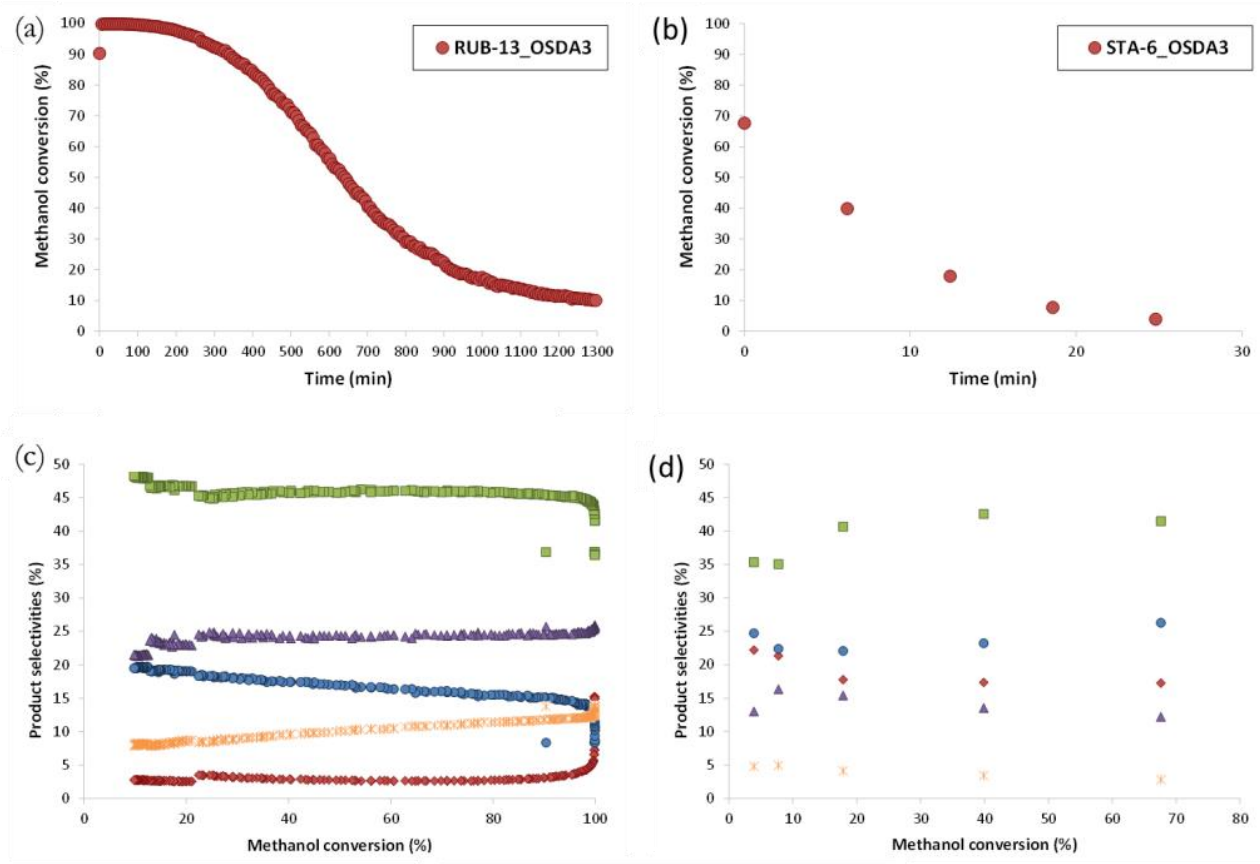

- $\mathrm{C} 1+$ Paraffins $\bullet \mathrm{C} 2=\triangle \mathrm{C} 3=\triangle \mathrm{C} 4=\times \mathrm{C} 5+$

Figure 5.21 Methanol conversion $(a, b)$ and product selectivities (c, d) achieved using the RUB-

13_OSDA2 (left) and STA-6_OSDA2 (right) as catalyst for the MTO reaction (reaction conditions: $\mathrm{T}=350^{\circ} \mathrm{C}, \mathrm{WHSV}=0.8 \mathrm{~h}^{-1}, \mathrm{w}_{\mathrm{cat}}=50 \mathrm{mg}$ ) 
Table 5.7 Catalytic properties for the different zeolites synthesized with OSDA2 for the MTO reaction.

\begin{tabular}{|c|c|c|c|c|c|c|c|}
\hline \multirow[b]{2}{*}{ Sample } & \multicolumn{2}{|l|}{ Lifetime } & \multicolumn{4}{|c|}{ Selectivity at Conv95\% } & \multirow[b]{2}{*}{$\mathrm{C}_{4}{ }^{=} / \mathrm{C}_{2}=$} \\
\hline & Conv95\% & Conv $_{50 \%}$ & $\mathrm{C}_{2}=$ & $\mathrm{C}_{3}=$ & $\mathrm{C}_{4}=$ & $\mathrm{C}_{3}=\mathrm{C}_{2}=$ & \\
\hline RUB-13 & 270 & 645 & 14.7 & 45.0 & 24.7 & 3.07 & 1.68 \\
\hline _OSDA2 & & & & & & & \\
\hline STA-6 & $\mathrm{N} / \mathrm{A}$ & $\sim 3$ & 23.0 & 39.8 & 13.1 & 1.74 & 0.57 \\
\hline _OSDA2 & & & & & & & \\
\hline
\end{tabular}

The MTO catalytic evaluation for these two materials has been carried out under the same conditions previously used in the case of SSZ-13 samples. RUB13_OSDA2 shows a catalyst lifetime maintaining 100\% conversion comparable to that of the standard SSZ-13, with conversion drop to $95 \%$ at TOS of $270 \mathrm{~min}$ (see Figure 5.18). On the other hand, the deactivation of RUB-13_OSDA2 is much slower than achieved with the SSZ-13 catalyst, requiring around $645 \mathrm{~min}$ TOS to reach a $50 \%$ conversion of methanol (see Figure 5.21, a). Meanwhile, the RTH catalyst gives a propene molar yield of $45.1 \%$, a butene yield of $24.7 \%$ and an ethene yield of $14.7 \%$, resulting in a $\mathrm{C}_{3}{ }^{2} / \mathrm{C}_{2}{ }^{=}$of 3.07 and $\mathrm{C}_{4}{ }^{=} / \mathrm{C}_{2}{ }^{=}$of 1.68 , while in the case of SSZ-13 materials the $\mathrm{C}_{3}{ }^{=} / \mathrm{C}_{2}{ }^{=}$is $0.76-0.96$ and $\mathrm{C}_{4}{ }^{=} / \mathrm{C}_{2}{ }^{=}$0.140.40 (see Table 5.7). Both ratios are highest among all samples, suggesting that RTH sample favors more the production of propene and butene than ethene. These results would indicate that the reaction mechanism would follow the paring route, as predicted taking into account the TS mimick used as OSDA.

In the case of STA-6_OSDA2, the catalytic activity could not be fully revealed since the initial methanol conversion at TOS $=0 \mathrm{~s}$ is around $70 \%$ and immediately started the deactivation (see Figure 5.21, b). The methanol conversion reached $50 \%$ in around $5 \mathrm{~min}$ and then soon loses all the conversion after $20 \mathrm{~min}$. This short catalytic lifetime could be attributed to the unidimensional small pore channel system of SAS structure, which can present strong spatial confinement 
and diffusion limitation for product olefins and could form coke very fast. Taking into consideration that cage-based small-pore zeotype materials has high tendency to form aromatic-based HP species, once the HP species are formed and occupy the cages, the undimensional channel connecting to that cage should be completely hindered. Thus, most reaction should only be taking place at the near external surface part of the crystals. This situation is worsened by the large crystal size, especially when the crystal is longer in the direction of the unidimensional channel, which makes all cavities inside the $4 \mu \mathrm{m}$ channel nearly inactive to the reactants. Despite this strong diffusion limitation, it is possible to obtain information on product selectivity since MTO catalysts usually show stable product selectivity during all lifetime in the period of deactivation (see Figure 5.21). In fact, STA-6_OSDA2 shows a selectivity toward propene higher than $40 \%$, with butene and ethene selectivity of $13 \%$ and $23 \%$, respectively, resulting in a $\mathrm{C}_{3}{ }^{3} / \mathrm{C}_{2}{ }^{=}$of 1.74 and $\mathrm{C}_{4}{ }^{=} / \mathrm{C}_{2}{ }^{=}$of 0.57 . At this point, one may point out that the large crystal should promote hydrogen transfer reactions and consume olefin products, which will change the overall product distribution. However, SAPO materials usually possess acidities weaker than aluminosilicates and does not cause strong hydrogen transfer. Nevertheless, if any hydrogen transfer happens, the olefin that is hardest to be consumed should be ethene due to the difficulty in protonation. Thus, if the product distribution was influenced by hydrogen transfer, the real $\mathrm{C}_{3}{ }^{=} / \mathrm{C}_{2}{ }^{=}$and $\mathrm{C}_{4}{ }^{=} / \mathrm{C}_{2}{ }^{=}$should be even higher than those values obtained. Consequently, it is clear that although STA-6_OSDA2 suffers heavily from fast deactivation and diffusion limitations, it still shows a preference toward propene and butene yields. The high selectivity to propene and butene of STA-6 has not been reported before.

Combining the catalytic tests of RUB-13_OSDA2 and STA-6_OSDA2, they support the concept that the materials obtained by mimicking intermediates in paring pathway, favor yield of propene and butene. Nevertheless, to confirm the hypothesis that RUB-13 is favoring the formation of intermediates in the paring route, it is necessary to observe the presence of such intermediates or, at least, their corresponding stable neutral molecules being formed within the cavity of the zeolite. A specially designed MTO reaction using ${ }^{13} \mathrm{C}$-labelled methanol was performed on RUB-13_OSDA2 and standard SSZ-13 (see experimental section 181 
in Chapter 3). The reaction has been carried out under the same conditions as in standard MTO test but using $100 \%{ }^{13} \mathrm{C}$ labeled methanol. The reaction was quenched at $20 \mathrm{~min}$ TOS, this time is set long enough to accumulate ${ }^{13} \mathrm{C}$ species while not too long to form coke. After carefully quenching the reaction at 20 min, the organic species trapped in the samples have been characterized by ${ }^{13} \mathrm{C}$ CP MAS NMR.

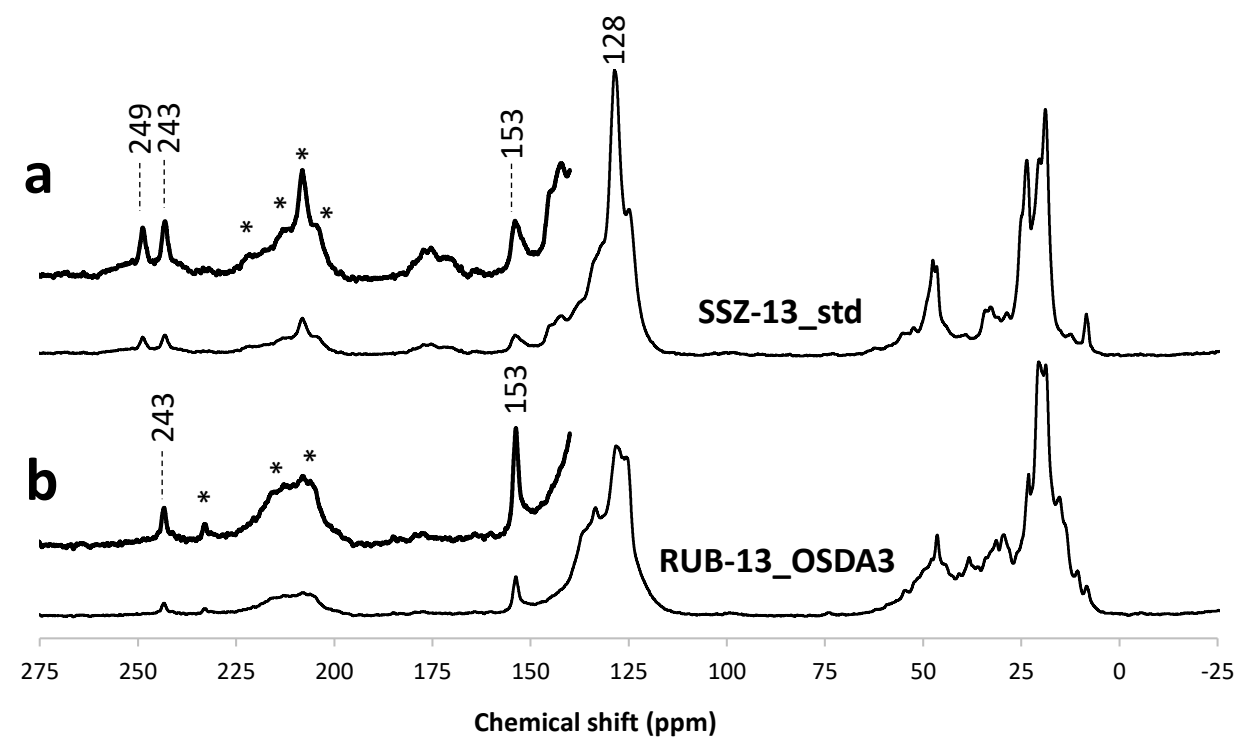

Figure 5.21 ${ }^{13} \mathrm{C} \mathrm{CP} /$ MAS NMR spectra of the retained organic species in the SSZ-13_std (a) and RUB-13_OSDA2 (b) zeolites after performing the MTO reaction using ${ }^{13} \mathrm{C}$ labelled methanol (*spinning sidebands).

The versatility of HP species as well as several parallel reaction pathways can generate a large number of carbon-containing compounds, including, but not limited to intermediates, coke, olefins and paraffins. All these compounds are prone to be trapped inside zeolite, especially when HP species are formed and occupy the cages, leaving little space for those species to diffuse out of the channel. For this reason, the C-NMR spectra of MTO catalysts collected during the reaction should be a collection of all those species. According to the NMR 
spectra in Figure 5.21, two groups of peaks could be envisaged. One group with signals between $0 \mathrm{ppm}$ and $75 \mathrm{ppm}$, and the other group between $100 \mathrm{ppm}$ and $150 \mathrm{ppm}$.

Table $5.8{ }^{13}$ Carbon shifts assigned in the literature and in this work for the different cyclopentenyl-derivatives (CP) and methyl-benzene derivatives (MB).

\begin{tabular}{|c|c|c|c|c|}
\hline & CP -1 & CP -2 & CP -3 & CP -4 \\
\hline & & & \\
& Ref.18 & Ref.19 & Ref.19 & Ref.18 \\
\hline C1, C3 & 245 & 245 & 250 & 134 \\
\hline C2 & 150 & 155 & 148 & 52 \\
\hline C4 , C5 & 58 & 43 & 48 & 138 \\
\hline
\end{tabular}

\begin{tabular}{|c|c|c|c|c|}
\hline & MB -1 & MB -2 & MB -3 & MB -4 \\
\hline & Ref.18 & Ref.20. & Ref.19 & 132 \\
\hline C1 & 53 & 65 & 138 & 132 \\
\hline C2, C6 & 198 & 209 & 129 & 132 \\
\hline C3, C5 & 141 & 139 & 129 & 126 \\
\hline C4 & 185 & 191 & 4 \\
\hline
\end{tabular}

By simulating the intermediates, transition states and neutral compounds, it can be said that the group with chemical shifts below $75 \mathrm{ppm}$ belongs to aliphatic 183 
groups that connect to different substituents. The other group with chemical shifts between 100 and $150 \mathrm{ppm}$ can be associated to molecules with carbons inside the rings, either in aromatic ones or their protonated carbocations (see Table 5.8). It is not realistic to assign peaks among these two groups to identify organic species trapped inside zeolite, since these two peaks are the result of the overlapping of numerous species. Nevertheless, it is noteworthy that the $\beta-C$ of the carbocation in the five-member ring intermediates (see C1, C3 in Table 5.8) should give chemical shifts between $240-250 \mathrm{ppm}$ according to the simulation. If these signals are observed, then it could be a proof of the formation of the five-member ring intermediates. In Figure 5.21, it can be observed the presence of the peak corresponding to fully methylated cyclopentenyl cations for both zeolites, indicating the feasibility of the paring route. SSZ-13 shows more than one peak in the range of $240-250$ ppm, while RUB-13_OSDA2 only shows a single peak at $243 \mathrm{ppm}$ (see Figure 5.21). This may indicate a higher tendency to stabilize the fully methylated cyclopentenyl cation in RTH than CHA. This point will be further discussed later.

The final step of the paring pathway is the ring expansion of the cyclopentenyl cation followed by alkylation with methanol to form polymethylbenzene (INT6) (see Scheme 5.6). As described previously, INT6 can be viewed as both beginning and the end of the paring pathway. Thus, the mimicking template OSDA3 is then tried in synthesis of zeolite and zeotype materials. In zeolite synthesis conditions, no obvious sign of crystallization has been observed, achieving amorphous materials and FAU-type zeolite (see Figure 5.22). However, OSDA3 allows the crystallization of SAPO-18 materials under several SAPO synthesis conditions. 


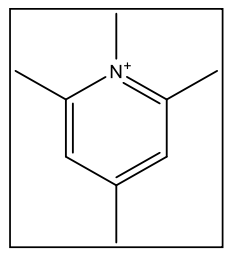

\begin{tabular}{|c|c|c|c|}
\hline \multirow{2}{*}{$\begin{array}{l}\text { (a) Zeolite } \\
\left(\mathrm{SiO}_{2}\right)\end{array}$} & & \multicolumn{2}{|c|}{$\mathrm{Si} / \mathrm{Al}=15$} \\
\hline & & $\mathrm{OSDA} / \mathrm{Si}=\mathbf{0 . 2}$ & $\mathrm{OSDA} / \mathrm{Si}=0.4$ \\
\hline \multirow{3}{*}{$\mathrm{H}_{2} \mathrm{O} / \mathrm{Si}$} & 3 & & \\
\hline & 10 & & \\
\hline & 15 & & \\
\hline
\end{tabular}

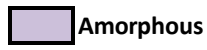

\begin{tabular}{|c|cc|c|c|c|}
\cline { 2 - 6 } \multicolumn{1}{c|}{\begin{tabular}{c} 
(b) Zeolite \\
\cline { 2 - 6 } \multicolumn{1}{c|}{ (FAU) }
\end{tabular}} & \multicolumn{2}{c|}{ CBV712 (Si/Al=6) } & \multicolumn{2}{c|}{ CBV720 (Si/Al=15) } \\
\cline { 2 - 6 } \multicolumn{1}{c|}{} & $\begin{array}{c}\text { OSDA/Si=0.2 } \\
\text { NaOH/Si=0.2 }\end{array}$ & $\begin{array}{c}\text { OSDA/Si=0.4 } \\
\text { NaOH/Si=0 }\end{array}$ & $\begin{array}{c}\text { OSDA/Si=0.2 } \\
\text { NaOH/Si=0.2 }\end{array}$ & $\begin{array}{c}\text { OSDA/Si=0.4 } \\
\text { NaOH/Si=0 }\end{array}$ \\
\hline \multirow{3}{*}{$\mathrm{H}_{2} \mathrm{O} / \mathrm{Si}$} & & & & \\
& 10 & & & & \\
\cline { 2 - 6 } & 15 & & & & \\
\hline
\end{tabular}

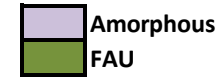

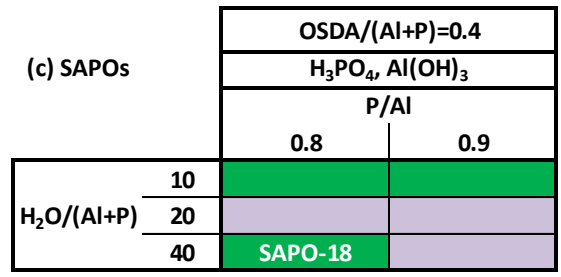

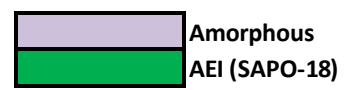

Figure 5.22 Phase diagram obtained with the OSDA3 as organic structure directing agent for the synthesis of: (a) silicoaluminates using amorphous silicon and aluminum sources, (b) silicoaluminates using FAU zeolites as silicon and aluminum sources, and (c) silicoaluminophosphate materials. Synthesis conditions: $\mathrm{T}=175^{\circ} \mathrm{C} ; \mathrm{t}=10$ days.

SAPO-18 is also a cage-based small pore zeotype material, which possesses three-dimensional eight-rings connected by a large cage (Scheme 5.7). AEI structure is highly related to CHA, since both present three-dimensional eightrings with similar framework density (both $15.1 \mathrm{~T}$ atoms per 1,000 $\AA^{3}$ ) and large cavities within the structures, as we described before. The difference between them is the shape of the cage. In the case of CHA the cage is cylinder-shaped from top to bottom along the long axis, whereas AEI cage is basket-shaped and its bottom part is wider than the CHA cage. The SAPO-18 obtained using 
OSDA3 as template is named here as SAPO-18_OSDA3, and has been fully characterized by various techniques.

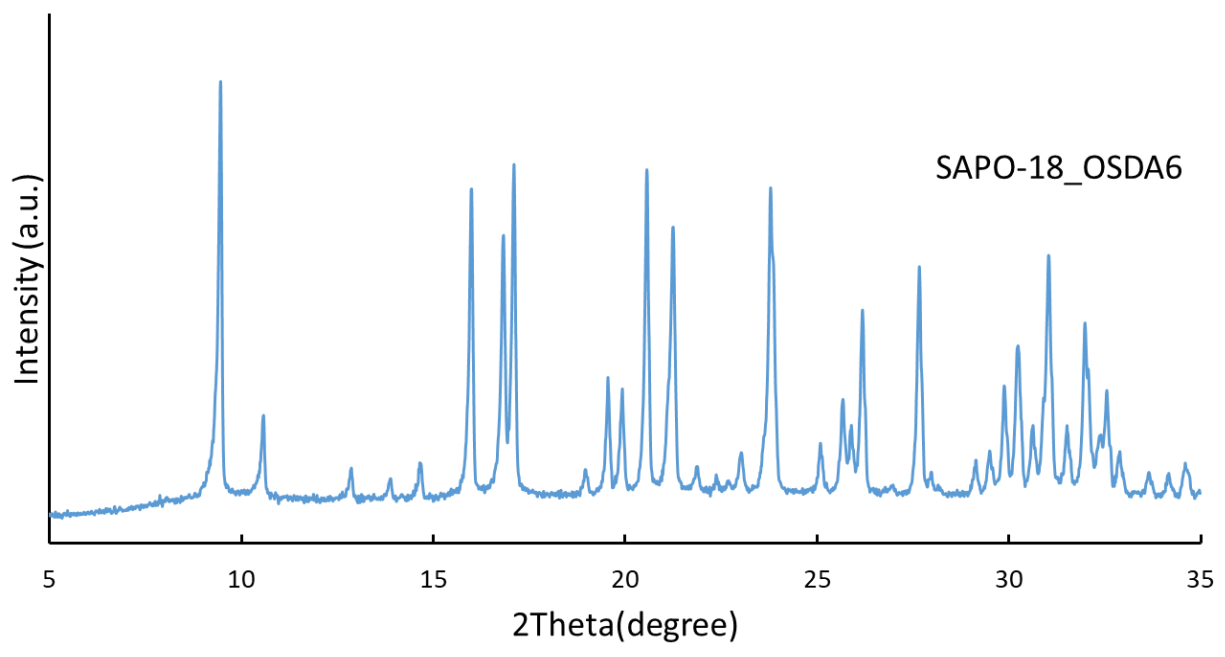

Figure 5.23 XRD pattern of SAPO-18 synthesized using OSDA3 as template

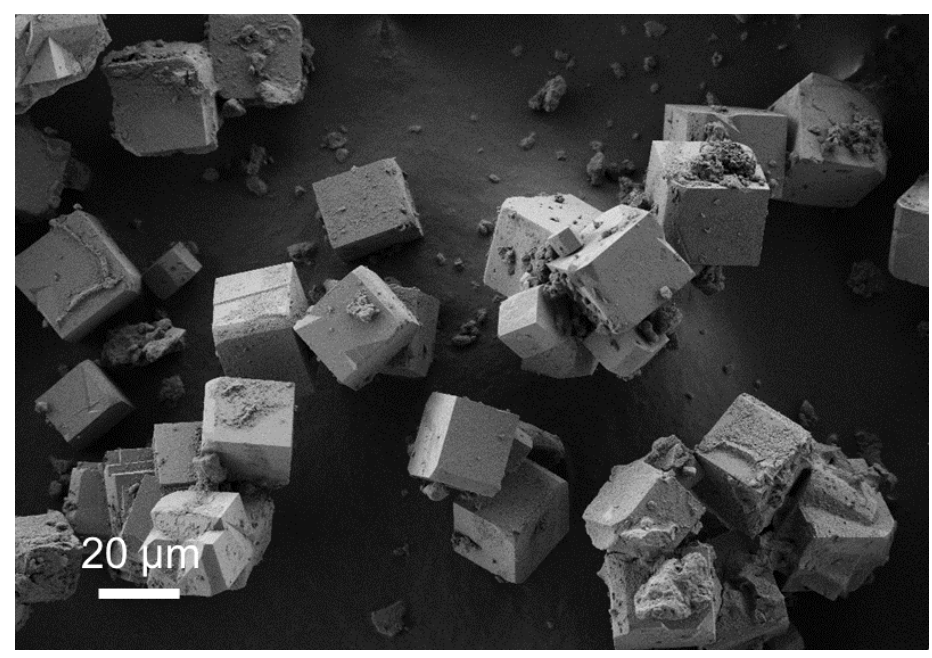

Figure 5.24 FESEM image of SAPO-18_OSDA3 
Table 5.9 Chemical composition and physicochemical properties of the sample

\begin{tabular}{cccccccc}
$\mathrm{Si} /(\mathrm{Al}+\mathrm{P})^{\mathrm{a}}$ & $\begin{array}{c}\mathrm{C}^{\mathrm{b}} \\
(\mathrm{wt} \%)\end{array}$ & $\begin{array}{c}\mathrm{N}^{\mathrm{b}} \\
(\mathrm{wt} \%)\end{array}$ & $\mathrm{C} / \mathrm{N}_{\text {real }} / \mathrm{C} / \mathrm{N}_{\text {theo }}$ & $\begin{array}{c}\mathrm{S}_{\mathrm{BET}}{ }^{\mathrm{c}} \\
\left(\mathrm{m}^{2} / \mathrm{g}\right)\end{array}$ & $\begin{array}{c}\mathrm{V}_{\text {micro }}{ }^{\mathrm{c}} \\
\left(\mathrm{cm}^{3} / \mathrm{g}\right)\end{array}$ & $\begin{array}{c}\mathrm{S}_{\text {ext }}{ }^{\mathrm{c}} \\
\left(\mathrm{m}^{2} / \mathrm{g}\right)\end{array}$ \\
\hline 0.13 & 14.89 & 2.35 & 7.5 & 9 & 303 & 0.14 & 13 \\
\hline
\end{tabular}

a Measured by ICP-AES

b Measured by elemental analysis

c Measured by $\mathrm{N}_{2}$ adsorption/desorption measurement

The PXRD pattern of the SAPO-18_OSDA3 sample shows a high crystallinity of the material with no presence of impurities or amorphous phase (see Figure 5.23). From the FESEM image, SAPO-18_OSDA3 has a large crystal size of $\sim 20 \mu \mathrm{m}$ (see Figure 5.24). This particle size will result in diffusion limitations even though AEI structure has a three-dimensional channel system. However, as discussed above for STA-6 materials, the product selectivity could be evaluated even if the activity could not reach $100 \%$ methanol conversion and the catalyst deactivates in a short time. The chemical composition according to ICP analysis reveals that the $\mathrm{Si} /(\mathrm{Al}+\mathrm{P})$ of SAPO-18_OSDA3 is 0.13 , similar as the chemical composition in the initial synthesis gel. Having confirmed that SAPO-18_OSDA3 shows high crystallinity with proper chemical and physicochemical properties, this material has been tested for the MTO reaction under the same conditions as for the previous samples. 

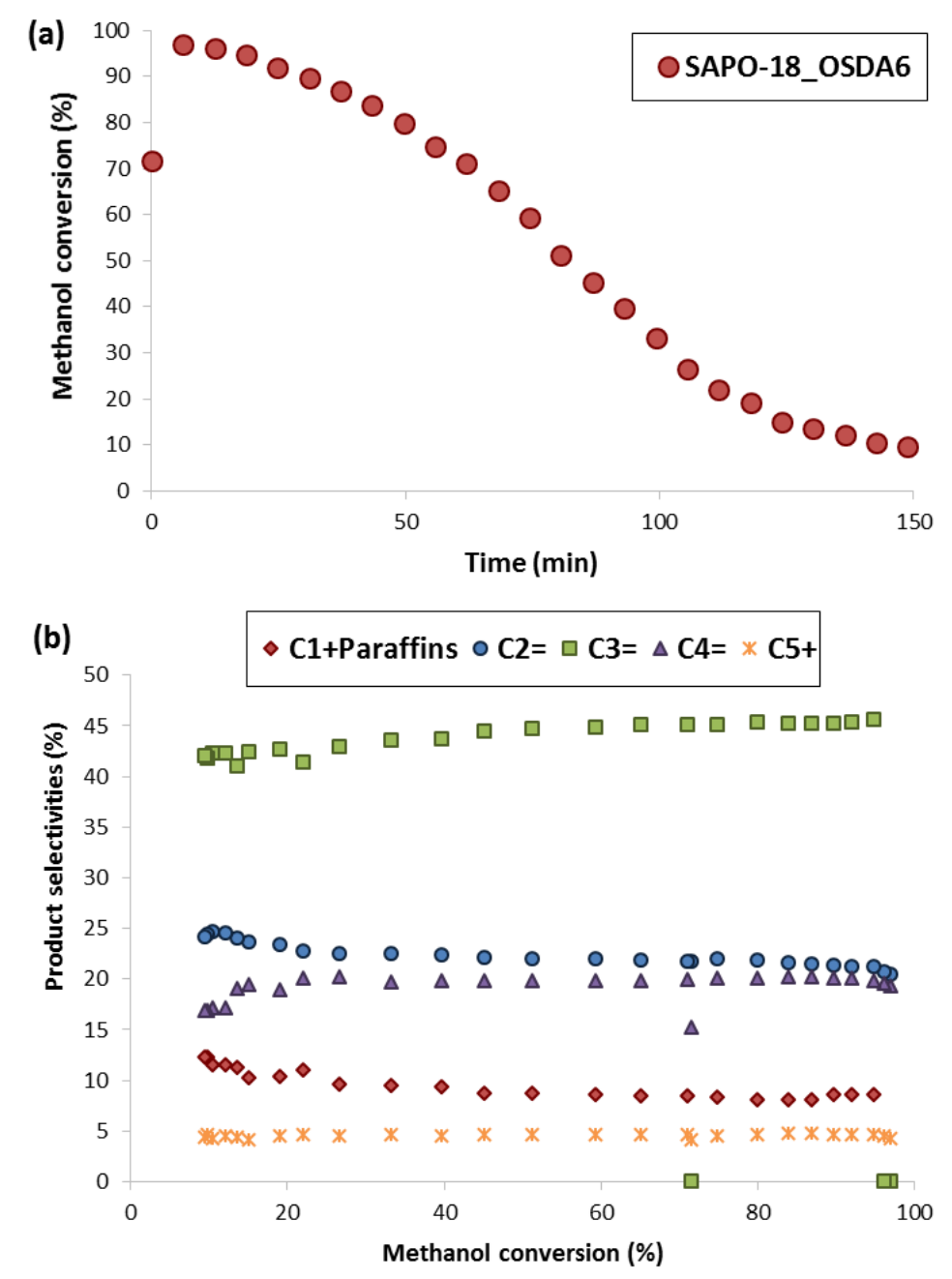

Figure 5.25 Methanol conversion (a) and product selectivities (b) achieved using the SAPO-

18_OSDA3 zeotype as catalyst for the MTO reaction (reaction conditions: $\mathrm{T}=350^{\circ} \mathrm{C}$, WHSV $=0.8$

$$
\left.\mathrm{h}^{-1}, \mathrm{w}_{\mathrm{cat}}=\mathbf{5 0} \mathrm{mg}\right)
$$

It is not surprising that the methanol conversion achieved does not reach $100 \%$ (see Figure 5.25) as the crystal size of SAPO-18_OSDA3 was near $20 \mu \mathrm{m}$. However, the SAPO-18_OSDA3 still shows a higher maximum methanol conversion compared with STA-6_OSDA2 with relatively smaller crystal size (4 
$\mu \mathrm{m})$, whose maximum methanol conversion reached only around $70 \%$. The conversion of methanol drops to 50\% for the SAPO-18_OSDA3 at around 75 min (see Figure 5.25). Although this behavior does not reveal a fascinating catalytic lifetime, it is possible to acquire the information on product selectivity. The selectivity of propene has reached $45.6 \%$, while ethene and butene selectivities are $21.4 \%$ and $19.9 \%$, resulting in $\mathrm{C}_{3}{ }^{\circ} / \mathrm{C}_{2}{ }^{=}$and $\mathrm{C}_{4}{ }^{=} / \mathrm{C}_{3}{ }^{=}$values were 2.13 and 0.93 , respectively.

Table 5.10 Catalytic properties for SAPO-18_OSDA3 and SAPO-34 for the MTO reaction.

\begin{tabular}{|c|c|c|c|c|c|c|c|}
\hline \multirow[b]{2}{*}{ Sample } & \multicolumn{2}{|l|}{ Lifetime } & \multicolumn{5}{|c|}{ Selectivity at Conv95\% } \\
\hline & Conv95\% & $\operatorname{Conv}_{50 \%}$ & $\mathrm{C}_{2}=$ & $\mathrm{C}_{3}=$ & $\mathrm{C}_{4}=$ & $\mathrm{C}_{3}=/ \mathrm{C}_{2}=$ & $\mathrm{C}_{4}{ }^{=} / \mathrm{C}_{2}=$ \\
\hline SAPO-18 & 5 & 75 & 21.4 & 45.6 & 19.9 & 2.13 & 0.93 \\
\hline _OSDA3 & & & & & & & \\
\hline
\end{tabular}

It should be taken into consideration that the paring pathway can favor both the formation of propene and butene. However, the production of butene in the side chain mechanism requires progressive methylation of methyl group to form butyl side chain, which is extremely unfavored. Thus, a concurrence of high $\mathrm{C}_{3}{ }^{=} / \mathrm{C}_{2}{ }^{=}$and $\mathrm{C}_{4}{ }^{=} / \mathrm{C}_{3}{ }^{=}$would indicate a higher percentage of paring mechanism than side-chain mechanism in the overall reaction inside the catalyst.

To sum up the findings so far, it is possible to say that some important intermediates in the paring pathway have been mimicked by the OSDAs, which have been later used in zeolite synthesis. By varying synthesis conditions, several crystalline materials have been obtained with high purity and crystallinity. All the materials obtained are cage-based small pore zeolites. Basically, most of the materials have been previously reported to be active in catalyzing MTO reactions, except STA-6, which is the first time reported to be active in MTO reactions. Although the material suffers from strong diffusion due to the large crystallites, it has been demonstrated to have high propene selectivity with potential applicability if its physicochemical properties could be properly optimized. 


\subsubsection{Insights into reaction mechanisms}

The experimental results illustrate that the mimicking synthesis strategy indeed gives materials that share common structural similarities, such as cages and small pore channels. In order to reveal the intrinsic connection between the OSDA, the zeolite and reaction mechanism, it is necessary to perform deeper investigation on whether and how the intermediates are stabilized in the zeolite cages.

Due to the aforementioned complexity of the reaction mechanism, where numerous species would be trapped in the zeolite at the same time, it will be difficult to extract information directly from experimental results. Thus, DFT calculations have been carried out at this point to get a deeper insight into the preferential stabilization within the zeolites of the different species involved in the paring and side-chain pathways. In order not to interfere with a potential influence of acidity, the calculations were performed on pure silica models of the RTH and CHA cavities to evaluate the influence of only the shape of the considered cavity. For theoretical calculations, both heptaMB ${ }^{+}$and 1,2,2,3,5pentaMB ${ }^{+}$cations have been employed as initial HP species and then the stabilization energy of each intermediate (INT) and transition state (TS) were calculated. The intermediates and transition states in their optimized configurations starting are shown in Figure 5.26, Figure 5.27 and Figure 5.28. 

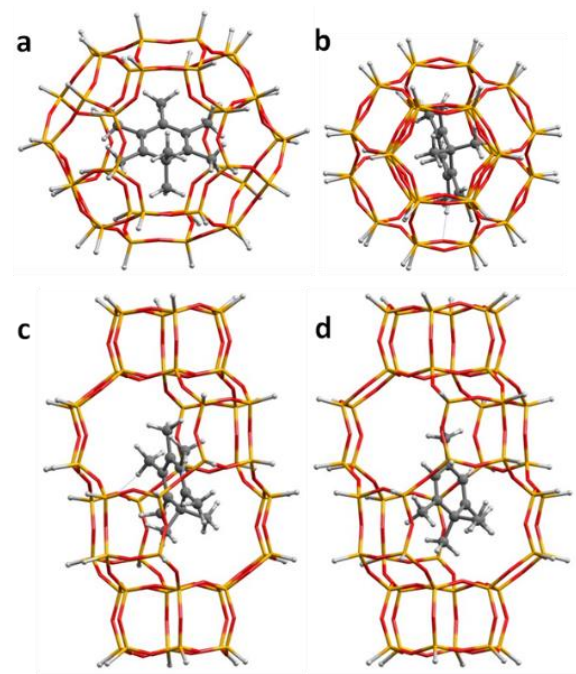

Figure 5.26 Minimization of MTO intermediates within zeolite cavities. a,b, DFT optimized structures of INT0 species in RTH (a) and CHA (b) cavity models. c,d, INT0 from HeptaMB ${ }^{+}$

(c) and PentaMB ${ }^{+}$(d) within CHA cavity.
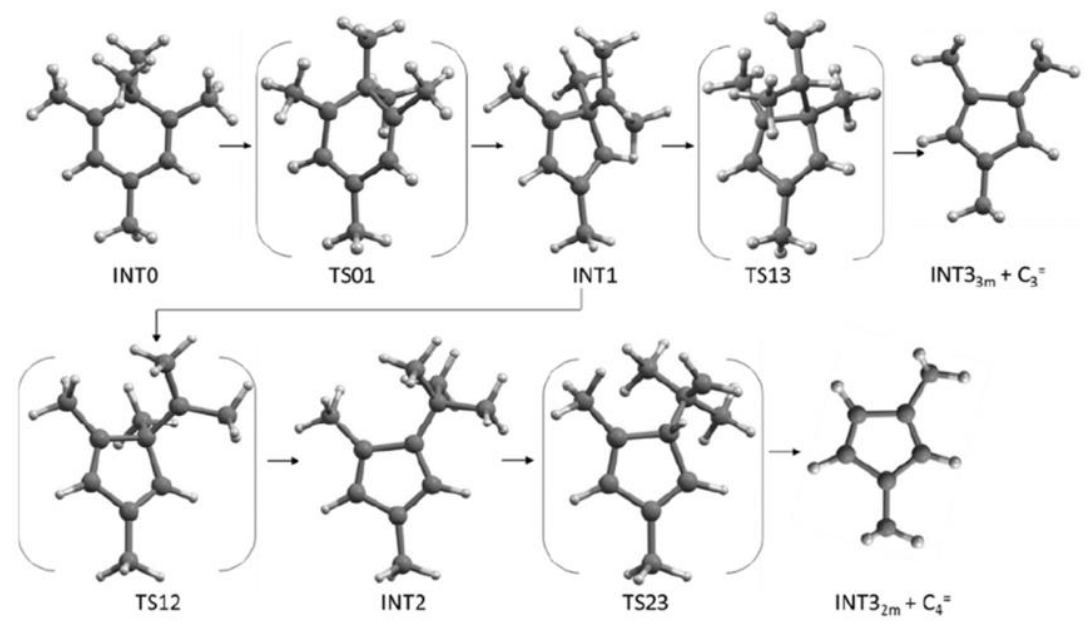

Figure 5.27 DFT optimized structures of species involved in the paring mechanism for pentaMB+ cation 


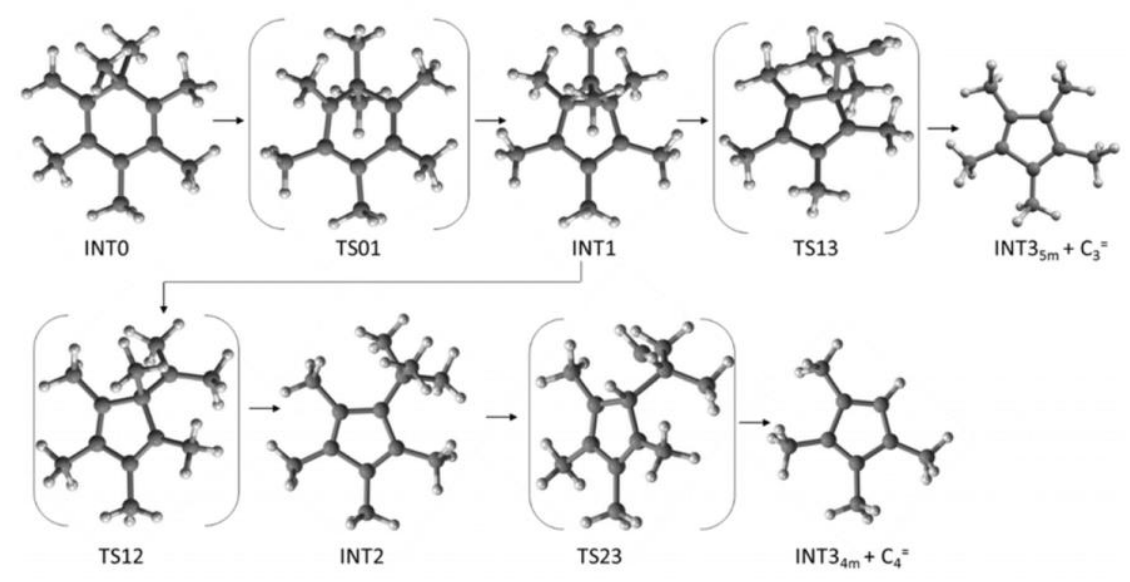

Figure 5.28 DFT optimized structures of species involved in the paring mechanism for heptaMB+ cation

The calculated interaction energies of all intermediates and transition states are listed in Table 5.11 and Table 5.12. In RTH cavity, there is a clear boundary at the "paring" step where isopropyl group is dealkylated. When starting with heptaMB ${ }^{+}$, before olefin-yielding step, meaning all the steps from INT0 to INT3+olefins, the interaction energy is in the range between -50 and -60 $\mathrm{kcal} / \mathrm{mol}$ (Table 5.11). After the elimination of propene or butene, this interaction energy is slightly lower, from -45 to $-55 \mathrm{kcal} / \mathrm{mol}$ (Table 5.12$)$. As for the intermediates involved in the side-chain pathway, being most important INT7 and INT8, the interaction energy shows differences, INT7, which is considered the precursor to produce ethene, can be stabilized within the cage of RTH since the interaction energy is $-51.7 \mathrm{kcal} / \mathrm{mol}$. However, INT8 is significantly less favored by RTH cage since its interaction energy is twenty $\mathrm{kcal} / \mathrm{mol}$ lower, reflecting a worse fitting of this bulkier intermediate within RTH cage. If the initial intermediate is substituted by pentaMB ${ }^{+}$cation, the value of interaction energy changes as one could expect due to the lower size of the molecule caused by the absence of two methyl groups. In general, all 
intermediates and transition states in paring pathways could still be stabilized since their interaction energy is higher than $-50 \mathrm{kcal} / \mathrm{mol}$. The combination of propene yielding step, INT $3_{5 \mathrm{~m} / 3 \mathrm{~m}}+$ propene, is especially more stable than other intermediates and transition states, with $57.6 \mathrm{kcal} / \mathrm{mol}$ and $63.3 \mathrm{kcal} / \mathrm{mol}$ of interaction energy correspondingly. Similarly, INT8 is less favored, with an interaction energy around $-21.2 \mathrm{kcal} / \mathrm{mol}$.

Table 5.11 Stabilization of cationic intermediates and transition states by interaction with RTH cavity models. Interaction energy calculated by DFT calculation

\begin{tabular}{|c|c|c|}
\hline & $\begin{array}{c}\text { RTH } \\
\text { (kcal/mol) }\end{array}$ & $\begin{array}{c}\text { RTH } \\
\text { (kcal/mol) }\end{array}$ \\
\hline INT0 & $-57,5$ & $-51,7$ \\
\hline TS01 & $-55,1$ & $-51,9$ \\
\hline INT1 & $-56,1$ & $-50,9$ \\
\hline TS12 & $-54,2$ & $-51,1$ \\
\hline INT2 & $-49,8$ & $-50,1$ \\
\hline $\mathrm{T} 23$ & $-54,5$ & $-52,3$ \\
\hline $\mathrm{INT}_{4 \mathrm{~m} / 2 \mathrm{~m}}+\mathrm{C}_{4}=$ & $-59,2$ & $-57,6$ \\
\hline TS13 & $-59,7$ & $-56,6$ \\
\hline $\mathrm{INT}_{5 \mathrm{~m} / 3 \mathrm{~m}}+\mathrm{C}_{3}=$ & $-57,5$ & $-63,3$ \\
\hline INT7 & $-51,7$ & $-42,4$ \\
\hline INT8 & $-25,8$ & $-21,2$ \\
\hline
\end{tabular}


Table 5.12 Stabilization of cationic intermediates and transition states involved in the ringexpansion part of the paring mechanism by interaction with RTH cavity models. Interaction energy calculated by DFT calculation

\begin{tabular}{|c|c|c|}
\hline & $\begin{array}{c}\text { RTH } \\
\text { (kcal/mol) }\end{array}$ & $\begin{array}{c}\text { RTH } \\
(\mathrm{kcal} / \mathrm{mol})\end{array}$ \\
\hline $\mathrm{INT}_{4 \mathrm{~m} / 2 \mathrm{~m}}$ & $-47,5$ & $-45,9$ \\
\hline TS34 & $-50,8$ & $-54,5$ \\
\hline INT4 & $-53,9$ & $-44,6$ \\
\hline TS45 & $-47,3$ & $-52,1$ \\
\hline INT5 & $-48,3$ & $-47,1$ \\
\hline
\end{tabular}

On the other hand, in the case of CHA where the cage is larger than in RTH, the calculations have been performed in the same way as in the case of RTH. In general, the stabilization of cationic species in CHA is weaker than in RTH and differs depending on the initial HP species (see Table 5.13 and Table 5.14). All those intermediates and transition states derived from pentaMB ${ }^{+}$are stabilized by $-40--55 \mathrm{kcal} / \mathrm{mol}$, while those derived from heptaMB ${ }^{+}$are always lower than $-50 \mathrm{kcal} / \mathrm{mol}$ (see Table 5.13). Clear differences are observed for intermediates INT0, INT7 and INT8, all derived from heptaMB ${ }^{+}$. These intermediates are less stable in CHA by twenty $\mathrm{kcal} / \mathrm{mol}$ compared to their counterparts derived from pentaMB ${ }^{+}$cation. This could possibly be related to the three-fold symmetry of CHA cavity, which will not favor the stabilization of the planar and fully methylated heptaMB ${ }^{+}$ring to have all the methyl groups pointing to the eight- 
ring windows. On the contrary, in the case of pentaMB ${ }^{+}$derived intermediates, the smaller size allows themselves to move slightly free toward the bottom of the cavity, which maximizes the stabilizing dispersion interactions (see Figure $5.26 \mathrm{~d}$ ). In the case of the RTH cage, although the size of the cage is smaller than CHA cage, its shape provides better fit with all structures involved in the paring route as well as less-methylated side-chain intermediates. Thus, these intermediates are selectively stabilized and produce more propene.

Table 5.13 Stabilization of cationic intermediates and transition states by interaction with CHA cavity models. DFT calculated interaction energies in $\mathrm{kcal} / \mathrm{mol}$.

\begin{tabular}{ccc}
\hline INT0 & $-29,4$ & $-46,1$ \\
TS01 & $-42,1$ & $-48,7$ \\
INT1 & $-39,3$ & $-47,8$ \\
TS12 & $-39,0$ & $-48,2$ \\
INT2 & $-40,1$ & $-48,1$ \\
T23 & $-36,1$ & $-48,5$ \\
$\mathrm{INT}_{4 \mathrm{~m} / 2 \mathrm{~m}}+\mathrm{C}_{4}=$ & $-51,6$ & $-51,5$ \\
$\mathrm{TS}_{3} 3$ & $-40,9$ & $-53,3$ \\
$\mathrm{INT}_{5 \mathrm{~m} / 3 \mathrm{~m}}+\mathrm{C}_{3}=$ & $-45,5$ & $-54,9$ \\
$\mathrm{INT}$ & $-26,1$ & $-48,2$ \\
$\mathrm{INT}$ & $-29,5$ & $-51,5$ \\
\hline
\end{tabular}


Table 5.14 Stabilization of cationic intermediates and transition states involved in the ringexpansion part of the paring mechanism by interaction with CHA cavity models. DFT calculated interaction energies in $\mathrm{kcal} / \mathrm{mol}$.

\begin{tabular}{ccc}
\hline INT3 ${ }_{4 \mathrm{~m} / 2 \mathrm{~m}}$ & $-39,7$ & $-39,6$ \\
$\mathrm{TS} 34$ & $-43,3$ & $-42,9$ \\
$\mathrm{INT} 4$ & $-44,5$ & $-44,3$ \\
$\mathrm{TS} 45$ & $-43,4$ & $-43,4$ \\
$\mathrm{INT5}$ & $-45,1$ & $-40,9$ \\
\hline
\end{tabular}

Energy profiles could illustrate the differences in reaction pathways in different cages. As shown in Figure 5.29, in both cages, the reactions are endothermic from the initial HP species up to olefin releasing, regardless if the initial HP species are pentaMB ${ }^{+}$or heptaMB ${ }^{+}$. According to the DFT calculations presented before, pentaMB ${ }^{+}$cation is stabilized in both cages similarly but its tendency to react towards the paring route is low due to the endothermicity of the first step to form the bi-cyclic intermediate INT1. Therefore, if pentaMB ${ }^{+}$ intermediate is the one to be stabilized in the cage, the reaction should have higher tendency to go through side-chain pathway, which will result in higher ethene yield. 

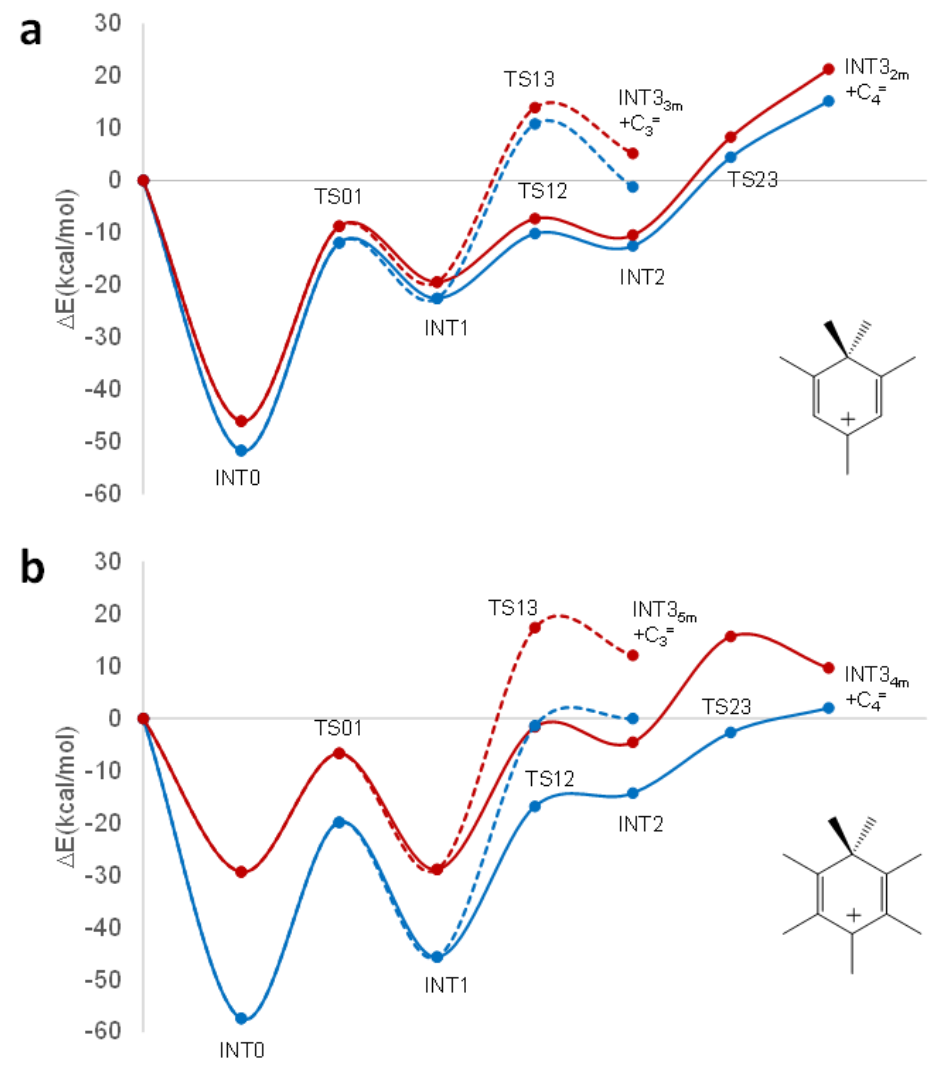

Figure 5.29 Energy profiles for the paring routes. a,b, Calculated potential energy profiles for the first part of the paring route in RTH (blue) and CHA (red) models starting from pentaMB+ (a) and heptaMB+ (b)

At this point, the theoretical and experimental results match perfectly. On the one hand, from experimental results, it has been observed that the RTH gives higher $\mathrm{C}_{3}{ }^{=} / \mathrm{C}_{2}{ }^{=}{ }(3.06)$ and $\mathrm{C}_{4}{ }^{=} / \mathrm{C}_{2}{ }^{=}$(1.68) than $\mathrm{CHA}(0.96$ and 0.40 , respectively). On the other hand, theoretical calculations allow concluding that paring pathway should be more favored in RTH than CHA via matching the shape of intermediates and zeolite cage. If both are true, then one could assume that the different organic species trapped in the zeolites during the MTO reactions 
should explain the different product selectivities. Then, the results of ${ }^{13} \mathrm{C} \mathrm{CP}$ MAS NMR should be reexamined for better interpretation.

When the ${ }^{13} \mathrm{C}$ CP MAS NMR spectra for the SSZ-13_standard and RUB13_OSDA2 were discussed (see Figure 5.21), the efforts were focused on assigning the chemical shifts to certain organic species, but less attention was paid to the level of methylation of those species. In general, it seems obvious that in the RTH zeolite, the group of peaks related to aliphatic carbons is taking higher percentage in total area than in the case of CHA. This could be a sign of higher level of methylation, since the more carbons are in the methyl groups, the higher amount of saturated carbons should be in the system.

Both structures allow the stabilization of methyl-substituted cyclopentenyl cations, which is testified by the presence of peaks in the range of 240-250 ppm and the peak at $153 \mathrm{ppm}$ (see Table 5.8). This indicates that the formation of the cyclopentenyl cation, as a symbol of paring mechanism, is possible in both structures. This coincides with the theoretical calculation that both structures have high interaction energy with cyclopentenyl cations. Moreover, the sole presence of a peak at $-243 \mathrm{ppm}$ in RTH, which should correspond to the cyclopentenyl cation with higher methylation, indicates that RTH prefers more the higher methylated cyclopentenyl cation than less methylated ones. It is worth noting that this highly methylated cyclopentynyl cation has high structural similarity to the OSDA used for the RTH synthesis (see Scheme 5.11). The double peak in the case of CHA should indicate non-preference of CHA cage toward level of methylation. This fact has also been proved independently by theoretical calculations, where RTH has higher interaction energy with the heptaMB ${ }^{+}$derived species than pentaMB ${ }^{+}$, while in $\mathrm{CHA}$ occurs the opposite situation. Thus, the organic species trapped inside both zeolites contain important polymethylcyclopentenyl intermediates, but they clearly show different preferential formation and stabilization depending on the zeolite. 


\subsubsection{Structure-performance relationship in MTO catalysts}

From the previous section, it is clear that using OSDA mimicking intermediates of MTO reactions, the obtained materials are predominantly cage-based small pore zeolites, indicating a potential relationship between the configuration of guest molecule and host cavity of zeolites. In later mechanistic analysis of organic species trapped in the cavity, preference of different cavities, such as $\mathrm{CHA}, \mathrm{AEI}$ and RTH, showed different distributions of organic species in terms of relative amount of aromatic carbons and aliphatic carbons.

After studying several zeolites for the MTO reaction, and comparing their catalytic performances, it is necessary to reveal the intrinsic reason that should lie in the structure-function relationship. According to the results obtained here and also as described in the introduction, effective catalysts for MTO are mostly cage-based small pore zeolites. Moreover, in contrast to other acid-catalyzed reactions, the acidity of zeolites is not the intrinsic reason to determine the suitability of material as catalyst for MTO reaction. ${ }^{35}$

Topologies of zeolites and their cages, on the other hand, have much greater impact on the reaction mechanism. It has been reported that the contribution of aromatic-based and olefin-based pathways to the global methanol conversion and product olefin product distribution depend more on topology of zeolite and, therefore, the shape of cage and dimensionality of the channel systems. First of all, the formation of HP species, regardless olefin-based or aromatic-based pathways, requires sufficient void space to be formed and this was reflected by the negligible activity achieved by zeolites with very small voids, such as ESV and MTF. ${ }^{36,37}$ Medium- and large-pore zeolites, on the other hand, give high yield of heavy products, such as aromatics, gasoline component, polyaromatic species or coke. For this reason, larger pore zeolites suffer from fast deactivation by coke. The only medium-pore zeolite currently used industrially is ZSM-5, which could give high catalytic lifetime and selectivity to propene or gasoline. However, its best behavior only appears at high $\mathrm{Si} / \mathrm{Al}(\mathrm{Si} / \mathrm{Al}>160)$, sacrificing the amount of active sites as a compromise with fast deactivation by coke. ${ }^{38}$

The above disadvantages narrow the scope of MTO catalysts to cage-based small pore zeolites. For instance, zeotype materials with CHA, AEI and RTH 199 
structures, either in aluminosilicate or silicoaluminophosphate forms, have been reported in the previous section of this thesis to be active catalysts for MTO. Recently, important efforts have been paid in the literature on describing the relationship between pore shape, dimensionality, symmetry and the catalytic performance of the materials. ${ }^{40}$ Using isotopic switch experiments between ${ }^{12} \mathrm{CH}_{3} \mathrm{OH}$ and ${ }^{13} \mathrm{CH}_{3} \mathrm{OH}$, Olsbye et al. proposed that the diffusion of reactants determines the product distribution of the MTO reaction, where the formation of bulky organic species could shift the product distribution to higher yield of lighter alkane and ethene by increasing the diffusion hinderance. ${ }^{35}$

Very recently, Davis et al. have proposed the concept of cage-defining ring size as a descriptor of cage-based zeolites. ${ }^{40}$ The cage-defining ring is defined as the minimum number of tetrahedral atoms of the ring encircling the center of the framework cages. It has been shown that the cage-defining ring size correlates with product distribution of MTO reactions. To be specific, when the cagedefining ring size is smaller than 12-ring, the predominant olefin product is ethene and, along with increasing the cage-defining ring size, ethene becomes less significant while propene and butene appear as main products. (Figure 5.30)

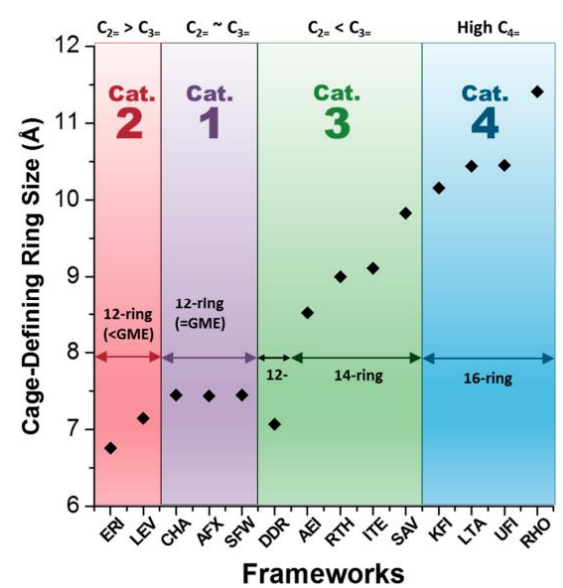

Figure 5.30 Correlation chart of cage-defining ring size by cage-based structures and light olefin product distribution categories. ${ }^{40}$ 
These descriptions support the concept that the product distribution of MTO over different zeolite catalysts depend mainly on topology. Following this idea, we have systematically investigated the intrinsic properties of the zeolites obtained in the previous section from the mimic approach combing theoretical calculations, characterization and catalytic reaction in order to reveal a potential correlation between the topology and their catalytic performance.

Within our group, outstanding DFT study has been done by Pau Ferri to depict energetic profiles of paring pathway starting from differently methylated benzene HP species. ${ }^{39}$ By analyzing the interaction energy of polymethylbenzenium species with different degrees of methylation as well as changes in Gibbs free energy during the following paring and side-chain pathway, has allowed to predicted that gem-methylated heptamethylbenzenium cation $\left(\mathrm{g} 7 \mathrm{MB}^{+}\right)$is the key intermediate that can initiate paring mechanism and its stability could be altered by zeolite cages (see Scheme 5.13). It shows different interaction energies when trapped in different cages due to its larger size, which could have more interaction with the cage. In RTH and AEI structures, g7MB could be well stabilized, resulting in higher percentage of MTO mechanism going through paring than through side-chain pathway, which is started by methylation of tetramethylbenzenium $\left(4 \mathrm{MB}^{+}\right)$. In $\mathrm{CHA}$ structure, gem methylation of $4 \mathrm{MB}^{+}$to form $g 5 \mathrm{MB}^{+}$is competitive to the formation of $\mathrm{g} 7 \mathrm{MB}^{+}$, leading to a comparable degree of the two pathways, which results in $\mathrm{C}_{3}{ }^{=} / \mathrm{C}_{2}=$ close to 1 . These theoretical predictions are in line with the experimental facts described in the previous section in the sense that RTH and AEI zeolites show higher selectivity to propene than CHA zeolites in MTO when tested under the same conditions. 


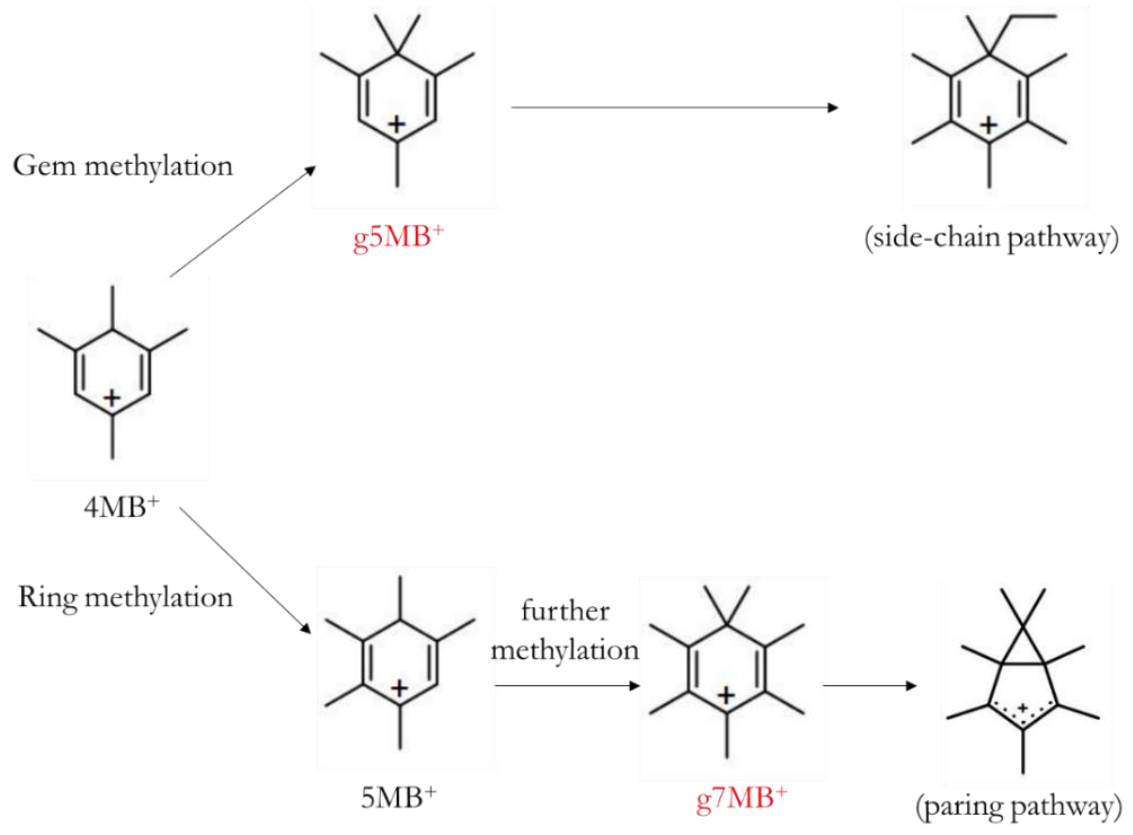

Scheme 5.13 Illustration of ring methylation and gem methylation of $4 \mathrm{MB}^{+}$toward side-chain and paring pathways and the key intermediates $\mathrm{g} 5 \mathrm{MB}^{+}$and $\mathrm{g} 7 \mathrm{MB}^{+}$

Table 5.15 Interaction energy of g5MB ${ }^{+}$and $\mathrm{g} 7 \mathrm{MB}^{+}$in different zeolite cages

\begin{tabular}{cccc}
\hline \multicolumn{1}{c}{$\mathrm{E}_{\text {int }}$} & CHA & AEI & RTH \\
\hline${\mathrm{g} 5 \mathrm{MB}^{+}}$ & -194.6 & -194.1 & -219.2 \\
$\mathrm{~g} 7 \mathrm{MB}^{+}$ & -149.4 & -190.0 & -243.9 \\
\hline
\end{tabular}

Based on this recently described theoretical approach, a proper descriptor that can describe certain properties of the structures and can be related to their catalytic activities in MTO reactions could be established. For doing that, 
different SSZ-13 (CHA), SSZ-39 (AEI) and RUB-13 (RTH) samples have been synthesized to experimentally study the MTO mechanism. In order to obtain general properties of the structures, each material has been synthesized using different recipes to obtain zeolites with different physicochemical properties. The detailed synthesis conditions are described in experimental section in Chapter 3.

According to PXRD patterns, all samples show characteristic diffraction peaks for CHA, AEI and RTH structures, with high crystallinity and without presence of impurities or amorphous phases (Figure 5.31). Uniform particle sizes and morphologies are observed for all the samples in their FESEM images (see Figure 5.32). The primary particles of all samples are controlled to be below 1 $\mu \mathrm{m}$ in order to avoid diffusion limitations in the catalytic reactions. SSZ-13 zeolites are prepared with two $\mathrm{Si} / \mathrm{Al}$ ratios, presenting CHA-1 and CHA-3 a $\mathrm{Si} / \mathrm{Al} \sim 15$, while CHA-2 and CHA-4 a Si/Al 25. Moreover, the crystal sizes for the CHA-type zeolites are either below $100 \mathrm{~nm}$ (CHA-3 and CHA-4) or around $1 \mu \mathrm{m}$ (CHA-1 and CHA-2). SSZ-39 has a very narrow Si/Al window and the two samples prepared show a $\mathrm{Si} / \mathrm{Al} \sim 8.6$, while the particle sizes are slightly different $(0.3 \mu \mathrm{m}$ for AEI-1 and $0.06 \mu \mathrm{m}$ for AEI-2, see Figure 5.32). Finally, two RUB-13 samples have been prepared with different Si/Al (15.8 for RTH-1 and 12.0 for RTH-2) and particle sizes $(0.08 \mu \mathrm{m}$ for RTH- 1 and $2 \mu \mathrm{m}$ for RTH2, see Figure 5.32) 


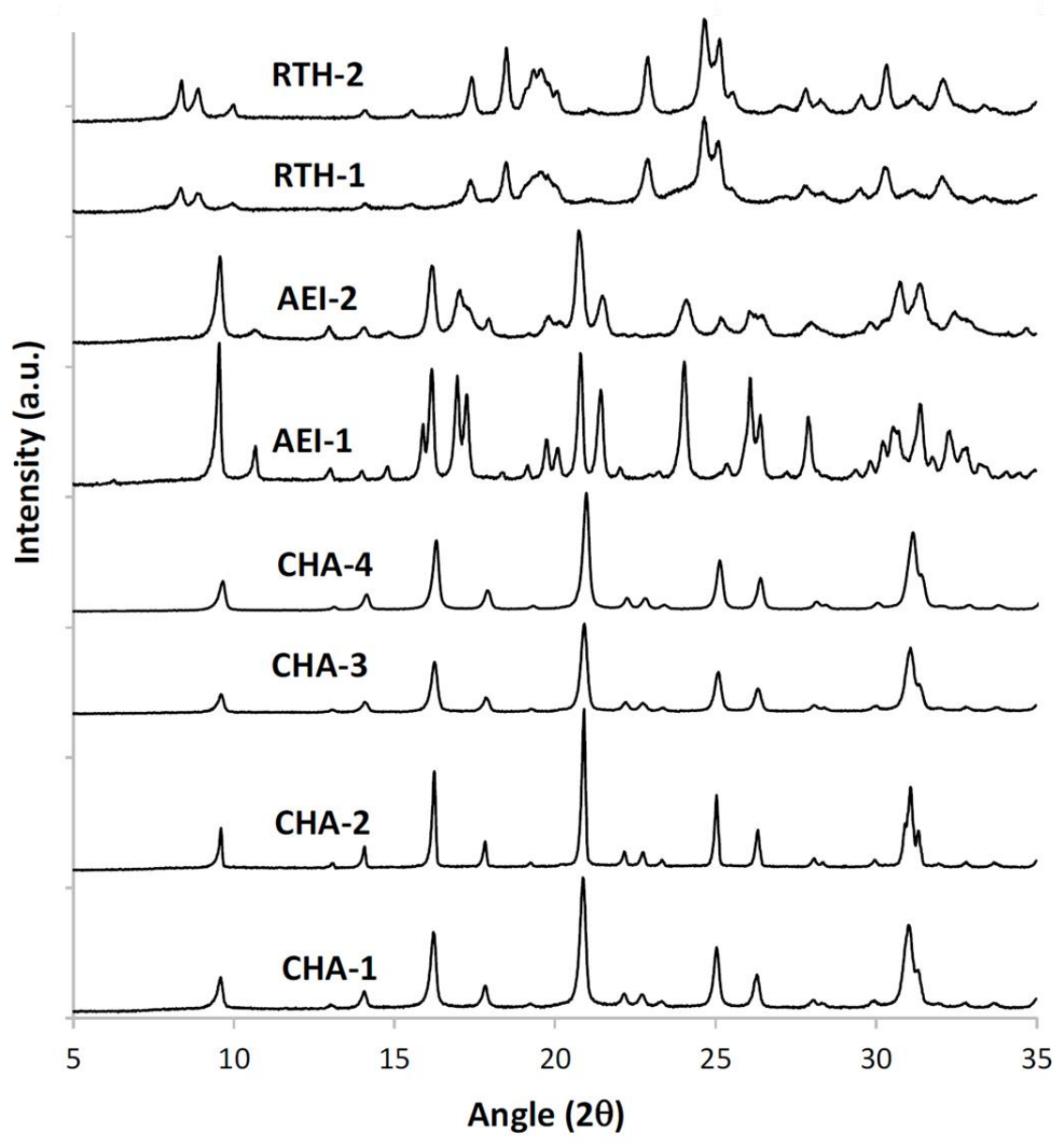

Figure 5.31 PXRD patterns of different samples involved in the study. 

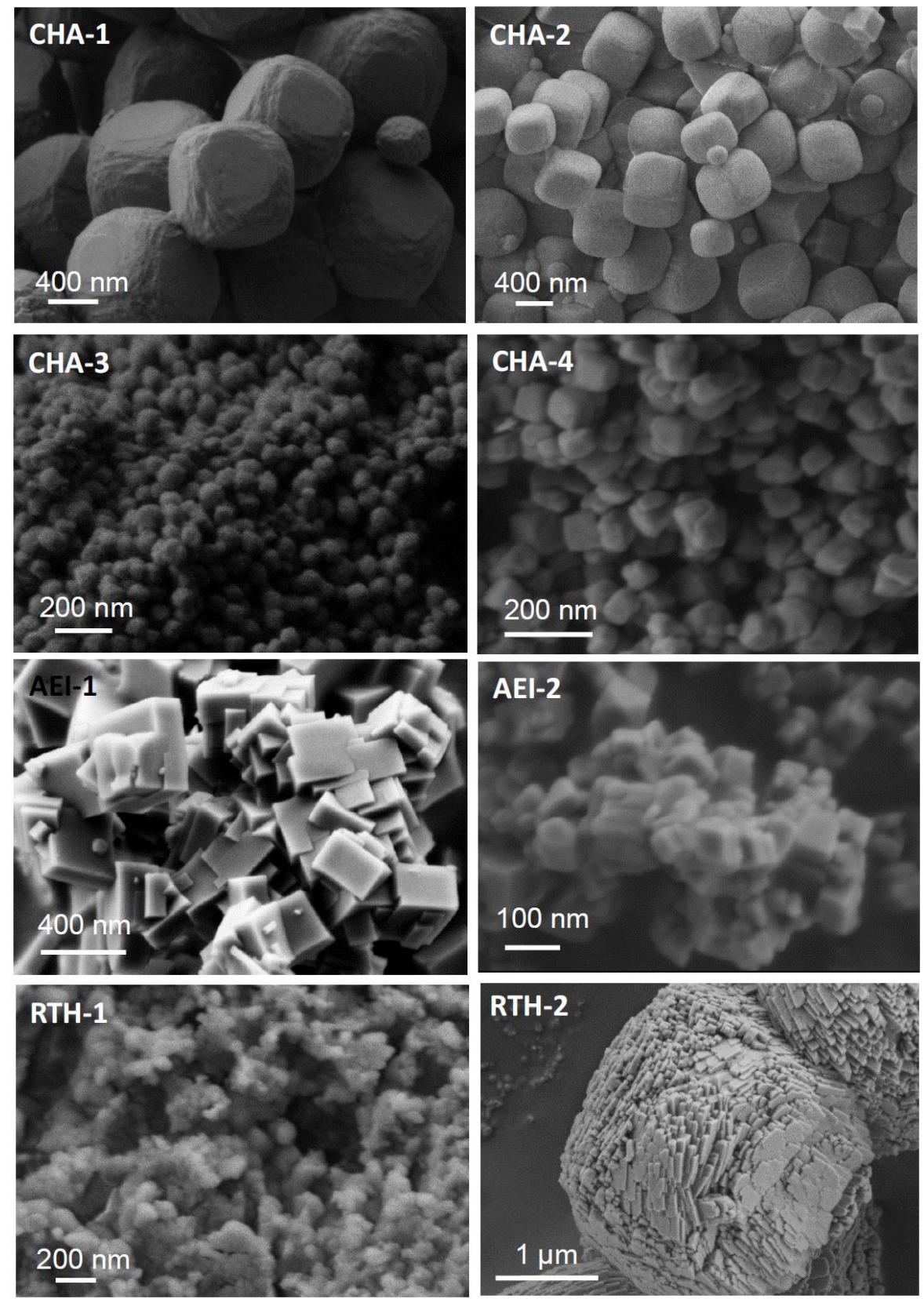

Figure 5.32 FESEM images of the different samples prepared in this study 
Table 5.16 Physicochemical properties of the different samples prepared in this study

\begin{tabular}{lccccc}
\hline & Si/Al & $\begin{array}{c}\text { Crystal size } \\
(\mu \mathrm{m})\end{array}$ & $\begin{array}{c}\mathrm{S}_{\mathrm{BET}}{ }^{\mathrm{c}} \\
\left(\mathrm{m}^{2} / \mathrm{g}\right)\end{array}$ & $\begin{array}{c}\mathrm{S}_{\text {micro }}{ }^{\mathrm{c}} \\
\left(\mathrm{m}^{2} / \mathrm{g}\right)\end{array}$ & $\begin{array}{c}\mathrm{V}_{\text {micro }}{ }^{\mathrm{c}} \\
\left(\mathrm{cm}^{3} / \mathrm{g}\right)\end{array}$ \\
\hline CHA-1 & 17.4 & 1.0 & 472 & 448 & 0.26 \\
CHA-2 & 26.7 & 1.0 & 596 & 586 & 0.28 \\
CHA-3 & 14.2 & 0.06 & 577 & 495 & 0.25 \\
CHA-4 & 24.1 & 0.08 & 630 & 480 & 0.25 \\
AEI-1 & 8.6 & 0.3 & 516 & 501 & 0.25 \\
AEI-2 & 8.6 & 0.06 & 526 & 484 & 0.23 \\
RTH-1 & 15.8 & 0.08 & 597 & 509 & 0.25 \\
RTH-2 & 12.0 & 2.0 & 467 & 448 & 0.22 \\
\hline
\end{tabular}

${ }^{a}$ Measured by ICP-AES

${ }^{\mathrm{b}}$ Measured from FESEM images

${ }^{c}$ Calculated based on $\mathrm{N}_{2}$ adsorption/desorption measurement

All samples possess high micropore volumes, which are close to the values normally reported in the literature for these materials (see Table 5.16). The calcined samples show that most of the $\mathrm{Al}$ are predominantly tetrahydrally coordinated in the framework in all samples, as reflected by ${ }^{27} \mathrm{Al}$ MAS NMR spectra(Figure 5.33). 


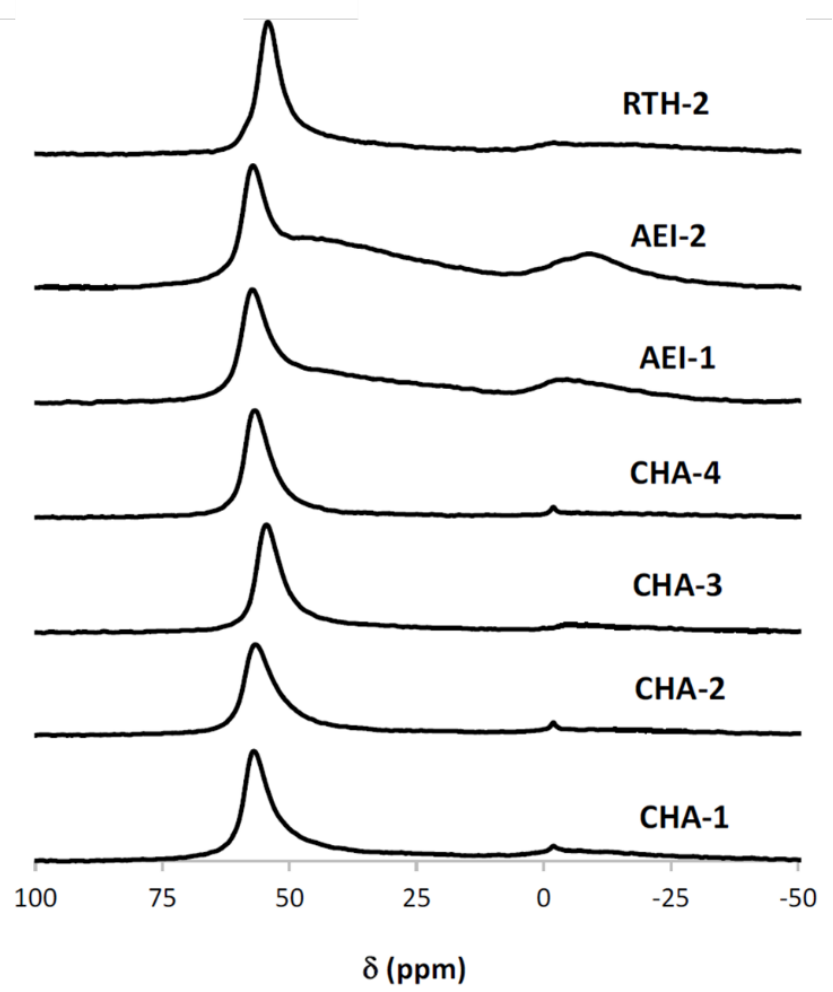

Figure $5.33{ }^{27} \mathrm{Al}$ MAS NMR spectra of the different samples prepared in this study

At this point, it is possible to say that the samples synthesized here could be considered representative for each structure and the physicochemical properties are diverse enough to avoid influence of any single parameter of the materials. Then, the samples have been tested for the MTO reaction under the same conditions as described in the previous section $\left(350^{\circ} \mathrm{C}, \mathrm{WHSV}_{\mathrm{MeOH}}=0.8 \mathrm{~h}^{-1}\right)$. 

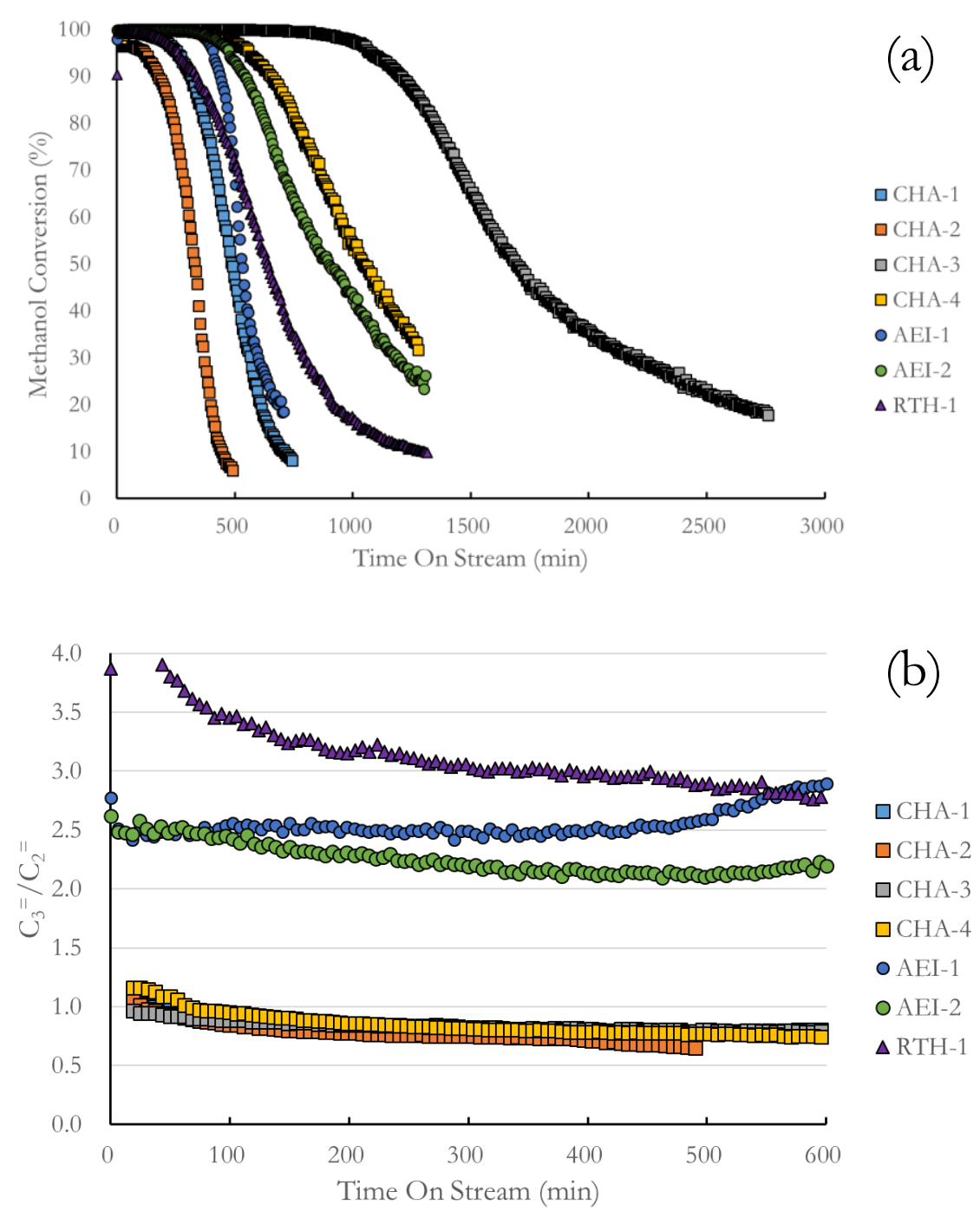

Figure 5.34 Methanol conversion with TOS (a) and $\mathrm{C}_{3}{ }^{=} / \mathrm{C}_{2}{ }^{=}$ratio with TOS (b) for MTO reactions of the different materials synthesized for this study. Reaction conditions: $50 \mathrm{mg}$ catalyst, $350^{\circ} \mathrm{C}$, $\mathrm{WHSV}_{\mathrm{MeOH}}=0.8 \mathrm{~h}^{-1}$. 
Clear differences are observed between all samples in the MTO test. For CHA samples, CHA-1 and CHA-2, both with micron-sized crystals, the catalyst deactivation starts at 200 and 100 min TOS, respectively (see Figure 5.34). The relative short catalytic lifetimes are due to their large crystal sizes, which would prevent product olefins to diffuse out of the crystals and, thus, suffer heavier coke formation and fast deactivation by coke. In contrast, CHA-3 and CHA-4, both with nano-sized crystals, show much longer catalytic lifetimes, with a conversion drop below $100 \%$ at 900 and 450 min TOS, respectively (see Figure 5.34).

Table 5.17 Catalytic lifetimes and light olefin selectivities for the MTO reaction using the different samples prepared in this study

\begin{tabular}{|c|c|c|c|c|c|c|}
\hline \multirow[t]{2}{*}{ Sample } & \multirow{2}{*}{$\begin{array}{l}\text { Lifetime } \\
\text { Conversion } 95 \%\end{array}$} & \multicolumn{3}{|c|}{ Selectivity $(\%)^{\mathrm{a}}$} & \multicolumn{2}{|c|}{ Olefin ratios } \\
\hline & & $\mathrm{C}_{2}=$ & $\mathrm{C}_{3}=$ & $\mathrm{C}_{4}=$ & $\mathrm{C}_{3}=/ \mathrm{C}_{2}=$ & $\mathrm{C}_{4}{ }^{=} / \mathrm{C}_{2}{ }^{=}$ \\
\hline CHA-1 & 260 & 45.1 & 37.0 & 12.4 & 0.82 & 0.27 \\
\hline CHA-2 & 117 & 44.1 & 36.6 & 13.0 & 0.83 & 0.29 \\
\hline CHA-3 & 1085 & 47.1 & 34.2 & 12.1 & 0.73 & 0.26 \\
\hline CHA-4 & 564 & 46.8 & 35.1 & 12.3 & 0.75 & 0.26 \\
\hline AEI-1 & 408 & 19.6 & 49.4 & 21.6 & 2.50 & 1.10 \\
\hline AEI-2 & 480 & 22.6 & 47.9 & 22.0 & 2.20 & 0.98 \\
\hline RTH-1 & 270 & 14.7 & 45.1 & 24.7 & 3.07 & 1.68 \\
\hline
\end{tabular}

${ }^{a}$ Calculated at conversion $95 \%$ 
The increase of their catalytic lifetimes compared to CHA-1 and CHA-2, could be efficiently explained by the contribution of decreasing particle size that could effectively prevent coke formation. The lifetime of those with Si/Al 25 (CHA2 and CHA-4) is half of those with Si/Al 15 (CHA-1 and CHA-3), being the overall catalyst lifetime proportional to the $\mathrm{Al}$ content in the catalysts (see Table 5.17). Similar results have been observed for AEI and RTH samples. In the case of the AEI-type materials, AEI-2 shows better catalyst lifetime together with a slower deactivation rate, which is possibly the result of its relatively smaller particle size compared to AEI-1. Finally, the RTH-1 catalyst shows a lifetime of $270 \mathrm{~min}$.

If the variation of the $\mathrm{C}_{3}{ }^{=} / \mathrm{C}_{2}{ }^{2}$ ratio with TOS is plotted for all catalysts, all the samples with the same structure show comparable value along their catalyst lifetimes (see Figure 5.35). As discussed previously, the paring pathway should favor the production of propene and butene, while the side-chain pathway should favor the formation of ethene. Moreover, as predicted by theoretical calculations, the selective stabilization of precursors toward each pathways $\left(\mathrm{g} 7 \mathrm{MB}^{+}\right.$for paring and $\mathrm{g} 5 \mathrm{MB}^{+}$for side-chain) could be significantly different

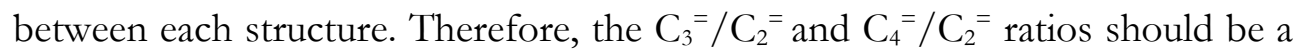
promising indicator to differentiate the reaction mechanisms in zeolites with different structures. The highest $\mathrm{C}_{3}{ }^{=} / \mathrm{C}_{2}{ }^{2}$ (3.07) was given by RTH, followed by AEI (2.20 and 2.50) and the lowest in CHA (0.73-0.83), observing the same tendency for the $\mathrm{C}_{4}{ }^{=} / \mathrm{C}_{2}{ }^{=}$values. The higher selectivities to propene and butene over RTH and AEI coincide with the prediction from theoretical calculations that these two structures could facilitate paring mechanism by stabilizing g $7 \mathrm{MB}^{+}$.

\subsubsection{Directing selection of catalysts: ITQ-3 zeolite}

At this point, it seems that the relative interaction energy to stabilize $g 5 \mathrm{MB}^{+}$and $\mathrm{g} 7 \mathrm{MB}^{+}\left(\mathrm{E}_{\text {int }}(7 / 5)\right)$ is theoretically indicating the preference of one structure toward paring and/or side-chain pathway, while $\mathrm{C}_{3}{ }^{=} / \mathrm{C}_{2}{ }$ from MTO is the experimental reflection of the distribution between the two pathways. Thus, there should be 
a strong relationship if the experimental indicator $\left(\mathrm{C}_{3}{ }^{=} / \mathrm{C}_{2}{ }^{2}\right)$ is plotted versus the theoretical indicator $\mathrm{E}_{\mathrm{int}(7 / 5) \text {. }}$

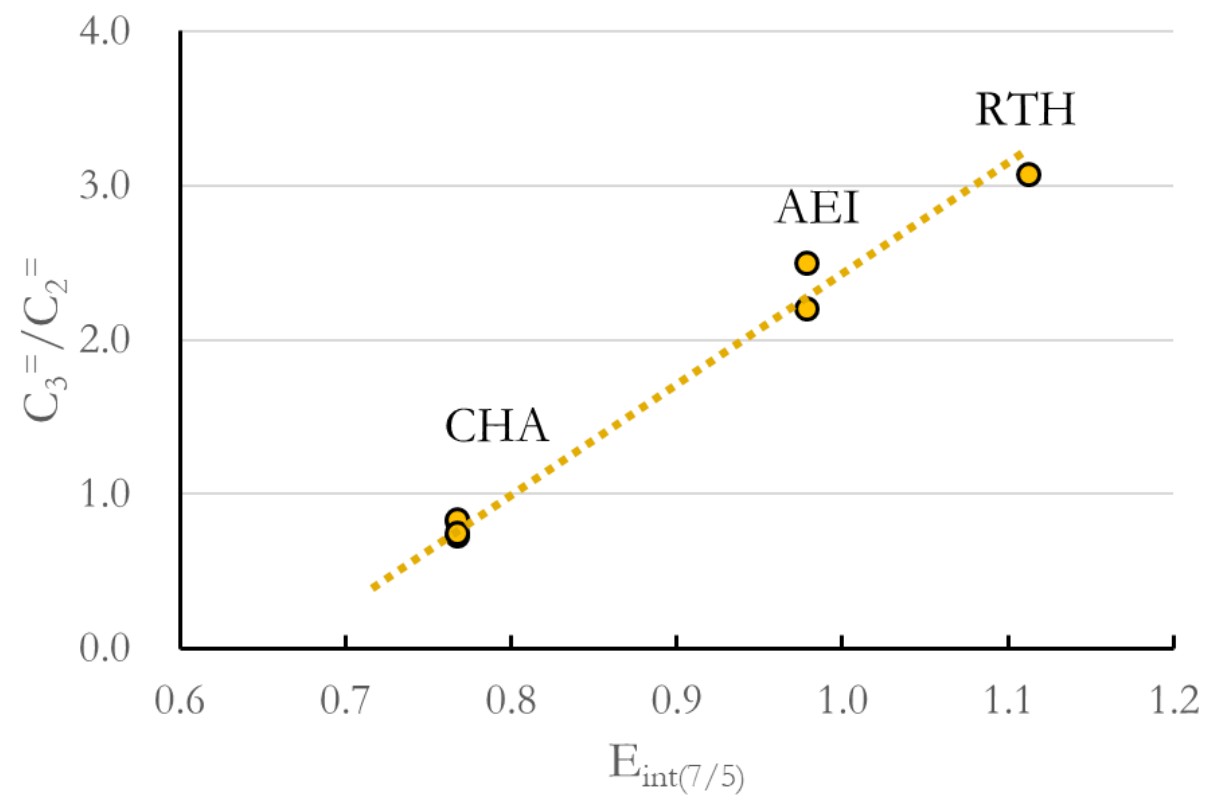

Figure 5.35 Relationship between the measured $\mathrm{C}_{3}=/ \mathrm{C}_{2}=$ ratio and the $\mathrm{E}_{\text {int }}(7 / 5)$ parameter in different small-pore cage-based zeolites. Reaction conditions: $50 \mathrm{mg}$ catalyst, $350^{\circ} \mathrm{C}, \mathrm{WHSV}_{\mathrm{MeOH}}$ : $0.8 \mathrm{~h}^{-1}$.

Indeed, a linear relationship can clearly observed between the $\mathrm{C}_{3}{ }^{2} / \mathrm{C}_{2}{ }^{=}$ratio obtained experimentally and the theoretical $\mathrm{E}_{\text {int }}(7 / 5)$ parameter (see Figure 5.35 ). If this correlation is reliable, then it should be able to predict the catalytic performance of other structures using the $E_{\text {int }}(7 / 5)$ indicator. In fact, ITE structure, a cage-based small pore zeolite (ITQ-3), shows a theoretically calculated Eint(7/5) value similar to RTH structure (1.09). According to the correlation obtained above, ITE structure should favor propene yield similarly to RTH. 
To check this hypothesis, an ITQ-3 zeolite in its aluminosilicate form has been synthesized using methyltritert-butylphosphonium (MTBP) as OSDA, TEOS as silica source, and aluminum isopropoxide as $\mathrm{Al}$ source (see detailed experimental conditions in chapter 2).

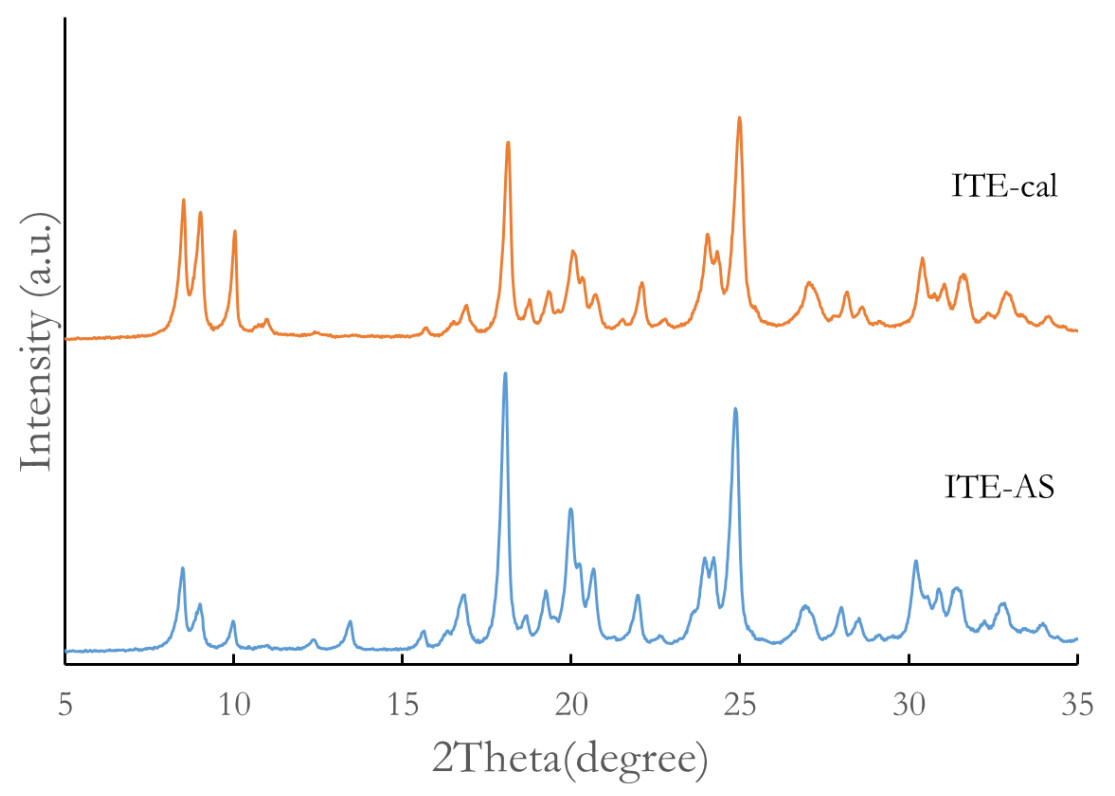

Figure 5.36 PXRD patterns of the as-synthesized (AS) and calcined (cal) ITQ-3 samples

Table 5.18 Physicochemical properties of the ITQ-3 sample

\begin{tabular}{lccccc}
\hline Si/Al & $\begin{array}{c}\text { Crystal size }^{\mathrm{b}} \\
(\mu \mathrm{m})\end{array}$ & $\begin{array}{c}\mathrm{S}_{\mathrm{BET}}{ }^{\mathrm{c}} \\
\left(\mathrm{m}^{2} / \mathrm{g}\right)\end{array}$ & $\begin{array}{c}\mathrm{S}_{\text {micro }}{ }^{\mathrm{c}} \\
\left(\mathrm{m}^{2} / \mathrm{g}\right)\end{array}$ & $\begin{array}{c}\mathrm{V}_{\text {micro }}{ }^{\mathrm{c}} \\
\left(\mathrm{cm}^{3} / \mathrm{g}\right)\end{array}$ \\
\hline ITQ-3 & 12.9 & 0.5 & 503 & 476 & 0.23 \\
\hline
\end{tabular}

a Measured by ICP-AES

${ }^{\mathrm{b}}$ Measured by elemental analysis

c Measured by $\mathrm{N}_{2}$ adsorption/desorption measurement 


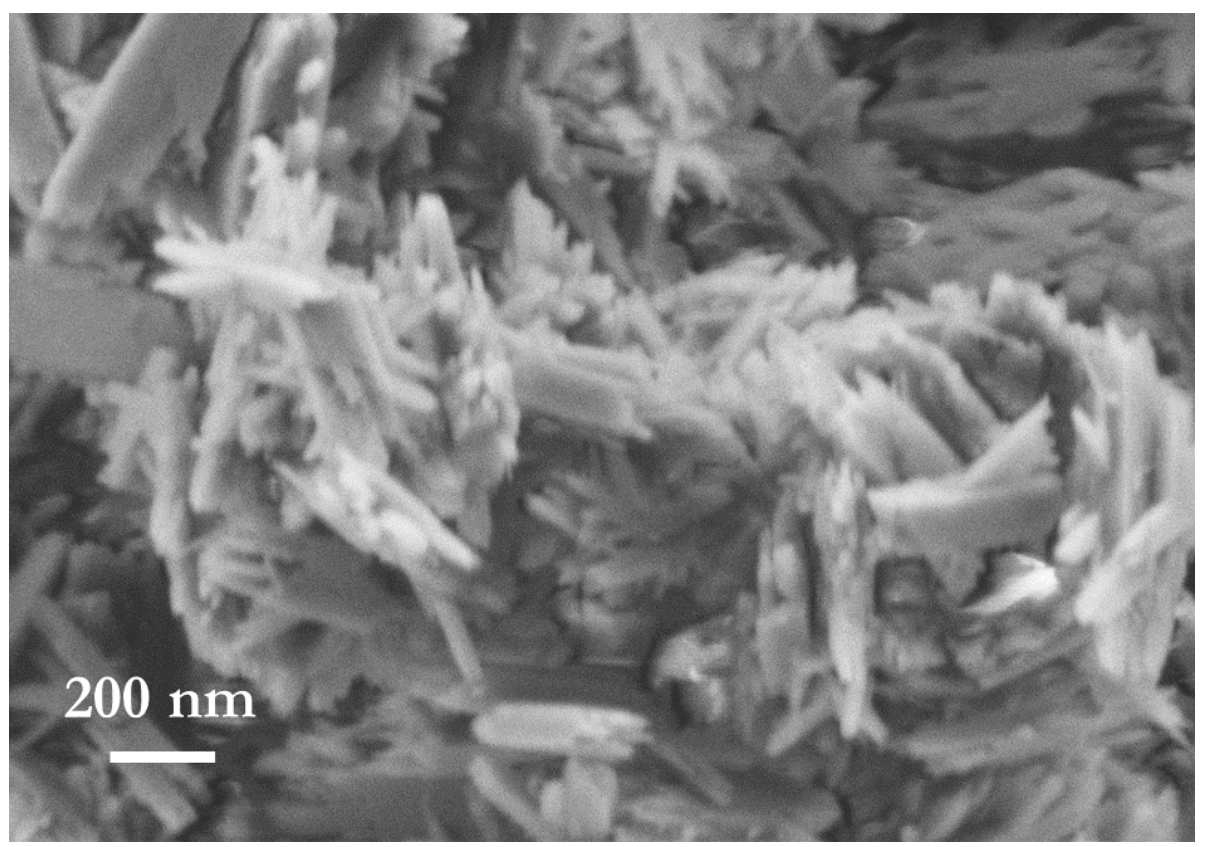

Figure 5.37 FESEM image of the ITQ-3 sample

The PXRD pattern of the ITQ-3 sample shows the characteristic diffraction peaks of the ITE structure without presence of amorphous phase or impurities (see Figure 5.36). The high crystallinity is reflected by a high microporous volume and surface area (see Table 5.18). The sample possesses a rod-like morphology with primary crystal size of $0.5 \times 0.2 \mu \mathrm{m}$ (see Figure 5.37 ). The Si/Al of this ITQ-3 sample is 12.9, similar to that achieved for the SSZ-13 and RUB13 materials. The similar chemical composition and physicochemical properties between ITQ-3, SSZ-13 and RUB-13 samples make possible to directly compare the influence of their topologies on the catalytic performance. 

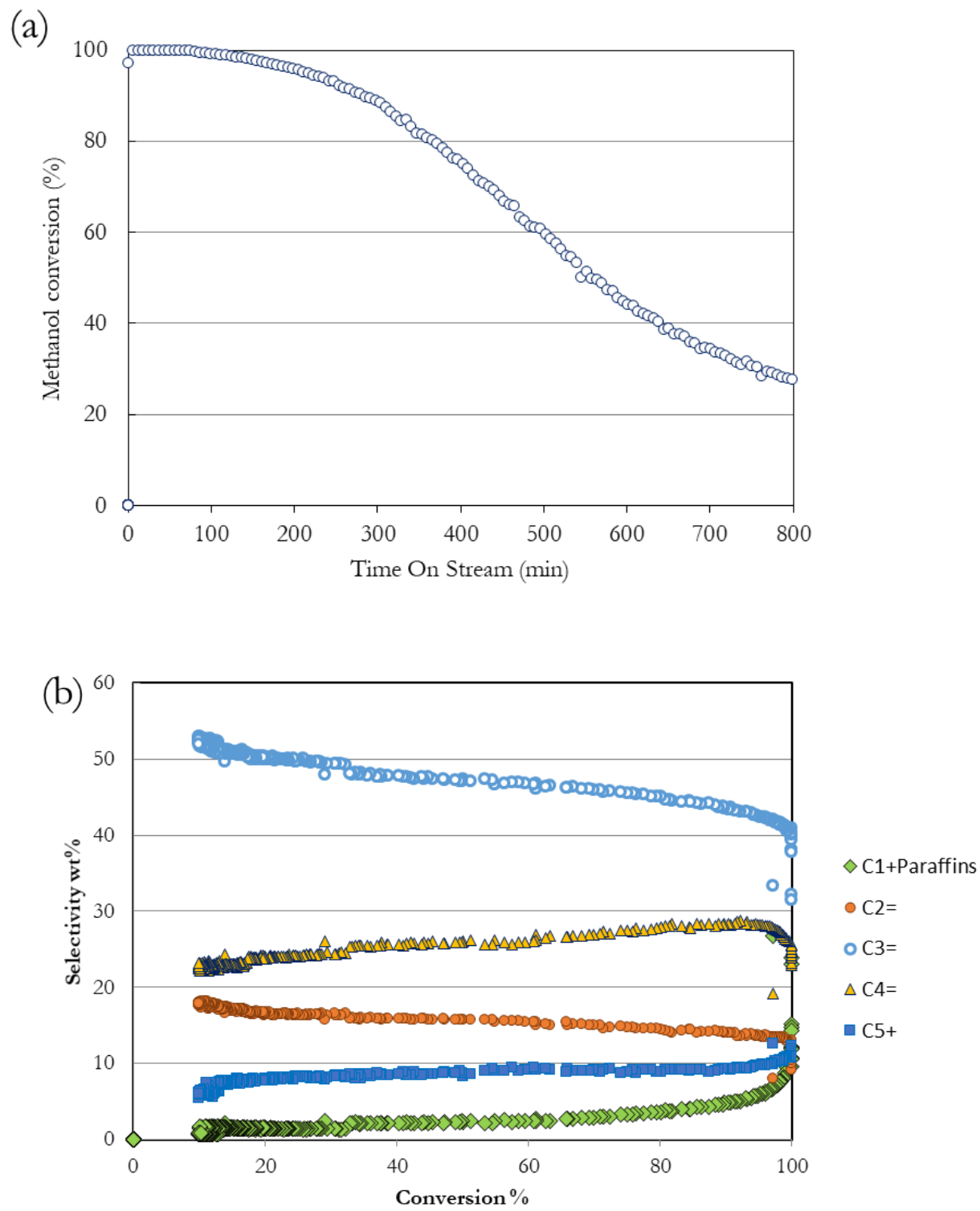

Figure 5.38 Methanol conversion against with TOS (a) and product selectivities against methanol conversion (b) of MTO over ITQ-3 sample 
Table 5.19 Catalytic lifetime and light olefin selectivities in MTO for ITQ-3(ITE)

\begin{tabular}{|c|c|c|c|c|c|c|}
\hline \multirow[t]{2}{*}{ Sample } & \multirow{2}{*}{$\begin{array}{l}\text { Lifetime } \\
\text { Conversion } 95 \%\end{array}$} & \multicolumn{5}{|c|}{ Selectivity $(\%)^{\mathrm{a}}$} \\
\hline & & $\mathrm{C}_{2}=$ & $\mathrm{C}_{3}=$ & $\mathrm{C}_{4}=$ & $\mathrm{C}_{3}{ }^{=} / \mathrm{C}_{2}=$ & $\mathrm{C}_{4}{ }^{=} / \mathrm{C}_{2}{ }^{=}$ \\
\hline ITQ-3 & 217 & 13.7 & 42.4 & 28.2 & 3.09 & 2.06 \\
\hline
\end{tabular}

${ }^{a}$ Calculated at conversion $95 \%$

The ITQ-3 (ITE) sample has been tested under the same conditions as before for the other materials. The catalytic lifetime measured as methanol conversion drops to $95 \%$ is around $200 \mathrm{~min}$. Interestingly, at $95 \%$ conversion, the experimentally achieved $\mathrm{C}_{3}{ }^{=} / \mathrm{C}_{2}{ }^{=}$and $\mathrm{C}_{4}{ }^{=} / \mathrm{C}_{2}{ }^{2}$ ratios are 3.09 and 2.06, respectively (see Table 5.19). If the $\mathrm{C}_{3}{ }^{2} / \mathrm{C}_{2}{ }^{=}$molar ratio obtained for ITE is now introduced in the plot relating experimental $\mathrm{C}_{3}{ }{ } / \mathrm{C}_{2}{ }{ }$ and the theoretical $\operatorname{Eint}(7 / 5)$ parameter, it can clearly be seen that this ITE material follows the linear trend (see Figure 5.39) This validates the use of relative interaction energy of $\mathrm{g} 7 \mathrm{MB}^{+}$ and $g 5 \mathrm{MB}^{+}$to predict the product selectivity of the structure. 


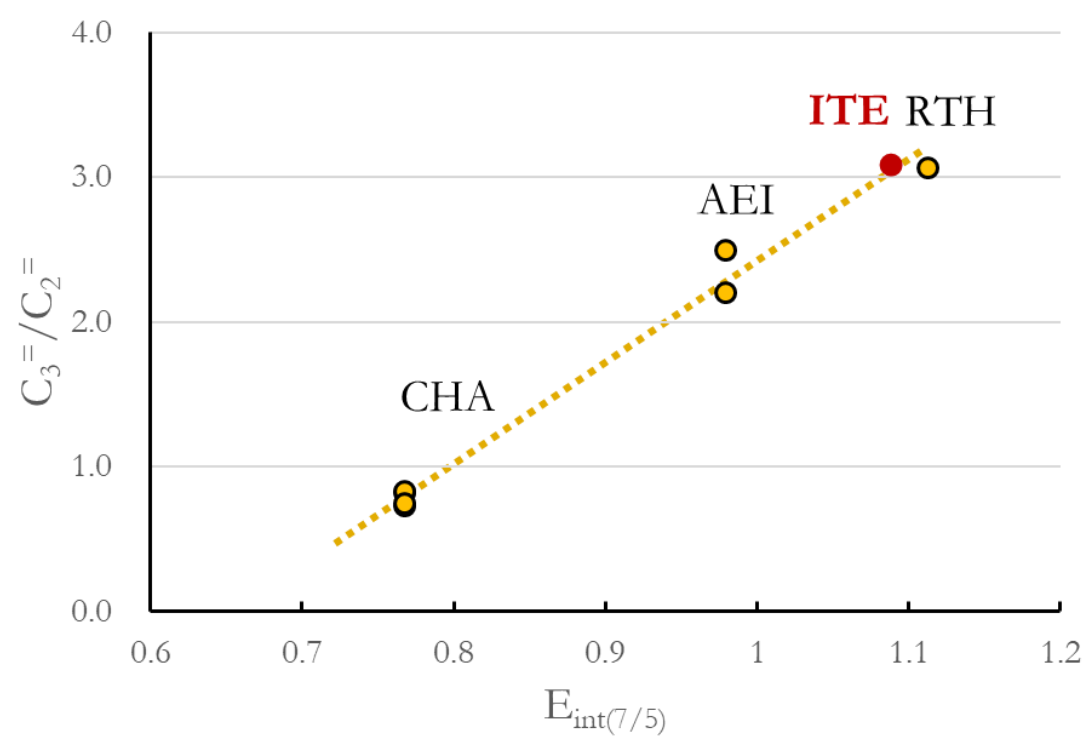

Figure 5.39 Relationship between the measured $C_{3}=/ C_{2}=$ ratio and the $E_{\text {int }}(7 / 5)$ parameter in different small-pore cage-based zeolites. Reaction conditions: $50 \mathrm{mg}$ catalyst, $350^{\circ} \mathrm{C}, \mathrm{WHSV}_{\mathrm{MeOH}}$ $=0.8 \mathrm{~h}^{-1}$.

\subsection{Conclusions and perspective}

Through the discussion in this chapter, it has been revealed that the synthesis approach using OSDAs that mimic reaction intermediates can yield zeolites that are adapted to the target reaction. In transalkylation reaction between benzene and DEB, the OSDA mimicking the diaryl intermediate led to formation of IWV zeolite, which shows higher catalytic activity and selectivity than all the zeolite catalysts described for this reaction. The TOF per aluminum site is higher in the case of IWV materials than FAU type materials, which are the two most active catalysts tested in this study. Later in the case of MTO reaction, several OSDAs mimicking intermediates in the paring pathway led to selective formation of cage-based small pore zeolites. These zeolites show high catalytic activity 
together with high selectivity to propene and butenes, which are the main products in the paring mechanism. Among all the materials, STA-6, with SAS topological structure which has never been reported for MTO reaction, shows high $\mathrm{C}_{3}{ }^{=} / \mathrm{C}_{2}{ }^{=}$and $\mathrm{C}_{4}{ }^{=} / \mathrm{C}_{2}=$ ratios. According to DFT calculations, these structures show preferential stabilization for different intermediates and this stabilization could alter the reaction between paring and side-chain pathways, which finally results in different product selectivities. Meanwhile, using ${ }^{13} \mathrm{C}$ labelled methanol for performing the MTO reaction and combining this with ${ }^{13} \mathrm{C}-\mathrm{NMR}$ analysis of the solid samples, HP species with different degrees of alkylation were observed. Furthermore, a linear correlation was observed between the $\mathrm{C}_{3}{ }^{=} / \mathrm{C}_{2}=$ in MTO reaction of the zeolites and their relative interaction energy with heptamethylatedbenzenium $\left(\mathrm{g} 7 \mathrm{MB}^{+}\right)$and pentamethylatedbenzenium $\left(\mathrm{g} 5 \mathrm{MB}^{+}\right)$. Based on this correlation, an indicator of interaction energy ratios of $\mathrm{g} 7 \mathrm{MB}^{+}$and $\mathrm{g} 5 \mathrm{MB}^{+}\left(\mathrm{E}_{\text {int }(7 / 5)}\right)$ was developed to evaluate the ability to produce propene of different zeolite structures. ITE structure was predicted by this indicator to be effective for producing propene selectively. Experimentally, the aluminosilicate form of ITE zeolite was synthesized and, indeed, showed high $\mathrm{C}_{3}{ }^{=} / \mathrm{C}_{2}{ }^{=}$in MTO reaction.

The study presented in this part of the thesis shows that the "ab initio" zeolite synthesis approach for particular industrially relevant reactions by properly selecting the OSDA molecules based on the reaction intermediates, is a very attractive methodology not only to develop efficient catalysts, but also to extract fundamental knowledge for complex reaction mechanism. 


\subsection{Reference}

1. J. Heilmann, W. F. Maier, Angew. Chem. Int. Ed., 1994, 33, 471.

2. G. Wulff, B. Heide, G. Helfmeier, J. Am. Chem. Soc., 1986, 108, 1089.

3. W. R. Ahmad, M. E. Davis, Catal. Lett., 1996, 40, 109.

4. E. M. Gallego, M. T. Portilla, C. Paris, A. Leon-Escamilla, M. Boronat, M. Moliner, A. Corma, Science, 2017, 355, 1051.

5. B. T. Loveless, J. W. Beeckman, C. G. Oliveri, S. J. Weigel, M. S. Ide, T. A. Baumrucker, WO201840149A1.

6. I. M. Gerzeliev, S. N. Khadzhiev, I. E. Sakharova, Pet. Chem., 2011, 51, 39.

7. W. F. Lai, C. N. Elia, N. S. Rollman, J. I. Cutler, US20180134637A1.

8. J. E. Schmidt, C.-Y. Chen, S. K. Brand, S. I. Zones, M. E. Davis, Chem. Eur. J., 2016, 22, 4022.

9. T. E. Helton, V. Nanda, M. Vincent, EP2571832A2.

10. T. Baumrucker, J. Beeckman, M. Ide, B. Loveless, C. Oliveri, S. Welgel, WO2018140149A1.

11. A. Corma, C. Corell, J. Perez-Pariente, Zeolites, 1995, 15, 2.

12. J.-B. Cary, WO2009127533A1.

13. M. C. Clark, V. Nanda, C. N. Lopez, B. Maerz, M. Bhandarkar, US2008033222A1

14. M. Bjørgen, F. Bonino, S. Kolboe, K.-P. Lillerud, A. Zecchina, S. Bordiga, J. Am. Chem. Soc., 2003, 125, 15863.

15. W. F. Lai, C. N. Ella, N. S. Rollman, J. I. Cutler, US20180134637A1.

16. N. Martin, Z. Li, J. Martinez-Triguero, J. Yu, M. Moliner, A. Corma, Chem. Commun., 2016, 52, 6072.

17. R. Martinez-Franco, Z. Li, J. Martinez Triguero, M. Moliner, A. Corma, Catal. Sci. Technol., 2016, 6, 2796. 
18. M. Stocker, Micropor. Mesopor. Mater. 1999, 29, 3.

19. P. Tian, Y. Wei, M. Ye, Z. Liu, ACS Catal., 2015, 5, 1922.

20. W. Zhang, Y. Zhi, J. Huang, X. Wu, S. Zeng, S. Xu, A. Zheng, Y. Wei, Z. Liu, ACS Catal., 2019, 9, 7373.

21. S. Xu, A. Zheng, Y. Wei, J. Chen, J. Li, Y. Chu, M. Zhang, Q. Wang, Y. Zhou, J. Wang, F. Deng, Z. Liu, Angew. Chem. Int. Ed., 2013, 52, 11564.

22. J. F. Haw, J. B. Nicholas, W. Song, F. Deng, Z. Wang, T. Xu, C. S. Heneghan, J. Am. Chem. Soc., 2000, 122, 4763.

23. T. Xu, D. H. Barich, P. W. Goguen, W. Song, Z. Wang, J. B. Nicholas, J. F. Haw, J. Am. Chem. Soc., 1998, 120, 4025.

24. J. E. Schmidt, M. A. Deimund, D. Xie, M. E. Davis, Chem. Mater., 2015, 27, 3756.

25. M. Zhang, S. Xu, Y. Wei, J. Li, J. Chen, J. Wang, W. Zhang, S. Gao, X. Li, C. Wang, Z. Liu, RSC Adv., 2016, 6, 95855.

26. Y. Bhawe, M. Moliner, J. D. Lunn, A. Malek, M. Davis, ACS Catal., 2012, 2, 2490.

27. J. H. Kang, R. Walter, D. Xie, T. Davis, C.-Y., Chen, M. E. Davis, S. I. Zones, ChemPhysChem, 2018, 19, 412.

28. M. Moliner, C. Martinez, A. Corma, A., Angew. Chem. Int. Ed., 2015, 54, 3560.

29. C. Li, M. Moliner, A. Corma, Angew. Chem. Int. Ed., 2018, 57, 15330.

30. J. R. Di Iorio, R. Gounder, Chem. Mater., 2016, 28, 2236.

31. E. M. Gallego, C. Li, C. Paris, N. Martin, J. Martinez-Triguero, M. Boronat, M. Moliner, A. Corma, Chem. Eur. J., 2018, 24, 14631.

32. Z. Li, M. T. Navarro, J. Martinez-Triguero, J. Yu, A. Corma, Catal. Sci. Technol., 2016, 6, 5856.

33. T. Yokoi, M. Yoshioka, H. Imai, T. Tatsumi, Angew. Chem. Int. Ed., 2009, 48, 9884.

34. R. Martínez-Franco, A. Cantin, M. Moliner, A. Corma, Chem. Mater., 2014, 26, 4346.

35. F. Bleken, M. Bjørgen, L. Palumbo, S. Bordiga, S. Svelle, K.-P. Lillerud, U. Olsbye, Top. Catal., 2009, 52, 218.

36. M. Deimund, J. Schmidt, M. Davis, Top. Catal., 2015, 58, 1. 
37. Q. Zhu, J. N. Kondo, T. Tatsumi, S. Inagaki, R. Ohnuma, Y. Kubota, Y. Shimodaira, H. Kobayashi, K. Domen, J. Phys. Chem. C, 2007, 111, 5409.

38. Z.-M. Cui, Q. Liu, W.-G. Song, L.-J. Wan, Angew. Chem. Int. Ed., 2006, 45, 6512.

39. P. Ferri, C. Li, C. Paris, A. Vidal-Moya, M. Moliner, M. Boronat, A. Corma, ACS Catal., 2019, 9, 11542.

40. J. H. Kang, F. H. Alshafei, S. I. Zones, M. E. Davis, ACS Catal., 2019, 9, 6012. 


\section{General conclusions and}

\section{perspectives}

Throughout the thesis it has been proved how deepening in the understanding reaction mechanism and interactions with the surface of the catalyst can help design better heterogeneous catalyst and improve the overall chemical processes. In this Ph.D work, we have attempted the design of zeolite catalyst by locating the acid sites in the preferential pore position and designing the pore and cavity topology of the zeolite for a preestablished reaction.

In this way, the first part of study was aimed to solve the problem of aluminum position in a zeolite framework with complex T-positions. As described, the characterization techniques is, and will still be in the near future, not advanced enough to give decisive conclusion of how aluminum are distributed in the zeolite frameworks. However, by understanding the impact of different aluminum distribution on the catalyzed reaction, an indicator that reveals the degree of monomolecular and bimolecular mechanisms in n-hexene cracking was proposed. This indicator was justified to be able to identify aluminum facing different spatial confinement. This spatial confinement in the case of ZSM-5 could be interpreted as the aluminum located in 10-ring channels or intersections. Then, using this indicator, boron-assisted ZSM-5 synthesis was revised. In pioneer studies, ZSM-5 zeolites synthesized with boron were reported to show improved propene selectivity and resistance to deactivation by coke in MTP reactions and it was attributed to the weak acidity introduced. However, in this thesis, this explanation was revised and was attributed to the higher percentage of aluminum sited in 10-ring with more spatial confinement and could avoid bimolecular hydrogen transfer reactions, avoiding consumption of light olefin and formation of coke. 
We have investigated the "ab-initio" synthesis of zeolites for specific reactions. This was done by preparing templates that mimick the structure, configuration and positive charge distribution of the transition states and intermediates of the target reaction. The concept has been proved first for the transalkylation reaction between benzene and diethylbenzene, where the reaction could either proceed through dealkylation-realkylation mechanism or one-step diaryl-mediated mechanism. A diphenyldimethylphosphonium template mimicking the diaryl intermediate has successfully led to a selective formation of ITQ-27 zeolite. The ITQ-27 zeolite showed superior DEB conversion and EB selectivity compared to other commercially used zeolites. After this first illustration, the concept of mimicking synthesis has been extended to MTO reaction, a more complex reaction network that is composed of multiple catalytic cycles. Using templates that mimic the intermediates in the paring pathway of the HP mechanism, several small-pore cage-based zeolites and zeotype silicoaluminosilicate were obtained. All of these zeolites showed good catalytic activity toward MTO reactions. Theoretical calculations revealed that the structure that lead to higher $\mathrm{C}_{3}{ }^{=} / \mathrm{C}_{2}{ }^{=}$and $\mathrm{C}_{4}{ }^{2} / \mathrm{C}_{2}{ }^{2}$ ratios could better stabilize intermediates that initiate the paring mechniasm. Moreover, feeding ${ }^{13} \mathrm{C}$ labeled methanol for MTO reaction combined with ${ }^{13} \mathrm{C}-\mathrm{NMR}$, it is possible to observe the different HP species trapped in the cage of these materials and rationalize of the above. In a further study on the mechanistic insight into the MTO reactions in these materials, it was found that the relative stability of intermediates that initiate paring pathway and side-chain pathway in different cages $(\operatorname{Eint}(7 / 5))$ is linearly related to the $\mathrm{C}_{3}{ }^{=} / \mathrm{C}_{2}{ }^{=}$and $\mathrm{C}_{4}{ }^{=} / \mathrm{C}_{2}{ }^{=}$ratios in MTO reactions. Following this correlation, ITQ3 was predicted to be an active catalyst. Indeed, an aluminosilicate ITQ-3 was synthesized and showed highest $\mathrm{C}_{3}{ }^{\circ} / \mathrm{C}_{2}{ }^{=}$and $\mathrm{C}_{4}{ }^{=} / \mathrm{C}_{2}{ }^{=}$ratios among all materials studied.

In both chapters, more than showing examples of how aluminum distribution and cavity structure could facilitate catalyzed reactions, we have attempted to illustrate how the understanding of reaction mechanisms can help developing efficient zeolite catalysts. 